\title{
Municipal Solid Waste Management \\ A Bibliography o \\ U.S. Department of Energy \\ Contractor Reports Through 1993
}

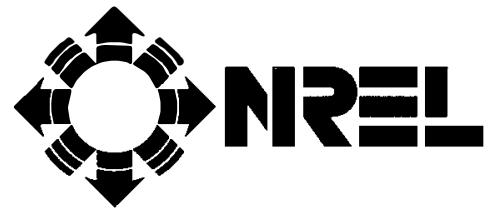

National Renewable Energy Laboratory

1617 Cole Boulevard

Golden, CO 80401-3393

A national laboratory of the U.S. Department of Energy

Managed by the Midwest Research Institute

for the U.S. Department of Energy

Under Contract No. DE-AC 36-83CH10093 


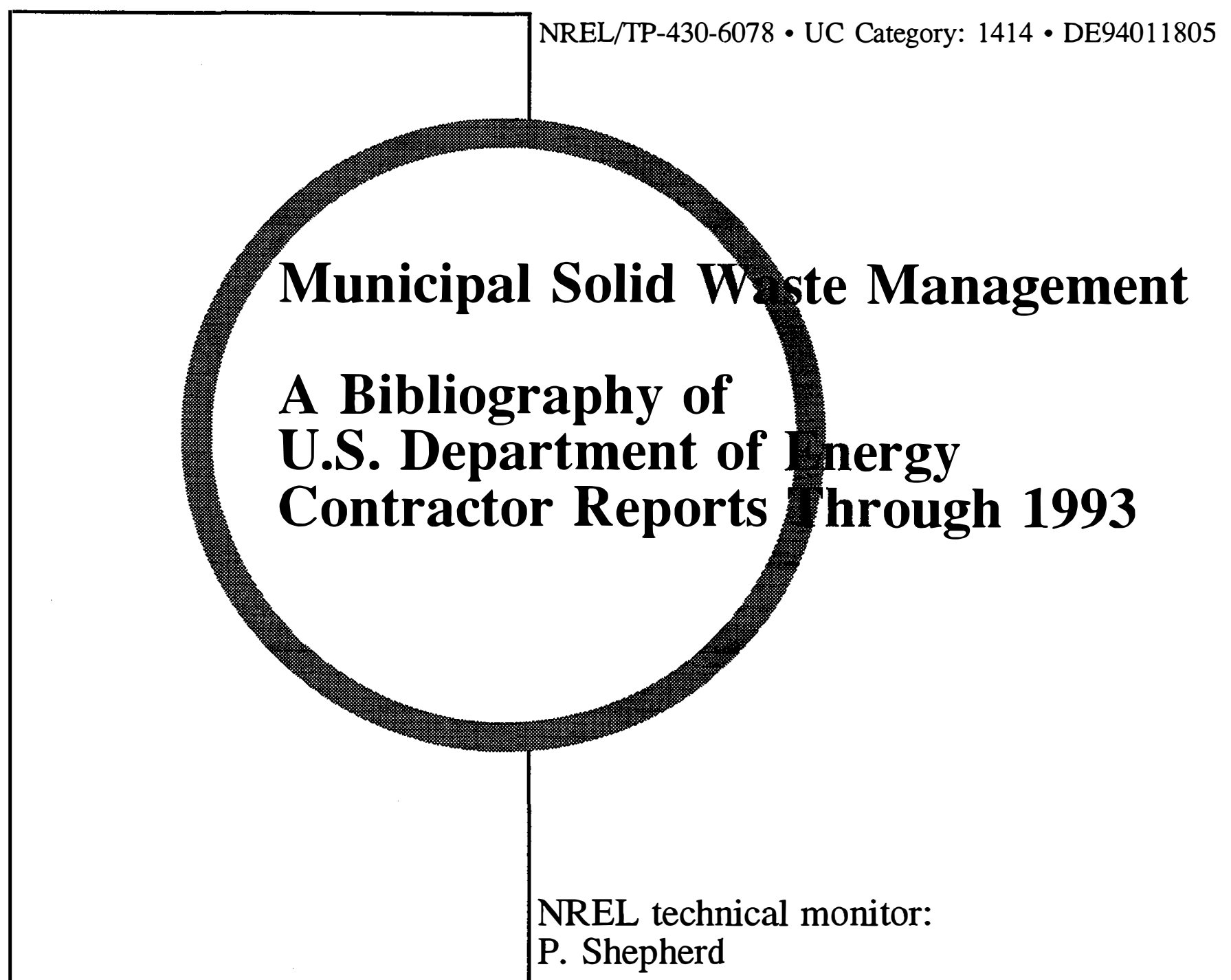

NREL technical monitor:

P. Shepherd

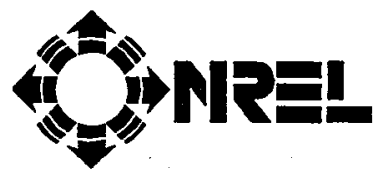

National Renewable Energy Laboratory 1617 Cole Boulevard Golden, Colorado 80401-3393

A national laboratory of the U.S. Department of Energy Managed by Midwest Research Institute Under Contract No. DE-AC36-CH10093

Prepared under task no. WM311010

July 1994 


\section{NOTICE}

NOTICE: This report was prepared as an account of work sponsored by an agency of the United States government. Neither the United States government nor any agency thereof, nor any of their employees, makes any warranty, express or implied, or assumes any legal liability or responsibility for the accuracy, completeness, or usefulness of any information, apparatus, product, or process disclosed, or represents that its use would not infringe privately owned rights. Reference herein to any specific commercial product, process, or service by trade name, trademark, manufacturer, or othenwise does not necessarily constitute or imply its endorsement, recommendation, or favoring by the United States government or any agency thereof. The views and opinions of authors expressed herein do not necessarily state or reflect those of the United States government or any agency thereof.

Printed in the United States of America

Available to DOE and DOE contractors from:

Office of Scientific and Technical Information (OSTI)

P.O. Box 62

Oak Ridge, TN 37831

Prices available by calling (615) 576-8401

Available to the public from:

National Technical Information Services (NTIS)

U.S. Department of Commerce

5285 Port Royal Road

Springfield, VA 22161

(703) 487.4650 


\section{Contents}

Introduction $\ldots \ldots \ldots \ldots \ldots \ldots \ldots \ldots \ldots \ldots \ldots \ldots \ldots$ iv

Anaerobic Digestion . . . . . . . . . . . . 1

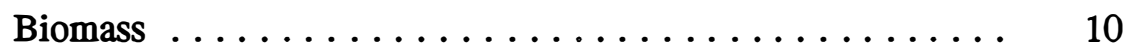

Combustion (Waste to Energy) $\ldots \ldots \ldots \ldots \ldots \ldots \ldots$

Emissions $\ldots \ldots \ldots \ldots \ldots \ldots \ldots \ldots \ldots \ldots \ldots \ldots$

Hazardous Waste $\ldots \ldots \ldots \ldots \ldots \ldots \ldots \ldots \ldots \ldots \ldots \ldots \ldots \ldots$

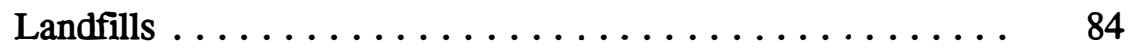

Recycling (Materials Separation) ............. 96

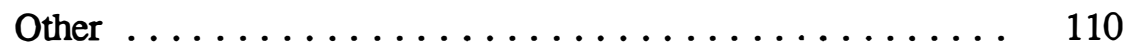

Appendix A-Pricing Schedule for U.S. Department

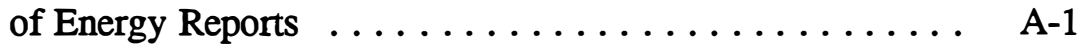

Appendix B-Alphabetical Listing of Titles $\ldots \ldots \ldots \ldots$ B-1

Appendix C_Alphabetical Listing of Authors $\ldots \ldots \ldots$ C-1 


\section{MUNICIPAL SOLID WASTE MANAGEMENT: \\ A BIBLIOGRAPHY OF U.S. DEPARTMENT OF ENERGY CONTRACTOR REPORTS THROUGH 1993}

\section{INTRODUCTION}

U.S. Department of Energy contractors continue to conduct research targeting the productive and responsible use of the more than 536,000 tons of municipal solid waste (MSW) that is generated each day in the United States. It is becoming more and more prudent to improve current methods of MSW management and to continue to search for additional cost-effective, energy-efficient means to manage our MSW resource.

This bibliography is an updated version of Municipal Waste to Energy: An Annotated Bibliography of U.S. Department of Energy Contractor Reports, by Caroline Brooks, published in 1987. Like its predecessor, this bibliography provides information about technical reports on energy from municipal waste that were prepared under grants or contracts from the U.S. Department of Energy. The reports listed focus on energy from municipal waste technologies and energy conservation in wastewater treatment. The bibliography contains three indexes-an author index, a subject index, and a title index. The reports are listed alphabetically in the subject areas and may appear under more than one subject. All of the reports cited in the original MSW bibliography are also included in this update.

The number of copies of each report originally published varied according to anticipated public demand. However, all reports are available in either microfiche or hard copy form and may be ordered from the National Technical Information Service (NTIS), U.S. Department of Commerce, Springfield, VA 22161. Explicit information on ordering reports is included in Appendix A. 


\section{Anaerobic Digestion}

Anaerobic Filters: An Energy Plus for Wastewaters Treatment, Proceedings of a Seminar/Workshop held January 9-10, 1980, at Howey-in-the-Hills, Florida, sponsored by the U.S. Department of Energy, Report No. ANL/CNSV-TM-50, 273 pp. (January 1980).

The objective of the workshop was to review current progress in anaerobic wastewater treatment processes, specifically bench-scale operations of submerged-media anaerobic reactors. Papers address the following topics: performance of fixed-film reactors; toxicity responses; uses for pharmaceutical wastes, high-strength wastes, phenols, and sludge; and use of anaerobic activated-carbon filters in wastewater treatment. A critique of the conference includes statements from the participants.

Antonopoulos, A.A., Biotechnological Advances in Processing Municipal Wastes for Fuels and Chemicals, Report No. ANL/CNSV-TM-167, 506 pp. (August 1984).

This report includes the papers presented at the Symposium on Biotechnological Advances in Processing Municipal Solid Wastes for Fuels and Chemicals sponsored by the U.S. Department of Energy's Division of Energy from Municipal Waste and by Argonne National Laboratory, held in Minneapolis, Minnesota, August 15-17, 1984. Symposium presentations covered many research areas, with emphasis on understanding the physiology, biochemistry, and genetics of microbes involved in anaerobic digestion; the various microecological interactions; the biological production of fuels and chemicals; and the generation and extraction of landfill gas.

Antonopoulos, A.A. and Wene, E.G., (Argonne National Laboratory) Bioconversion of Municipal Solid Waste and Recovery of Short-Chain Organic Acids for Liquid Fuels Production, Report No. ANL/CNSV-TM-205, Order No. DE88013967, 41 pp. (May 1988).

The purpose of this investigation was to determine the feasibility of bioprocessing municipal solid waste (MSW) to produce organic acids and recover the acids for hydrocarbon fuels production. This work has focused on acid production from anaerobic digestion of a simulated MSW material and a densified refuse-derived-fuels MSW substrate using 5-L continuously stirred and 12-L packed-bed anaerobic digesters. Methane generation was inhibited by heat treatment, addition of a methanogen-inhibiting compound, low $\mathrm{pH}$, inoculum from a long-term acid-adapted culture, and short retention times. Steady-state operation was reached with acid concentrations of $15,000 \mathrm{mg} / \mathrm{L}$ to $18,000 \mathrm{mg} / \mathrm{L}$. Nitrogen supplements to the feedstock increased volatile acid concentrations to between $27,000 \mathrm{mg} / \mathrm{L}$ and $30,000 \mathrm{mg} / \mathrm{L}$. Extraction of digester fluids containing $15,000 \mathrm{mg} / \mathrm{L}$ total acids with trioctylphosphine oxide in heptane recovered more than $82 \%$ of the acid in a single extraction. Work was continuing on maximizing the acid production and recovery from anaerobically digested MSW substrate.

Antonopoulos, A.A. and Wene, E.G., (Argonne National Laboratory) Bioconversion of MSW (Municipal Solid Waste) and Recovery of Organic Acids, presented at the Anaerobic Digestion Program Review Meeting, Golden, Colorado, 1 December 1987, Report No. CONF-871269-3, Order No. DE88005992, 11 pp. (1987).

Research was conducted to determine the feasibility of bioprocessing municipal solid waste (MSW) to produce organic acids and recover the acids for hydrocarbon fuels production. This work focused on acid production from anaerobic digestion of a simulated MSW material, and densified refuse-derived-fuel MSW substrate, using 5-L continuously stirred and 12-L packed bed anaerobic 
digesters. Methane generation was inhibited by heat treatment, addition of a methanogen inhibitory compound, low pH, inoculum from a long-term acid adapted culture, and short retention times. Steady state operation was reached with acid concentrations of 15,000 to $18,000 \mathrm{mg} / \mathrm{L}$. Nitrogen supplementations to the feedstock increased volatile acid concentrations to between 27,000 and $30,000 \mathrm{mg} / \mathrm{L}$. Aerobic sewage sludge additions to feedstock increased peak levels of acid production to $22,000 \mathrm{mg} / \mathrm{L}$. Acid extraction with trioctylphosphine oxide in heptane extracted more than $82 \%$ of the acid content in a single extraction of digester fluids with $15,000 \mathrm{mg} / \mathrm{L}$ total acids.

Brooks, C., Bioconversion: A New Technology for Waste and Sludge Disposal-Workshop Proceedings, Report No. ANL/CNSV-TM-174, 128 pp. (February 1986).

Anaerobic digestion of biomass offers a solution to the disposal of sewage sludge, municipal wastes, and other organic materials and produces a methane-rich gas. These proceedings are the result of a bioconversion workshop held to introduce a technology that results in bioconversion of these wastes to gas. The technology is based on bacterial decomposition of organic material into simpler compounds. The principal products of this process are methane and carbon dioxide. The workshop agenda included discussions of anaerobic technology and presentations of operating data and economic forecasts developed at RefCoM (Refuse Conversion to Methane), an experimental plant operating in Pompano Beach, Florida. The workshop was held May 22-24, 1985, in Ft. Lauderdale, Florida.

Dague, R., Anaerobic Biological Treatment of Liquid Wastes for Pyrolysis Processes, Final Report, University of Iowa Report No. COO/4455/3 (August 1980).

Wastewater derived from the PUROX ${ }^{\circledR}$ pyrolysis process is high in chemical oxygen-demanding substances and contains polynuclear aromatic hydrocarbons and other organic compounds, some of which are toxic. Both suspended and attached-growth anaerobic biological processes have been used to treat strong wastes. This research evaluates these two anaerobic processes for possible application to PUROX ${ }^{\circledR}$ waste.

Data Summary of Municipal Solid Waste Management Alternatives, (National Renewable Energy Laboratory), Report No. NREL/TP-431-4988J, Order No. DE93008307, 59 pp. (October 1992).

This report is one of a series on Municipal Solid Waste (MSW) management alternatives. While MSW thermoconversion and recycling technologies have been described in Appendices A through $\mathrm{E}$, this appendix addresses the role of bioconversion technologies in handling the organic fraction in MSW and sewage sludge. Much of the organic matter in MSW, consisting mainly of paper, food waste, and yard waste, has potential for conversion, along with sewage sludge, through biochemical processes to methane and carbon dioxide providing a measurable, renewable energy resource potential. The gas produced may be treated for removal of carbon dioxide and water, leaving pipeline quality gas. The process also has the potential for producing a stabilized solid product that may be suitable as a fuel for combustion or used as a compost fertilizer. Anaerobic digestion can occur naturally in an uncontrolled environment such as a landfill, or it can occur in a controlled environment such as a confined vessel. Landfill gas production is discussed in Appendix F. This appendix provides information on the anaerobic digestion process as it has been applied to produce methane from the organic fraction of MSW in enclosed, controlled reactors. 
Drexel University, Recovery of Anaerobic Digestion after Exposure to Toxicants, Final Report, Report No. DOE/CS/40049-1, 170 pp. (December 1979).

This study examines the effects on methane production of a wide variety of toxicants, heavy metals, inorganic salts, organic chemicals, solvents, and antibiotics that are used in industrial processes and, therefore, appear in industrial wastewaters. Methane fermentation of unacclimated cultures, as well as cultures acclimated to increasing concentrations of the toxicant over long periods, was tested. The reversible nature of the toxicants was assayed by adding slug doses to plug flow anaerobic filters and recording gas production before, during, and after toxicant addition.

Dynatech R\&D Co., Engineering Economic Analysis of Biomethanation of Pyrolysis Gas, Report No. DOE/CE/20098-1, 250 pp. (June 1981).

This report gives detailed results of an engineering economic analysis of the biomethanation of pyrolysis gas from municipal solid waste by the PUROX ${ }^{\circledR}$ process. A process model developed for the bubble column reactor gives material and energy balances, reaction kinetics, mass transfer rates, capital and operating costs, and a utility financing cost analysis. Unit gas costs from published economic analyses are compared for anaerobic digestion, $\mathrm{PUROX}^{\circledR}$ pyrolysis plus catalytic methanation, $\mathrm{PUROX}{ }^{\circledR}$ pyrolysis with sequential shift conversion and methanation, and PUROX ${ }^{\circledR}$ pyrolysis with simultaneous conversion and methanation.

Finney, C., et al., Fast Production of Methane by Anaerobic Digestion, Volumes 1 and 2, Report No. COO-2900-16, 275 pp. (June 1978).

Methane gas is produced as the organic fraction of solid refuse and is rendered inert by anaerobic digestion. Objectives of this research were to show that product gases are inhibiting and their transfer is rate-limiting, anaerobic digesters can be optimized to promote faster methane production, and optimal performance requires separation of hydrolysis from gasification. The research revealed that there is a purely economic justification for a two-stage technology: the masses of bacterial cells and methane were found to be about equal, and the protein content of the concentrated cells has potential as a premium agricultural feed stock.

Genung, R.K., et al., Summary of the Oak Ridge ANFLOW Pilot Plant Project, Report No. ORNL/TM-7582, 154 pp. (July 1981).

Oak Ridge National Laboratory has developed an energy-conserving wastewater treatment system based on an anaerobic, upflow (ANFLOW) bioreactor that uses films of bacteria fixed to inert, stationary packing material. The treatment process is based on passing wastewaters upward through the bioreactor for continuous treatment by gravitational settling, biophysical filtration, and biological decomposition. A two-year pilot plant project using a bioreactor was conducted with raw wastewater on a municipal site in Oak Ridge, Tennessee. The system was compared with activated-sludge treatment systems (also operating under secondary treatment requirements) and was found to consume as little as $30 \%$ of the energy required by the activated-sludge systems. 
Idaho National Engineering Laboratory, Municipal Solid Waste Bioconversion Technologies, Report No. EGG-2193, 68 pp. (October 1982).

Relevant literature on bioconversion of municipal solid waste (MSW) is reviewed. The availability, composition, and properties of MSW are reported. Pretreatment of lignocellulosic material, the predominant component of MSW, is described, including mechanical (separation and size reduction), chemical (acid hydrolysis, enzymatic hydrolysis, enzymatic hydrolysis, caustic treatment, and other chemical treatment), and physical (thermomechanical/hydropulping and irradiation) processes. The bioconversion processes described include anaerobic digestion, including a description of methanogens and their biochemistry; the results of laboratory research that used MSW as feedstock, and product and by-product recovery; pilot-scale MSW digestion facilities and the results of pilot-scale research; and the production of ethanol and chemicals by fermentation.

Isaacson, R. and Pfeffer, J., Advanced System Experimental Facility-Solid Waste to Methane Gas: Background and Process Description, Report No. ANL/CNSV-22, 15 pp. (August 1981).

The technical issues of methane production from anaerobic digestion of municipal solid waste are being investigated on a pilot-plant scale at the Refuse Conversion to Methane (RefCoM) facility in Pompano Beach, Florida. This report covers the background and theory involved in applying this technology to solid waste and the details of the specific process used in the RefCoM facility. The plant capacity is 100 tons/d. In current tests, 40 tons/d of volatile solids are fed to the digesters, which convert about 25 tons/d into gas. For each pound of solids destroyed, 6 standard cubic feet (scf) of methane and $6.6 \mathrm{scf}$ of carbon dioxide are produced. Eventually, the test facility will produce about $300,000 \mathrm{scf} / \mathrm{d}$ of each.

Mooij, H.P. and Brooks, C. (Argonne National Laboratory) "RefCOM Commercialization Program: Anaerobic Digestion," Energy from Municipal Wastes: Opportunities for the Southwest, presented at the Workshop on Energy from Municipal Waste: Opportunities for the Southwest, Austin, Texas, 23 June 1986, Report Nos. ANL/CNSV-TM-173, CONF-8606334, Order No. DE87014258, pp. 82-86 (May 1987).

The RefCOM Commercialization Program is the culmination of a developmental program that verified that the generation of methane gas from waste in a digestion process was of the same quantity and quality as established in laboratory testing. This technology resulted in establishing criteria for the construction and operation of a plant in the ptivate sector, to utilize MSW and sewage sludge.

Muller, D. and Norville, C., Sludge Storage Lagoon Biogas Recovery and Use, Report No. DOE/IR/05106-2-Vol.2, Order No. DE93005622, 69 pp. (July 1991).

The City of Memphis has two wastewater treatment plants. The SWTP employs two large anaerobic digestion sludge lagoons as part of the sludge treatment system. Although these lagoons are effective in concentrating and digesting sludge, they can generate offensive odors. The SWTP uses aerobic digesters to partially stabilize the sludge and help reduce objectionable odors before it enters the lagoons. The anaerobic digestion of sludge in the lagoons results in the dispersion of a large quantity of biogas into the atmosphere. The city realized that if the lagoons could be covered, the odor problem could be resolved, and at the same time, biogas could be recovered and utilized as a source of energy. In 1987, the city commissioned ADI International to conduct a feasibility study to evaluate alternative methods of covering the lagoons and recovering and utilizing the biogas. The study recommended that the project 
be developed in two phases: recovery of the biogas and utilization of the biogas. Phase 1 consists of covering the two lagoons with an insulated membrane to control odor and temperature and collect the biogas. Phase 1 was found to be economically feasible and offered a unique opportunity for the city to save substantial operating costs at the treatment facility. The Memphis biogas recovery project is the only application in the world where a membrane cover has been used on a municipal wastewater sludge lagoon. It is also the largest lagoon cover system in the world.

National Renewable Energy Laboratory, Anaerobic Digestion: Annual Report, FY 1988, Report No. SERI/SP-231-3520, Order No. DE89009453, 163 pp. (June 1989).

Anaerobic digestion research is being undertaken by the U.S. Department of Energy under the field management of the National Renewable Energy Laboratory to produce methane from biomass and waste. The primary focus is on municipal solid waste (MSW) as a feedstock but some efforts are ongoing using other biomass feedstocks. MSW represents a vast resource for energy production; however, its variability presents unique problems in using it as a feedstock. To make methane production from waste and biomass economical, researchers are addressing three major technological improvements: increasing solids loading, decreasing solids residence time, and improving conversion efficiency. Improvements were made in all three areas through biological and engineering research activities and resulted in a decrease in methane production cost from approximately $\$ 8.00 /$ million Btu in 1980 to less than $\$ 5.00 /$ million Btu in 1989 . Future research will continue to increase our understanding of the organisms involved in the anaerobic digestion process and their interactions. Both biological and engineering research will continue in order to decrease the cost in methane to less than $\$ 3.50 /$ million Btu by the year 2000 .

National Renewable Energy Laboratory, FY 1987 Anaerobic Digestion: Annual Report, Report No. SERI/SP-231-3331, Order No. DE88001172, 221 pp. (July 1988).

Anaerobic digestion research is being undertaken by the U.S. Department of Energy under the field management of the National Renewable Energy Laboratory and is sponsored as part of the Energy from Municipal Waste Research Program to produce methane from biomass and waste. Primary focus is on municipal solid waste (MSW) as a feedstock; however, some efforts are ongoing using other biomass feedstocks. MSW represents a vast resource for energy production; however, its variability presents unique problems in using it as a feedstock. To make methane production from waste and biomass economical, researchers are addressing three major technological improvements: increasing solids loading, decreasing solids residence time, and improving conversion efficiency. Improvements have been made in all three areas through biological and engineering research activities and have resulted in a decrease in methane production cost from approximately $\$ 8.00 /$ million Btu in 1980 to $\$ 5.00 /$ million Btu in 1988 . Future research will continue to increase our understanding of the organisms involved in the anaerobic digestion process and their interactions. Both biological and engineering research will continue in order to decrease the cost of methane to less than $\$ 3.50 /$ million Btu by the year 2000 .

Oak Ridge National Laboratory, "Vegetation Helps Microbes Clean Up Contaminated Soils," Oak Ridge National Laboratory Review, v 23:2, pp. 57-58 (1990.

According to research sponsored by DOE's Hazardous Waste Remedial Action Program, chemically contaminated soils may be cleaned up more rapidly by soil microorganisms if vegetation is present. The research was done at Oak Ridge National Laboratory using soils collected from the Savannah River Site. It was found that trichloroethylene was decontaminated faster in soils surrounding plant roots than in soil without vegetation. 
Pacific Northwest Laboratory, Operational Characteristics of Anaerobic Digesters at Selected Wastewater-Treatment Facilities in the United States, Report No. DOE/CS/20300-2, 46 pp. (July 1981).

Operating characteristics of 60 anaerobic digester facilities in the United States were surveyed to determine the number of stressed digesters and the value of the gas being produced. Median values correspond to those digesters operating well, but $30 \%$ of the digesters surveyed were stressed with regard to at least one important parameter. Methane off-gas is conservatively thought to total $2.36 \times 10^{13} \mathrm{Btu} / \mathrm{yr}$, with a present value of $\$ 40$ million.

Pacific Northwest Laboratory, Production and Utilization of Methane from Anaerobic Sludge Digestion in U.S. Wastewater-Treatment Plants, Report No. DOE/CS/20300-3, 109 pp. (July 1981).

This study estimates the energy potential from anaerobic digestion of municipal sewage sludge and assesses the present digester-gas utilization schemes with respect to energy and cost-effectiveness. Use was determined from limited survey data. To determine the most cost-effective use of digester gas, conventional on-site and off-site uses were considered. Three generic on-site uses were selected for energy and cost accounting analysis: generation of heat, mechanical energy, and electrical energy. A sensitivity analysis was also performed to assess the effects of change in the economic analysis variables. Of the gas-utilization methods analyzed, the most energy-efficient and cost-effective is the direct production of mechanical energy to drive aerators and pumps. The scheme for mechanical energy generation uses all of the digester gas by buming it directly in internal-combustion engines. Between $50 \%$ and $80 \%$ of the mechanical energy required for wastewater treatment can be provided by digester gas. In addition, waste heat can be recovered from the engines to aid in heating the digesters and buildings.

Pacific Northwest Laboratory, Enhancement of Methane Production in the Anaerobic Digestion of Municipal Sewage Sludge, Report No. DOE/CS/20300-1, 151 pp. (June 1981).

Research conducted over a two-year period demonstrated that additions of powdered activated carbon to digesters with less than normal levels of efficiency enhance operation. However, carbon addition does not improve the efficiency of well-operating digesters. Six types of powdered activated carbon were approximately equally effective in enhancing the operation of stressed digesters. Additions of coal or fly ash did not significantly improve operations. Carbon addition should be considered at fullscale treatment plants where digesters are operating poorly. However, in the initial design of new facilities, maintaining closely controlled environmental conditions, including temperature and mixing, is more important than basing the design on continuous carbon addition. A preliminary economic analysis indicated that the increase in methane production probably would not offset the cost of carbon. Economics improve when the effect of carbon on sludge handling, sludge transportation, and plant chemical requirements is included in the analysis.

Pfeffer, J. and Isaacson, R., Biochemical Conversion of Municipal Solid Waste: A Technology Status Report, Report No. ANL/CNSV-TM-122, 80 pp. (December 1982).

This is one of nine assessment reports prepared for Argonne National Laboratory to document the current state of development of energy from municipal-waste disposal/recovery technologies. This report focuses on biomass and its conversion to energy. One significant source of biomass is the organic material present in urban solid waste. Used paper, garbage (food waste), and yard and garden debris contain significant quantities of energy that originated as solar energy. Processes are being developed to recover this energy in a useful form. Biochemical-conversion processes are capable of producing methane, 
a gaseous fuel; ethanol, a liquid fuel; or synthesis chemicals that can be used in place of petroleum-based synthesis chemicals. The status of these bioconversion processes is discussed in this report.

Reutter (John G.) Associates, The Review and Evaluation of a Bioconversion Process Demonstration Plant and Its Related Technologies, Report No. DOE/CS/20101-1, 214 pp. (February 1983).

This study continues research on the implementation of a commercial-size bioconversion facility. The study was done to evaluate pertinent data related to the development and implementation of the bioconversion process, identify institutional barriers, develop realistic estimates of costs and revenues, and develop the methodology for implementing a commercial-scale bioconversion facility. The variables upon which this study was predicated are the review of the existing resource-recovery processing system and the evaluation of the biological process as cultivated at the Refuse Conversion of Methane (RefCoM) facility at Pompano Beach, Florida, under the supervision of Waste Management, Inc.

Rivard, C.J., Adney, W.S., and Himmel, M.E., (National Renewable Energy Laboratory), Enzymes for Anaerobic Municipal Solid Waste Disposal, presented at the National Meeting of the American Chemical Society (ACS), American Chemical Society, Cellulose, Paper and Textile Division, Boston, Massachusetts, 22-27 April 1990, Washington, DC: American Chemical Society, 1990, Paper CELL 9, p. 3 (1990).

It is estimated that of the 320 billion pounds of industrial and domestic waste generated in the United States each year, approximately 240 billion pounds are biodegradable. This fraction is composed primarily of paper products, food and yard waste, and a wide array of organic byproducts. The fastest growing component in municipal solid wastes are the plastics group. Although the major polymers developed and used are essentially non-biodegradable, recent state and local legislation has mandated the use of biodegradable plastics. The majority of municipal solid wastes are deposited in landfills which permit decomposition through natural anaerobic processes. These anaerobic processes are complex, with a consortia of microorganisms responsible for the production of specific enzyme mixtures necessary for effective breakdown of the polymeric substrates. Controlled anaerobic digestion systems may be used in small scale to develop appropriate microbial consortia and to determine optimal nutrient levels and environmental parameters necessary for effective degradation rates in large scale processing. This paper discusses the advances made in the biodegradation of cellulosic waste in general, with specific focus on the hydrolysis of both cellulosics and experimental and established biodegradable plastics.

Systems Technology Corp., Energy Recovery from the Effluent of Plants Anaerobically Digesting Urban Solid Waste, Report No. DOE/CS/20451-, 92 pp. (March 1983).

This report discusses a study of the parameters of concentration, time, temperature, and $\mathrm{pH}$ to find optimum conditions for enzymatically converting unreacted cellulose in the effluent of an anaerobic digester to glucose for ultimate conversion to methane, and then to project the economics to a 100-ton/d plant. The data presented illustrate the amount of cellulose hydrolysis (in percent solubilized mass) for enzyme concentrations from 5 to $1,000 \mathrm{C}_{1} \mathrm{U} / \mathrm{g}$ of substrate, using either filter paper or anaerobically digested municipal solid waste reacted over periods of $0-72 \mathrm{~h}$. With an active bacterial culture present, the optimum temperature for the hydrolysis reaction was found to be $40^{\circ} \mathrm{C}$. The feasibility of recycling enzymes by ultrafilter capture was studied, and it was found that the recovered enzyme is not denatured by any of several possible enzyme loss mechanisms - chemical, physical, or biological. Although rather stable enzyme-substrate complexes seem to be formed, various techniques permit a $55 \%$ enzyme recovery. 
Systems Technology Corp., Evaluation of Mixing Systems for Biogasification of Municipal Solid Waste, Report No. DOE/CE/20100-1, 85 pp. (June 1981).

Two specially selected mixing systems are tested and evaluated to determine how effectively they prevent the formation of fibrous mats and stringers during the anaerobic digestion of a slurried mixture of preprocessed municipal solid waste and sewage sludge. One mixing system is a mechanical agitator-a vessel-centered rotary shaft with four blades at each of two levels to drive the slurry downward. The second system is made up of three equidistant gas gun assemblies that produce bubbles at a constant rate to draw the slurry upward. Under common test conditions, the solids accumulations are generally the same for the two mixing systems. In all tests, the percentage of solids in the top level is higher than percentages in the middle and bottom levels. As the feed ratio and the percentage of solids in the feedstock are increased, this differential becomes progressively more pronounced. Moreover, the percentage of volatile solids (in a given amount of total solids) in the top level becomes disproportionately higher than percentages in the other two levels.

Tsao, T., "Pretreated High-Solids MSW for Anaerobic Digestion to Methane," Biofuels and Municipal Waste Technology Research Program Summary: FY 1986, Report No. DOE/CH/10093-6, Order No. DE87001140, p. 154 (July 1987).

A novel process for treating and digesting high-solids municipal solid waste (MSW) for rapid methane generation was designed. This process enhances the solubilization of the cellulosics in MSW by applying cooking with lime in which the solids are solubilized in a very short time. After precipitation of calcium with recycled carbon dioxide, the cooked liquor is fed to a column anaerobic digester packed with immobilized bacterial cells to complete the methane generation. The calcium precipitation removes the excess carbon dioxide from the gaseous output and makes high-Btu methane gas. The use of a continuous extruder for the alkali-cooking pretreatment of MSW feedstock is under experimentation.

Waste Management, Inc., RefCoM Research Project: Monthly Technical Report, July 1984, Report No. DOE/CS/20038-T13, 23 pp. (July 1984).

Data are presented depicting the July statistics for the operation of Digesters 1 and 2 of the RefCoM garbage-to-gas project in Pompano Beach, Florida. In addition, data on the analysis of solid and liquid effluents are tabulated.

Waste Management, Inc., Preliminary Engineering for Advanced System Experimental Facility (ASEF) Solid Waste to Methane Gas, Report No. CONS/2770-1, 249 pp. (January 1976).

This report documents the preliminary engineering effort for an Advanced System Experimental Facility (ASEF) at Pompano Beach, Florida. The ASEF is designed to produce methane gas from urban solid waste. A general description of the project, justiflcation of basic need, process design, preliminary drawings, outline specifications, estimates of cost, and time schedules for design and construction in Phases I and II are presented. 
Wene, E.G. and Antonopoulos, A.A., (Argonne National Laboratory) Liquid-Liquid Extraction of Short-Chain Organic Acids from Anaerobic Digesters, presented at the Anaerobic Digestion Review Meeting, Golden, Colorado, 25 January 1989, Report No. CONF-8901100-1, Order No. DE89009823, 11 pp. (1989).

Anaerobic digesters with glucose or municipal solid waste feed were operated to maximize production of short-chain organic acids. Digester effluent was extracted by liquid-liquid extraction with trioctylphosphine oxide (TOPO) or trioctylamine (TOA) in heptane or 2-heptanone as the water immiscible phase. Digester effluent was recycled to digesters after extraction. Both TOPO and TOA in organic solvents effectively extract organic acids from anaerobic digester fluid. Longer chain acids have a higher distribution coefficient than shorter-chain acids. Long term extraction of digester fluid with recycle was not toxic to the anaerobic production of short-chain acids.

York Services Corp., Refuse Conversion to Methane (RefCoM): Design and Modification Rationale for Proof-of-Concept Facility, Report No. ANL/CNSV-TM-102, 52 pp. (September 1981).

The report describes the design evolution of an advanced experimental plant that converts solid waste to methane. Built in 1978 in Pompano Beach, Florida, to process up to 100 tons/d of refuse, the plant is the first commercial-scale facility employing anaerobic digestion to produce methane-rich gas. The report summarizes plant operating problems, as well as the progressive refinement of the facility design. It concludes with a section on the criteria that will have to be met before anaerobic digestion can be successfully applied on a commercial scale in municipalities. 


\section{Biomass}

Bloomquist, R.G.; Simpson, S.J., District Heating and Cooling for the City and Port of Tacoma: Phase 1, Feasibility Study, Report Nos. DOE/CE/26552-T2, WAOENG-88-02, Order No. DE88004806, 307 pp. (5 January 1988).

Expansion and upgrade of Tacoma's largest sewage treatment facility together with a proposed biomass cogeneration plant sparked the interest of Washington State Energy Office (WSEO) to look at the district heating and cooling potential. Sewage effluent is used in several Swedish cities as a heat source in heat pump assisted district heating systems. The treament facility is located adjacent to downtown and the new effluent transfer pipeline will run through the port district in route to the Commencement Bay. Other potential heat sources are the proposed biomass cogeneration plant and Simpson Tacoma Kraft Pulp and Paper Mill. The pulp mill is also adjacent to downtown, however, the proposed cogeneration plant will be about a mile away. A preliminary district heating analysis was performed using a computer analysis tool called HEATPLAN. The analysis was favorable and a decision to move ahead with further study was made by WSEO.

Kuzel, F., Great Lakes Regional Biomass Energy Program, Report No. DOE/OR/21390-28, Order No. DE90015072, 15 pp. (June 1990).

This is the third quarterly report of the seventh year of operation of the Great Lakes Regional Energy Program. The program was initiated in 1983 with a grant to the Council of Great Lakes Governors from the Biofuels and Municipal Waste Technology Division of the U.S. Department of Energy. Stressing near-term biomass feedstock production techniques and conversion processes, the objective of the program is to increase the use of biomass energy by the public and private sectors in the seven-state Great Lakes region. States that are in the Great Lakes region include: Illinois, Indiana, Iowa, Michigan, Minnesota, Ohio and Wisconsin. Future planning was a major emphasis of the program this quarter. Thirty-one members of the Technical Advisory Committee met in Chicago and proposed a wide variety of projects that may be undertaken through the subcontractor component. Demonstration, technology transfer, and market development projects were suggested within the broad areas of forestry, municipal waste, and agricultural products/residue. In addition, the states of Indiana and Michigan completed state-specific planning efforts for their biomass energy programs, while the Iowa at the Crossroads comprehensive energy plan for the state of Iowa was widely distributed throughout that state and nationwide. Major technology transfer endeavors this quarter included the Waste-to-Energy and Recycling in Wisconsin: Lessons for the 90s seminar cosponsored by the Wisconsin biomass program, participation by the Ohio biomass program at the 87th Annual Meeting of the Ohio Forestry Association/Ohio Society of American Foresters, and publication and distribution of a report on the results of densified refuse-derived fuel emissions tests conducted in Iowa. Additional newsletter/ journal articles, fact sheets, and brochures relating to biomass energy were published by the Illinois, Iowa, Minnesota, Ohio, and Wisconsin programs.

Kuzel, F., Great Lakes Regional Biomass Energy Program, Report No. DOE/OR/21390-27, Order No. DE90015071, 15 pp. (March 1990).

This is the second quarterly report of the seventh year of operation of the Great Lakes Regional Biomass Energy Program. The program was initiated in 1983 with a grant to the Council of Great Lakes Governors from the Biofuels and Municipal Waste Technology Division of the U.S. Department of Energy. Stressing near-term biomass feedstock production techniques and conversion processes, the objective of the program is to increase the use of biomass energy by the public and private sectors in the 
seven-state Great Lakes region. States that are in the Great Lakes region include: Illinois, Indiana, Iowa, Michigan, Minnesota, Ohio and Wisconsin. During this quarter, technical assistance programs were expanded in several states. Iowa implemented a Biomass Prefeasibility Program by analyzing the potential for installing biofueled cogeneration systems at two sites. Three contractors began making sites visits in Minnesota to assist operators of wood-fired boiler plants make necessary corrections so that these plants can be properly operated at full capacity. Ohio plans to institute a computer-based assistance program for biomass combustion and alcohol fuel production systems. Technology transfer continued to be a major emphasis of the program. Three papers were presented at the Institute of Gas Technology's Energy from Biomass and Wastes XIV conference dealing with wood waste-to-energy, anaerobic digestion for energy recovery, and densified refuse-derived fuel emissions testing projects that were undertaken in the region. Newsletter articles, fact sheets, and brochures were published by the Ilinois, Iowa, Minnesota, and Wisconsin state programs. In addition, biomass and other alternative forms of energy made a significant contribution to Iowa at the Crossroads, the comprehensive energy plan for the state of Iowa.

National Renewable Energy Laboratory, Biofuels Program Summary, Report No. DOE/CH/10093-54, Order No. DE89000869, 240 pp. (April 1989).

The Biofuels and Municipal Waste Technology Division of the U. S. Department of Energy is responsible for research and development (R\&D) of technologies for producing liquid and gaseous fuels from biomass (organic materials such as trees, municipal solid waste, aquatic plants, and crops). The program addresses both production (growth) of biomass and its conversion to fuels. Major progress has been made toward the goal of developing cost-competitive biofuels technologies for the next decade and beyond. The Biofuels Program Summary consists of a two-volume reference set describing the technological advances and future R\&D directions of the Biofuels Program for fiscal year 1988. Volume 2 (Research Summaries) is a compilation of detailed descriptions of the various $R$ and $D$ projects performed by the national laboratories and their subcontractors from industry, university, and nonprofit research institutions. It also contains a bibliography of the various journal articles and publications produced under the program in recent years.

National Renewable Energy Laboratory, Biofuels Program Summary: Volume 1, Overview Fiscal Year 1988, Report No. DOE/CH/10093-53, Order No. DE89012254, 24 pp. (March 1989).

Within the U.S. Department of Energy, the Biofuels and Municipal Waste Technology Division is working to ensure that the technology for providing economical, plentiful, and renewable supplies of liquid and gaseous fuels will be available when the nation needs them. To this end, research is being pursued on carefully selected pathways leading to the production of renewable gasoline, diesel, and alcohol fuels, as well as pipeline-quality gas. During fiscal year 1988, the National Biofuels program continued to make progress in all areas of research, reinforcing the confidence that the research goals necessary to unlock the energy potential of biofuels are both reasonable and achievable.

Walter, D.K, "Biofuels and Municipal Waste Research Program of the U.S. Department of Energy, Biofuels and Municipal Waste Technology" Energy from Biomass and Wastes XII, Klass, D.L., ed. Presented at the Twelfth Annual Conference on Energy from Biomass and Wastes, New Orleans, Louisiana, 15-19 February 1988, Chicago, IL: Institute of Gas Technology, Report No. CONF-880215, pp. 1-14 (1989).

Biofuels are safe, secure, affordable sources of energy. The U. S. Department of Energy (DOE) is focusing its research efforts on the development of gaseous and liquid fuels, the energy sources the 
nation needs most. Biofuels are the only renewable option for producing liquid transportation fuel. The paper discusses the DOE Biofuels Program, which has narrowed its focus to five fuel cycles: alcohol fuels from wood or herbaceous crops; biogas from wet wastes; medium-Btu synthesis gas from wood and wastes; gasoline from wood; and diesel fuel from oil-bearing microalgae and terrestrial oilseed crops.

Walter, D.K., "The U.S. Department of Energy Biofuels Research Program," Energy from Biomass and Wastes XIII, Chicago, IL: Institute of Gas Technology, pp. 47-62 (1989).

This paper reports how the U.S. Department of Energy biofuels research program has focused and defined biofuels and municipal waste technology research to ensure cooperation between the various growth and conversion elements. Researchers in the conversion areas conduct experiments with energy crops that are available in commercial practice. For example, ethanol research that was formerly conducted with aspen heartwood chips has been converted to whole tree short rotation poplar chips. The energy crop program has expanded from growing more mass (cellulose) per acre to add research to improve the energy conversion quality of feedstock. 


\section{Combustion (Waste-to-Energy)}

Abbasi, H.A., Khinkis, M.J., Dunnette, R., and Nakazato, K., Use of Natural Gas to Reduce Emissions in Waste Combustors, presented at the International Gas Research Conference, Orlando, Florida, 16-19 November 1992, Report No. CONF-921152-12, Order No. DE93005408, 17 pp. (1992).

The Institute of Gas Technology, together with industrial parmers, is developing a technology that utilizes natural gas to reduce air pollutant emissions from municipal waste combustors (MWCs). This natural gas injection technology is termed METHANE de-NOX ${ }^{\mathrm{sm}}$. The results of field evaluation tests carried out at a 90 tonne/day MWC in 1991 show simultaneous reductions of $60 \%$ in nitrogen oxides and $50 \%$ in carbon monoxide with natural gas injection equal to $15 \%$ of total waste heat input. Excess air requirements were also reduced by $40 \%$ thus increasing the overall waste-to-energy plant efficiency. This approach is now being combined with injection of sorbents to also reduce the emissions of hydrochloric acid, sulfur oxides, dioxins, and furans. This paper describes the overall system design, the results of field evaluations to date and the schedule for sorbent injection trials.

Agrawal, R.K., Helt, J.E., and Klass, D.L., (Argonne National Laboratory) "Production of Oxygenated Fuels from Municipal Solid Waste Components," Energy from Biomass and Waste X, presented at the Tenth Annual Symposium on Energy from Biomass and Wastes, Washington, D.C., 7 April 1986, Chicago, IL: Institute of Gas Technology, Report No. CONF-860405, pp. 1691-1694 (1987).

There is a worldwide concern over both future energy supplies and the disposal of municipal solid wastes (MSW). Most MSW is cellulosic in nature, comprising paper, newsprint, packaging materials, wood wastes, and yard clippings. This paper reports on the investigation of the basic mechanisms of pyrolysis of these materials undertaken in both a TGA and a bench-scale, fixed-bed reactor that generates adequate quantities of gaseous and liquid products to allow them to be characterized analytically. The end products of MSW pyrolysis are a highly carbonaceous solid char, a highly oxygenated liquid tar, and a mixture of gases with low- to medium-Btu content. Depending on the type of fuel preferred, the pyrolysis conditions can be varied to maximize the desired product yield. Experimental results on the thermal decomposition of MSW components (Whatman numberl, newsprint, kraft paper, and cardboard) over a temperature range of $275^{\circ} \mathrm{C}-475^{\circ} \mathrm{C}$ were gathered. From product distributions during exploratory runs, indications are that the heating rate (for the range studies, $5^{\circ} \mathrm{C}-35^{\circ} \mathrm{C} / \mathrm{min}$ ) has no significant effect on the yields. However, the final temperature of the pyrolysis reaction does have a significant effect on the yields of the various products.

Ahmed, S., Kumar, R., and Helt, J.E., (Argonne National Laboratory) "Computer Simulation of a Municipal Solid Waste Combustor," JAPCA, the International Journal of Air Pollution Control and Hazardous Waste Management, v 39:10, pp. 1328-1333 (October 1989).

A mathematical model was developed to study the thermal and chemical processes occurring in a municipal solid waste mass combustor. Treating the solids feed as a mixture of pseudo-components, the model determines the interrelationships between the solids feed rate, grate travel rate and length, amounts and distributions of primary and secondary air, extent of solids bum out, and the bed and flame temperatures. The model incorporates the kinetics of pyrolysis of solids and simulates heat and mass transfer within the bed. The temperature and mass flow profiles generated show that much of the grate is taken up by the heatup and burnout zones. The heatup zone can be reduced by distributing the primary air to maintain minimal air flow in that region, thereby permitting rapid heatup. Increasing the solids feed rate and adjusting the air flow distributions can reduce the length of the bumout zone. The computer program, available on both PCs and mainframe, can be used for different MSW incinerator dimensions 
and feed parameters to investigate the effects of the control variables and optimize the desired output characteristics, e.g., maximize solids throughput.

Ahmed, S., Kumar, R., and Helt, J.E., (Argonne National Laboratory) Combustion Products Kinetics Model, presented at the Thermochemical Conversion Program Review Meeting, Golden, Colorado, 21 June 1988, Report No. CONF-8806176-4, Order No. DE89005850, 13 pp. (1988).

There is a need to better understand the combustion process, and the processes leading to the formation and emission of toxic or hazardous products, to improve the efficiency and the operation of energy from municipal waste (EMW) facilities. Design and operation of EMW facilities could be improved if an analytical computer model could predict the formation of combustion products under different sets of operating conditions. Preliminary work is being undertaken to determine if adequate data are available to develop a model that would describe the combustion process and the formation of products not only during combustion, but also during cooling of the combustion products in the heat recovery and gas cleanup systems. As an initial step, development of the model at the solid/gas interface at the incinerator grate is under way. Also, collection of available data on the reaction mechanisms and the kinetics of combustion has been initiated.

American Public Works Assn., Resource Recovery Options in Solid-Waste Management: A Review Guide for Public Officials, Report No. DOE/CS/20156-Tl, 51 pp. (April 1981).

This document has a twofold purpose: it serves as a guide for public works directors and others interested in implementing resource-recovery systems, and it provides background material that can be used in presenting information on resource-recovery systems to city managers, mayors, legislative bodies, and citizens' advisory groups. Additionally, the report raises issues of which local communities must be aware before developing resource-recovery systems. The document focuses on possible institutional problems that may arise in planning waste-to-energy systems, presents some solutions and alternatives, and references other publications on resource-recovery systems.

Aubum University and Alabama Department of Energy, Opelika Resource Recovery Project: Report on the Technological and Economic Evaluation, Report No. DOE/CS/20243-1, 127 pp. (July 1981).

The feasibility of waste combustion in this eastern Alabama industrial center (population 25,000) was explored because acquiring new landfill sites can be difficult, and the two industries under consideration are not receptive to purchasing steam. The report characterizes the available waste supply and steam from the Uniroyal Tire Co. plant (which can contribute shredded tires, powdered rubber, and oil to enhance the waste stream) and the West Point Pepperell, Inc., textile manufacturing plant.

Bachovchin, D.M., Yang, W.C., D'Amico, N., Newby, R.A., Ulerich, N.H., Keaims, D.L., and Chamberlin, R.M., MSW (Municipal Solid Waste) Subscale Rotary Combustor R\&D Support Program, Report No. DOE/CE/30839-T2, Order No. DE90010845, 210 pp. (29 January 1990).

The incineration of MSW is an important source of renewable energy. The present support studies extend our understanding of important hydrodynamic and chemical mechanisms that affect incinerator efficiency and environmental performance. The work is broken down into several tasks, each with specific goals as summarized here. Task 1, Chemical Reaction Phenomena, is intended to develop an understanding of the formation and destruction mechanisms for polychlorinated dibenzo-p-dioxins and 
polychlorinated dibenzofurans. A model basis for examining the effects of incinerator operating conditions and design parameters on the emissions of these species was developed. The objective of Task 2, Hydrodynamics, was to develop an understanding of the solids and gas flow and mixing phenomena in rotary incinerators. The goal of Task 3, Process Design, was to develop the basis for engineering modelling of overall combustor performance, particularly as related to minimization of toxic and regulated emissions. The purpose of Task 5, Monitoring, Instrumentation, and Control, was to. make recommendations for the utilization of advanced control techniques, in particular of on-line diagnostics, that can be used to improve rotary combustor operation, particularly with regard to emissions control.

Barrett, R.E., Krause, H.H., Jr., Engdahl, R.B., Levy, A., and Oxley, J.H., Municipal Waste-to-Energy Technology Assessment, Report No. EPRI-TR-100058, 280 pp. (January 1992).

Two major technologies are available to burn municipal solid waste to generate steam for the production of electricity: mass-burn and refuse-derived fuel (RDF) systems. Mass-burn systems process as-received waste directly in a combustor, such as a reciprocating, rotary, or roller-grate furnace, with only limited removal of undesirable objects. RDF systems first process the waste to produce RDF via shredding and other operations before combustion in spreader-stoker, fluidized-bed, and other suitable combustors. Although mass-bum systems with specially designed grates are considered proven technology, there is much interest in RDF systems, because RDF can be used in a wide range of combustors, including some utility power plants of conventional design. However, a number of technical issues remain for both mass-bum and RDF-firing systems, and further research is warranted. Disposal of the ash residues from the combustor and/or the waste from the air-pollution control equipment is a major issue preventing more widespread use of this technology. Selection of materials of construction is also an important issue. Continuous-emission-monitoring requirements may be exceeding the technical capabilities for reliable, long-term operation. The occasional receipt of biologically active waste or waste containing heavy metals is still a troublesome issue. Dioxin emissions seem to be a problem only in plants of early design, although the issue of dioxin emissions continues to be a major one in permit applications and public relations.

Battelle Columbus Division, Feasibility of Implementing a Municipal Waste-to-Energy System to Supply Youngstown Thermal with a Solid Fuel or Steam System, Report No. DOE/RA/50364, 235 pp. (1984).

This report discusses municipal solid waste and the economics of disposal; Youngstown Thermal's existing system and its economics; and the technical feasibilities of refuse-derived fuels and refuse mass-burning. Economic evaluations and institutional considerations are included.

Battelle Columbus Division, Energy Recovery from Municipal Solid Waste and Sewage Sludge Using Multi-Solid Fluidized-Bed Combustion Technology, Report No. DOE/CS/20424-1, 210 pp. (July 1981).

The multisolid fluidized-bed-combustion (MS-FBC) process for simultaneous recovery of highand low-pressure steam is investigated. Results show that the MS-FBC process concept for coutilization of municipal solid waste and domestic sewage sludge is technically feasible. Thermal efficiency of the process is $76-82 \%$, based on experiments conducted in a $70-85-1 \mathrm{~b} / \mathrm{h}$ pilot plant and on calculations of three conceptual cases. The process is recommended for scale-up to 10 tons/d. 
Beeghly, J.H., Dick, W.A., and Wolfe, W., Land Application Uses of Pressurized Fluidized-Bed Combustion (PFBC) Ash, presented at the Coal-Fired Power Systems 93: Advances in IGCC and PFBC Review Meeting, Morgantown, West Virginia, 28-30 June 1993, Report No. DOE/MC/28060-93/C0232, CONF-9306148-23, Order No. DE93019875, 20 pp. 1993.

Dry alkaline flue gas desulfurization by-products (dry lime and limestone FGD scrubber ashes) including the American Electric Power Tidd PFBC bed and cyclone ash, are being evaluated for beneficial uses via land application for agriculture, mine reclamation, and soil stabilization in a 5-year study that began in December 1990. A 1989 Battelle Memorial Institute report recommended that the highest priority in stimulating reuse of FGD by-products was the sponsoring of in-field research of coal combustion products generated from high sulfur midwestern coals to better understand and quantify the leach rate, fate and transport of sulfates and trace metals, and to demonstrate the level of protection necessary to build public acceptance of land-based reuses. The specific objectives of the demonstration project are as follows: to characterize the material generated from dry FGD processes, to demonstrate the utilization of dry FGD by-products as soil amendment material on agricultural lands and on abandoned and active surface coal mines in Ohio, to demonstrate the use of dry FGD by-products as an engineering material for soil stabilization, to determine the quantities of dry FGD material that can be used in each of these applications, and to determine the environmental and economic impact of utilizing the material.

Bigham, J., Dick, W., Forster, L., Hitzhusen, F., McCoy, E., Stehouwer, R., Traina, S., Wolfe, W., and Haefner, R., Land Application Uses for Dry FGD By-Products, Report No(s). DOE/MC28060-T4 and OCDO-93017597, Order No. DE93017597, 354 pp. (April 1993).

The 1990 amendments to the Clean Air Act have spurred the development of flue gas desulfurization (FGD) processes, several of which produce a dry, solid by-product material consisting of excess sorbent, reaction products containing sulfates and sulfites, and coal fly ash. Presently FGD byproduct materials are treated as solid wastes and must be landfilled. However, landfill sites are becoming more scarce and tipping fees are constantly increasing. It is, therefore, highly desirable to find beneficial reuses for these materials provided the environmental impacts are minimal and socially acceptable. Phase 1 results of a 4 1/2-year study to demonstrate large volume beneficial uses of FGD by-products are reported. The purpose of the Phase 1 portion of the project was to characterize the chemical, physical, mineralogical and engineering properties of the FGD by-product materials obtained from various FGD technologies being developed in the state of Ohio. Phase 1 also involved the collection of baseline economic data related to the beneficial reuse of these FGD materials. A total of 58 samples were collected and analyzed. In summary, Phase 1 results revealed that FGD by-product materials are essentially coal fly ash materials diluted with unreacted sorbent and reaction products. High volume beneficial reuses will depend on the economics of their substituting for existing materials for various types of applications (e.g. as an agricultural liming material, soil borrow for highway embankment construction, and reclamation of active and abandoned surface coal mines). Environmental constraints to the beneficial reuse of dry FGD byproduct materials, based on laboratory and leachate studies, seem to be less than those for coal fly ash.

Bi-State Development Agency, Bi-State Solid Waste to Energy Project, Report No. DOE/CS/20233-1, 177 pp. (December 1982).

The Bi-State Development Agency developed information in this report to evaluate whether resource recovery was technically feasible and an institutionally practical solution to solid-waste disposal problems for a region that includes the City of St. Louis; St. Louis, St. Charles, and Jefferson Counties in Missouri; and Madison, Monroe, and St. Clair Counties in Illinois. The Phase I feasibility investigation concluded that resource-recovery opportunities existed and that implementation of several economically 
attractive and technically feasible projects appeared to be prudent. On the basis of the Phase I investigation and results, Bi-State decided to proceed with the implementation of two projects that would dispose of waste from those areas of the Bi-State region facing the most imminent waste disposal problems. Two projects were identified as the prime project opportunities as a result of the Phase I feasibility investigation. The first was a cogeneration facility with a rated capacity of 2,250 tons/d that would be located in downtown St. Louis and process waste from the City of St. Louis and contiguous Illinois counties to produce steam for sale to Union Electric's (UE's) downtown district heating loop, as well as electricity for sale to UE. The second project was a 1,000-ton/d facility that would be located in south St. Louis County or north Jefferson County and would convert solid waste (primarily from south St. Louis County) into refuse-derived fuel (RDF) for sale to UE for cofiring with coal in its Meramec Station. Bi-State subsequently modified the system concept and structure for the steam loop project to constitute a 600 -ton/d waste-fired facility (with supplemental oil- or gas-fired package boilers) selling steam to the City of St. Louis. The concept for the RDF project has remained the same.

Borchardt, F.A., Gesell, G.H., and Brooks, C., (Argonne National Laboratory) "Mass Burning: Do In-Place Systems Work," Energy from Municipal Wastes: Opportunities for the Southwest, presented at the Workshop on Energy from Municipal Waste: Opportunities for the Southwest, Austin, Texas, 23 June 1986, Report Nos. ANL/CNSV-TM-173, CONF-8606334, Order No. DE87014258, pp. 6-32 (May 1987).

Mass-burn waste-to-energy plants take the solid waste as received and burn it as fuel on one of a variety of grate types. Depending on their size, the plants may have a tipping floor and a front-end loader or a refuse pit and cranes for storing and handling the waste. Field-erected furnaces, used for large-scale facilities, may either have a refractory furnace chamber and separate boiler or a waterwall furnace and boiler. Modular units, used for smaller-scale facilities, typically have a refractory combustion chamber and are somewhat less efficient. Mass-burn facilities have experienced problems in such areas as receiving and storing wastes, refuse cranes, grates, boiler tubes, slagging, and ash handling. Effective solutions have been found for these problems, however, and most facilities have been very successful.

Bradshaw, W.M. and Krishnan, R.P., Removal of Acidic Gases from Incinerator Flue Gas in a Fluidized Bed Scrubber, presented at the American Institute of Chemical Engineers Annual Meeting, Washington, D.C., 27 November-2 December, 1988, New York: American Institute of Chemical Engineers, Report No. CONF-881143, Technical Paper 162E, 11 pp. (1988).

This paper describes a parametric study conducted in a 5-cm bubbling bed to determine the feasibility of scrubbing acidic gases from incinerator flue gas by direct contact with an alkaline sorbent in a fluidized bed. The effects of process parameters on removal of $\mathrm{HCl}, \mathrm{P} /{ }_{2} / 0_{5} /$, and $\mathrm{SO} / 2 /$ were investigated experimentally. The relationship between removal efficiency and sorbent utilization was determined at $542^{\circ} \mathrm{C}\left(1000^{\circ} \mathrm{F}\right)$ and twice the minimum fluidization velocity.

Brooks, C., (Argonne National Laboratory) Municipal Waste to Energy, An Annotated Bibliography of U.S. Department of Energy Contractor Reports, Report No. ANL/CNSV-TM-183, Order No. DE87009806, 110 pp. (January 1987).

Annotated reports listed are limited to those that focus on energy from municipal waste technologies and energy conservation in wastewater treatment. 
Brooks, C., Energy from Municipal Waste Research: A Technical Review of Thermochemical Systems-Workshop Proceedings, Report No. ANL/CNSV-TM-144, 336 pp. (September 1984).

This workshop was held to present technical information developed through government-funded and private-sector research and plant operations. The workshop focused on combustion of municipal solid waste (MSW) and thermal methods of converting MSW to usable fuels. State-of-the-art information on these subjects was prepared for an audience of consulting engineers, design engineers, contractors specializing in this field, and others seeking in-depth information on waste-to-energy technologies.

The technical data presented were developed empirically from operating benchscale and demonstration projects. Speakers stressed environmentally acceptable methods of disposing of MSW using currently available combustion technologies, as well as those in various stages of research, development, and proof.

A session on environmental issues presented new developments in emission standards and measurements. Speakers at this session addressed such topics as environmental impediments facing operational combustion facilities and those under construction, ways of dealing with environmental issues in states with rigid environmental regulations, and the current direction of governmental acceptance standards for energy-from-municipal-waste facilities.

Brooks, C., Energy from Municipal Waste: State-of-the-Art and Emerging Technologies-Workshop Proceedings, Report No. ANL/CNSV-TM-137, 272 pp. (February 1984).

During 1982, Argonne National Laboratory and its subcontractors prepared a series of nine assessments to document the state of development of energy from municipal-waste disposal/ recovery technologies. These proceedings provide summaries of the information included in the state-of-the-art reports. Specific topics include large-scale waterwall systems, external combustion, mechanical equipment and systems, firing refuse-derived fuel (RDF), RDF cofiring by the electric utility industry, modeling techniques for characterizing the performance of waste conversion facilities, pyrolytic conversion, fluidized-bed combustion, biological conversion of wastes, solid waste to methane gas, trace emissions, and environmental issues.

Brooks, C., Proceedings of the Waste-to-Energy Workshop on Small-Scale Combustion Systems, Report No. ANL/CNSV-TM-130, 192 pp. (February 1984).

The proceedings consist of papers presented at a workshop that focused on small waste-to-energy combustion systems for energy from municipal waste. The workshop was held July 20-22, 1983, in Nashville, Tennessee. Information presented at the workshop was for city officials and planners, consultants, industrial engineers, citizens, and others concerned with waste-to-energy technologies. Recognized authorities in various areas of waste-to-energy technology, as well as experts in financing and marketing, discussed the feasibility and economics of available systems. 
Buhler, F. and Brooks, C., (Argonne National Laboratory) "Siting a Waste-to-Energy Facility: the First Acceptance Test," Energy from Municipal Wastes: Opportunities for the Southwest, presented at the Workshop on Energy from Municipal Waste: Opportunities for the Southwest, Austin, Texas, 23 June 1986, Report Nos. ANL/CNSV-TM-173, CONF-8606334, Order No. DE87014258, pp. 155-164 (May 1987).

The purpose of this presentation is to review briefly the technical and environmental requirements for site selection and address the facility siting process itself, including strategies that can move the site selection task along in a manner that avoids the expensive delays and defeats that kill projects. In addition to the technical/environmental criteria, summarized various energy market siting considerations are presented that should be addressed in the preliminary facility site assessment.

Bushnell, D.J., Canova, J.H., and Dadkhah-Nikoo, A., Municipal Solid Waste Combustion: Fuel Testing and Characterization, Report No. DOE/BP/07014-1, Order No. DE92040083, 209 pp. (1 October 1990).

This study screens and characterizes potential biomass fuels from waste streams by determining the types of pollutants produced while buming selected municipal waste, i.e., commercial mixed waste paper residential (curbside) mixed waste paper, and refuse derived fuel. These materials are fired alone and in combination with wood, equal parts by weight. The data from these experiments can be used to size pollution control equipment required to meet emission standards. This document provides detailed descriptions of the testing methods and evaluation procedures used in the combustion testing and characterization project. The fuel samples are examined thoroughly from the raw form to the exhaust emissions produced during the combustion test of a densified sample.

Cal Recovery Systems, Composition and Properties of Municipal Solid Waste and Its Components, Report No. DOE/SF/11724-Tl, 105 pp. (May 1984).

This report includes data obtained through waste composition surveys and laboratory analyses. It provides information on generation rates and waste-stream composition and properties. In addition to the results obtained in waste composition surveys conducted in cities in various parts of the United States, the report includes a listing of the mechanical, thermal, and chemical properties of the waste. Among the properties reported are bulk densities, ash contents, ash fusion temperatures, proximate and ultimate analyses, and heating values.

Central Wayne County Sanitation Authority, Refuse Incinerator Electrostatic Precipitator Installation, Final Report, Report No. DOE/CS/20232-Tl, 481 pp. (September 1984).

This report contains the specifications, notice to bidders, instruction to bidders, proposal, contract, bonding information, and general conditions for the construction and installation of a refuse-incinerator pollution-control device (electrostatic precipitator). The installation was to be used in Dearborn Heights, Michigan, for the combustion of municipal solid wastes. 
Central Wayne County Sanitation Authority, Energy Recovery and Cogeneration from an Existing Municipal Incinerator: Phase IIA, Progress Report on Final Design, Report No. DOE/CS/20232-2, 78 pp. (February 1982).

The Central Wayne County Sanitation Authority owns and operates an 800-ton/d incinerator facility that discharges its combustion heat into the environment. Incinerators Nos. 1 and 2 were placed in operation in 1964, and incinerator No. 3 was started up in 1972. The plant is well maintained and is operated efficiently. This report summarizes a feasibility study prepared on energy recovery and cogeneration from an existing municipal incinerator. The report shows a waste heat boiler for each of the three incinerators. Steam from these waste heat boilers will supply energy to two turbine-generators, which in turn will supply auxiliary power to the incinerator plant; the balance of the power will be sold to Detroit Edison Co. Exhaust steam from each turbine will be directed into a surface condenser operating under vacuum. The water to be supplied to each condenser will be recirculated water that has been cooled by means of a cooling tower. Other cooling water that could be subjected to oil contamination will be supplied from a separate recirculating water system. The water in this system will be cooled by an evaporative condenser. The main steam, boiler feedwater, and condensate systems will be similar to those used in central power stations. Flow diagrams for all systems, together with heat balances, electrical on-line diagrams, and plant layouts, are included in the Appendix. Also included in the Appendix are logic diagrams for instruments and controls.

Central Wayne County Sanitation Authority, Feasibility Study-Energy Recovery and Cogeneration from an Existing Municipal Incinerator, Phase 1, Final Report, Report No. DOE/CS/20232-1, 458 pp. (July 1981).

The technical and economic feasibility of retrofitting an 800-ton/d, three-unit incineration complex to recover heat energy is reported. The Central Wayne County Sanitation Authority proposes installation of waste heat boilers with each unit and a turbine generator.

Chung, P., Vertical Combustor for Refuse Combustion, Report No. ANL/CNSV-TM-80, 56 pp. (August 1981).

A vertical combustor for refuse-particles is analyzed for waste-to-energy recovery. Combustion chemistry and devolatilization kinetics are discussed for typical refuse fuel. The fuel particle combustion model considers three separate temperatures for gas, fuel, and inert particles. A simplified version of the model is given for use in the Texas Instruments TI-59 programmable calculator.

Churney, K.L., et al., Assessing the Credibility of the Calorific Value of Municipal Solid Waste, Report No. NBSIR-84-2825, 48 pp. (February 1984).

A study was made at the National Bureau of Standards to establish the limits of reliability of the calorific value of municipal solid waste determined by the bomb calorimetric procedure currently used in commercial test laboratories. This procedure involves using gram-size samples derived from municipal solid waste (MSW) that was reduced to a particle size of $2 \mathrm{~mm}$ or less. Critics of the procedure argue that gram-size samples are too small to be representative of a large quantity of such a heterogeneous material, and that processing MSW may also alter its composition. To test the bomb calorimetric procedure, a 2.5-kg-capacity combustion flow calorimeter was designed and constructed for the determination of the enthalpies of combustion of kilogram-size samples of MSW in flowing oxygen near atmospheric pressure. Calorimetric data on processed MSW were obtained using both the kilogram-size 
flow and a gram-size bomb calorimeter. Intercomparison of results show that the calorific value (on a dry basis) of gram-size test samples agrees, within the uncertainty of the experiments, with the corresponding values for their kilogram-size parent samples, provided that the sample division technique used to obtain the gram-size samples is that described in this work.

City of Columbia, City of Columbia, Missouri: Development of a Waste-to-Energy Plan, Report No. DOE/CS/20239-1, 85 pp. (February 1982).

This report summarizes findings of investigations for the development of a waste-to-energy plan for the City of Columbia. Three approaches were explored in the development of the plan: (1) use of shredded solid waste in the existing stoker-fired boilers of the city's water and light department, (2) use of unprocessed solid waste as fuel in modular burning units equipped with waste heat boilers for the production of steam, and (3) use of the gases of combustion from the primary chambers of modular burning units for direct injection into one of the existing boilers of the city's power plant.

City of Dalton, Georgia, MunicipalIndustrial Waste Gasification Feasibility Study, Report No. DOE/CS/50319-1, 59 pp. (August 1982).

The City of Dalton, Georgia, carried out a feasibility study to investigate converting the waste from the local tufted-carpet industry into useful energy using the atmospheric fluidized-bed gasification process. Study findings constitute the body of this report. Section 2 addresses preliminary facility design. Economic and financial analysis is covered in Secs. 3 and 4.3. Sections 4.3 and 4.4 cover the subject of ash disposal. Siting considerations are reported in Secs. 2.10 and 4.4. Environmental, health, safety, and socioeconomic assessments are covered in Sec. 4.

City of Denton, Texas, Urban Waste as a Potential Energy Source for Brick Plants, Report No. DOE/CS/24311-1, 36 pp. (December 1982).

A joint project between the City of Denton, Texas; Acme Brick Co.; and North Texas State University, Department of Chemistry, addresses the technical feasibility of utilizing municipal solid waste (MSW) as a commercial fuel for the brick industry. Specifically, the refuse-derived fuel (RDF) from MSW was investigated for three potential applications in the brick industry: rotary brick kilns, tunnel brick kilns, and moisture dryers. This report describes the sampling and collection of MSW, the analysis of the MSW, the analysis of RDF, and the potential utilization of RDF as an alternative source of fuel for the brick industry.

City of Fort Smith, Arkansas, Preliminary Engineering Report for Fort Smith Refuse-Derived Energy Project, Report No. DOE/RA/50302-1, 140 pp. (March 1983).

Phase 2 of a project by Fort Smith, Arkansas, to develop sufficient information on design parameters and economics of the waste-to-energy concept to allow the city to make a "go" or "no go" decision on proceeding with implementation is presented in this report. An additional objective of the work was to determine the feasibility of using the garbage-burning facility as a means for disposal of wastewater plant sludge. The sludge-disposal concept, codisposal, was considered an optional feature for the solid-waste plant. 
City of Orlando, Florida, City of Orlando: Resource Recovery Project Final Feasibility Study, Report No. DOE/CE/20236-1, 266 pp. (October 1982).

The purpose of the study this report presents was to provide information to enable the City of Orlando to proceed or not to proceed with a waste-to-energy project. This report contains the findings, conclusions, and recommendations of the consulting engineers, sanitation department, and legal department. The study specifically considered the following: expansion of the existing incinerator plant, recovery of waste heat energy from the waste heat energy process to produce electric power, and use of the refuse-derived electric power to supplement or replace existing supplies of electricity provided to the city incinerator and wastewater treatment plants.

City of San Francisco, Solid Waste Management Program, City and County of San Francisco, Final Report, Report No. DOE/CS/24319-Tl, 12 pp. (September 1982).

The financial, legal, pollution-control, and contractual aspects of San Francisco's planned waste-to-energy project are described in this report. Particulate matter will be removed from flue gas by means of a baghouse consisting of a series of fabric filters in parallel. The acid-gas $\left(\mathrm{HCl}\right.$ and $\left.\mathrm{SO}_{\mathrm{x}}\right)$ emissions will be controlled by means of staged combustion and flue-gas recirculation. The technology to be used for controlling the discharge of hazardous polyorganic materials is high-temperature thermal destruction of the material in the combustion chamber. The cost of air-pollution control will be approximately $15 \%$ to $30 \%$ of the $\$ 170$ million cost for the facility.

City of Tacoma, Washington, Tacoma Refuse-Fired Combustor Feasibility Study, Report No. DOE/CS/20009-1, 32 pp. (January 1983).

This report outlines a study conducted by the City of Tacoma of the densification of refuse-derived fuel (RDF). The study examined several areas, including investigation of densification methods and equipment, the purchase and adaptation of a densifier unit to operate with an existing resource-recovery system, operating experience and modifications of the unit to adapt it to RDF, and actual manufacturing and burning of densified RDF in industrial waste fuel boilers and waste fuel gasifiers.

Clay, N.A. and Brooks, C. (Argonne National Laboratory) "San Diego Experience in Resource Recovery," Energy from Municipal Wastes: Opportunities for the Southwest, presented at the Workshop on Energy from Municipal Waste: Opportunities for the Southwest, Austin, Texas, 23 June 1986, Report Nos. ANL/CNSV-TM-173, CONF-8606334, Order No. DE87014258, pp. 203-205 (May 1987).

San Diego's only landfill is receiving about 1.2 million tons/year or 4000 tons/day of trash. The SANDER facility is sized to take about 2250 tons/day and an active recycling program disposes of the other 1750 tons/day. The citizens of San Diego are recycling newspaper and aluminum cans at a rate close to $40 \%$ to $50 \%$ through community buyback centers and volunteer organizations such as churches and schools. The city has plans on the drawing board for a major buyback center at the landfill and is looking at a curbside recycling program for certain communities. A feasibility study for mechanical separation of raw garbage at the landfill has been completed and submitted to private industry for their input before issuing a request for proposal.

Clearwater, S.W. and Hill, M.A., "The Effects of Proposed Environmental Legislation and Rulemaking on Waste-to-Energy Facilities," Energy from Biomass and Wastes XIV, Klass, D.L., ed. Presented at the 
Fourteenth Annual Conference on Energy from Biomass and Wastes, Lake Buena Vista, Florida, 29 January-2 February 1990; Chicago, IL: Institute of Gas Technology, Report No. CONF-900117, pp. 317-335 (1991).

The United States is experiencing very rapid growth in the number of municipalities and counties proposing the construction of waste-to-energy facilities for processing municipal solid waste. The matrix of environmental regulation that affects these waste-to-energy facilities is evolving at an equally rapid pace. This paper focuses on three aspects of currently proposed regulation of waste-to-energy facilities. First, the U. S. Environmental Protection Agency (EPA) has proposed extensive regulations for new and existing municipal waste combustors, EPA's proposal, expected to be finalized by December 1990, may require retrofitting air pollution control devices on many existing facilities, as well as installing new technology, such as ammonia injection, on newly proposed plants. EPA has also proposed a controversial $25 \%$ recycling requirement for both new and existing facilities. This paper also addresses the Senate's most recent draft legislation to amend the Clean Air Act with detailed provisions related to air emissions and ash disposal from municipal waste incinerators. The Clean Air Act legislation will almost certainly be enacted this coming term and will, no doubt, have significant effects on waste-to-energy facilities. Finally, this paper discusses recent proposals to amend the Resource Conservation and Recovery Act to specifically address ash disposal from municipal waste incinerators, and include a nationwide recycling strategy.

Commonwealth Research Group, Inc., Risks Involved in Commercialization of Multiple Hearth Furnaces for Sludge Disposal Using Refuse-Derived Fuels, Report No. DOE/CS/21305-1, 215 pp. (November 1981).

This assessment determines the organizational, social, economic, and technical risks associated with sludge disposal in multiple-hearth furnaces that use primarily refuse-derived fuel (RDF). The proposed Memphis, Tennessee, sludge-disposal project is examined in a case study. This complex project involves sludge dewatering plants, an RDF manufacturing facility, a facility for handling flammable liquid wastes, a secondary plant for coal-fired and RDF-fired steam generation, and a 1200-ton/d plant for sludge drying, steam drying, and steam generation.

Connecticut Resources Recovery Authority, Mid-Connecticut Project on Resource Recovery from Municipal Solid Wastes, Final Status Report, Report No. DOE/CS/20168Tl, 8 pp. (December 1984).

This is the final status report on the Connecticut Resources Recovery Authority and the Metropolitan District Commission jointly sponsored program to investigate the feasibility of a resource-recovery project for the mid-Connecticut region. The municipal solid waste (MSW) processing and steam boiler plant configuration will be designed by Combustion Engineering. The technology selected for the mid-Connecticut project includes an MSW collection and transfer system and two processing lines, which produce steam suitable to generate electricity. The residue, by-pass and boiler ash (bottom and fly), is transported to a regional landfill located in the North Meadows area of Hartford. The front-end processing system is technically straightforward. The processing facility will prepare the MSW for combustion by removing noncombustible and valuable material and will reduce the remainder to a size that can be used as fuel in the dedicated boilers. A major component to the success of the project is the ability to burn Appalachian low-sulfur bituminous coal in combination with the processed MSW in the stoker boilers. 
Connecticut Resources Recovery Authority, Two-Phase Procurement Procedure for Selection of $a$ Resource Recovery System Contractor, Report No. DOE/CS/20168-1, 96 pp. (February 1983).

This report presents information on a two-phase procurement procedure designed to select a resource-recovery system contractor to supply, construct, and possibly operate essential elements of a waste-to-energy conversion center for the Connecticut Resources Recovery Authority.

Consumat Systems, Inc., Evaluation of the Feasibility of Co-Producing Sewage Sludge with Municipal Solid Waste, Final Report, Report No. DOE/CS/20238-T1, 74 pp. (March 1980).

The feasibility of coprocessing sewage sludge with municipal waste in Consumat modular controlled-air incinerators is discussed. Attention is directed principally to the effect of sludge addition on waste processing capacity, steam production rates, and air quality conditions. Both the quantity of the sludge processed and the moisture content of the sludge are considered as primary parameters.

CSI Resource Systems, Inc., Large-Scale Commercial Combustion Systems for Producing Energy from Municipal Solid Waste, Report No. DOE/CS/24312-8, 39 pp. (February 1985).

This report presents an overview of the large-scale combustion systems available on the U.S. market today that use only municipal solid waste as fuel. Its purpose is to provide waste-to-energy project participants with basic technical information to facilitate an understanding of the operation and performance of the technologies employed. General technical descriptions of the two types of large-scale systems, mass-burning and refuse-derived fuel buming, are presented. Performance characteristics of each system, based on material and energy balances, are discussed. Also included is a description of the typical energy product options (steam only, cogeneration of steam and electricity, or electricity only) that may be considered for both types of systems depending on the available markets for energy. A discussion of the sources and types of emissions from these systems (air, water, ash and other residue, noise, and odor) is presented. References used in the preparation of the report are included. Appendix B identifies the vendors and gives brief descriptions of variations in their system designs.

CSI Resource Systems, Inc., Analysis of the Financial Impacts to the Industrial Energy User of Using Coal or Municipal Solid Waste in a New Process-Steam-Generating Plant, Report No. DOE/CS/24312-7, 114 pp. (October 1983).

This report presents an analysis of the financial impacts on the industrial energy user of using either coal or municipal solid waste in a new process-steam-generating plant. The results of the analysis indicate that the use of coal or solid waste, rather than oil, in a new energy-production plant represents an attractive investment. The financial analysis is based on replacing an existing oil-fired plant with a new plant financed via $100 \%$ debt. The analysis was structured to cover a range of steam demands, different plant ownership and operating structures, and the tax benefits available to these types of plants. While this report is indicative only, it should be of use to industrial managers who are considering solid-fuel options for new energy-production plants. 
Curlee, T.R., Schexnayder, S.M., Vogt, D.P., Wolfe, A.K., Kelsay, M.P., and Feldman, D.L., (Oak Ridge National Laboratory), Waste-to-Energy in the United States: Socioeconomic Factors and the DecisionMaking Process, Report No. NREL/TP-430-5694, Order No. DE93018226, 159 pp. (October 1993).

This study takes an in-depth look at the socioeconomic factors that have played a role in the decisions of communities that have considered WTE as a component of their solid waste management strategies. More specifically, a three-pronged approach is adopted to investigate the relationships between a municipality's decisions to consider and accept or reject WTE and key socioeconomic parameters, the potential impacts of recent changes in financial markets on the viability of WTE, and the WTE decisionmaking process and the socioeconomic parameters that are most important in the municipality's decision. The first two objectives are met by the collection and analysis of aggregate data on all U.S. WTE initiatives during the period from 1982 to 1990. The latter objective is met by way of four in-depth case studies - two directed at communities that have accepted WTE and two that have cancelled WTE projects.

Data Summary of Municipal Solid Waste Management Alternatives, (National Renewable Energy Laboratory), Report No. NREL/TP-431-4988C, Order No. DE93008312, 140 pp. (October 1992).

This appendix on mass burn technologies is the first in a series designed to identify, describe and assess the suitability of several currently or potentially available generic technologies for the management of municipal solid waste (MSW). These appendices, which cover eight core thermoconversion, bioconversion and recycling technologies, reflect public domain information gathered from many sources. Representative sources include: professional journal articles, conference proceedings, selected municipality solid waste management plans and subscription technology data bases. The information presented is intended to serve as background information that will facilitate the preparation of the technoeconomic and life cycle mass, energy and environmental analyses that are being developed for each of the technologies. Mass bum has been and continues to be the predominant technology in Europe for the management of MSW. In the United States, the majority of the existing waste-to-energy projects utilize this technology and nearly 90 percent of all currently planned facilities have selected mass bum systems. Mass burning generally refers to the direct feeding and combustion of MSW in a furnace without any significant waste preprocessing. The only materials typically removed from the waste stream prior to combustion are large, bulky objects and potentially hazardous or undesirable wastes. The technology has evolved over the last 100 or so years from simple incineration to the most highly developed and commercially proven process available for both reducing the volume of MSW and for recovering energy in the forms of steam and electricity. In general, mass bum plants are considered to operate reliably with high availability.

Data Summary of Municipal Solid Waste Management Alternatives, (National Renewable Energy Laboratory), Report No. NREL/TP-431-4988D, Order No. DE93008313, 147 pp. (October 1992).

This appendix contains background information, technical descriptions, economic data, mass and energy balances, and information on environmental releases for the refuse-derived fuels option in municipal solid waste management alternatives. Demonstration programs at St. Louis, Missouri; Franklin, Ohio; and in Delaware are discussed. Information on pellet production and cofiring with coal is also presented. 
Data Summary of Municipal Solid Waste Management Alternatives, (National Renewable Energy Laboratory), Report No. NREL/TP-431-4988E, Order No. DE93008314, 59 pp. (October 1992).

This appendix provides information on fluidized-bed combustion (FBC) technology as it has been applied to municipal waste combustion (MWC). A review of the literature was conducted to determine to what extent FBC technology has been applied to MWC, in terms of number and size of units was well as technology configuration; the operating history of facilities employing FBC technology; and the cost of these facilities as compared to conventional municipal solid waste (MSW) installations. Where available in the literature, data on operating and performance characteristics are presented. Tabular comparisons of facility operating/cost data and emissions data are compiled and presented. The literature review shows that FBC technology shows considerable promise in terms of providing improvements over conventional technology in areas such as $\mathrm{NO}_{\mathrm{x}}$ and acid gas control and ash leachability. In addition, the most likely configuration to be applied to the first large scale FBC dedicated to MSW will employ circulating bed (CFB) technology. Projected capital costs for the Robbins, Ilinois, 1600 ton per day CFB-based waste-to-energy facility are competitive with conventional systems, in the range of $\$ 125,000$ per ton per day of MSW receiving capacity.

Data Summary of Municipal Solid Waste Management Alternatives, (National Renewable Energy Laboratory), Report No. NREL/TP-431-4988F, Order No. DE93008304, 60 pp. (October 1992).

This appendix summarizes information available in the open literature describing the technology and operating experience of pyrolysis technology as applied to the management of municipal solid waste (MSW). The literature search, which emphasized the time frame of greatest activity in MSW pyrolysis (i.e., the mid-1960s to the mid-1980s), focused on the scale of application, material feedstock, technical limitations and economic considerations. Smaller scale facilities, either laboratory/research scale $(<1$ ton per day [TPD]) or process development/pilot scale plants (1-20 TPD) for municipal waste and related materials (agricultural, forest residues, industrial wastes, etc.), are mentioned in the literature. However, such data are sparse, dated, and often have limited applicability to MSW in general, and for design scale-up in particular. Therefore, greatest emphasis was placed on identifying demonstration scale (20-150 TPD) will commercial seals ( $>150$ TPD) studies which could be expected to provide economic, environmental, and energy data that can be scaled with possibly less risk. While the promise of pyrolysis of MSW lies in its ability to transform municipal waste into gaseous and liquid chemicals and fuel products, the major limitation is the unproven technical and economic feasibility of a large scale facility.

Delaware County, Pennsylvania; Scott Paper Co.; and Roy F. Weston, Inc., Demonstration of Synergistic Industrial Energy/Municipal Solid Waste Disposal Facility, Volume 1, Report No. DOE/CS/20245-1, 164 pp., and Volume II, Report No. DOE/CS/20245-2, 174 pp. (September 1981).

This study reports on Phase II of a six-phase program to establish a waterwall combustion unit and resource-recovery system for steam sales to the Scott Paper Co. plant in Chester, Pennsylvania. High-pressure steam from the refuse-fired boiler is proposed to serve Scott's existing cogeneration facility, which directs its low-pressure steam to the paper manufacturing process. The new system may save $64,000 \mathrm{bbl} / \mathrm{yr}$ of low-sulfur No. 6 fuel oil. 
Delaware State Solid Waste Authority, Energy Recovery for Kent and Sussex Counties, Delaware, Phase II Study Report, Report No. DOE/CS/20234-2, 98 pp. (December 1982).

This Phase II study is on potential energy resource-recovery alternatives for Kent and Sussex Counties, Delaware. Under Phase I, which was completed in June 1980, surveys were made of waste quantities and characteristics and potential energy markets and sites, and alternative resource-recovery systems were developed and evaluated. Two of the most promising resource-recovery alternatives were identified for further evaluation under Phase II. The purpose of the Phase II study is to evaluate in greater detail two alternative resource-recovery systems that would produce a fuel or an energy product (steam) for sale to the General Foods Corp. plant in Dover, Delaware. The two alternatives are as follows:

(1) A refuse-derived fuel (RDF) production facility, which would process waste to produce RDF for sale to General Foods. The RDF would be cofired with coal in new boilers being considered by General Foods as a replacement for their existing oil- or gas-fired toilers. (2) A mass-burning steam-generation facility, which would produce high-pressure superheated steam for sale to General Foods. The steam would be used by General Foods to cogenerate electricity and for process use. The process steam would replace steam now being generated by oil or gas.

Dennis, C.B., et al., Analysis of External Combustion of Municipal Solid Waste, Report No. ANL/CNSV-53, 52 pp. (March 1986).

External combustion of municipal solid waste allows the waste to be burned separately from an existing fossil-fuel-fired facility. An MSW combustor and a fossil-fuel combustor are fired separately, and either the combustion products or the energy produced are then combined. The Systems Analysis Language Translator (SALT) computer code was modified and extended to analyze this concept. This report describes how the modified code, SALT/MSW, was used to analyze the performance and cost benefits of retrofitting a fossil-fuel-fired boiler with an external MSW combustor. Also presented are preliminary results from using the SALT/MSW model to analyze various options for integrating the external combustor with an existing fossil-fuel-fired facility.

Dewberry and David, Solid-Waste Energy Recovery Project, Galax, Virginia: Feasibility Analysis, Report No. DOE/CS/24362-T13, 50 pp. (September 1982).

The report concludes that an energy-from-solid-waste system can be built and can operate in compliance with all existing applicable state air, water, and health regulations and that heat energy can be sold at an economically feasible price. The high capital cost of steam distribution piping and the distances between the potential consumers preclude, at least initially, the feasibility of serving more than one consumer. There is at present only one customer who has a sufficiently large demand for heat energy and whose costs for this energy are great enough to make the purchase of energy from the waste-burning facility attractive. Therefore, it is recommended in the report that the energy-recovery incinerator plant should be located on the customer's property; only solid waste from the City of Galax should be used, because the amount will closely match that required to adequately serve Hanes without excess; and the City of Galax landfill should remain open to receive the ash residue and nonburnables from the plant.

Domalski, E.S., Thermodynamic Data for Waste Incineration, Report No. NBSIR-78-1479, 169 pp. (August 1978).

A table of thermodynamic data on 331 selected materials was compiled to provide information on materials that are not easily identifiable by a stoichiometric formula. Examples of such materials are 
foods, wood species, oils, animals, plants, polymers, etc. The table is arranged alphabetically according to the names of the various materials, and whenever possible, the chief components of all readily identifiable components are supplied. In addition, the physical state, the kind of thermodynamic property, specific-property values, and citations to a list of 142 references are furnished. In order to assist the reader with finding a specific material or property, a material name and property index has been assembled. A section on units and definitions explains the various thermodynamic properties being reported and the conditions under which they apply. An appendix supplies auxiliary information on symbols for thermodynamic quantities, units, physical constants, and atomic weights. The table is oriented chiefly toward engineers involved in the disposal of municipal wastes; however, applications in other engineering and scientific sectors can easily be made.

Domalski, E.S., et al., Monitoring the Fate of Ch orine from MSW Sampling through Combustion: Part 1, Analysis of the Wisste Stream for Chlorine, Report No. DOE/CE/30801-Tl, 17 pp. (1985).

The total chlorine and water-soluble chlorine contents of the components of municipal solid waste (MSW) have been determined from sampling studies carried out at two sites-Baltimore County, Maryland, and Brooklyn, New York-for a five-day period. The total chlorine contents of the MSW samples from Baltimore County and Brooklyn are reported.

Domalski, E.S., et al., Monitoring the Fate of Chlorine from MSW Sampling through Combustion: Part 2, Combustion Studies, Report No. DOE/CE/30789-Tl, 24 pp. (1984).

Combustion measurements were carried out in a multikilogram-capacity flow calorimeter on cellulose and cellulose/sand samples in $100 \%$ oxygen and in several oxygen/nitrogen mixtures. Some measurements were made on cellulose/sand samples, which had 1 mass\% of polyvinylchloride as part of their composition, to study the conditions related to the formation and destruction of chlorinated organic compounds as combustion products. Qualitative identifications of a significant variety of chlorinated organic compounds were made.

Domalski, E.S., et al., 25-Gram Capacity Combustion Flow Calorimeter, Report No. NBSIR-82-2457, 50 pp. (March 1982).

A new calorimeter being developed at the National Bureau of Standards to determine the enthalpies of combustion of kilogram-size samples of municipal solid waste (MSW) in flowing oxygen near atmospheric pressure is reported. The organic fraction of $25-\mathrm{g}$ pellets of highly processed MSW has been burned in pure oxygen to $\mathrm{CO}_{2}$ and $\mathrm{H}_{2} \mathrm{O}$ in a small prototype flow calorimeter. The carbon content of the ash and the uncertainty in the amount of $\mathrm{CO}$ in the combustion products contribute calorimetric errors of $0.1 \%$ or less to the enthalpy of combustion.

Domalski, E.S., Churney, K.L., Ledford, A.E., Jr., Bruce, S.S., Buckley, T.J., and Tsang, W., MSW (Municipal Solid Waste) Emissions and Characterization Research and Destruction of Aromatics by Hydrogen Atoms: Final Report, Report No. DOE/CE/30835-T1, Order No. DE88013488, 59 pp. (June 1988).

A multi-kilogram capacity flow calorimeter was used in combustion measurements on municipal solid waste (MSW) and refuse-derived fuel. Cellulose (with and without sand), and MSW doped with PVC were combusted. Gas chromatography was used to study the combustion products. Chlorine mass 
balance experiments were conducted. Finally, the destruction of chlorinated aromatics by hydrogen atoms was studied.

Duke University, Pulsed-Flow Air Classification for Waste to Energy Production, Final Report, Report No. DOE/CS/20544-Tl, 153 pp. (September 1983).

The development and testing of pulsed-flow air classification for waste-to-energy production are discussed. Standard designs generally permit large amounts of combustible material to escape as reject while producing a fuel that is high in metal and glass contaminants. Pulsed-flow classification is presented as a concept that can be used to avoid both pitfalls. Each aspect of theory and laboratory testing is summarized: particle characteristics, theory of pulsed-flow classification, laboratory testing, and pulsed-flow air classification for waste-to-energy production. Conclusions from the research are summarized.

Eco Corp., Tri-County Solid-Waste-to-Fuel Production Project Feasibility Study, Report No. DOE/RA/50327-1, 425 pp. (September 1983).

The analysis and preliminary findings of refuse-derived fuel and recovered-components markets are presented. Other topics covered are municipal solid waste composition, quantity, and constraints; technical assessment and capital cost assessment; economic feasibility of burning process residue to generate steam; review of commercially available equipment for the densification of refuse-derived fuel; final prefeasibility analysis for the Tri-County (Illinois) Municipal Solid-Waste-to-Fuel Production Project; preliminary economic and sensitivity analysis for the Tri-County project; risks assessment; and environmental, health, safety, and socioeconomic assessment for the project.

Electric Power Research Institute, Proceedings: Municipal Solid Waste as a Utility Fuel, Report No. EPRI-CS-4900-SR (November 1985).

These proceedings document presentations made at the seminar, Municipal Solid Waste as a Utility Fuel, held in Madison, Wisconsin, November 20-22, 1985. The participants included representatives from electric utilities, equipment vendors, architect/ engineering companies, regulatory and other government agencies, and universities. Seminar objectives were to update recent utility experience with energy recovery from municipal refuse, to present the results of the Electric Power Research Institute/ U.S. Deparment of Energy-cosponsored project "Guidelines for Cofiring Refuse-Derived Fuels in Utility Boilers," and to discuss the environmental issues of waste-to-energy technology. The papers presented at the seminar discussed both cofiring of refuse-derived fuel (RDF) with coal in utility boilers and 100\% mass burning of municipal solid waste or semisuspension firing of RDF in dedicated boilers. During 1985, four utilities were cofiring RDF in retrofitted and new pulverized-coal-fired boilers, and two others were planning conversion of existing units to RDF firing. Utilities are involved in most of the other waste-to-energy projects as customers for steam and electricity generated by dedicated boilers. The latter should continue to be the predominant mode of participation by utilities in the future. The RDF cofiring guidelines project presentation includes discussion of the RDF cofiring boiler performance model, "RDFCOAL." This model estimates the impact of RDF cofiring on boiler efficiency, flue-gas flow rate, and ash production. 
Elliot, D.C., Baker, E.G., Bumer, R.S., and Sealock, L.J., Jr., (Pacific Northwest Laboratory) "Bench-Scale Reactor Tests of Low Temperature, Catalytic Gasification of Wet Industrial Wastes," Journal of Solar Energy Engineering, v 115:1, pp. 52-56 (February 1993).

Bench-scale reactor tests are under way at Pacific Northwest Laboratory to develop a low temperature, catalytic gasification system. The system, licensed under the trade name Thermochemical Environmental Energy System (TEES@), is designed for a wide variety of feedstocks ranging from dilute organics in water to waste sludges from food processing. The current research program is focused on the use of a continuous feed, tubular reactor. The catalyst is nickel metal on an inert support. Typical results show that feedstocks such as solutions of 2 percent para-cresol or 5 percent and 10 percent lactose in water or cheese whey can be processed to $>99$ percent reduction of chemical oxygen demand (COD) at a rate of up to $2 \mathrm{~L} / \mathrm{hr}$. The estimated residence time is less then $5 \mathrm{~min}$ at $360^{\circ} \mathrm{C}$ and $3,000 \mathrm{psig}$, not including 1 to $2 \mathrm{~min}$ required in the preheating zone of the reactor. The liquid hourly space velocity has been varied from 1.8 to $2.9 \mathrm{~L}$ feedstock $/ \mathrm{L}$ catalyst/hr depending on the feedstock. The product fuel gas contains 40 percent to 55 percent methane, 35 percent to 50 percent carbon dioxide, and 5 percent to 10 percent hydrogen with as much as 2 percent ethane, but less than 0.1 percent ethylene or carbon monoxide, and small amounts of higher hydrocarbons. The byproduct water stream carries residual organics amounting to less than $500 \mathrm{mg} / \mathrm{L}$ COD.

Elliott, D.C., Sealock, L.J., Jr., and Baker, E.G. (Pacific Northwest Laboratory) "Chemical Processing in High-Pressure Aqueous Environments. 2. Development of Catalysts for Gasification," Industrial and Engineering Chemistry Research (United States) v 32:8, pp. 1542-1548, (August 1993).

A liquid water processing environment was used at $20 \mathrm{MPa}$ and $350^{\circ} \mathrm{C}$ to convert organic compounds to methane and carbon dioxide in the presence of catalysts. This paper describes the evaluation of various types of base and noble metal catalysts and numerous support compositions for the process. The feedstock used in these tests was a mixture of p-cresol and water. Nickel, ruthenium, and rhodium were identified as active metals for the reaction. Other metals from groups VIII, VIB, IB, and IIB were inactive or readily oxidized and lost activity. Stable supports in the processing environment included $\alpha$-alumina and zirconia. Silica and titania did not react chemically, but the tablet forms lost their physical integrity. Alumina forms, other than $\alpha$-alumina, reacted with water to form boehmite $(\gamma-\mathrm{A} 1 \mathrm{OOH})$ with significant loss of surface are and physical strength.

Energy, Inc., Energy Recovery from Municipal Waste Development Program for Idaho Falls, Idaho; Final Report, Report No. DOE/CS/20240-1, 155 pp. (July 1981).

The technical and economic feasibility of a proposed resource-recovery facility for the city of Idaho Falls, Idaho, is reported. Total refuse generated is about 27,000 tons/yr and is close in quality to the national average of 4,500 Btu/lb. The proposed technology is based on proven designs without materials recovery. The fuel will burn with $40 \%$ to $50 \%$ excess air and exit the bumer at $1,500^{\circ} \mathrm{F}$.

Energy from Municipal Waste Program, (U.S. Department of Energy), Report No. DOE/CH/10093-153, Order No. DE92010578, 53 pp. (5 May 1992).

Each year, Americans throw away 3 quads of energy in the form of municipal waste and pay $\$ 6$ billion for the privilege. Only about $21 \%$ of our municipal wastes are used productively to generate electricity or produce new products by recycling. In 1990, waste-to-energy (WTE) plants and recycling efforts contributed roughly half a quad of energy in the form of electricity and reduced energy use. This 
productive use of waste avoided the disposal of about 50 million tons of wastes to landfills in that year. The Administration National Energy Strategy estimates that with proper federal, state, local, and private action, the electric generating capacity of WTE facilities could increase $600 \%$ by 2010 and by more than $1200 \%$ by 2030, compared to the 1990 capacity. This would result in about 55 gigawatts (GW) of capacity by 2030, up from roughly $4 \mathrm{GW}$ today. The Department of Energy supports an integrated approach to waste management that includes source reduction, WTE, recycling, and landfilling as complementary pieces of a solution to the municipal waste disposal problem. The Energy from Municipal Waste Program, described in this plan, seeks to minimize the productive use of municipal waste as an energy resource to improving its economic and environmental characteristics. While the Program focuses on WTE systems, it is conducted as part of a larger federal effort that includes source reduction and recycling of wastes to save energy.

Energy from Municipal Waste Program, Chemical Technology Division, Annual Technical Report, 1982, Report No. ANL-83-55, 85 pp. (1982).

Argonne National Laboratory is the lead laboratory for the U.S. Department of Energy's Energy from Municipal Waste Program. The program undertakes research activities aimed at enhancing the ability of the private sector to complete the development, demonstration, and commercialization of municipal solid waste (MSW) technologies. The following thermal conversion technologies were assessedlarge-scale mass burners, small-scale modular mass burners, dedicated combustors of refuse-derived fuel, pyrolysis reactors, and fluidized-bed combustors. The operating history, the emission control technologies employed, and the available emission monitoring data for MSW combustors have been collected by surveying combustor operators.

Escalante, E., Mathews, D., and Fink, J., Corrosion of Materials Used in Steam-Generating Boiler Systems, Final Report, Report No. NBSIR-84-2959, 50 pp. (October 1984).

Five alloys-SA178, SA192, SA213-T11, SA213-T22, and type 304 stainless steel-were evaluated on their resistance to pitting in a coal-burning boiler and in a residential refuse-buming incinerator. The materials were introduced into the vicinity of the boiler types using a probe, the temperature of which was controlled and monitored to simulate conditions of the boiler tubes. After three to six months, the probes were withdrawn and the alloy specimens removed for evaluation. The data indicate that the environment of the refuse-burning incinerator was considerably more aggressive than that of the coal-burning boiler. Chloride was found in practically all the pits examined in the alloys from the refuse-burning system, but no chloride was found in the pits examined on the material exposed in the coal-burning boiler. The data suggest that the moisture from lawn clippings increases the rate of attack, which is further aggravated by large temperature fluctuations.

Evans, R.J. and Milne, T.A., (National Renewable Energy Laboratory) Mechanisms of Pyrolysis of Municipal Solid Waste: Annual Report, Report No. SERI/PR-234-3295, Order No. DE88001158, 73 pp. (December 1987).

Studies of the effect of heating rate on the pyrolysis mass spectra of an refuse-derived fuel (RDF) sample and a pyrolysis oil are presented. The time evolution of many ions from RDF pyrolysis species are shown. The foundations of factor analysis of mass spectra are given and application to pyrolysis oils shown and discussed in the context of compound classes in the very complex pyrolysis vapors. 
Evans, R.J., Milne, T.A., and Klass, D.L., (National Renewable Energy Laboratory) "Liquid Fuels from the Pyrolysis of Municipal Solid Waste and Its Components," Energy from Biomass and Wastes, presented at the Eleventh IGT Conference on Energy from Biomass and Wastes, Orlando, Florida, 16 March 1987, Report No. CONF-870364, pp. 807-838 (1988).

The production of liquid fuels by the pyrolysis of municipal solid waste (MSW) requires an understanding of the composition of the liquid products and the factors that control the composition and yield. The analysis of pyrolysis oils by conventional techniques is difficult and time consuming because of their chemical complexity and polar and reactive nature. This makes the systematic study of process parameters difficult since changes in reaction conditions cannot be readily related to changes in product composition. Furthermore, the composition must be related to the chemical and physical properties of the oil which need to be known in the context of the potential fuel utilization or upgrading route. A method of oil characterization was developed based on flash volatilization and direct molecular-beam, mass-spectrometric analysis utilizing multivariate statistical analysis techniques. This rapid data collection and analysis system was used as a basis of compound class analysis, which characterizes collected pyrolysis oils by indexing the major classes of products, such as methoxyphenols, carbonyl compounds, anhydrosugars, hydrocarbons, etc. This experimental system is also used for real time sampling of pyrolysis products in the vapor phase for process parameter screening.

Fiscus, D.E., et al., Study of Existing RDF-Cofiring Experience, Vol. 1: Phase I Final Report; Vol. 2: Appendixes to the Phase I Final Report; and Vol. 3: Phase II Final Report, Report No. ANL/CNSV-TM-134, Vol. 1, 96 pp.; Vol. 2, 411 pp.; Vol. 3, 184 pp. (October 1983).

This three-volume report documents the findings of Phases I and II of a four-phase program, Guidelines for Cofiring Refuse-Derived Fuels in Utility Boilers. Phases I and II were funded by the U.S. Deparment of Energy through Argonne National Laboratory. Phases III and IV were funded by the Electric Power Research Institute. The study assembled relevant data from experiences with refuse-derived fuel (RDF) in electric utility suspension-fired or cyclone-fired boilers at nine locations. The electric utility cofiring experience (except the early Ames experience in stoker boilers) is also included. All data obtained from the electric utility and RDF processing plants are contained in the three appendixes.

Gainesville-Hall County Joint Resource Recovery Development Authority, Feasibility Study Report of Energy Recovery of Municipal Waste for Gainesville-Hall County, Report No. DOE/CS/20169-1, 234 pp. (January 1982).

The study discussed in this report provided the Gainesville-Hall County Joint Resource Recovery Authority with the data to determine the feasibility of developing a waste-to-energy project. The study evaluated resource-recovery methods and technologies. A financial and economic assessment was developed to assist in the selection of the financing approach necessary for project accomplishment. The objectives of the feasibility study were to obtain information regarding the solid waste generated in the demonstration area, to identify energy markets, and to identify those energy-recovery technologies that would support the requirements of the identified energy markets. The quantity of wastes being delivered to the landfill were established, and measurements and observations were made to establish the data with respect to the composition and heating values of the waste delivered to the existing landfill.

Ganotis, C.G., "Six Years of Operation: The Pinellas Refuse-to-Energy Project," Energy from Biomass and Wastes XIV, Klass, D.L., ed. Presented at the Fourteenth Annual Conference on Energy from Biomass 
and Wastes, Lake Buena Vista, Florida, 29 January-2 February, 1990, Chicago, IL: Institute of Gas Technology, Report No. CONF-900117, pp. 647-652 (1991).

The Pinellas County Refuse-to-Energy Project is, in every respect, a success story for solid waste disposal. Since operations started in May 1983, this project has processed more municipal solid waste (MSW) to produce electricity than any other refuse-energy facility in the nation. Last December the plant processed its 5 millionth ton of Pinellas County's MSW. Each day the plant continues to process some 3,000 tons of MSW, while producing over 1.5 million kilowatt hours of electricity-enough to supply about 45,000 homes. In addition, the residue that is left following burning undergoes further recovery to recycle metals and aggregate. This paper describes the project and highlights some of the unique lessons learned in six years of operations.

Gavette, K.B., The Impact of Source Separation on Municipal Waste-to-Energy Project Feasibility, Report No. DOE/IR/05106-T88, Order No. DE89013853, 70 pp. (1989).

The report is organized to present the methodology, findings, and method of analysis in determining the impact of reducing the waste stream through recycling on a waste-to-energy plant. The report is organized in the following way: Chapter 2 presents an overview of the problem, the purpose of the study, the objectives, and an introduction to some waste-to-energy technologies; Chapter 3 describes the development of the sampling methodology; Chapter 4 discusses the findings of the samples as related to generation rates, composition, moisture content, and Btu content; Chapter 5 describes how the findings of the survey sample may be used to determine the effect on the energy output of a waste-to-energy plant when various amounts of recyclable goods are removed; Chapter 6 discusses the barriers to implementing a recycling program and task force recommendations regarding implementation of such a program; and Chapter 7 provides a summary of the report and its uses.

Gershman, Brickner, and Bratton, Inc., Waste-to-Energy Systems Institutional Barriers Assessment Workshop, Report No. ANL/CNSV-TM-78, 50 pp. (February 1981).

A one-day workshop, sponsored by the U.S. Department of Energy and Argonne National Laboratory, was held on February 19, 1981, in Washington, D.C., to identify and rank institutional barriers to the advancement of waste-to-energy technologies. Thirty-seven participants represented a spectrum of viewpoints, including those of legal and financial experts, trade groups, system vendors, state and local governments, and public interest groups. Output from group discussions was used to compile a master list of barriers, which were weighted by each attendee and discussed by the group. (A statistical weighting was made later and can be found in a companion volume, The Severity of Institutional Barriers Affecting Energy-from-Municipal-Waste Technologies, by Los Alamos Technical Associates.) Barriers are reported under the categories of legal, intergovenmental coordination, educational, financial, environmental, and social.

Gloucester, New Jersey, County Board of Chosen Freeholders, Feasibility Study: Codisposal with Energy Recovery from Wastewater Sludge and Municipal Refuse, Phase II, Report No. DOE/CS/20212-1, 157 pp. (July 1981).

This report examines the feasibility of thermal reduction of dewatered sludge and mixed municipal refuse with steam recovery and electricity generation at a wastewater treatment complex in Gloucester County, New Jersey. An estimated 300 tons/d of solid waste with a heating value of $4800 \mathrm{Btu} / \mathrm{lb}$ is available for processing. The report concludes that detailed engineering effort should begin toward a 
waterwall furnace design and that commitments should be obtained from participating communities and the local utility for public bonds and market sales.

Goldbach, G., et al., Program to Develop MSW-Fired Fluidized-Bed Boilers, Report No. DOE/CS/24321-Tl, 250 pp. (June 1983).

Combustion Power Co. conducted a U.S. Department of Energy-funded study of fluidized-bed municipal solid waste combustion for the purpose of assessing the technical and economic viability of the nonadiabatic fluidized-bed boiler in this service. The program consisted of mathematical process modeling, pilot testing, design studies, and economic analyses.

Goodman, B.J., (National Renewable Energy Laboratory) "Overview of Thermochemical Conversion of Municipal Solid Waste," Thermochemical Conversion Program Annual Meeting: Proceedings, presented at the Thermochemical Conversion Program Review Meeting, Golden, Colorado, 21 June 1988, Report Nos. SERUCP-231-3355; CONF-8806176-, Order No. DE88001187, pp. 123-128 (July 1988).

The research program focuses its thermochemical conversion research on feedstock preparation, advanced combustion, and pyrolysis. To convert municipal solid waste (MSW) into liquid or gaseous fuels, it must first be separated by mechanical systems into components. The products of sizing and separating include a solid fuel called fluff refuse-derived fuel (RDF). With additional processing, fluff RDF can be converted to densified RDF (dRDF) by pelletizing, briqueting, or extruding with or without binders, or into powdered RDF (pRDF) by adding an embrittling agent. dRDF is easier to store and transport and has better energy density than RDF. pRDF can be mixed with oil and burned in existing oil-fired boilers. In addition, materials can be recovered for recycling. Current research efforts on feedstock preparation include evaluation of pulsed air classifiers and shear shredders and preparation of densified and powdered fuels from MSW. Research efforts are also being pursued to investigate the potential of thermochemically transforming MSW into gasoline via two sequential steps: converting feedstock into a biocrude liquid and upgrading the biocrude by advanced catalytic processes to gasoline. Current efforts focus on evaluation of the basic mechanisms of pyrolysis, experimentation of fast pyrolysis, demonstration of a novel pyrolysis mill, and determination of the dynamics of heat transfer and fluid flow.

Goodman, B., (National Renewable Energy Laboratory) Thermal and Biochemical Options for Advanced RDF Technologies, presented at the American Institute of Chemical Engineers Spring National Meeting, New Orleans, Louisiana, 6-10 March 1988, New York: American Institute of Chemical Engineers, Report No. CONF-880348, Technical Paper 14H, 29 pp. (1988).

This report details the current commercial status of the use of refuse-derived fuel (RDF) technologies and the future thermal and biochemical options. RDF is prepared by processing municipal solid waste to modify its size and to separate components that are not desirable. In the simplest form, RDF is sold as a solid fuel that displaces coal. However, coal is an inexpensive and plentiful energy source. Further, since RDF has a lower energy density than coal, substitution in existing boilers normally requires system derating. The options are to use combustion systems designed for RDF or emerging technologies that produce liquid or gaseous fuels. These conversion technologies may be either thermal or biochemical. Each system has a unique set of specifications that are imposed on the feedstock. In this paper the status of these advanced technologies and their preparation needs are discussed. 
Grohse, E.W., Steinberg, M., and Koppel, P.E., (Brookhaven National Laboratory, Economical Disposal of Municipal Solid Waste with Minimal Discharges to the Atmosphere and Maximum Recycling of Energy and Metal Values, presented at the International Conference on Municipal Waste Combustion, Hollywood, Florida, 11-14 April 1989, Report Nos. BNL-42593, CONF-890422-3, Order No. DE90000530, 22 pp. (Mar 1989).

A process was developed at Brookhaven National Laboratory for the disposing of municipal solid wastes with minimal discharges to the atmosphere and maximum recycling of the energy and metal values contained therein. The energy values are recovered as zero ash, zero sulfur, zero nitrogen, zero chlorine particulate carbon (carbon black) fuels and a hydrogen-rich (or methane-rich) gaseous coproduct. The process is especially adaptable to the disposal of plastic wastes and recycling of its energy values. Also, the inclusion of medical wastes should be no problem. The process consists of hydrogasifying prepared municipal solid waste (MSW) (or any carbonaceous feedstock) to form a methane-rich process gas, which is then thermally decomposed (cracked) to form the primary product, carbon black, and hydrogen which is recycled to the hydrogasifier. Oxygen in the MSW is presently removed as water from the hydrogasifier effluent before it enters the methane decomposer. Any remaining hydrogen in the MSW feed is ultimately removed from the process as a coproduct gas as hydrogen per se and/or methane. Chlorine in feed containing PVCs, for example, is removed as relatively minute amounts of hydrogen chloride in the condensed water discharged from the recuperative partial condenser. Desulfurization is not required to produce sulfur-free carbon black per se. Various options are available for desulfurization of the coproduct gas. Since the process operates under a highly reducing hydrogen atmosphere, toxic oxygenated compounds such as dioxins cannot form and metals entering with the MSW are removed with the" ash" as metals, not oxides.

Guillory, J.L., Gasification of Municipal Solid Waste in an Oxygen-Blown Fluidized-Bed Reactor, Final Report, Report No. DOE/SF/11723-Tl, 177 pp. (December 1984).

The purpose of the municipal solid waste gasification program at Combustion Power Co. (CPC) was to demonstrate the technical feasibility of producing a medium-Btu gas from municipal solid waste (MSW) by means of oxygen-based fluidized-bed gasification. A 12-in.-I.D. fluidized-bed-gasification system was constructed using CPC facilities and existing equipment where applicable, and a gas chromatograph system for the analysis was provided on contract from Battelle Columbus Division. A series of parametric tests using simulated MSW (artificially wetted newsprint) and a limited number of tests addressing air-blown operation and different fuels (actual MSW and wood) were conducted. It was shown that moisture content in the fuel is the most important factor in determining product composition and that MSW product gas closely resembles that from biomass gasification. Gas heating values of more than $400 \mathrm{Btu} / \mathrm{sdcf}$ and $\mathrm{H}_{2} / \mathrm{CO}$ molar ratios over 0.45 were produced. An equilibrium-based analytical model of oxygen-blown gasification was developed to assist in sizing the test system and evaluating its performance. It was shown that this model predicts gross flow rates and product heating values adequately from first principles. A method of predicting the most likely product gas composition from statistically valid regression models is proposed.

Hainsworth, E., Mayberry, J., and Piscitella, R., Energy from Municipal Solid Waste Mechanical Equipment and Systems Status Report, Report No. EGG-PSE-5974, 232 pp. (March 1983).

This report summarizes the state of the technology for the mechanical equipment used in systems producing refuse-derived fuel (RDF). Emphasis is on size reduction and separation equipment. Densifiers, storage facilities, conveyors, and material recovery equipment are also discussed. The authors visited 14 
RDF plants to obtain information on operating experience. Operating problems and solutions are discussed for each type of equipment.

Hasselriis, F., Thermal Systems for Conversion of Municipal Solid Waste, Volume 4, Burning Refuse-Derived Fuels in Boilers: A Technology Status Report, Report No. ANL/CNSV-TM-120, Vol. 4, 170 pp. (March 1983).

This is one of nine assessment reports prepared for Argonne National Laboratory to document the current state of development of energy from municipal-waste disposal/recovery technologies. This report describes the development and current status of systems for the preparation, combustion, and direct recovery of energy from refuse-derived fuel (RDF) produced from municipal solid waste. Facilities that have been operated, are currently operating, or are under construction are reviewed. The report discusses problems encountered and solved in the preparation and burning of RDF as a supplementary fuel in existing or dedicated boilers fired with coal and oil (and as the sole fuel in boilers designed for the purpose). Relationships between the methods of processing and the design of the combustion and heat-recovery systems are explored, and the design parameters of boilers suitable for RDF burning and their relationship to the fuels are discussed. Economic implications of RDF systems are reviewed. The report also describes research and development efforts to date and identifies research needs.

Helt, J.E. and Agrawal, R.K., (Argonne National Laboratory) Production and Characterization of Pyrolysis Liquids from Municipal Solid Waste, presented at the 193rd National Meeting of the American Chemical Society, Denver, Colorado, 5 April 1987, Report No. CONF-870410-33, Order No. DE87011526, 9 pp. (April 1987).

Bench-scale studies characterizing the liquids produced in the pyrolysis reactions are addressed for experimental results on the thermal decomposition of typical municipal solid waste components (Whatman No. 1, newsprint, kraft paper, cardboard, aspen, and pine) over a temperature range of $275^{\circ} \mathrm{C}$ to $475^{\circ} \mathrm{C}$.

Helt, J.E., Agrawal, R.K, and Myles, K.M., (Argonne National Laboratory) Pyrolysis of Municipal Solid Waste: Annual Report, July 1985-June 1986, Report No. ANL/CNSV-62, Order No. DE88005784, 57 pp. (October 1987).

The pyrolysis of municipal solid waste (MSW) is a promising method of producing useful fuels. Current research sponsored by the U.S. Department of Energy at Argonne National Laboratory is directed toward gaining an improved understanding of the basic thermokinetic mechanisms associated with the pyrolytic conversion of MSW. Results from nonisothermal and isothermal bench-scale experiments of some MSW components are presented. Feedstocks included not only individual components but also mixtures of components. The effects of heating rate and sample size on overall degradation and product formation over the temperature range from $300^{\circ} \mathrm{C}$ to $475^{\circ} \mathrm{C}$ are discussed. Some preliminary higher-temperature runs (up to $700^{\circ} \mathrm{C}$ ) were completed in preparation for future work in the gasification regime. Work also continued on the characterization of the liquids produced during the pyrolysis process. 
Helt, J.E. and Mallya, N., (Argonne National Laboratory) Experiments on Basic Mechanisms of Pyrolysis, presented at the Thermochemical Conversion Program Review Meeting, Golden, Colorado, 21 June 1988, CONF-8806176-5, Order No. DE89005849, 22 pp. (1988).

A majority of the combustible portion of municipal solid waste (MSW) is cellulosic in nature, comprising paper, newsprint, packaging materials, wood wastes, and yard clippings. If this material is pyrolyzed, the end products are a highly carbonaceous solid char, a highly oxygenated liquid tar, and a mixture of gases with low- to medium-Btu content. All of the pyrolysis products offer the potential of being useful fuels or the intermediates for producing useful fuels. Current research at Argonne National Laboratory is focused on obtaining a better understanding of the basic mechanisms, kinetics, and chemistry involved in the pyrolytic conversion of MSW and its components. Newsprint, kraft paper, polyethylene, and densified refuse-derived fuel (RDF) have been used individually and in mixtures as feedstock in a batch laboratory reactor. The pyrolysis has been at atmospheric pressure and temperatures of $350^{\circ} \mathrm{C}-800^{\circ} \mathrm{C}$. The products from the pyrolysis reaction have been analyzed for both fuel properties (e.g., viscosity, calorific value, acid group concentrations) and chemical composition. The liquid products have been studied extensively using Fourier transform infrared spectrometry. Discussion is provided on the overall chemical mechanisms associated with the pyrolytic decomposition.

Helt, J.E., Mallya, N., and Goswami, D.Y., (Argonne National Laboratory) "Pyrolysis Experiments with Municipal Solid Waste Components," Proceedings of the 23rd Intersociety Energy Conversion Engineering Conference, presented at the Twenty-Third Intersociety Energy Conversion Engineering Conference, Denver, Colorado, 31 July 1988, New York: American Society of Mechanical Engineers, Report No. CONF-880702, pp. 427-432, v 4 (1988).

A majority of the combustible portion of municipal solid waste is cellulosic in nature, comprising paper, newsprint, packaging materials, wood wastes, and yard clippings. If this material is pyrolyzed, the end products are a highly carbonaceous solid char, a highly oxygenated liquid tar, and a mixture of gases with low- to medium-Btu content. All of the pyrolysis products offer the potential to be useful fuels or the intermediates to produce useful fuels. Current research at Argonne National Laboratory is focused on obtaining a better understanding of the basic mechanisms, kinetics, and chemistry involved in the pyrolytic conversion of municipal solid waste and its components. Newsprint, kraft paper, polyethylene, and densified refuse-derived fuel have been used individually and in mixtures as feedstock in a batch laboratory reactor. The pyrolysis has been at atmospheric pressure and temperatures of $350^{\circ}-800^{\circ} \mathrm{C}$. The products from the pyrolysis reaction have also been analyzed for both fuel properties (e.g., viscosity, calorific value, acid group concentrations) and chemical composition. The liquid products were studies extensively using Fourier transform infrared spectrometry. Discussion is provided on the chemical mechanisms associated with the pyrolytic decomposition.

Helt, J.E. and Myles, K.M., Energy from Municipal Waste-Preliminary Assessment of External Combustion, Report No. ANLCNSV-40, 52 pp. (December 1983).

To date, three concepts for extracting energy from municipal waste have predominated: mass burning of municipal solid waste (MSW) in a dedicated boiler, burning of refuse-derived fuel (RDF) in a dedicated boiler, and cofiring of RDF with a conventional fuel. A different approach is to combust the conventional fossil fuel and MSW separately, thereby optimizing the design of the two combustors to most efficiently extract heat energy from each fuel. In this report, five examples of this external combustion concept (using from $60 \%$ to just over $200 \%$ stoichiometric air) are discussed, and mass and energy balances are given for each case. Advantages and disadvantages of the external combustion concept are identified. 
Hendrickson, B., Rodgers, B., and Brooks, C. (Argonne National Laboratory) "Waste-to-Energy Projects in Texas: Selecting Systems to Meet Permitting Requirements," Energy from Municipal Wastes: Opportunities for the Southwest, presented at the Workshop on Energy from Municipal Waste: Opportunities for the Southwest, Austin, Texas, 23 June 1986, Report Nos. ANL/CNSV-TM-173, CONF-8606334, Order No. DE87014258, pp. 174-179 (May 1987).

In October 1984, American Ref-Fuel Company, a joint undertaking of Browning-Ferris Industries, Inc. and Air Products and Chemicals, Inc., formed to market waste-to-energy plants, announced plans to build a 1500-ton-per-day mass burn, waste-to-energy facility in Pasadena, Texas. Since that time, work has continued on applications to secure the numerous permits required to build the facility. As of the date of this report, all required environmental permits except the air permit from the Texas Air Control Board were received. The following discussion describes the process followed to secure the two major permits for this project: the Permit to Operate a Municipal Solid Waste Site from the Texas Department of Health and the Permit to Construct from the Texas Air Control Board.

Hickman, H.L. Jr., Thermal Systems for Conversion of Municipal Solid Waste, Volume 1, An Overview, Report No. ANL/CNSV-TM-120, Vol. 1, 60 pp. (May 1983).

This report provides an overview of the information included in the five other volumes of a technology status report on thermal systems for conversion of municipal solid waste (MSW). The other volumes and this overview were prepared for Argonne National Laboratory. The six-volume report on various ways of using MSW as an energy source reflects information as of 1982 and, in some cases, mid-1983.

Holcomb, R.S., (Oak Ridge National Laboratory), A High Efficiency Mixed Solid Waste-Fossil Fuel Combustion Power System, presented at the International Joint Power Generation Conference, Atlanta, Georgia, 18-22 October 1992; Report No. CONF-921004-1, Order No. DE92016520, 11 pp. (1992).

A novel concept is presented in which refuse-derived fuel is burned along with coal to produce electric power at a high thermodynamic cycle efficiency. The concept embodies a combined cycle in which a natural gas-fired turbine-generator produces electric power and the exhaust gas is routed to a circulating fluidized bed combustion boiler. There the excess air in the exhaust gas is utilized in the combustion of pelletized solid waste, in combination with coal, to produce superheated steam for driving a turbine-generator.

Hopper, R., Thermal Systems for Conversion of Municipal Solid Waste, Volume 3, Small-Scale Systems: A Technology Status Report, Report No. ANL/CNSV-TM-120, Vol. 3, 176 pp. (July 1983).

This is one of nine assessment reports prepared for Argonne National Laboratory to document the current state of development of energy from municipal-waste disposal/recovery technologies. The report discusses small-scale systems and includes detailed technical, economic, and environmental data. Several representative operating systems and case histories are discussed.

Indianapolis Center for Advanced Research, Demonstration of Waste Sludge Incinerator Fuel Reduction-Pilot Project Report, Report No. DOE/CS/20321-1 (July 1981).

This report presents the results of a successful field research and demonstration project to reduce fuel consumption at Indianapolis, Indiana, in existing multiple-hearth sewage sludge incinerators. A 
comparative analysis determines the relationship among the incinerator operating variables and specific fuel consumption. In a demonstration of a new fuel-efficient operating mode, fuel consumption was reduced by $50 \%$ at sludge loading rates $10 \%$ higher than normal operating averages.

Iowa State University, Water-Related Environmental Control Requirements at Municipal Solid-Waste-toEnergy Conversion Facilities, Report No. DOE/EV-0116, 205 pp. (September 1980).

Water use and wastewater production, requirements for water-pollution control technology, and water-related limitations to design and commercialization are identified at municipal-solid-waste-to-energy conversion systems. Part I summarizes conclusions and recommendations about water management and wastewater treatment in four municipal-solid-waste-to-energy conversion categories. These include mass-burming to produce steam for use as a supplemental energy source; mechanical processing to produce a refuse-derived fuel for cofiring in gas-, coal-, or oil-fired power plants; pyrolysis to produce a burnable oil or gas; and biological conversion of organic wastes to methane. Part II briefly describes each waste-to-energy facility visited during the subject survey. One or more facilities of each type were selected for wastewater samples and follow-up tests to determine requirements for water-related environmental controls. A comprehensive summary of the results is presented.

Kolb, J.O., Use of Municipal Solid Waste for District Heating in St. Paul, Minnesota, Report No. ORNL/TM-8076, 106 pp. (September 1982).

An initial assessment of the advantages and disadvantages of utilizing thermal energy from a waste-to-energy facility as a heat source for the developing district heating system in St. Paul is provided. On the basis of engineering estimates of total annual costs of a 1000-ton/d, 10.5-kg/s capacity resource-recovery facility, the required revenues from industrial steam customers, district heating sales, and community disposal (tip) fees are developed for a 1986 facility start-up. The economic analysis develops the relationship of disposal fees and costs of thermal energy for district heating for several specific combinations of St. Paul industrial markets, district heating, and cogenerated electric power sold to NSP under marginal electric production cost conditions. The results of the preliminary market and systems analyses indicate that, for industrial markets that do not use the total output of a 1000-ton/d facility, the sale of available thermal energy to the St. Paul district heating utility at costs equivalent to those of coal-based thermal energy can lower the required disposal fee (or indifference value) compared with a market mix of industrial steam and cogenerated electric power. The political, developmental, environmental, and financial advantages and disadvantages of integrating the district heating market with industrial markets are discussed. The major conclusion of the study is that a moderate amount of district heating market could be supplied from a resource-recovery facility at competitive energy costs if facility siting, financing, and integrated marketing of energy products issues could be resolved.

Kolb, J.O. and Wilkes, K.E., (Oak Ridge National Laboratory) Power Generation from Waste Incineration, Report No. ORNL/TM-10484, Order No. DE88012162, 117 pp. (June 1988).

Incineration of municipal solid wastes (MSW) with heat recovery for power generation is being used increasingly in the United States to reduce the volume of wastes to be landfilled. High-temperature incineration is also beginning to be used to decontaminate sites where hazardous chemicals were disposed of in the past with large amounts of heat usually wasted in such incinerators. This report presents a characterization of MSW incineration technologies, an energy market evaluation in the DADS area, an evaluation of energy recovery from waste tires, a conceptual design of an integrated incineration power plant, and an economic analysis of hazardous waste processing costs and potential savings with an 
integrated facility. Analyses of the amount and types of hazardous wastes, appropriate incineration technologies, a process design to size flue gas heat recovery equipment, and cost estimates for hazardous waste incinerator systems and heat recovery equipment were performed by Science Applications International Corporation in a companion study and used in this report. The primary conclusion of this study is that processing cost savings with an integrated waste incinerator power plant range from $6 \%$ to $20 \%$ of costs compared to separate hazardous waste incineration. However, this result depends on the amount and moisture content of the waste material and the electricity value sold to the local utility. Other results and conclusions include the types of hazardous waste incineration technologies recommended, the market for energy products, and institutional restraints and requirements.

Kuester, J.L., Thermal Systems for Conversion of Municipal Solid Waste, Volume 5, Pyrolytic Conversion: A Technology Status Report, Report No. ANL/CNSV-TM-120, Vol. 5, 100 pp. (June 1983).

This is one of nine assessment reports prepared for Argonne National Laboratory to document the current state of development of energy from municipal-waste disposal/recovery technologies. This report reviews the state of the art of pyrolytic technologies as applied to municipal-waste feedstocks. Included in the discussion are those pure-pyrolysis and incomplete-combustion processes that produce either a final product or a synthesis gas for further processing. The feedstock resource base is reviewed, and possible options for utilizing the feedstock base for energy production are described. Following a review of fundamental concepts about pyrolysis, descriptions and evaluations of both present and emerging technologies are presented.

Kuester, J.L. and Brooks, C., (Argonne National Laboratory) "Thermochemical Conversion of Municipal Waste: Pyrolysis, Gasification, and/or Liquefaction," Energy from Municipal Wastes: Opportunities for the Southwest, presented at the Workshop on Energy from Municipal Waste: Opportunities for the Southwest, Austin, Texas, 23 June 1986, Report Nos. ANL/CNSV-TM-173, CONF-8606334, Order No. DE87014258, pp. 66-81 (May 1987).

The role of thermochemical pyrolysis, gasification and/or liquefaction systems for producing energy and chemicals from municipal waste is presented. A more versatile, higher quality product, as compared with complete combustion routes, is obtained with this method. The primary drawback to the use of this method is that a higher degree of processing sophistication is needed. Technology options and considerations, the present status, and future projections are discussed.

Ledford, A.E., et al., Trial Combustions of Kilogram-Size Samples of Municipal Solid Waste, Report No. NBSIR-83-2711, 18 pp. (June 1983).

A new calorimeter is being developed at the National Bureau of Standards to determine the enthalpies of combustion of kilogram-size samples of municipal solid waste (MSW) in flowing oxygen near atmospheric pressure. Experiments were carried out to develop a prototype combustor in which pellets of relatively unprocessed MSW can be rapidly and completely bumed with minimal scattering of ash. Pellets of up to $2.2 \mathrm{~kg}$ mass with ash content between $20 \%$ and $35 \%$ have been successfully bumed at a rate of 15 minutes per kilogram initial mass with $\mathrm{CO} / \mathrm{CO}_{2}$ ratios not greater than 0.1 .

Lewis, S.G. and Brooks, C., (Argonne National Laboratory) "Resource-Recovery Facility Development: Steps to Successful Implementation," Energy from Municipal Wastes: Opportunities for the Southwest, presented at the Workshop on Energy from Municipal Waste: Opportunities for the Southwest, Austin, 
Texas, 23 June 1986, Report Nos. ANL/CNSV-TM-173, CONF-8606334, Order No. DE87014258, pp. 95-104 (May 1987).

This report discusses implementing a resource recovery project. A resource recovery project normally takes about 5 years from its inception through completion. The author first discusses the four major tests the project must first satisfy: The Community Acceptance Test; The Regulatory Test; The Political Test; and The Financial Test. Second, the author focuses on facility procurement-a very different process from any other procurement process.

Los Alamos Technical Associates, Inc., The Severity of Institutional Barriers Affecting Energy-fromMunicipal-Waste Technologies, Report No. ANL-CNSV-TM-79, 58 pp. (June 1981).

Thirty-two institutional barriers to the advancement of waste-to-energy technologies were identified in a Feb 19, 1981, workshop conducted by the U.S. Department of Energy and Argonne National Laboratory. (See Report on the Waste-to-Energy Systems Institutional Barriers Assessment Workshop by Gershman, Brickner, and Bratton, Inc.) Barriers were identified and weighted by the participants. This report presents a statistical analysis of the weights assigned at the workshop. In addition to describing the results in terms of means and standard deviations, an analysis of variance determines the effect of weighting by technology type to compare pairs of technologies and determine whether the scores within a technology differ significantly from each other. Combinations of barriers and technologies with the highest mean scores are highlighted as possible focal points for future research.

Luderer, L.M., Communicating With the Public About Environmental Health Risks: A Case Study of Waste-To-Energy, Report No. DOE/IR/05106-T146, Order No. DE91013441, 41 pp. (October 1990).

Attempts to implement waste-to-energy as part of a comprehensive solid waste management strategy frequently arouse intense local opposition, and potential health risks are often stressed in the public debate. How local governments respond to the public's concerns about these types of risks can either build or undermine public trust and support of the solid waste management decision process. Over the past several years, a number of different guidelines have been developed for encouraging more effective communication between government and the public about environmental health risks. This study applies those guidelines to waste-to-energy systems. It is a simple guide designed to help local officials understand public concerns about the risks from waste-to-energy and provide guidelines for encouraging informed and constructive discussion about comparative risks and benefits.

Lynch, J.F. and Young, J.C., Air Pollution Control Technology for Municipal Solid-Waste-to-Energy Conversion Facilities: Capabilities and Research Needs, Report No. DOE/EV0115, 53 pp. (September 1980).

This study describes three major categories of waste-to-energy conversion processes in the United States and tabulates information on conversion facilities. Conclusions and recommendations are given on the operation, performance, and research needs for these facilities. Section II identifies research needs concerning air-pollution aspects of the waste-to-energy processes and reviews significant operating and research findings for the cocombustion, mass incineration, and pyrolysis waste-to-energy systems.

Lyons, J.K. and Kerstetter, J.D., "Markets and Economics of Mixed Waste Paper as a Boiler Fuel," Energy from Biomass and Wastes XIV, Klass, D.L., ed. Presented at the Fourteenth Annual Conference on Energy 
from Biomass and Wastes, Lake Buena Vista, Florida, 29 January-2 February, 1990, Chicago, IL: Institute of Gas Technology, Report No. CONF-900117, pp. 601-645 (1991).

Mixed waste paper (MWP) is a large component of the municipal solid waste steam disposal in the state of Washington. State legislation mandates source separation of recycled material including MWP. The quantity collected will saturate both domestic and foreign markets. An alternative market is use as a fuel in existing combustors. The use of MWP as a fuel requires environmental and economic acceptance by potential users. MWP was analyzed for heavy metal concentrations and elemental composition and found to be similar to existing solid and fossil fuels burned in existing boilers. Existing regulations, however, may classify MWP as a municipal solid waste, thus increasing the capital and administrative costs of using this fuel. The cost of processing MWP into a fluff and a pellet is determined. Three existing facilities are studied to determine the capital and operating costs to use MWP fuel. In all cases, the cost of processing and transporting the fuel is greater than the break-even price that could be paid by the potential users.

Mallya, N. and Helt, J.E., (Argonne National Laboratory) "Potential for Converting MSW to Useful Fuels Through Pyrolysis," Proceedings of the 1988 National Waste Processing Conference, presented at the Thirteenth National Waste Processing Conference and Exhibit, Philadelphia, Pennsylvania, 1-4 May 1988, New York: American Society of Mechanical Engineers, Report No. CONF-8805107, pp. 295-300 (1988).

The authors discuss how pyrolysis of municipal solid waste (MSW) has the potential for helping solve two problems: the disposal of the waste generated by our society and the need for additional sources of energy. Experiments on the pyrolysis of MSW components in a bench-scale reactor are reported. The liquid and solid products formed are analyzed for physical and chemical properties to help determine their potential as useful fuels.

Maximization of Revenues for Power Sales From a Solid Waste Resources Recovery Facility, Report No. DOE/IR/05106-7, Order No. DE93009048, 304 pp. (December 1991).

The report discusses the actual implementation of the best alternative in selling electrical power generated by an existing waste-to-energy facility, the Metro-Dade County Resources Recovery Plant. After the plant processes and extracts various products out of the municipal solid waste, it burns it to produce electrical power. The price for buying power to satisfy the internal needs of our Resources Recovery Facility is substantially higher than the power price for selling electricity to any other entity. Therefore, without any further analysis, it was decided to first satisfy those internal needs and then export the excess power. Various alternatives were thoroughly explored as to what to do with the excess power. Selling power to the power utilities or utilizing the power in other facilities were the primary options.

Mayberry, J.L., "Update Mechanical Status Report," Biofuels and Municipal Waste Technology Research Program Summary: FY 1986, Report No. DOE/CH/10093-6, Order No. DE87001140, p. 98 (July 1987).

The objective of this task is to update the EG and G Energy from Municipal Solid Waste Mechanical Equipment and Systems Status Report. The first task will be to develop a current list of refuse-derived fuel (RDF) plants (large and small) from the literature, U.S. Department of Energy sources, and personal contacts; to establish the current status of operation (operating, shutdown, intermittent); and to develop an initial equipment configuration and basic operating data on each plant. A follow-on activity will include visits to selected RDF facilities to evaluate their current status, problems, equipment flow, 
configuration, equipment vendors and models, and the effectiveness of the equipment being used. An analysis of the plant visits will be done.

McGowin, C.R., "Impact of RDF Cofiring on Power Plant Operation and Economics," Energy from Biomass and Wastes XII, Klass, D.L., ed. Presented at the Twelfth Energy from Biomass and Wastes, New Orleans, Louisiana, 15-19 February 1988, Chicago, IL: Institute of Gas Technology, Report No. CONF-880215, pp. 567-590 (1989).

Energy recovery from municipal solid waste is accelerating in the United States in response to the declining availability of sanitary landfill sites caused by groundwater pollution and other environmental concerns. Electric utilities will participate in most refuse-to-energy projects as customers for electricity, steam, and/or refuse-derived fuel (RDF) or as owner/operators of facilities. This paper presents a case study of the design, performance, and economics of cofiring RDF with coal in an existing or new pulverized coal-fired utility boiler. RDF cofiring reduces boiler efficiency and power plant thermal efficiency and increases ash production.

Meridian Corp. and Science Applications International Corp., Electric Power from Biofuels: Planned and Existing Projects in the U.S., Revised January 1985, Report No. DOE/CE/30784-2 (August 1985).

This report summarizes current and planned use of biomass as a fuel to produce electricity in the United States. The specific biomass fuel types are wood wastes, agricultural residues, and animal manure. The paper also summarizes the electric generating capacity represented by the use of municipal solid waste, landfill gas, and sewage methane as energy feedstocks. These municipal wastes can be classified under the general category of biomass feedstocks. The study found that current utility use of biomass is typically on a relatively small scale, in a capacity range similar to that for small power production and cogeneration facilities (i.e., 5 to $50 \mathrm{MW}$ ).

Miller, J.H., "Design and Operation of the World's Largest RDF-to-Energy Plant," Energy from Biomass and Wastes XIV, Klass, D.L., ed. Presented at the Fourteenth Annual Conference on Energy from Biomass and Wastes, Lake Buena Vista, Florida, 29 January-2 February, 1990, Chicago, IL: Institute of Gas Technology, CONF-900117, pp. 653-662 (1991).

With its 4,000 tons per day capacity, the Detroit, Michigan, refuse-derived fuel resource recovery facility is billed as the world's largest. The interesting story about this plant is not its size, but the circumstances that surrounded its permitting, construction, and start-up operations. Permitted just as the U. S. Environmental Protection Agency was in the process of changing its determination of B.A.C.T. from electrostatic precipitators to dry scrubber/fabric filter, the project has been the subject of law suits, the cause of Michigan state ash legislation, and the target of recent proposed federal regulations that would mandate removing certain recyclable materials from the waste stream and retrofitting the facility with a baghouse/scrubber. In the process of meeting these challenges, the facility has undergone certain waste processing adjustments that indicate, from both a materials recovery and clean air perspective, prepared fuel could be poised to make a significant contribution to our national goal of an integrated solid waste management policy featuring recycling, materials recovery, incineration and landfilling. Combustion Engineering, Inc.'s (C-E) recent acquisition by ABB Asea Brown Boveri of Switzerland augments C-E's combustion and steam generating technologies with the worldwide power generation, transmission and distribution strengths of $\mathrm{ABB}$, all of which are directly applicable to waste-to-energy systems. 
Miller, R.D., Waste-to-Energy, Energy Task Force Status Report for First Quarter, Year Ten, Urban Consortium for Technology Initiatives, Report No. DOE/IR/05106-T52, Order No. DE89014845, Paper 16, 4 pp. (1989).

Improving the effectiveness of waste management is one of the most crucial challenges facing urban govemments today. Solutions are needed to capture the waste materials potential as renewable energy resources. The project emphasis is placed on specific applications and technologies, well-designed methods for cost and risk management, and improved means to generate institutional and public support for implementation. The status is reported for participating jurisdictions in Hennepin County, Minnesota, Memphis, Tennessee, Montgomery County, Maryland, Seattle, Washington, St. Louis, Missouri, and Philadelphia, Pennsylvania.

Monroe, E.S., Energy Conservation and Incinerators, Report No. SR/H-613, Order No. DE93019315, 22 pp. (June 1981).

This report discusses the proper selection of equipment for incinerating wastes and its operation which can play a major factor in reducing energy costs. Emphasis is placed upon utilizing existing boilers where it is feasible.

Monsanto Research Corp., Oil/Refuse Homogenization: An Approach to Cocombustion of Refuse in Existing Oil-Fired Boilers, Report No. DOE/CS/ 20175-1, 25 pp. (February 1982).

In this study, the feasibility of grinding and mixing refuse-derived fuel (RDF) with No. 6 (bunker C) fuel oil to obtain a fuel potentially combustible in existing oil-fired boilers was investigated. The ground refuse oil (refoil) mix, however, contained deformed metal palrticles that required removal to prevent clogging of burner nozzles. The study recommended investigations into refoil atomization and metal-particle removal and firing the refoil in a pilot-, small-, or medium-size oil-fired boiler to establish the refoil atomization and combustion characteristics and the impact of refoil on boiler operation and emissions.

Moretti, C.J., Fly Ash Utilization in McLean County, North Dakota, Report No. DOE/MC/10637-3377, Order No. DE93000295, 17 pp. (March 1993).

In 1989, the McLean County Commissioners requested assistance from personnel at the University of North Dakota Energy and Environmental Research Center (EERC) with the construction of a section of road and a boat ramp in their county. Assistance was sought from the EERC because the county's construction plans called for partial replacement of the lime and portland cement normally used for soil stabilization with fly ash. Since the EERC had recently conducted several research projects dealing with the use of coal combustion by-products for road construction, the commissioners requested that EERC personnel help to determine appropriate formulas for the stabilized soil mixtures to be used for both the road and boat ramp applications. An additional incentive was provided when the management of the Coal Creek Power Plant offered to donate the necessary fly ash at no cost. This project was performed as a joint venture between McLean County and the EERC. The EERC was primarily responsible for conducting a laboratory testing program to develop soil stabilization mixtures for the two construction activities. These mixtures were to contain a relatively high percentage of fly ash and to exhibit sufficient strength and durability so that the road and boat ramp would both have a service life of 20 years to more. McLean County would be primarily responsible for the road and boat ramp construction activities. The 
funding for the EERC portion of the project was provided by the U.S. Department of Energy through a joint venture support program.

Moretti, C.J. and Olson, E.S., Geotechnical/Geochemical Characterization of Advanced Coal Process Waste Streams: Task 2, Report No. DOE/MC/26255-3370, Order No. DE930002875, 29 pp. (September 1992).

Successful disposal practices for solid wastes produced from advanced coal combustion and coal conversion processes must provide for efficient management of relatively large volumes of wastes in a cost-effective and environmentally safe manner. At present, most coal-utilization solid wastes are disposed of using various types of land-based systems, and it is probable that this disposal mode will continue to be widely used in the future for advanced process wastes. Proper design and operation of land-based disposal systems for coal combustion wastes normally require appropriate waste transfer, storage, and conditioning subsystems at the plant to prepare the waste for transport to an ultimate disposal site. Further, the overall waste management plan should include a by-product marketing program to minimize the amount of waste that will require disposal. In order to properly design and operate waste management systems for advanced coal-utilization processes, a fundamental understanding of the physical properties, chemical and mineral compositions, and leaching behaviors of the wastes is required. In order to gain information about the wastes produced by advanced coal-utilization processes, 55 waste samples from 16 different coal gasification, fluidized-bed coal combustion, and advanced flue gas scrubbing processes were collected. Thirty-four of these wastes were analyzed for their bulk chemical and mineral compositions and tested for a detailed set of disposal-related physical properties. The results of these waste characterizations are presented in this report. In addition to the waste characterization data, this report contains a discussion of potentially useful waste management practices for advanced coal utilization processes.

Moss, L.E. and Brooks, C., (Argonne National Laboratory) "Waste-to-Energy Facility: Cleburne, Texas," Energy from Municipal Wastes: Opportunities for the Southwest, presented at the Workshop on Energy from Municipal Waste: Opportunities for the Southwest, Austin, Texas, 23 June 1986, Report Nos. ANL/CNSV-TM-173, CONF-8606334, Order No. DE87014258, p. 212 (May 1987).

Early in 1980 it became apparent that the City of Clebume had a landfill that was quickly running out of room. At that time, the decisions was made to explore the alternative of incineration instead of beginning the pursuit of another landfill site. Today, the City of Clebume has in operation a 115-ton-perday modular waste-to-energy facility. The plant is capable of producing 23,000 pounds of steam per hour and utilizing the steam to produce up to 860 kilowatts of electricity. Based upon hard numbers currently available, the cost for disposal, if the city were selling the steam to an industry and processing 100 tons per day of solid waste, would be approximately $\$ 14.00$ per ton. As it is, with no steam sales, selling power to Texas Power and Light Company and only processing approximately 50 tons per day, the cost more nearly approximates $\$ 45.00$ per ton. The vast majority of this cost is going for debt retirement. The community has been, and still is, committed to the incineration alternative. The authors task now is to find a steam customer, and increase the processed tonnage up to more nearly 100 per day.

Municipal-Waste Combustion: Background Information for Materials Separation, Final Report, Report Nos. PB-91-168567/XAB, EPA--450/3-90/021, 168 pp. (January 1991).

Several issues related to materials separation from municipal solid waste (MSW) are discussed. Current nationwide rates of materials separation and recycling, as well as the methodology for determining 
municipal solid waste separation rates, are presented. Case studies of four community curbside separation programs include performance data and program costs. Two centralized materials-separation facilities, which separate materials from unsorted MSW, are described with respect to the separation mechanisms employed, performance, and available cost data. Available data on the impacts of materials separation on municipal waste combustor (MWC) air emissions, combustor operation, and MWC ash are presented. The potential occupational risks of the handpicking process used to separate materials from MSW at some centralized separation facilities are discussed. The use of mercury in household batteries, and current information on community battery separation and collection programs and recycling efforts, are also discussed.

Municipality of Caguas, Puerto Rico, Feasibility Study for Small-Scale Waste-to-Energy System in Caguas, Puerto Rico, Report No. DOE/CS/20242-1, 94 pp. (February 1983).

A study was made to determine the feasibility of a small-scale resource recovery facility for the Municipality of Caguas, Puerto Rico, a community with a population of 125,000 persons. The study was structured to produce potentially viable energy buyers whose requirements would utilize all or most of the processible waste generated; a sufficient tonnage of usable, or processible, solid waste from which enough energy could be produced to meet the requirements of one or more potentially viable buyers; technologies capable of processing the available waste and incorporating utilization of sewage sludge to produce a reliable supply of energy and salable materials in the form, quantity, and quality required by prospective buyers; potentially available sites for a recovery facility that appear to be environmentally satisfactory and are well situated with respect to the shipment of solid waste and the delivery of energy to prospective buyers; and a net-annual-cost estimate (debt service plus operating and maintenance cost, less revenues) for a resource-recovery plant that appears to be reasonably competitive with continued reliance on landfilling as the primary means of disposing of solid waste.

National Center for Resource Recovery, Inc., A Model Contract for a Full-Service Resource Recovery Program, Report No. DOE/CS/20167-14, 82 pp. (March 1982).

This model contract is designed for use by a local govemmental entity to procure a resource-recovery facility on a full-service basis. In the model, the facility is to produce refuse-derived fuel (RDF) and recover materials. It is to be designed, constructed, and operated by a private contractor. The city supplies the site on which the facility is built and delivers refuse to the plant when completed. In addition, the city supplies a landfill site, which may be adjacent to the facility site. The contractor has full responsibility for the design of the facility, within technical specifications drawn up by the city or its consulting engineer. The model cites possible disagreements and other provisions that a city preparing a similar contract might consider and then modify to suit its needs.

National Center for Resource Recovery, Inc., An Analysis of Removal of Ash Components from Refuse-Derived Fuel during Pneumatic Transport, Report No. DOE/CS/20167-10, 108 pp. (February 1982).

This study was to determine the feasibility of removing a portion of the inorganic fines (particles less than a few millimeters in diameter) from refuse-derived fuel (air classifier light fraction) during the pneumatic conveying of the fuel from the production point to the storage silo or user's site. The relevant parameters, geometric and dynamic, of the pneumatic circuit and mixture of particles being conveyed are discussed. An experimental determination of the multidimensional size distribution and shape of combustible elements (mostly paper flakes) is made to provide realistic data in the calculation. Equations 
of motion for glass and larger combustible particles in a particular device (slitted bend of a conveyor pipe) are integrated using a specially written computer program (DUSTTRACK). A graphical procedure applied to the results allows prediction of the collection efficiency as a function of nondimensional design parameters. It appears that theoretical efficiencies of $40 \%$ or better can be achieved in one compact stage, at low hydraulic loss. Accordingly, a full-scale experiment at actual industrial scale is recommended, and the scope of the experiment is described.

National Center for Resource Recovery, Inc., Survey of Waste Fuel Storage, Metering, Transport, and Feed Systems, Report No. ANL/CNSV-TM-98, 74 pp. (November 1981).

This report provides design and performance information on the systems and equipment used to store, meter, transport, and feed solid-waste fuels onto several types of combustion systems. Of principal concern are systems buming fuels derived from municipal solid waste (MSW)-i.e., refuse-derived fuel (RDF), densified refuse-derived fuel (d-RDF), and unprocessed or minimally processed (MSW). A system that burns wood wastes as its primary fuel is also described. Twenty-eight waste-burning facilities are surveyed in the report. The plants are either operational and buming waste on a regular basis; closed temporarily due to equipment modifications or the unavailability of waste fuels; closed permanently due to serious and irreconcilable performance, operational, or financial problems; or no longer burning waste fuel after having completed combustion testing. For each facility, information is divided into two sections: description and performance. The description provides background information on the plant's past and present status, properties of the waste fuel burned, and a description of the systems and equipment installed to store, meter, transport, and feed the fuel. The performance section details operation of the systems and related equipment maintenance problems. Previous technical or operational approaches to solving particular problems and the relative success of each are discussed, as well as any ongoing efforts. Performance (both positive and negative) is discussed as it relates to the operation of the storage, metering, transport, and feed systems and their effect on combustor performance.

National Center for Resource Recovery, Inc., Assessment of the Present Status of Burning Refuse-Derived Fuel as a Fuel Supplement in the Cement Kiln Industry, Report No. ANL/CNSV-TM-97, 44 pp. (September 1981).

This report presents information from a survey of 10 companies that had experience using refuise-derived fuel in their kilns. From the information obtained, the following conclusions were reached: while there has been some test activity using RDF in cement kilns, there is no ongoing effort; few test data are available in this area; while RDF appears to be a suitable fuel, there is no push for commercialization; and because of the ad hoc nature of trial runs at the individual plants, a survey is not likely to collect a substantial data base in this area.

National Center for Resource Recovery, Inc., Proposed Draft Document for GSA Office Waste Removal and Procurement of Densified Refuse-Derived Fuel for Use as a Supplemental Fuel in GSA-Operated Boilers, Report No. DOE/CS/20167-8, 90 pp. (September 1981).

The General Services Administration (GSA) and the National Center for Resource Recovery (NCRR) studied the characteristics of federal office-building waste in the District of Columbia area, the possibility of making fuel pellets from this waste, and the ability of several GSA steam-generation plants to burn blends of coal and refuse-derived fuel pellets. A series of short-duration test burns were made at the Pentagon steam-generation plant. After the tests, GSA and NCRR, under the auspices of the U.S. Department of Energy, conducted a further evaluation of the long-term use of this fuel to ensure a constant 
process of refuse removal and production of densified, refuse-derived fuel. The NCRR prepared this draft procurement contract for review by GSA. The contract specifies waste collection and disposal from buildings managed by GSA in the Washington, D.C., area and production and delivery of pelletized fuel for burning with coal in one or two GSA steam-generating plants.

National Center for Resource Recovery, Inc., Waste-to-Energy Compendium, Final Report, Report No. DOE/CE/20167-5, 125 pp. (April 1981).

This report presents the status of 35 operating waste-to-energy projects in the United States. Three types of facilities are surveyed: refuse-derived-fuel (RDF) production facilities, RDF user facilities, and municipal-solid-waste combustion facilities with energy recovery. Only fully operating plants or those in advanced stages of start-up or shakedown are presented. Data are given on capacity, equipment specifications, capital and operating costs, current status, and operational and mechanical problems.

National Center for Resource Recovery, Inc., Feasibility of Burning Refuse-Derived Fuel in Institutional-Size Oil-Fired Boilers, Final Report, Report No. DOE/CS/20167-3, 78 pp. (October 1980).

This study examines the feasibility of retrofitting oil-fired boilers to cofire refuse-derived fuel (RDF). Boilers of a scale currently in use in institutions $\left(8-80 \times 10^{3} \mathrm{lb}\right.$ steam $\left./ \mathrm{h}\right)$ are studied. Data on oil, RDF, and combustion-products mixtures are computed for various levels of excess air. Cost savings projected from using RDF are derived under several assumptions. An extensive survey of manufacturers shows that no boilers, burners, and combustion systems of proven design are yet available for the retrofit required. Two approaches with significant promise are outlined: the stagging burner and a dry-ash, double-vortex burner for low heat input from the RDF. Both systems are recommended for future study, together with a small, separate, dedicated RDF combustor to support the oil-fired boiler.

National Center for Resource Recovery, Inc., The Use of RDF as a Kiln Fuel, Final Report, Report No. DOE/CS/20167-4, 136 pp. (October 1980).

Refuse-derived fuel (RDF) has been used experimentally in kilns to produce three major types of construction materials: portland cement, quick lime, and expanded shale (light-weight) aggregate. Each material requires a substantial amount of energy for production. This report reviews the technological issues affecting the use of RDF in kilns, as well as the results of tests in which RDF actually was used as kiln fuel. The report also outlines three future research and demonstration projects that could help resolve the remaining issues and lead to commercial use of RDF as a kiln fuel. The projects include tests in a lime plant and a precalcining furnace and an extended test in a cement kiln.

National Center for Resource Recovery, Inc., Use of Waste Oils to Improve Densified Refuse-Derived Fuels, Final Report, Report No. DOE/CS/20167-1, 67 pp. (October 1980).

Test firings of waste-oil-treated, densified, refuse-derived fuels were conducted to analyze powerconsumption savings and increased throughput potential over normal dry-pellet buming. The calorific value of the prepared fuel increased in proportion to the amount of oil added; however, oil levels exceeding $20 \%$ resulted in denatured or weakened pellets. Throughput rate showed no noticeable improvement when oil- and water-soaked pellets were used. Power consumption decreased when any liquid, even water, was added to the pelletizer feedstock. 
National Energy Corp., DOE Feasibility Report on Lake Calumet Area Refuse-to-Energy Facility, Report No. DOE/R5/10105-1, 241 pp. (June 1980).

Site analyses and literature reviews were conducted to determine the feasibility of building an energy-producing municipal waste incinerator at Calumet Lake near Chicago. The amount of bumable waste produced within 5-10 miles of the site, the composition and heating value of this solid waste, and the air pollution impacts of waste incineration were determined. The report concludes that refuse in the area is sufficient to support a refuse-processing center, increasing landfill costs make such a center economically attractive, the Btu content of the refuse is adequate to produce steam for heat and power, and replacing existing oil-fired power plants with this facility would reduce current pollutant emission levels by $88 \%$.

Niemann, K. and Campbell, J., Mobilizable RDF/d-RDF Burning Program, Report No. DOE/CS/20167-13, 107 pp. (March 1982).

The mobilizable $\mathrm{RDF} / \mathrm{d}-\mathrm{RDF}$ buming program was conceived to promote the utilization of refuse-derived fuels (RDF) as a supplement to existing fossil fuel sources in industrial-sized boilers. The program explores the design, development, and eventual construction of densified-RDF (d-RDF) for use in boiler combustion testing as a supplement to stoker coal or wood wastes. The equipment would be mounted on trailers and assembled and operated at preselected sites throughout the country where approximately 750 tons of RDF would be produced and test burned in a local boiler. The equipment, to include a transportable RDF boiler metering and feed system, would then be moved and operated at two to three test sites annually. The program is intended to encourage the construction of permanent resource-recovery facilities by involving local waste handling groups in operating the equipment and producing fuel and involving potential local fuel users in testing the fuel in their boilers.

Ohlsson, O., Daugherty, K.E., Venables, B.J., (Argonne National Laboratory) Densified Refuse Derived Fuel: An Alternative Energy Source, presented at the Ninth World Energy Engineering Congress, Atlanta, Georgia, 21-24 October 1986, Report No. CONF-861033-1, Order No. DE90013668, 5 pp. (1986).

The objective of this research effort is to produce an environmentally acceptable, chemically/biologically stable, and storable densified refuse-derived fuel (dRDF) pellet. To accomplish this, a suitable binder(s) must be used. More than 150 binders were investigated by a laboratory screening procedure. Thirteen binder/binder combinations of the initial group of 150 binders were selected for further pilot plant studies. Approximately seven tons of RDF from Ames, Iowa and Refcom, Pompano Beach, Florida were pelletized in the summer of 1985 in a series of experiments at the Jacksonville, Florida, Naval Air Station using these binders. The pelletized dRDF was then subjected to a battery of chemical and physical tests. Results to date and work to be accomplished during the next fiscal year are discussed.

Ohlsson, O.O. and Lazar, J., (Argonne National Laboratory) Densified RDF: Technologies and Applications, presented at the American Institute of Chemical Engineers Spring National Meeting, New Orleans, Louisiana, 6-10 March 1988, New York: American Institute of Chemical Engineers, Report No. CONF-880348, Technical Paper 14G, 1 p. (1988).

Densified refuse-derived fuel (dRDF) is municipal solid waste that has undergone several steps of sizing, separation and screening to produce a refuse-derived fuel (RDF) and other soluble or recyclable by-products. The RDF is then densified in a pelletizing or cubing extrusion process. This dRDF product 
offers several advantages compared to RDF: ease and cost of transportation; increased storability; and the capability of firing in a variety of combustor configurations. This paper discusses the problems encountered with dRDF processing systems, the current status of dRDF facilities, technologies presently used, and the economics of existing systems.

Ohlsson, O.O., Livengood, C.D., and Daugherty, K.E., (Argonne National Laboratory) Results of Emissions and Ash Testing in Full-Scale Co-Combustion Tests of Binder-Enhanced dRDF Pellets and High-Sulfur Coal, presented at the Eighty-Third Annual Meeting and Exhibition of the Air and Waste Management Association, Pittsburgh, Pennsylvania, 24-29 June 1990, Report No. CONF-900676-5, Order No. DE90011118, 29 pp. (14 May 1990).

As existing landfills become filled to capacity and new landfills become more costly to site, the development of alternative disposal methods of municipal solid wastes (MSW) is becoming critical. In addition, the refuse being buried contains considerable quantities of energy that could potentially replace conventional fossil fuels. Some of the main problems of using MSW as a feedstock have been variability, biological and chemical instability, and poor fuel quality. An improved method for turning MSW into an environmentally safe and economical fuel has recently been developed. Recyclable metals, glass, and some plastics are mechanically and manually separated from the waste. The remaining (combustible) fraction is combined with a calcium hydroxide binding additive, and formed into cylindrical pellets. These pellets are dense and odorless, can be stored for up to three years without significant biological or chemical degradation, and are easily transported. These pellets have been successfully confined with coal in existing spreader-stoker combustors. Other benefits include significant reductions of sulfur dioxide $\left(\mathrm{SO}_{2}\right)$, nitrogen oxides $\left(\mathrm{NO}_{\mathrm{x}}\right)$ and $\mathrm{CO}_{2}$ in the flue gases, and the trapping of the chlorine combustion products (such as $\mathrm{HCl}$ ) that are formed during the combustion process from the remaining plastics in the refuse. This paper describes the b-dRDF pellet/coal cofiring tests, emission and ash samples collected, analyses that were conducted on these samples, and study conclusions.

Ohlsson, O.O., Pearson, C.V., and Lazar, J., (Argonne National Laboratory) "Cofiring of Pelletized Refuse-Derived Fuel with Coal to Achieve Sulfur Dioxide Emissions Requirements," Proceedings of the American Power Conference, presented at the American Power Conference, Chicago, Ilinois, 18-20 April 1988, Report No. CONF-880403, pp. 794-797, v 50 (1988).

Processing municipal solid waste with lime additives produces a high quality, storable, fuel pellet. Earlier studies of the beneficial effect of lime addition to coal and of the cofiring of lime-rich refuse-derived fuel pellets with coal suggested cofiring these pellets with Illinois or Kentucky coals in order to reduce sulfur dioxide emissions. A series of burn tests were conducted at Argonne National Laboratory in the summer of 1987 to verify the rate and conditions for optimum sulfur capture. Pellets with lime additions of $4-8 \%$ (by weight) were fired at $10 \%, 20 \%$, or $30 \%$ (by ratio of heat input) with coal. This paper presents the results to date.

Ohlsson, O.O., Walter, D.K, and Goodman, B.J., (Argonne National Laboratory), An Overview of RDF Processing Systems: Current Status, Design Features, and Future Trends, presented at the Joint Power Generation Conference, San Diego, California, 6-9 October, 1991, Report Nos. ANL/CP-74114, CONF-911018--3, Order No. DE92000359, 9 pp. (1991).

This paper discusses the recent history of refuse-derived fuel (RDF) processing facilities in the United States. The current status of these facilities, including environmental, institutional, and economic considerations is discussed. The unit operations used to produce a desired RDF product are described, 
and the future potential of RDF processing systems is evaluated. Current research sponsored by the U.S. Department of Energy is also presented.

One America, Inc., Energy from Municipal Waste: Program Evaluation, Report No. DOE/CS/24312-6, 96 pp. (May 1983).

This report is the result of a four-month independent evaluation of the U.S. DOE Energy from Municipal Waste (EMW) program. The evaluation was requested by the DOE program manager and by the House Appropriations Committee. The purpose of the evaluation was to provide a review of the activities of the program and to assist in the redefinition and prioritization of future EMW programs.

One America, Inc., Who's Who in Energy Recovery from Waste, Report No. DOE/CS/24312-5, 112 pp. (October 1982).

This publication has 790 entries that include names and addresses of organizations (and contacts within the organizations) involved in energy recovery from waste. The directory also lists waste-to-energy facilities in operation or under construction in the United States. Organizations are listed in the following categories: federal government; state and local associations; public interest groups; design engineers; systems vendors and equipment manufacturers; system operators; financial, legal, and bonding engineers; engineering, management, and technical consultants; and trade journals and publications.

One America, Inc., Questions and Answers about Energy Recovery from Waste, Report No. DOE/CS/24312-4, 30 pp. (September 1982).

This report contains questions and answers about the waste-to-energy industry. It is intended as a reference for the general public and others interested in the options of using municipal waste as a renewable energy resource. Questions and answers are grouped in six categories: general information, state-of-the-art, economics/financial, environmental, institutional, and project implementation.

One America, Inc., Energy Recovery from Waste: Workshop Proceedings, Report No. DOE/CS/24312-2, 172 pp. (August 1982).

These proceedings were produced following a series of four workshops held to present information on Public Law 95-617, the Public Utility Regulatory Policies Act (PURPA). The workshops were sponsored by the U.S. Department of Energy, the National Association of Regulatory Utility commissioners, and the American Public Power Association.

One America, Inc., Waste-to-Energy Compendium, Revised 1982 Edition, Report No. DOE/CS/24312-1, 298 pp. (August 1982).

This report provides an update of the Waste-to-Energy Compendium prepared by the National Center for Resource Recovery, Inc., published in April 1980. The compendium includes comprehensive information on three basic resource-recovery systems: refuse-derived fuel (RDF) production facilities; RDF user facilities; and municipal solid waste mass-burning facilities with energy recovery. Relevant technical, operational, and economic information on each system is provided in narrative descriptions, process flow schematics, and data summary sheets. The report covers those facilities that are currently operational or 
in advanced stages of startup and shakedown. It excludes four new facilities for which information was not received before the publication deadline. These four are mass-buming facilities located in Pittsfield, Massachusetts; Gallatin, Tennessee; and Gatesville and Palestine, Texas. Projects under construction at the close of 1981 were also excluded because operating and cost data were not yet available.

Opportunity Systems, Inc., State of California: Resource Recovery Profile, Report No. DOE/CS/24456-2, 114 pp. (January 1983).

This report documents the results of a two-month effort to identify and describe the municipal refuse-to-energy conversion projects in California. Most of the data were collected by telephone interviews with project directors and their key staff. In many instances, the information includes project descriptions, progress reports, and other literature supplied by the contact persons. The profiles are organized alphabetically within system technologies, with the exception of the methane-from-wastewater treatment facilities. Because of the large number of wastewater treatment facilities in California, it was agreed to omit the profile format for those facilities. In lieu of the profile format, a listing of the facilities is provided, with a brief description of each large-scale producer.

Opportunity Systems, Inc., State of New Jersey: Resource Recovery Profile, Report No. DOE/CS/24456-1, 101 pp. (October 1982).

This report represents a two-month study identifying all municipal solid waste to energy projects in New Jersey. The profiles contain historical, technological, institutional, and financial information on each project. Most of the data were collected by telephone interviews with project directors and their key staff. In many instances, the information includes project descriptions, progress reports, and other literature supplied by contact persons.

Paisley, M.A., Creamer, K.S., Tweksbury, T.L., and Taylor, D.R., (Pacific Northwest Laboratory) Gasification of Refuse Derived Fuel in the Battelle High Throughput Gasification System, Report No. PNL-6998, Order No. DE89017754, 33 pp. (July 1989).

This report presents the results of an experimental program to demonstrate the suitability of the Battelle high throughput gasification process to non-wood biomass fuels. An extensive data base on wood gasification was generated during a multi-year experimental program. This data base and subsequent design and economic analysis activities led to the discussion to study the gasification character of other fuels. The specific fuel studied was refuse-derived fuel (RDF), which is a prepared municipal solid waste (MSW). The use of RDF, while providing a valuable fuel, can also provide a solution to MSW disposal problems. Gasification of MSW provides advantages over landfill or mass burn technology because a more usable form of energy, medium Btu gas, is produced. Land filling of wastes produces no usable products, and mass buming, while greatly reducing the volume of wastes for disposal, can produce only steam. This steam must be used on site or very nearby, thus limiting the potential locations for mass burn facilities. Such a gas, if produced from currently available supplies of MSW, can contribute 2 quads to the U. S. energy supply. 
Pearson, C.V., National Survey of Industrial Markets for Steam Produced from Burning Municipal Solid Waste, Report No. ANL/CNSV-TM-125, 164 pp. (September 1983).

This report presents the methodology and findings of an analysis to determine the maximum size of the industrial market for steam produced from municipal solid waste in the United States. The data used in the analysis were developed from the 1980 census report and the U.S. Chamber of Commerce's 1979 Standard Industrial Classification (SIC) listing. The process used to match potential steam users with populations large enough to generate suitable quantities of waste is presented. No attempt was made to rank the markets or analyze the market economics. The report concludes that no more than $23 \%$ of the nation's municipal solid waste could be used to produce marketable steam. However, included in the total market for this steam were industries that produce either fuel, burnable waste, or high-quality waste heat. Industries in the following categories were major candidates for using steam from municipal waste: SIC 29 (petroleum and coal products industry, which produces fuel), SIC 33 (primary metals industry, which produces high-quality waste heat), and SIC 26 (paper and allied products industry, which produces burnable waste). Removing any of these industries from the potential steam market could remove markets for steam equivalent to $3.8 \%, 3.5 \%$, and $2.8 \%$ of the nation's waste, respectively. No attempt was made to include new industrial plants built and operated after 1979 or those closed since 1979. The study assumes that new construction will counterbalance plants being phased out of operation and that a municipal-waste-burning facility could always be sited near the market identified.

Penetrante, B.M., (Lawrence Livermore National Laboratory), Pollution Control Applications of Pulsed Power Technology, presented at the 9th IEEE Pulsed Power Conference, Albuquerque, New Mexico, 21-23 Jun 1993, Report No(s). UCRL-JC-114976 and CONF-930616-33, Order No. DE93019611, 7 pp. (16 August 1993).

Much of the activity and growth in the field of pulsed power technology has been spawned by government-sponsored research for military applications. During the last two decades, significant advances have been made in pulsed power modulators and accelerators. Pollution control systems for large industrial applications could benefit a great deal by exploring the results of this research and development. This paper presents the history of how pulsed power technology got involved in pollution control applications. Emphasis will be placed on the application of pulsed power to pollution control in utility and industrial coal-fired power plants. The use of pulsed techniques for improving the efficiency of electrostatic precipitators are first discussed, then the parallel developments in electron beam and pulsed corona processing for flue gas treatment are presented. Pulsed power techniques are essential as supporting technologies for these advanced pollution control methods. To illustrate the large scale of these applications, the author discusses the power requirements of these methods.

Phase 1, Background Study Results Under the Council of Great Lakes Governors Program to Perform Stack Sampling and Analysis of Emissions from Densified Refuse Derived Fuels (d-RDF), Report No. DOE/OR/21390-T27, Order No. DE91000975, 62 pp. (7 April 1989).

This report covers the results of the first part of the study. Chapter 2 contains a summary of the d-RDF literature which was surveyed. Chapter 3 contains a compilation of existing and proposed regulation information from the seven participating Great Lakes States. Chapter 4 includes identification of pellet producers in the region. Chapter 5 contains a description of the pellet producers and test bum facilities selected for the experimental work to be undertaken in the second part of the program study. Chapter 6 contains a list of references. 
Podolak, P. and Fagan, M., (U.S. Department of Energy Assistant Secretary for Policy, Planning and Analysis, Office of Policy Integration) "Trash to Energy: A Burning Issue," 1988 Selected Papers and Presentations by DOE's Policy Integration Office Staff, Report No. DOE/PE-0088, Order No. DE89004611, Paper 13, 11 pp. (December 1988).

Simulating historical trends of economic factors and their affect on tonnage resulted in a forecast of nearly 26 million tons of waste-to-energy by the year 2000 . This projection is smaller than the EPA estimates (done in 1986) of 32 million tons and the Governmental Advisory Associates, Inc. 1988 estimate of 44 million tons per year if all plants in the advanced planning stage are constructed. But 26 million tons is three times what was made into energy in 1984. There seems to be a change from historical patterns, resulting in a more conservative estimate. Converting our 26, 32, and 44 million tons per year waste estimates into energy estimates gives us ranges of 2,047,2,519, and 3,463 MW for gross power output, and 1,144, 1,409, and 1,937 MW for net power output. Using the average household electricity use of 32 million BTUs per year, the highest estimate of net power generation would be sufficient to provide electricity to 2.8 million households, or about the population of the Los Angeles-Long Beach metropolitan area. The trash can has not yet replaced the oil barrel as an energy symbol, but it's on the way.

Proceedings: Energy from Urban Wastes Workshop, held September 11-12, 1978, in Washington, D.C., Report No. ANL/CNSV-TM-5, 173 pp. (September 1980).

The activities, goals, and objectives of three federal agencies (the Department of Energy, the Environmental Protection Agency, and the Department of Commerce) for energy-recovery research, development, and demonstration were presented to 50 representatives of public interest groups. This document covers presentations on state-of-the-art resource-recovery technologies; implementation of projects through financial, marketing, legal, and institutional agreements; and the role of the agencies in developing energy-conserving technologies in compliance with current law.

Proceedings: 1991 Conference on Waste Tires as a Utility Fuel, presented at the 1991 Conference on Waste Tires as Utility Fuel, San Jose, California, 28 January, 1991, Palo Alto, CA: Electric Power Research Inst., Report Nos. EPRI-GS-7538, CONF-9101116, 210 pp. (28 January 1991).

The objective of the 1991 EPRI Conference on Waste Tires as a Utility Fuel was to provide a status report on tire-derived fuel (TDF) preparation and combustion for power generation. Interest in use of waste tires as fuel is growing because of the need to dispose of the more than 200 million scrap tires generated each year and about two billion tires that now reside in scrap tire piles and landfills in the United States. Thirteen papers were presented at the conference on a range of topics, including alternate fuel cofiring, state scrap tire management programs, tire-derived fuel preparation and properties, cofiring TDF and coal in utility boilers, and fluidized bed combustion of TDF. Based on laboratory testing and early utility test burns of up to 10\% TDF with coal in cyclone and wet bottom pulverized-coal boilers, it appears that TDF cofiring is technically feasible and does not adversely affect environmental emissions. However, careful control of TDF quality is needed to produce fuel with acceptable particle size and loose metal content in order to avoid fuel handling problems at the power plant.

Proceedings of the International Conference on European Waste-to-Energy Technology, held October 29-31, 1980, in Reston, Virginia, Report No. ANL/CNSV-TM-14, 278 pp. (September 1980).

Major European designers of waste-to-energy systems describe their plants and discuss planning and implementation, including site selection, construction, and operating experience. In addition, the 
results of studies made by the U.S. Department of Energy and U.S. Environmental Protection Agency on European waste-to-energy systems are given.

Proceedings of the International Conference on Prepared Fuels and Resource Recovery Technology, held February 10-13, 1981, in Nashville, Tennessee, Argonne National Laboratory Report No. ANL/CNSV-TM-60, 527 pp. (April 1981).

These proceedings document presentations made at the International Conference on Prepared Fuels and Resource Recovery under the sponsorship of the U.S. Department of Energy and U.S. Environmental Protection Agency. Session 1 covers approaches to selecting a technology and includes papers on architectural, engineering, turnkey, fullservice, and combined approaches. Session 2, on front-end technology for prepared fuels, covers shredding, trommeling, air classification, densification, and reduction of the potential for explosion damage. Session 3 reviews current experience with industrial systems. Session 4, on marketing issues, reviews considerations affecting use of refuse-derived fuel in utility and dedicated boilers and as a kiln fuel. Session 5 considers the effects of waste flow control at an Akron, Ohio, facility on policy and financial issues. Legal aspects are presented using Delaware County, Pennsylvania, as a case study. Private and public perspectives are also surveyed (e.g., those of contractors, utilities, investors, government, and the general public).

Proceedings of the U.S. Department of Energy/Argonne National Laboratory Contractors' Research and Development Workshop: Converting Waste to Energy, December 1-4, 1981, Report No. ANL/CNSV-TM-96, 378 pp. (February 1982).

This report documents presentations given at the U.S. Department of Energy/Argonne National Laboratory (DOE/ANL) Contractors' Research and Development Workshop, held December 1-4, 1981, in Savannah, Georgia. Papers are based on work and funding of persons and businesses working under contract in the area of energy from municipal waste for ANL or DOE.

Public Service Electric and Gas Co., Sewage Sludge as a Supplementary Utility Boiler Fuel, Vol. 1, Report No. DOE/CS/20061, 243 pp. (May 1986).

The use of dried sewage sludge as a supplementary fuel, up to $30 \%$ of fuel input in utility boilers, appears feasible. Only coal-fired utility boilers (600 MW or larger) and oil-fired boilers (300 MW or larger) originally designed for future coal capability were found to be practicable candidates for conversion to burning dried sludge as a supplementary fuel. Boilers designed for coal and converted to oil could be added to this latter category, but these constitute only $3 \%$ of the U.S. boiler capacity.

Pyrolysis of Municipal Solid Waste, Annual Report, July 1983-June 1984, Report No. ANL/CNSV-45, 49 pp. (December 1984).

Current Argonne National Laboratory research is directed at improved understanding of the basic thermokinetic mechanisms associated with the pyrolytic conversion of municipal solid waste (MSW) and upgrading of pyrolysis liquids by catalytic hydrotreating. To improve the understanding of basic mechanisms, initial experiments were carried out using both thermogravimetric analysis and a bench-scale reactor. Results of the analysis, as well as the initial data from the bench-scale reactor, are presented and discussed, and future plans are outlined. With regard to upgrading pyrolysis liquid, general background information on catalytic hydrotreating of pyrolysis liquids is given. Experiments to determine the kinetics 
of catalytic reactions that remove oxygen-containing compounds from MSW pyrolysis liquids are described. Preliminary data and plans for future work are discussed.

Raytheon Service Co., Feasibility Study for Alternative Fuels Production from Solid Waste, Report No. DOE/RA/50375-1, 100 pp. (February 1982).

This report outlines a study to determine the feasibility of producing refuse-derived fuel at an existing shredding station in Charleston, South Carolina, and selling this product to local industry to replace fossil and wood-products fuels. During the study, a complete survey of significant energy consumers in Charleston was conducted. From among the 77 consumers contacted, full-scale testing was carried out at the two facilities offering the greatest potential to purchase all the fuel that could be produced.

Resource Planning Associates, Inc., European Waste-to-Energy Systems: Case Study of Ivry-sur-Seine, France, Report No. HCP/M2103-0009, 66 pp. (September 1978).

The Paris region has more than 10 million inhabitants. Treatment for nearly all the waste generated in the Paris region is the responsibility of the Service du Traitement Industriel de Residus Urbains (TIRU). Ninety percent of the waste generated in the region is burned in one of TIRU's three combustion units. These units (all of which produce steam and electricity) are located at Issy-les-Moulineaux, Saint Ouen, and Ivry-sur-Seine, all on the outskirts of Paris. The plant at Ivry-sur-Seine (commonly called Ivry II, because it is the second combustion unit to occupy the site) has two Martin furnaces with an hourly capacity of 40 to 50 metric tons (44 to 55 short tons). Its total cost was 164 million F ( $\$ 33$ million) in 1968. Operations began in 1969. The paper describes waste collection and treatment in the Paris region, the design and operation of the Ivry II combustion unit, and the costs of that unit.

Resource Planning Associates, Inc., European Waste-to-Energy Systems: Case Study of Landshut, West Germany, Report No. HCP/M2103-0007, 47 pp. (September 1978).

The municipal combustion unit of Landshut, West Germany, burns the solid waste of this small city (population 56,000) and a surrounding area with an equal number of inhabitants. Two Von Roll furnaces, coupled with tail-end boilers, treat up to 4.8 metric tons (5.3 short tons) of waste per hour. The simple design of the furnaces and fire-tube boilers (developed in response to the corrosion problems of waterwall furnaces) and the provision for cleaning the boiler tubes by a knocking system have resulted in nearly trouble-free operations. Since the first furnace began firing waste in 1972, it has been available more than $80 \%$ of the time. The second fumace, which came on line two years later, has an equally good record. The superheated steam produced in the boilers is used to generate electricity. The combustion unit supplies approximately $30 \%$ of Landshut's electrical demand. The city buys this electricity at the same rate it pays for electricity from the regional grid. Despite the revenue from the sale of electricity, the combustion of solid waste cost Landshut more than DM 64 per metric ton ( $\$ 23$ per short ton) in 1976. Nevertheless, the lack of a suitable alternative and the smooth operation of the current system have convinced the municipal authorities to expand the system. A third furnace with a capacity of 6 metric tons (6.6 short tons) per hour is to be added. 
Resource Planning Associates, Inc., European Waste-to-Energy Systems: Case Study of Rennes, France, Report No. HCP/M2103-0008, 45 pp. (September 1978).

Rennes, France, is a city of 205,000 inhabitants with heavy industry (automobiles, railway equipment, refineries) and electronics industries, and it is a university town. Villejean Malifeu is the site of the Rennes waste-to-energy unit. The unit burns the municipal solid waste of the city and 26 surrounding small communities and is connected to the district heating network. Along with an oil-fired heating plant, the Rennes combustion unit provides space heating and domestic hot water for nearly 5,000 housing units, hospital buildings, university buildings, and other institutional and commercial buildings. The sale of energy recovered from municipal solid waste more than pays for the operation of the combustion unit. As a result, the total cost for waste treatment (including amortization) is only $15 \mathrm{~F}$ per metric ton (\$3.06 per short ton, 1977). The system design, its operation, and economics are discussed in separate chapters.

Resource Planning Associates, Inc., European Waste-to-Energy Systems: An Overview, Report No. CONS/2103-6, 62 pp. (June 1977).

This overview discusses common features of Western European waste-to-energy systems. Specific topics include combustion techniques available, end uses of recovered energy, economics of waste-to-energy systems, and identification of systems currently operating or under construction in Western Europe.

Resource Planning Associates, Inc., European Waste-to-Energy Systems: Case Study of the Thermal Complex of Brive, France, Report No. CONS/2103-5, 37 pp. (June 1977).

A joint facility for solid-waste combustion and sludge treatment is studied in this report. Heat from the combustor is used to dry sewage sludge, which is subsequently combusted with the solid waste.

Resource Planning Associates, Inc., European Waste-to-Energy Systems: Case Study of Geneve, Cheneviers (Switzerland), Report No. CONS/2103-2, 41 pp. (May 1977).

This report examines Geneva's combustion waste-treament facility. The plant consists of two Von Roll integrated boiler combustion units that recover electricity, which is subsequently sold to the Canton grid.

Resource Planning Associates, Inc., European Waste-to-Energy Systems: Case Study of Korsor, Denmark, Report No. CONS/2103-3, 37 pp. (May 1977).

This case study evaluates an unusual waste-to-energy system that serves a population of only 20,000 in Korsor, Denmark. Energy recovered in the form of waste heat is applied to district heating. The apparent success of the system suggests applications for waste-to-energy systems in communities far smaller than those generally considered of optimum size. 
Resource Planning Associates, Inc., European Waste-to-Energy Systems: Case Study of the Thernal Complex of Toulouse-le Mirail, France, Report No. CONS/2103-1, 45 pp. (May 1977).

This case study examines a complex composed of a combustion unit with heat-recovery equipment and an oil-fired heating facility. The complex burns the household waste of a city of 400,000 and simultaneously provides central heating and hot water to a suburb of 100,000 inhabitants.

Resource Planning Associates, Inc., Waste Flow Characteristics and Resource Recovery, Report No. EY-76-C-02-4011, 128 pp. (October 1976).

In order to provide technical assistance for the planning, design, and optimum economic operation of solid municipal waste processing plants for materials or energy recovery, a study was made of information on solid-waste flows. The quantity and quality of waste flow data is discussed, the effects of waste flows on resource-recovery facilities are analyzed, and recommendations are made for government action for improving the accuracy and availability of waste flow data.

Resource Planning Associates, Inc., and Consultex, S.A., European Waste-to-Energy Systems: Case Study of Munich-Munich North IA \& 1B, Munich North II, Munich South IV \& V, Report No. CONS/2103-4, 92 pp. (May 1977).

In this case study, Munich's innovative experiments for recovering energy from waste are reviewed. Since 1960, Munich has constructed five waste-combustion units that capture energy as steam, hot water, or electricity to supply power for the city's grid.

Riley, B.T., Preliminary Investigation of the Application of Modified Soil Compaction Technologies to Densify Prepared Municipal Wastes into Fuel Nodules, Report No. ANL/CNSV-TM-170, 89 pp. (November 1985).

This report documents the results of a study conducted to investigate the efficiency of soil-compaction equipment to produce fuel nuggets that would be suitable either as a boiler fuel or as a gasifier fuel. The study consisted of a brief literature and theory review and development of order-ofmagnitude cost estimates of the various potential fuel nugget production scenarios that were examined. Laboratory studies were used to identify the most relevant variables to prepare and carry out the field test phase of this work.

Roy, R., Stuart, J., Couithard, J., and Korenberg, J., "CFB Technology Demonstrates Medical Waste Combustion," Proceedings of the 1993 International Conference on Fluidized-Bed Combustion. Volume 2, Rubow, L., ed., presented at the 12th International Conference on Fluidized-Bed Combustion, San Diego, California, 9-13 May 1993; New York: The American Society of Mechanical Engineers, Report No. CONF-930521, pp. 735-741 (1993).

CFB technology has been successfully utilized for coal and medical waste combustion testing. The medical waste was shredded into approximately 1 in. wide by 3 in. long strips before being fed into the CFB. The medical waste consisted of noninfectious waste taken from the Lebanon Veteran's Affairs Medical Center. The coal-fired CFB provides inherent medical waste destruction advantages. CFB technology utilizes better combustion practices than typical incinerators. Typical incinerators are hearth or rotary kiln types, which have lower levels of turbulence. CFBs utilize limestone, which provides $\mathrm{HCl}$ 
as well as $\mathrm{SO}_{2}$ gaseous emissions abatement. $\mathrm{HCl}$ is one of the more abundant pollutants formed during medical waste combustion. A CFB system typically possesses a baghouse which provides particulate and heavy metal capture. Heavy metal emissions levels are restricted by incinerator regulations. The operating temperatures, residence times and chemical constituents inherent to the CFB system provide dioxin and furan emissions levels that are one to two orders of magnitude below typical medical waste incinerators. The Lebanon VA Medical Center is the site of the first commercial coal and medical waste co-fired CFB, which is the second phase of a Department of Energy funded project. Donlee Technologies is the prime contractor for the second phase of the contract and is the CFB developer. Lebanon facility emissions predictions based on pilot facility testing demonstrate that the technology will meet all emission requirements. The Lebanon VA facility emission requirements consist of both NSPS regulations and the new Pennsylvania Best Available Technology (BAT) guidelines for incinerators. The BAT guidelines are based on assessments of risk to people from pollutants at ground level. Ambient air modeling predicted ground level concentrations of toxic pollutants.

Schexnayder, S.M. and Wolfe, A.K.; (Oak Ridge National Laboratory), Decision Making and the Decisions Made, presented at the Eighteenth National Association of Environmental Professionals (NAEP) Annual Conference on Current and Future Priorities for Environmental Management, Raleigh, North Carolina, 24-26 May 1993, Report No. CONF-930523-3, Order No. DE93011862, 16 pp. (1993).

During the early 1980s, it was projected that waste-to-energy (WTE) facilities would manage as much as half of all municipal solid waste by the turn of the century. However, during the latter part of the 1980s, the cancellation rate for WTE facilities grew to the point that the portion of the waste stream WTE will handle in the long-term future is less certain. This study, conducted as part of a larger study, identifies factors that influence municipalities' decisions regarding WTE. This study takes a broad perspective about decision-making within communities, emphasizing the context within which decisions were made and the decision-making process. It does not seek to judge the correctness of the decisions.

Scott, D.S., Czemik, S.R., and Radlein, D. "Fast Pyrolysis of Waste Plastics," Energy from Biomass and Wastes XIV, Klass, D.L., ed. Presented at the Fourteenth Annual Conference on Energy From Biomass and Wastes, Lake Buena Vista, Florida, 29 January-2 February, 1990, Chicago, IL: Institute of Gas Technology, Report No. CONF-900117, pp. 1009-1017 (1991).

Preliminary results using the Waterloo Fast Pyrolysis Process are obtained for the fast pyrolysis of commercial grades of polystyrene, polyvinylchloride and polyethylene. Based on these tests, polyethylene is selected for detailed study because of the difficulty in regenerating the monomer in good yields, and because of its abundance as a waste material-about $70 \%$ of all plastic waste. A test program attempts to produce higher value products from polyethylene, rather than monomer. This approach not only disposes of the waste, but offers the possibility of cost return. Both thermal and catalytic pyrolysis tests are done in an atmospheric pressure fluidized bed reactor. Initial results suggest that catalytic pyrolysis gives promising yields of a liquid hydrocarbon product that could be refined to yield a transportation fuel. Further research, particularly to produce a hydrocarbon liquid with a high content of aromatics, is under way.

Sirrine (J.E.) Co., Energy Utilization: Municipal Waste Incineration, Final Report, Report No. DOE/CS/40400-Tl, 100 pp. (March 1981).

This report assesses the technical and economical feasibility of converting municipal waste into useful and usable energy. The concept presented-retrofitting an existing municipal incinerator with the 
systems and equipment necessary to produce process steam and electric power-is economically attractive because the cost of the necessary waste-heat-recovery equipment is usually a comparatively small percentage of the cost of the original incinerator installation. Technical data obtained from operating incinerators that were designed specifically for generating energy document the technical feasibility and indicate certain design constraints. The report includes a cost summary, description of the process and facilities, conceptual design, economic analysis, itemized estimated costs, design and construction schedule, and some drawings.

Solid Waste Association of North America, Mercury Emissions From Municipal Solid Waste Combustors: An Assessment of the Current Situation in the United States, Report No. NREL/TP-430-5399, Order No. DE93000100, 106 pp. (May 1993).

This report examines issues related to emissions of mercury from municipal solid waste (MSW) combustors, based on an examination and analysis of currently available literature. The report provides a generalized forecast of potential emissions reductions. The forecast is based on assumptions for reducing the amount of mercury that enters MSW combustors, and achievement of various levels of air pollution control equipment efficiencies. The report consists of a composite summary discussion of issues, and it includes illustrative annexed materials, selected to provide more in-depth information on specific aspects of mercury emissions issues. The report examines source strength characterization, but it does not attempt to address the fate and transport of mercury in the environment, nor does it undertake any hazard or risk analyses.

Solid Waste Association of North America, Polyvinyl Chloride Plastics in Municipal Solid Waste Combustion, Report No. NREL/TP-430-5518, Order No. DE93010013, 24 pp. (April 1993).

This report examines the issue of whether the polyvinyl chloride (PVC) plastics content of municipal solid waste (MSW) is a significant contributor to emissions of chlorinated dibenzo-p-dioxins (dioxins) that are associated with MSW combustion. Indications based on a consideration of this issue are developed through a synthesis of available information. While there is convincing experimental evidence that various conditions can cause production of dioxins when PVC is thermally treated, a fundamental issue that remains to be solved is how these findings relate to operating conditions that are characteristic of well designed, maintained, and operated MSW combustion facilities, equipped with modern air pollution controls. These findings largely were derived from laboratory or pilot scale experimentation and from full-scale studies that were carried out at facilities of varying design and purpose.

Sommer, E.J., Jr., Kenny, G.R., Kearley, J.A., and Roos, C.E., "Mass Burn Incineration with a Presorted MSW Fuel," JAPCA, International Journal of Air Pollution Control and Waste Management, v 39:4, pp. 511-516 (April 1989).

This research, supported by the U.S . Department of Energy, investigates potential benefits to mass burn incineration from buming a presorted municipal solid waste (MSW) fuel. Comparative boiler efficiency tests at three mass bum incineration sites utilizing as-received MSW and a presorted MSW fuel are reported. Test results indicate that waste presorting can provide substantial benefits to the mass burn process. Flue gas and ash heavy metals are significantly reduced. Discarded automobile batteries substantially contribute to lead levels in the waste stream. Reductions in emissions of $\mathrm{CO}, \mathrm{HC}, \mathrm{HCl}, \mathrm{HF}$, and $\mathrm{NO}_{\mathrm{x}}$ are reported. Increases in facility boiler efficiency and MSW disposal capacity are measured. 
Steisel, N. and Brooks, C. (Argonne National Laboratory) "Promise of Resource Recovery: Lessons from the New York Experience in Gaining Public Approval," Energy from Municipal Waste: Opportunities for the Southwest, presented at the Workshop on Energy from Municipal Waste: Opportunities for the Southwest, Austin, Texas, 23 June 1986, Report Nos. ANL/CNSV-TM-173, CONF-8606334, Order No. DE87014258, pp. 180-193 (May 1987).

Faced with only 10-12 years of remaining disposal capacity, New York City has mounted a comprehensive solid waste management program, involving in its first phase the construction of five waste-to-energy facilities to process more than $40 \%$ of the city's waste and the implementation of a variety of materials recycling and reuse programs intended to increase recycling rates from $13 \%$ to $25 \%$. In order to gain approval for the waste-to-energy component of the plan in the face of significant public controversy, the city conducted one of the most thorough public reviews of the environmental impact of these plants with special emphasis on the emissions of dioxin. This paper describes the process New York City followed to gain public approval for its projects and offers the central arguments in refutation of the four major arguments of resource recovery critics; to wit: dioxin is so toxic that human exposure should not be allowed; proponents seriously underestimate the risks of exposure because they employ overly optimistic plant emission data; proposed pollution control systems do no reduce emissions; and, viable, safer altematives are available.

Stodolsky, F. and Moses, D.O., (Argonne National Laboratory), Energy and Cost Impact of Materials Separation on Municipal Waste Combustors, presented at the Eighty-Fourth Annual Meeting and Exhibition of the Air and Waste Management Association, Vancouver, Canada, 16-21 June 1991, Report Nos. ANL/CP-73177, CONF-910659-29, Order No. DE91014467, 19 pp. (1991).

New Source Performance Standards for new municipal waste combustors (MWCs) and emission guidelines for existing MWCs have been promulgated by the Environmental Protection Agency (EPA). A $25 \mathrm{wt} \%$ materials separation requirement was included in the standards (new sources) and guidelines (existing sources), but was subsequently dropped. In proposing the requirements, EPA believed that there would be both direct air emissions reduction, and nonair quality benefits considering net costs, energy, and other environmental impacts. In this paper, we assess the energy impact and associated costs of materials separation. Impact from a national perspective and from the perspective of the MWC owner is assessed. From a national perspective, the energy required to recycle must be compared against the energy needed for extraction and manufacture from virgin raw materials, and this in turn must be compared against the energy value of the combustible MSW fraction. At times, the economics of material separation and recycling appear poor because of competing efficiencies of scale of traditional extraction and processing of virgin raw materials, as well as a lack of markets for recovered materials. In this analysis, we address these issues.

Systems Technology Corp., Conversion of Municipal Solid Waste to Energy: Jacksonville, Florida, Phase 1 Report; Report No. DOE/CS/20231-1, 237 pp. (July 1981).

This report assesses the feasibility of burning wastes from the City of Jacksonville in the Scientific Energy Engineering (SEE) auger combustor, a two-chamber, starved-air incinerator. The following parameters are determined: the amount and characteristics of solid waste, location, requirements of candidate energy and materials markets, applicable incineration and heat-recovery technologies, and institutional requirements for facility construction. The SEE system's performance is characterized, and a test report is included as an appendix to the report. 
Teledyne National, Co-Combustion of Refuse-Derived Fuel and Coal in a Cyclone Furnace at the Baltimore Gas \& Electric Company, C.P. Crane Station, Report No. DOE/CS/24320-1, 55 pp. (March 1982).

Tests conducted by the Baltimore Gas and Electric Co. in cooperation with Teledyne National, on cocombustion of coal and refuse-derived fuel (RDF) in cyclone furnaces at the 400-MW C.P. Crane Station are described. RDF was burned (with coal) at heat substitution rates of $7 \%$ to $63 \%$ for 40 days during the period July 7,1980 , to September 15,1980 . The report provides background information, a description of the facilities involved, a description of test operations, and results and conclusions.

Tennessee Valley Authority, Sumner County Solid-Waste Energy Recovery Facility, Volume 2, Performance and Environmental Evaluation, Final Report, Electric Power Research Institute Report No. EPRI-CS-4164, Vol. 2, 75 pp. (September 1985).

This report summarizes the operation of the Sumner County solid-waste-to-energy recovery facility for a two-year period beginning with initial operation of the plant in Dec. 1981. The 200-ton/d facility in Gallatin, Tennessee, converts municipal solid waste to steam and electricity. The report addresses physical and chemical properties of process and waste streams, other operating factors (including thermal efficiency and availability), and the initial operating expenses and revenues. Two series of tests were carried out approximately one year apart. An environmental analysis was performed to determine the potential solid, liquid, and gaseous emissions from the plant. Results of the testing may be of interest to persons considering a resource-recovery facility for the production of energy. The principal conclusions of the report are that the initial operation of the facility has been satisfactory; the ash-drag system and air-pollution-control device must be extensively modified; waste quantities and steam sales have been less than predicted, causing some economic difficulties; and cadmium and lead concentrations in the ash have been high (especially in fly ash). The long-range outlook for the facility is encouraging, according to the report.

Tennessee Valley Authority, Sumner County Solid-Waste Energy Recovery Facility, Volume 1, Feasibility Studies, Design, and Construction, Final Report, Electric Power Research Institute Report No. EPRI-CS-4164, Vol. 1, 117 pp. (August 1985).

This report covers the operating history of the 200-ton/d municipal solid waste energy-recovery cogeneration facility at Gallatin, Tennessee. Milestones and feasibility studies that led to the development, design, and construction of this cogeneration facility are reviewed. An equipment description of the massbuming system is given, including the water-cooled rotary combustor and an electrostatically assisted baghouse. A fast-tract design and construction method provided initial startup 18 months after groundbreaking.

Travis, C.C., (Oak Ridge National Laboratory) Workshop on Municipal Waste Combustion, Cincinnati, Ohio, June 6-11, 1989, Foreign trip report by Eros Bacci, University of Siena, Italy, Report No. ORNL/FTR-3290, Order No. DE89009036, 12 pp. (27 June 1989).

Dr. Bacci was supported by the U.S. Environmental Protection Agency through an interagency agreement with the U.S. Department of Energy to participate in a workshop on food chain impacts of municipal waste combustion. The focus of the workshop was on atmospheric deposition modeling, food chain impacts, and uncertainty analysis. Dr. Bacci is a world-recognized expert on foliar uptake of organics by vegetation. He presented measured values for the air-to-vegetation bioconcentration factor 
for ten organic compounds. His research demonstrated that foliar bioconcentration is a function of both octanol-water partition coefficient and Henry's Law Constant.

Travis, C.C. and Yambert, M.W., (Oak Ridge National Laboratory), "Accounting for Dry Deposition in Incinerator Risk Assessment," presented at the U.S. EPA/ORNL Workshop on Municipal Waste Combustion: Deposition, Food Chain Impacts, Uncertainty, and Research Needs, Cincinnati, Ohio, 8-9 June 1989, Report No. CONF-8906180-6, 12 pp. (1989).

The incineration of municipal solid waste (MSW) results in the release of small amounts of hazardous pollutants. Determining the health and environmental risks associated with MSW incineration requires knowledge of the rate at which facility-emitted pollutants disperse. The deposition of airborne pollutants onto plants, soil, and water surfaces can contribute substantially to human exposure. For example, the deposition of facility-emitted pollutants onto plants and soil surfaces, ingestion of contaminated plants and soil by cattle, and the ingestion of contaminated beef and dairy products can be a significant pathway of human exposure. Direct measurement of deposition rates (mug/cm $\left./ \mathrm{cmc}^{2}\right)$ is not practical, and they must therefore be estimated from known air concentrations. The standard approach is multiplying ambient ground-level air concentrations by a proportionally constant known as the deposition velocity $(\mathrm{cm} / \mathrm{sec})$. Deposition velocities used in health risk assessments typically range from $0.1 \mathrm{~cm} / \mathrm{sec}$ to $3 \mathrm{~cm} / \mathrm{sec}$. Historically, deposition velocities were assumed to be constant and independent of particle size, meteorological conditions, and terrain surrounding the facility. More recently, the California Air Resources Board developed a particle-size-dependent deposition model based on the work of Sehmel and Hodgson (1978). In addition to this model, two other particle-size-dependent models exist. The purpose of this paper is to evaluate the relative effectiveness of these three models along with the classical particle size-independent model developed by Shieh, et al.

Trezek, G.J., Thermal Systems for Conversion of Municipal Solid Waste, Volume 6, Fluidized-Bed Combustion: A Technology Status Report, Report No. ANL/CNSV-TM120, Vol. 6, 98 pp. (January 1983).

This is one of nine assessment reports prepared for Argonne National Laboratory to document the current state of development of energy from municipal-waste disposal/recovery technologies. This report deals with the development of fluidized-bed combustion (FBC) and its application to treating solid waste. The author discusses the experience gained at pilot plants, the problems encountered in attempting to operate a commercial system, the economic aspects of FBC, and the additional research and development needed to make this technology commercially viable as a method of treating waste. Application of FBC to other wastes, such as sludges and wood wastes, is also considered; the only commercial-size system that has been operated with solid waste is a system for codisposal of sludge from wastewater treatment and solid waste.

Tsang, W., et al., Combustion Characteristics of Refuse-Derived Fuels, Final Report, Report No. DOE/CS/24328-Tl, 205 pp. (1983).

The purpose of the laboratory studies presented here was to furnish preliminary input to the technologists in the sense of providing relative rankings through comparisons of appropriate coal and municipal solid waste combustion-related properties. Support for a future program of subscale (demonstration or pilot) experiments to expand on the concepts and quantify themfor scale-up to industrial sizes should be provided. A complete plan for this second-phase study is included as an appendix to this report. 
Tumer, W.D., Thermal Systems for Conversion of Municipal Solid Waste, Volume 2, Mass Burning of Solid Waste in Large-Scale Combustors: A Technology Status Report, Report No. ANL/CNSV-TM-120, Vol. 2, 217 pp. (December 1982).

This is one of nine assessment reports prepared for Argonne National Laboratory to document the current state of development of energy from municipal waste disposal/recovery technologies. This report discusses conventional, mass-burning waterwalled systems that employ no preprocessing of the waste stream. A detailed discussion of each plant's performance is included in the report. The history and evolution of the mass-buming technology, the present status of North American plants, and planned refuse-to-energy plants are included. Economic analysis and recommendations for additional work are also discussed.

United Engineers and Constructors, Inc., Feasibility Analysis and Conceptual Design for the Demonstration of Energy Recovery from Municipal Waste, Report No. DOE/CS/20241-T2, 152 pp. (March 1980).

The objective of this study is to establish small-scale solid-waste burning as an economically viable and environmentally acceptable means of providing energy requirements for urban area municipal buildings. The specific objective of this study is the development of a conceptual design for a system to supply energy requirements for the Philadelphia, Pennsylvania, City Hall, City Hall Annex, and Municipal Services Building utilizing the combustion of available high-grade refuse collected from center-city office buildings. This report includes the feasibility analysis and a conceptual design for a 50-ton/d waste-to-energy recovery plant, employing clean-burning incineration technology for the production and supply of steam and electricity to City Hall, City Hall Annex, and the Municipal Services Building.

Vander Molen, R.H. and Brooks, C., (Argonne National Laboratory) "Fluidized-Bed Boilers: An Emerging Alternative Technology," Energy from Municipal Wastes: Opportunities for the Southwest, presented at the Workshop on Energy from Municipal Waste: Opportunities for the Southwest, Austin, Texas, 23 June 1986, Report Nos. ANL/CNSV-TM-173, CONF-8606334-, Order No. DE87014258, pp. 56-65 (May 1987).

Fluidized bed boilers (FBB) are becoming well established for most industrial applications. They are only now emerging for application in resource recovery plants. The heterogeneous nature of MSW and the concern over acid gas and other emissions are areas where the FBB has natural advantages over more conventional combustion systems. In addition, the FBB has the capability to obtain more steam per pound of fired fuel through its high overall efficiency. Fluidized-bed boilers are sufficiently developed to be considered as viable candidates for resource recovery.

Velzy (Charles R.) Associates, Inc., Dutchess County Resource Recovery Task Force Report: Dutchess County Pyrolysis Program, Report No. DOE/CS/20094-1, 461 pp. (July 1980).

In 1971, Dutchess County, New York, initiated development of a long-range master plan for solid-waste management. The plan included development of a resource-recovery facility using a PUROX ${ }^{\circledR}$ pyrolysis facility. The county reassessed the feasibility of a resource-recovery facility, technology, waste availability, energy recovery, and sale and siting of the plant. The conclusions reached in the new study and covered in this report are as follows: (1) a resource-recovery facility is feasible for the county; (2) sufficient waste for such a facility is available and subject to control; (3) although PUROX ${ }^{\circledR}$ technology is feasible, it is not the most appropriate available technology for the county; (4) mass burning 
with steam recovery is the most appropriate technology; (5) resource-recovery, while presently more expensive than landfilling, represents the only cost-effective, energy-efficient, and environmentally sound way to handle solid waste in the county.

Walsh, P., "Waste-to-Energy Workshops," Biofuels and Municipal Waste Technology Research Program Summary: FY 1986, Report No. DOE/CH/10093-6, Order No. DE87001140, 257 pp. (July 1987).

This project provides municipal and industrial leaders with current information regarding waste-to-energy incinerators through a series of one-day workshops. The workshops cover the generation and disposal of wastes including refuse-derived fuel, types of incinerators, risk management, project financing, project evaluation, emission control, case studies, and other appropriate topics. The information is presented by speakers knowledgeable in the field of municipal solid waste-to-energy systems. Audio-visual material highlights major points of discussion. Workshop participants receive a comprehensive and well-written handbook that contains all pertinent information and data presented at the workshop. A total of nine workshops will be presented with one in the Great Lakes region.

Warren Spring Laboratory, under contract to National Center for Resource Recovery, Inc., Evaluation of Trommels for Waste to Energy Plants, Phase 2: Report of the Warren Spring Laboratory Pilot Test Series, Report No. DOC/CS/24315-19, 56 pp. (February 1983).

This report discusses the results of the second and final phase of the trommel test work carried out in the United Kingdom by Warren Spring Laboratory. The U.K. work forms part of a test program designed to develop and prove mathematical models for use in designing rotary screens and in predicting their performance.

Warren Spring Laboratory, under contract to National Center for Resource Recovery, Inc., Evaluation of Trommels for Waste to Energy Plants, Phase 1: Report of the Doncaster and Byker Test Series, Report No. DOE/CS/24315-1, 72 pp. (March 1982).

This report discusses the performance testing of two commercial-scale trommels used for size separation of bulk municipal waste. The work is to develop and prove mathematical models for use in designing rotary screens and in predicting their performance. The commercial-scale trommels examined during this test work are sited at Doncaster and at Byker, United Kingdom. The former is operated by the South Yorkshire County Council and the latter by the Tyne and Wear County Council. The major difference between the two plants is that raw refuse is processed in the Doncaster plant trommel, and pulverized refuse in the Byker plant trommel. Both plants produce a magnetic ferrous fraction, as well as a refuse-derived fuel prepared by upgrading the intermediate-sized product from the rotary screen using air classification, magnetic separation, further size reduction, and pelletization. However, the plants differ in many respects; the feed to the Byker trommel is preshredded, while at Doncaster it is treated as received. The latter plant also has additional facilities for glass and paper recovery. The contents of this report are intended to provide detailed accounts of the Byker and Doncaster tests and to compare the two screening operations, highlighting the effects of the major variables investigated. 
Waste Tire Recycling by Pyrolysis, Report No. DOE/CE/27504-11, Order No. DE93005618, 116 pp. (October 1992).

This project examines the City of New Orleans' waste tire problem. Louisiana State law, as of January 1, 1991, prohibits the knowing disposal of whole waste tires in landfills. Presently, the numerous waste tire stockpiles in New Orleans range in size from tens to hundreds of tires. New Orleans' waste tire problem will continue to increase until legal disposal facilities are made accessible and a waste tire tracking and regulatory system with enforcement provisions is in place. Tires purchased outside of the city of New Orleans may be discarded within the city's limits; therefore, as a practical matter this study analyzes the impact stemming from the entire New Orleans metropolitan area. Pyrolysis mass recovery (PMR), a tire reclamation process which produces gas, oil, carbon black and steel, is the primary focus of this report. The technical, legal and environmental aspects of various alternative technologies are examined. The feasibility of locating a hypothetical PMR operation within the city of New Orleans is analyzed based on the current economic, regulatory, and environmental climate in Louisiana. A thorough analysis of active, abandoned, and proposed pyrolysis operations (both national and international) was conducted as part of this project. Siting a PMR plant in New Orleans at the present time is technically feasible and could solve the city's waste tire problem. Pending state legislation could improve the city's ability to guarantee a long term supply of waste tires to any large scale tire reclamation or recycling operation, but the local market for PMR end products is undefined.

Waste-to-Energy Compendium: Revised 1988 Edition, Report No. DOE/CE/30844-H1, Order No. DE89004767, 371 pp. (December 1988).

The Waste-to-Energy Compendium presents detailed profiles of all commercial-scale facilities in the United States that are currently processing municipal solid waste to recover energy. This summary of technical, operational, and economic experience at existing plants is intended to serve the community of engineers, consultants, planners, plant operators and maintenance personnel, public and private interest groups, and public officials that will be involved in developing and operating future projects. The Compendium covers only those facilities that were operational as of July 1988, although some of the facilities included may be temporarily shut down for various reasons. Projects under construction or in shake-down were excluded from consideration because operating experience and cost information would not be available. Noncommercial pilot and demonstration facilities and projects that recover methane from sanitary landfills were also excluded. This report is the second update of the Waste-to-Energy Compendium, originally prepared by the National Center for Resource Recovery, Inc., and published by Idaho National Engineering Laboratory in April 1980. A revised edition was prepared by One America, Inc. and published by the U.S. Department of Energy in August 1982.

Wenaas and Associates, Solid-Waste Electrical Generating Feasibility Study, Report No. DOE/F8/05031-Tl, 229 pp. (May 1982).

The feasibility of recommissioning the existing 3-MW, steam-turbine-driven electrical generator of the municipal utilities of Valley City, North Dakota, using steam generated in a new facility from the incineration of municipal solid waste generated in the area is examined. It is concluded that sufficient municipal waste can be obtained from Valley City, Moorehead, and Jamestown (and/or West Fargo) to fuel the plant; the seasonal fluctuation in the amounts of municipal solid waste indicates that a supplementary source of fuel for use during the winter would increase plant efficiency; the probable capital cost of the project will be $\$ 3,590,000$; the cost of production of electricity could range from $3.72 \phi / \mathrm{kWh}$ to $4.90 \mathrm{c} / \mathrm{kWh}$, depending on the construction costs, interest rate, lifetime of the project, and municipal solid waste; there is no compelling reason not to use the tertiary cell of the sewage lagoon for cooling the 
water; the State Health Department is ambivalent toward the project; and the public perception of the project is positive. The recommendations include the following steps: obtain the backing of the appropriate authorities to proceed to the next steps, obtain letters of intent to commit municipal solid-waste streams to this project from other municipalities, develop a complete and detailed request for proposals based on demonstrated performance, and explore vigorously the possibilities of obtaining grant monies to offset part of the cost.

Wohadlo, S., Abbasi, H., and Cygan, D., Field Evaluation of Natural Gas and Dry Sorbent Injection for MWC Emissions Control, Report No. NREL/TP-430-5700, Order No. DE93018227, 211 pp. (October 1993).

The Institute of Gas Technology (IGT), in cooperation with the Olmsted Waste-to-Energy Facility (OWEF) and with subcontracted engineering services from the Energy and Environmental Research Corporation, completed the detailed engineering and preparation of construction specifications for an Emissions Reduction Testing System (ERTS). The ERTS was designed for retrofit to one of two 100-ton/day municipal waste combustors at the OWEF, located in Rochester, Minnesota. The purpose of the retrofit is to conduct a field evaluation of a combined natural gas and sorbent injection process (IGT's METHANE de-TOX ${ }^{\text {sm }}$, IGT Patent No. 5,105,747) for reducing the emissions of oxides of nitrogen $\left(\mathrm{NO}_{\mathrm{x}}\right)$, hydrochloric acid $(\mathrm{HCl})$, oxides of sulfur $\left(\mathrm{SO}_{\mathrm{x}}\right)$, carbon monoxide $(\mathrm{CO})$, total hydrocarbons, and chlorinated hydrocarbons (dioxins/furans). The design includes modifications for the control of heavy metals. Development of the process should allow the waste-to-energy industry to meet the Federal New Source Performance Standards for these pollutants at significantly lower costs when compared to existing technology of Thermal deNO $\mathrm{x}_{\mathrm{x}}$ combined with spray dryer scrubber/fabric filters. The process should also reduce boiler corrosion and increase both the thermal and power production efficiency of the facility.

Zolnick, E.L., Markus, A.R., Seigfried, J.N., Powers, T.J., Shepherd, P.B., Graziano, G.J., and Battles, R.L., Recovery and Reuse of Asphalt Roofing Waste Burning of Asphalt Roofing Waste, Report No. DOE/ID/12560-3, Order No. DE87000571, 118 pp. (15 September 1986).

The research described in this report was designed to determine the general feasibility and specific requirements for burning asphalt roofing waste and recovering the energy resource as steam. The study combined technical market research with test buming in a three-task program to identify how to use burning as a means for recovering the $7 \times 10^{13} / \mathrm{Btu}$ in roofing waste landfilled annually. 


\section{Emissions}

Abbasi, H.A., Khinkis, M.J., Dunnette, R., and Nakazato, K., Use of Natural Gas to Reduce Emissions in Waste Combustors, presented at the International Gas Research Conference, Orlando, Florida, 16-19 November 1992, Report No. CONF-921152-12, Order No. DE93005408, 17 pp. (1992).

The Institute of Gas Technology, together with industrial partners, is developing a technology that utilizes natural gas to reduce air pollutant emissions from municipal waste combustors (MWCs). This natural gas injection technology is termed METHANE de-NOX ${ }^{\text {sm }}$. The results of field evaluation tests carried out at a 90 tonne/day MWC in 1991 show simultaneous reductions of $60 \%$ in nitrogen oxides and $50 \%$ in carbon monoxide with natural gas injection equal to $15 \%$ of total waste heat input. Excess air requirements were also reduced by $40 \%$ thus increasing the overall waste-to-energy plant efficiency. This approach is now being combined with injection of sorbents to also reduce the emissions of hydrochloric acid, sulfur oxides, dioxins, and furans. This paper describes the overall system design, the results of field evaluations to date and the schedule for sorbent injection trials.

Bradshaw, W.M. and Krishnan, R.P., Removal of Acidic Gases from Incinerator Flue Gas in a Fluidized Bed Scrubber, presented at the American Institute of Chemical Engineers Annual Meeting, Washington, D.C., 27 November-2 December, 1988, New York: American Institute of Chemical Engineers, Report No. CONF-881143, Technical Paper 162E, 11 pp. (1988).

This paper describes a parametric study conducted in a $5-\mathrm{cm}$ bubbling bed to determine the feasibility of scrubbing acidic gases from incinerator flue gas by direct contact with an alkaline sorbent in a fluidized bed. The effects of process parameters on removal of $\mathrm{HCl}, \mathrm{P} / 2 / 0_{5} /$, and $\mathrm{SO} / 2 /$ were investigated experimentally. The relationship between removal efficiency and sorbent utilization was determined at $542^{\circ} \mathrm{C}\left(1000^{\circ} \mathrm{F}\right)$ and twice the minimum fluidization velocity.

Daugherty, K., Ohlsson, O.O., Venables, B., Goswami, D.Y., (Argonne National Laboratory) "Emission Studies of Full-Scale Cofiring of Pelletized RDF/Coal at Argonne National Laboratory," Proceedings of the 23rd Intersociety Energy Conversion Engineering Conference, presented at the Twenty-Third Intersociety Energy Conversion Engineering Conference, Denver, Colorado, 31 July 1988, New York: American Society of Mechanical Engineers, Report No. CONF-880702, pp. 415-420, v 4 (1988).

In FY 1984, Argonne National Laboratory (ANL) issued a competitively solicited research contract to North Texas State University (NTSU) to conduct a multi-phase research study to examine the use of low-cost binders for producing improved densified refuse-derived fuel (dRDF) pellets. The laboratory test phase of this study was completed in FY 1984 and the pilot plant phase in FY 1985. The results of these tests indicated that lime (calcium hydroxide) was the top-ranked binding agent. As the third and final phase of the multi-phase study, ANL/NTSU conducted full-scale cofired combustion tests of binder-enhanced dRDF pellets and high-sulfur coal. These tests were conducted during June and July of 1987 in ANL's Boiler number 5, which is a spreader-stoker boiler. These tests were conducted with industry, state, and municipality participation both in critiquing the test plan and in witnessing the actual test runs. Approximately 600 tons of dRDF containing $0 \%, 4 \%$, or $8 \%$ binder were blended with high-sulfur coal at levels of up to $30 \%$, based on the Btu content. This paper describes the dRDF/coal cofining test, the emission and ash samples that were taken, the analyses which were conducted on these samples, preliminary test results, and future research plans. 
Domalski, E.S., Churney, KL., Ledford, A.E., Jr., Bruce, S.S., Buckley, T.J., and Tsang, W., MSW (Municipal Solid Waste) Emissions and Characterization Research and Destruction of Aromatics by Hydrogen Atoms: Final Report, Report No. DOE/CE/30835-T1, Order No. DE88013488, 59 pp. (June 1988).

A multi-kilogram capacity flow calorimeter was used in combustion measurements on municipal solid waste (MSW) and refuse-derived fuel. Cellulose (with and without sand), and MSW doped with PVC were combusted. Gas chromatography were used to study the combustion products. Chlorine mass balance experiments were conducted. Finally, the destruction of chlorinated aromatics by hydrogen atoms was studied.

Hattemer-Frey, H.A. and Travis, C.C., (Oak Ridge National Laboratory) Dioxin Emissions from Municipal Solid Waste Incinerators and the Potential for Human Exposure, presented at the Symposium on Municipal Solid Waste Management: Making Decisions in the Face of Uncertainty, Toronto, Canada, 25-27 April 1990, Report No. CONF-900496-1, Order No. DE90008901, 35 pp. (1990).

Although sanitary landfills are currently the primary method of municipal solid waste (MSW) management, the U. S. Environmental Protection Agency estimates that half of all municipalities will lack adequate landfill space within 10 years. Numerous cities and counties are considering MSW incineration as an alternative waste management option. Because combustion is widely recognized as a source of polychlorinated dibenzo-p-dioxins (PCDDs) and polychlorinated dibenzofurans (PCDFs), including the highly toxic 2,3,7,8,-tetrachlorodibenzo-p-dioxin, considerable local and national opposition to MSW incineration has arisen. Many people living near MSW incinerators fear that they will be exposed to high levels of PCDDs and PCDFs and subsequently develop cancer. As the controversy surrounding MSW incineration intensifies, government agencies, public officials, and the public question whether municipal waste combustion is a feasible waste management alternative. Given the sensitivity and importance of this issue, however, we have attempted such an evaluation. This paper is intended to examine the following issues concerning human exposure to facility-emitted dioxins and furans: (1) Are environmental concentrations of PCDDs and PCDFs around MSW incinerators elevated (2) Are MSW incinerators the major source of human exposure to PCDDs and PCDFs and (3) Are incinerators the major source of PCDD/PCDF input into the environment.

Hattemer-Frey, H.A. and Travis, C.C., (Oak Ridge National Laboratory), "Human Exposure to Dioxin from Combustion Sources," Emissions from Combustion Processes, Clement, R.E. ed., Chelsea, MI: Lewis Publishers; pp. 439-448 (1990).

Because of their extreme toxicity, much concern and debate has arisen about the nature and extent of human exposure to dioxin. Because municipal solid waste (MSW) incinerators are known to emit polychlorinated dibenzo-p-dioxins (PCDDs) and polychlorinated dibenzofurans (PCDFs), many people who live near MSW incinerators fear that they will be exposed to high levels of dioxin and subsequently develop cancer. What is often overlooked in this debate, however, is the fact that the general population is continuously being exposed to trace amounts of dioxin as exemplified by the fact that virtually all human adipose tissue samples contain dioxin at levels of 3 parts per trillion (ppt) or greater. This paper provides a perspective on MSW incineration as a source of human exposure to dioxin by comparing this exposure source with exposure to background environmental contamination and evaluates some of the potential key sources of PCDD/PCDF input into the environment. 
Helt, J.E., Agrawal, R.K., and Mallya, N., (Argonne National Laboratory) Pyrolysis of Municipal Solid Waste, presented at Alternative Energy in the Midwest: Research and Applications, Rosemont, Ilinois, 18 Mar 1987, Report No. CONF-870366-1, Order No. DE87011540, 11 pp. (1987).

The pyrolysis of municipal solid waste (MSW) is a potential method of producing useful fuels. However, past attempts to utilize the technology have resulted in facilities that have not performed as expected, producing low yields of inferior products. Background on past pyrolytic concepts and the current status of the technology are discussed. Most MSW is cellulosic in nature, comprising paper, newsprint, packaging materials, wood wastes, and yard clippings. The end products of MSW pyrolysis are a highly carbonaceous solid char, a highly oxygenated liquid tar, and a mixture of gases with low- to medium-BTU content. Current U.S. Department of Energy/Argonne National Laboratory research has been undertaken to gain a better understanding of the basic mechanisms, kinetics, and chemistry involved in the pyrolytic conversion of MSW and its components. The objectives of this program, current research efforts, results to date, and future plans are discussed.

Helt, J.E. and Myles K.M., Energy from Municipal Waste-Assessment of Control Technologies for Stack Gas Emissions, Report No. ANL/CNSV-39, 104 pp. (September 1983).

The environmental impact of energy-from-municipal-waste (EMW) processes is still questionable. This report identifies stack gas emissions of concern, identifies to what extent the emissions have been monitored, and describes present and potential future control technologies for EMW facilities. The work focused on identifying and characterizing the combustors, their operating history, the control technologies employed, and the emission monitoring data collected. This information has been compiled into a working matrix, which gives a short description for each of the locations involved in MSW combustion. The table is divided into seven different groups or classes of MSW commercial combustors: (1) large-scale mass burners, (2) small-scale modular mass burners, (3) dedicated refuse-derived fuel (RDF) combustors, (4) cofired RDF combustors, (5) fluidized-bed RDF combustors, (6) pyrolysis units, and (7) unclassified combustors and combustors of unknown type. Over a hundred locations are represented in the matrix, including facilities that have been or are operational, as well as those in the design or construction phase.

Hospital Waste Shredder Test Series at the DONLEE Pilot Test Facility, (U.S. Department of Energy), Report No. DOE/MC/25033-3237, Order No. DE93000243, 41 pp. (September 1992).

This report describes the coal firing and coal and noninfectious hospital waste co-firing testing and emissions rates for the tests conducted at the DONLEE pilot plant facility during mid-December 1991 through early March 1992. The emissions obtained during these tests are in turn used to predict the emission rates for the proof-of-concept facility that is to be built at the Lebanon Veterans Affairs Medical Center. In addition, the reliability and performance of the waste shredding/feeding system were evaluated from this testing.

Huang, H.S., and Sather, N.F., (Argonne National Laboratory) Process for Removal of Hydrogen Halides or Halogens from Incinerator Gas, Application/Priority No.: US 6-087835, Report No. PATENTS-US-A6087835, 12 pp. (21 August 1987).

A process for reducing the amount of halogens and halogen acids in high temperature combustion gas and through their removal, the formation of halogenated organics at lower temperatures, with the reduction being carried out electrochemically by contacting the combustion gas with the negative electrode 
of an electrochemical cell and with the halogen and/or halogen acid being recovered at the positive electrode.

Shepherd, P.B., "DOE Project Examines Dual-Sorbent Injection," Solid Waste and Power, v 7:1, p. 46 (January-February 1993).

The U.S. Department of Energy's (DOE) National Renewable Energy Laboratory is sponsoring a project to test low-cost, retrofit technology for controlling emissions at waste-to-energy plants. Researchers are studying a dual-sorbent injection process designed to reduce emissions of sulfur dioxide and hydrogen chloride at a cost DOE estimates to be 15 times less than the cost of adding an acid scrubber to an existing combustion unit. The DOE project will establish the equipment, design parameters, and operating approach for MSW combustors to comply with new Clean Air Act acid gas emission guidelines at a reasonable retrof cost. Massachusetts Refusetech Inc. is conducting the project at its North Andover, Massachusetts, facility. Testing started in September with calibration and adjustment of the chemical-handling machinery and will continue through phases of optimization, emissions testing and long-term evaluation.

Wohadlo, S., Abbasi, H., and Cygan, D., Field Evaluation of Natural Gas and Dry Sorbent Injection for MWC Emissions Control, Report No. NREL/TP-430-5700, Order No. DE93018227, 211 pp. (October 1993).

The Institute of Gas Technology (IGT), in cooperation with the Olmsted Waste-to-Energy Facility (OWEF) and with subcontracted engineering services from the Energy and Environmental Research Corporation, completed the detailed engineering and preparation of construction specifications for an Emissions Reduction Testing System (ERTS). The ERTS was designed for retrofit to one of two 100-ton/day municipal waste combustors at the OWEF, located in Rochester, Minnesota. The purpose of the retrofit is to conduct a field evaluation of a combined natural gas and sorbent injection process (IGT's METHANE de-TOX ${ }^{\mathrm{sm}}$, IGT Patent No. 5,105,747) for reducing the emissions of oxides of nitrogen $\left(\mathrm{NO}_{\mathrm{x}}\right)$, hydrochloric acid $(\mathrm{HCl})$, oxides of sulfur $\left(\mathrm{SO}_{\mathrm{x}}\right)$, carbon monoxide $(\mathrm{CO})$, total hydrocarbons, and chlorinated hydrocarbons (dioxins/furans). The design includes modifications for the control of heavy metals. Development of the process should allow the waste-to-energy industry to meet the Federal New Source Performance Standards for these pollutants at significantly lower costs when compared to existing technology of Thermal deNO ${ }_{\mathrm{x}}$ combined with spray dryer scrubber/fabric filters. The process should also reduce boiler corrosion and increase both the thermal and power production efficiency of the facility. 


\section{Hazardous Waste}

A Beginners Guide for Video Production, Report No. DOE/CE/27504-8, Order No. DE93005614, 31 pp. (November 1991).

The Seattle-King County Hazardous Waste Management Plan provides the framework for an intensive effort to keep Household Hazardous Waste (HHW) and Small Quantity Generator (SQG) wastes from entering the municipal solid and liquid waste streams. Many innovative programs for managing small sources of hazardous waste have been developed in response to the Plan. With the assistance of Urban Consortium grants, the City of Seattle has researched and developed a series of reports describing the planning, operation and evaluation of the plan's HHW collection programs. Three of the Plan's programs that are of particular interest to other jurisdictions are the fixed site and mobile HHW Collection Facilities, and the Business Waste Consultations provided to SQG's. In 1991, Seattle received an Urban Consortium grant to produce two videos showing how the HHW Collection Facilities and Business Consultations programs work. This report provides an overview of the video development and production process and a discussion of the lessons learned by the staff directing the production.

Berry, J.B. and Homan, F.J., (Oak Ridge National Laboratory) "Minimizing Waste by Charging the Generator," Hazardous and Industrial Solid Waste Minimization Practices, Conway, R.A., ed. Presented at the Eighth Symposium on Hazardous and Industrial Solid Waste Testing and Disposal, Clearwater, Florida, 12-13 November 1987, Philadelphia, PA: American Society for Testing and Materials, Report No. CONF-871187, pp. 29-40 (1989).

This paper reports on a program to include the cost of waste management in product costs. The following steps are being used: planning and implementation tailored to institutional constraints, methods for conflict resolution, and administrative structure that places responsibility for minimizing waste on the generators. Changes in waste disposal practices required to meet regulatory requirements increase the cost of waste management and are reflected in the rate structure. Rate structure and changes in waste disposal practices are compared. Rates are dependent on the type of waste handled, compliance with waste acceptance criteria, processing steps required for treatment, and disposal requirements.

Brothers, R., Miller, D.B., and Armstrong, A., (Oak Ridge National Laboratory), Canyonville Case Study, presented at the Agency for Toxic Substances and Disease Registry (ATSDR)/Department of Defense (DOD) Workshop, Salt Lake City, Utah, 28-30 January 1992, Report No. CONF-920173-5, Order No. DE92010456, 64 pp. (1992).

This document addresses the analytical results for the site assessment of the Canyon Waste Dump area in Canyon County, Calizona. The objectives of this study were to: further document the nature and extent of hazardous substances in the ground water; determine the extent of subsurface contamination by soil gas monitoring and soil and waste material sampling; determine the extent of off-site contamination from surface water discharges and air vapors; and summarize the known geological and hydrogeological features near the site. The site investigation by EPA took place in June of 1987. During the investigation the field investigation team (FIT) conducted the following activities: collection of waste material samples from the dump pit; collection of surface and subsurface soil samples from on-site and off-site areas including within the City of Canyonville; collection of sediment samples from Canyon Creek and Canyon Wash; collection of surface water samples from Canyon Creek and the Canyon Spring stream; installation and development of five monitoring wells; and sampling of air and soil vapors. 
Burke, M., Brogan, J.A., and Sepanski, L.M., Evaluation and Comparison of Selected Household Hazardous Waste Collection Facilities, Report No. DOE/IR/05106-T138, Order No. DE91013433, 123 pp. (May 1990).

In 1988, the City of Seattle's Office for Long-range Planning and the Solid Waste Utility implemented a permanent household hazardous waste (HHW) collection program in an effort to decrease hazardous waste disposal in municipal solid and liquid waste streams. A detailed description of this program may be found in Household Hazardous Waste: Implementation of a Permanent Collection Facility, published by the Urban Consortium Energy Task Force. An integral part of Seattle's Household Hazardous Waste collection effort is a three-part evaluation strategy that includes: an assessment of the effectiveness of the permanent facility; a comparison of the city's facility with other HHW collection programs; and a user survey to evaluate customer satisfaction and compare the Seattle and King County collection approaches. This evaluation strategy was conducted during Year 10 of the Urban Consortium Energy Task Force, and its results are documented in this report. Several different collection programs were compared during the evaluation.

Carpenter, A. and Cirillo, R.R., (Argonne National Laboratory), From Grave to Cradle: Trends in Hazardous Waste Management, presented at the 1990 Pacific Basin Conference on Hazardous Waste, Honolulu, Hawaii, 12-16 November, 1990, Argonne, IL: Argonne National Laboratory, Report Nos. ANL/CP-74762, CONF-9011171, 452 pp. (1990).

This book is an attempt to publish the important findings and interpretations of a conference on chemical hazardous wastes in a compact and useful package that is available quickly and at reasonable cost. The 1990 Pacific Basin Conference on Hazardous Waste generated more than 60 invited and submitted papers totaling over 1000 pages of typed manuscript. A set of papers was provided to each of the 200 conference registrants. Presentations were grouped into sessions on various treatment techniques, waste minimization, data bases, health effects, and management issues. Some papers are included virtually in total, whereas others are represented by excerpts. The references, which appear at the end of the sections, are published as the authors submitted them in their original papers. No attempt has been made to edit for consistency or to omit any of the references not cited in the abridged texts. All authors had an opportunity to approve the way in which their work has been used. Chapter 1 is an overview of the main themes of the conference: the trend toward waste minimization, problems in international transfer of wastes, and transfer of technology to developing countries. Chapter 2 deals with elimination of the use of hazardous chemicals to the extent possible and with minimization of wastes. Chapter 3 surveys advances in treatment and disposal methods. Restrictions on landfilling are bringing more attention to preparative treatment such as stabilization and to incineration. Chapter 4 illustrates the importance of expressing the risks to human health from hazardous chemicals in quantitative probabilistic terms. Chapter 5 discusses the growing risks of municipal solid waste becoming contaminated with hazardous materials.

Chidambariah, Venkatesh, Garrett, J.K, King, K.H., Yambert, M.W., and Travis, C.C., (Oak Ridge National Laboratory) Risk Assessment Department of Energy Kansas City Plant (DOEKCP) PCB Discharge to Blue River Sewage Treatment Plant, Kansas City, Missouri, Report No. ORNL/M-966, Order No. DE90001287, 96 pp. (29 September 1989).

The Environmental Protection Department of the U. S. Department of Energy Kansas City Plant (DOE/KCP) requested that a risk assessment be performed on the potential health effects of discharges of polychlorinated biphenyls (PCBs) from the DOE/KCP to the Blue River Sewage Treatment Plant, Kansas City's largest publicly owned treatment works facility (Kansas City POTW). The major objectives of this risk assessment are (1) to determine the potential health impacts of DOE/KCP's current discharges 
of PCBs to the Kansas City POTW via all reasonable exposure pathways and (2) to determine a health-based, "safe" discharge level for PCBs to the Kansas City POTW. The present risk assessment considers both occupational and public impacts of PCB discharges from the DOE/KCP. Two occupational exposure scenarios assessed are (1) risk to Kansas City POTW sewer line maintenance workers and (2) risk to Kansas City POTW workers during routine operations of the facility. Both types of workers may be dermally exposed to PCBs in sewage. Public risks considered include risk to populations living within $50 \mathrm{~km}$ of the Kansas City POTW via inhalation of PCBs from sludge incinerated at the facility. Additionally, risk to the general public associated with PCB releases from the Kansas City POTW to the Missouri River is assessed. These pathways include ingestion of PCBs in drinking water supplied by the Missouri River, dermal adsorption and accidental ingestion of PCBs while swimming in the Missouri River, and ingestion of PCBs through consumption of fish taken from the Missouri River. Risk to breastfed infants from ingestion of PCBs through mothers' milk is also assessed.

Cleaning up With the Sun: Industry's Opportunities in the DOE Initiative on Solar Detoxification of Hazardous Wastes, (National Renewable Energy Laboratory), Report No. SERITP-253-3687, 4 pp. (March 1990).

Although the severity or the hazardous waste crisis is undeniable, a promising solution that uses solar thermal technology is emerging from the laboratories of the U.S. Department of Energy (DOE). To move this solution from the laboratory into the marketplace, the office of DOE's Assistant Secretary of Conservation and Renewable Energy proposed a new initiative. To encourage involvement in the initiative effort, this pamphlet familiarizes the reader with the scope of the initiative and the opportunities it holds.

Clinton, J.H., (Oak Ridge National Laboratory) Dynamic Computer Model for Heat Transfer and Incineration in the Oak Ridge TSCA (Toxic Substances Control Act) Hazardous Waste Incinerator, presented at the Eighth International Conference on Thermal Destruction of Hazardous, Radioactive, Infectious and Mixed Wastes Conference, Knoxville, Tennessee, 1 May 1989, Report No. CONF-890521-2, Order No. DE89009626, 5 pp. (1989).

The Oak Ridge Toxic Substances Control Act incinerator was designed to burn toxic wastes such as PCBs. During the course of certification, concern was expressed by the U.S. Environmental Protection Agency that unburned PCBs might not continue to be destructed if the "burning" in the incinerator ceased. For example, it is possible that the flow of auxiliary fuel could be interrupted during the course of incinerator operation. The situation could occur at the time when a fresh batch of waste was introduced into the incinerator, which would be the worst time for normal incinerator operation to cease. In response to the question concerning the destruction of PCBs during such an accidental cooling period, a dynamic model was constructed to approximate the situation, and thus obtain an estimate of the time period that the exit gas would remain above the necessary temperature required to detoxify the undesirable substance.

Demos, E.K., Energy and Waste Management, Energy Task Force Status Report for First Quarter Year Ten, Urban Consortium for Technology Initiatives, Energy Task Force, Report No. DOE/IR/05106-T52, Order No. DE89014845, Paper 3, 4 pp. (1989).

Various household waste management methods are investigated to determine options for implementation of plans for discarding, safely collecting, recycling or reusing hazardous household wastes; also to examine potential byproducts of hazardous waste and possible waste-to-energy production applications by municipalities. The status is reported for studies being conducted in Seattle, Hennepin County, Albuquerque, Baltimore and Detroit. 
DeRienzo, D.P. and Adkisson, T.P., "Municipal Hazardous Materials Management Programs in Califomia," Hazardous Wastes and Hazardous Materials. Presented at the Fifth Annual Hazardous Materials Control Research Institute Conference, Las Vegas, Nevada, 19-21 April, 1988, Silver Spring, MD: Hazardous Materials Control Research Institute, Report No. CONF-880437, pp. 536-540 (1988).

As implementing agencies of hazardous materials storage regulations, municipalities are required to develop programs and procedures for inspecting and permitting businesses and for maintaining records and databases of hazardous materials information. This paper addresses the implementation and startup of a hazardous materials storage ordinance enforcement program for a city in California. Included are discussions on identifying businesses that are regulated under the ordinance, reviewing and approving business plans, performing compliance inspections and addressing the data management and records management necessary to comply with the state laws. The experiences encountered in California will be useful to local communities throughout the country for complying with the federal requirements of HSWA and SARA with regard to hazardous materials storage, community right-to-know and emergency planning.

Evaluation Program Effectiveness of Household Hazardous Waste Collection: The Seattle-King County Experience, Report No. DOE/IR/05106-4, Order No. DE93005625, 83 pp. (October 1991).

The Seattle-King County Hazardous Waste Management Plan provides the framework for an intensive effort to keep Household Hazardous and Small Quantity Generator (SQG) wastes from entering the "normal" municipal waste streams. The plan sets ambitious goals for diverting thousands of tons of hazardous wastes from being thrown, poured or dumped in the municipal waste stream. During the first five years, more than $\$ 30$ millon will be spent for a variety of household hazardous waste (HHW) and SQG programs. The plan incorporates a wide range of elements, including education, collection, and compliance components. Many of the hazardous waste education and collection programs have been developed in response to the plan, so their effectiveness is still undetermined. A key component of the plan is program evaluation. This report provides descriptions of two evaluation methods used to establish baselines for assessing the effectiveness of the Hazardous Waste Management Plan's programs. Focusing on the plan's HHW programs, the findings of the baseline evaluations are discussed and conclusions are made. A general population survey, conducted through telephone interviews, was designed to assess changes in knowledge, attitudes, and behaviors of area residents. Characterization of the solid waste stream was used to identify the hazardous constituents contributed to municipal solid waste by households. Monitoring changes in the amount of hazardous materials present in the waste stream was used to indicate whether or not Program strategies are influencing disposal behaviors. Comparing the data gathered by these two evaluation methods provided a unique opportunity to cross-check the findings and validate that change, if any, has occurred. From the comparisons, the report draws a number of conclusions.

Francis, A.J. and Dodge, C.J., "Reclamation with Recovery of Radionuclides and Toxic Metals from Contaminated Materials, Soils, and Wastes," Technology 2002: The Third National Technology Transfer Conference and Exposition, Volume 1, Hackett, M., ed., presented at the Technology 2002: National Aeronautics and Space Administration Conference, Baltimore, Maryland, 1-3 December 1992, Report No(s). N-93-25561, NASA-CP--3189-VOL-1, NAS--1.55:3189-VOL-1, CONF-921230, pp. 109-117, (Feb 1993).

A process has been developed at Brookhaven National Laboratory for the removal of metals and radionuclides from contaminated materials, soils, and waste sites. In this process, citric acid, a naturally occurring organic complexing agent, is used to extract metals such as $\mathrm{Ba}, \mathrm{Cd}, \mathrm{Cr}, \mathrm{Ni}, \mathrm{Zn}$, and radionuclides $\mathrm{Co}, \mathrm{Sr}$, Th, and $\mathrm{U}$ from solid wastes by formation of water soluble, metal-citrate complexes. Citric acid forms different types of complexes with the transition metals and actinides, and may involve 
formation of a bidentate, tridentate, binuclear, or polynuclear complex species. The extract containing radionuclide/metal complex is then subjected to microbiological degradation followed by photochemical degradation under aerobic conditions. Several metal citrate complexes are biodegraded, and the metals are recovered in a concentrated form with the bacterial biomass. Uranium forms binuclear complex with citric acid and is not biodegraded. The supernatant containing uranium citrate complex is separated and upon exposure to light, undergoes rapid degradation resulting in the formation of an insoluble, stable polymeric form of uranium. Uranium is recovered as a precipitate (polyuranate) in a concentrated form for recycling or for appropriate disposal. This treatment process, unlike others which use caustic reagents, does not create additional hazardous wastes for disposal and causes little damage to soil which can then be returned to normal use.

Gentry, D.E., Environmentally Conscious Manufacturing Integrated Demonstration, Report No. KCP-613-5132, Order No. DE93019774, 64 pp. (July 1993).

The objective of the Environmentally Conscious Manufacturing Integrated Demonstration was to show that several of the individually developed materials and processes to reduce hazardous materials and waste could be successfully used on a single assembly. A methodology was developed that could be used on any product to plan the approach to eliminating hazardous materials. Sample units of an existing design electronic unit were fabricated applying this methodology and substituting nonhazardous materials and processes. The results of this project show that total waste can be drastically reduced by at least an order of magnitude and hazardous material and waste can be essentially eliminated in the manufacture of this type of electronic devices.

Glatzmaier, G.C., National Renewable Energy Laboratory, "Analysis of Applications of Solar Technology for the Treatment of Chlorinated Organic Waste," Solar Engineering 1991, Mancini, T.R., Watanabe, K. Klett, D.E., eds. Presented at the American Society of Mechanical Engineers (ASME)/Japan Solar Energy Society (JSES)/Japan Society of Mechanical Engineers (JSME) International Solar Energy Conference, Reno, Nevada, 17-22 March, 1991, New York: American Society of Mechanical Engineers, Report No. CONF-910318, pp. 283-288 (1991).

Concentrated solar energy can destroy many hazardous chemicals that are of national concern including dioxins, polychlorinated biphenyls, and chlorinated solvents. A detailed systems analysis determines the applicability of solar detoxification to the treatment of chlorinated solvents. This work determines the cost of the destruction of trichloroethylene using both conventional technology and solar-based technology. The cost of solar detoxification and that of the conventional technology are compared for this application. This paper provides a basis for choosing an application in which solar energy can be used to its fullest potential to solve a growing national problem.

Harkness, J.B.L., Doctor, R.D., and Daniels, E.J., (Argonne National Laboratory) Plasma-Chemical Waste Treatment of Acid Gases, presented at the 86th Annual Meeting and Exhibition of the Air and Waste Management Association(AWMA), Denver, Colorado, 13-18 June 1993, Report No(s) ANL/ES/CP-78708 and CONF-930647--9,Order No. DE93040821, 15 pp. (1993).

The research to date has shown that a $\mathrm{H}_{2} \mathrm{~S}$ waste-treatment process based on plasma-chemical dissociation technology is compatible with refinery and high-carbon-oxide acid-gas streams. The minor amounts of impurities produced in the plasma-chemical reactor should be treatable by an internal catalytic reduction step. Furthermore, the plasma-chemical technology appears to be more efficient and more economical than the current technology. The principal key to achieving high conversions with relatively 
low energies of dissociation is the concept of the high-velocity, cyclonic-flow pattern in the plasma reaction zone coupled with the recycling of unconverted hydrogen sulfide. Future work will include testing the effects of components that might be carried over to the plasma reactor by upset conditions in the amine purification system of a plant and testing the plasma-chemical process on other industrial wastes streams that contain potentially valuable chemical reagents. The strategy for the commercialization of this technology is to form a cooperative research and development agreement with the Institute of Hydrogen Energy and Plasma Technology of the Russian Scientific Center/Kurchatov Institute and with an American start-up company to develop an American version of the process and to build a commercial-scale demonstration unit in the United States. The timetable proposed would involve building a field test facility which would test the plasma-chemical reactor and sulfur recovery unit operations on an industrial hydrogen sulfide waste $s$ at a scale large enough to obtain the energy and material balance data required for a final analysis of the commercial potential of this technology. The field test would then be followed by construction of a commercial demonstration unit in two to three years. The commercial demonstration unit would be a fully integrated plant consisting of one commercial-scale module.

Hazardous Waste as An Energy Manager's Issue, Report No. DOE/IR/05106-T155, Order No. DE91013450, 62 pp. (December 1988).

Environmental Protection Agency (EPA) regulations brought municipalities into the hazardous waste arena as small quantity generators (SQG). As a SQG, there are certain procedures that must be followed to comply with hazardous waste regulations. This project examines municipal operations to identify potential hazardous materials that are directly related to the production and consumption of energy. Proper methods of managing these materials are examined. Guidelines assist the local energy manager in establishing policies for proper hazardous waste handling and disposal. With the effort to deliver low cost and wise use of energy, the local energy manager has taken on many new technologies and added responsibilities. District heating, for example, requires an understanding of boilers and steam distribution systems. This is mentioned because boilers and their stacks have to be cleaned; chemical treatment of heat exchangersi also required. Many of the solvents used in this process are "listed" hazardous materials. The same is true for engine degreasers, antifreeze, hydraulic fluids and other materials used in the everyday operation of a vehicle fleet. Waste-to-energy plant operators have discovered that once the air pollution problem was solved something had to be done with the stack residue. Also, hazardous materials were found in the resulting ashes. Even if the hazardous materials are somehow identified and separated from the waste stream, they then require proper handling. The abovementioned examples are a few of the problems facing local energy managers. This project presents hazardous waste issues and accepted solutions for local energy managers to utilize in formulating policy.

Keener, T.C., "Reduction of Hazardous Solvent Wastes Through the Application of a Mobile Solvent Recovery System," 1987 Oak Ridge Model Conference. Proceedings: Volume I, Part 3, Waste Management, presented at the Third Oak Ridge Model Conference on Waste Problems, Oak Ridge, Tennessee, 13 October 1987, Report No. CONF-871075-Vol.1-Pt.3, Order No. DE88007805, pp. 251-253 (1987).

A novel mobile solvent recovery system for reclaiming usable solvents and thereby minimizing the amount of waste generation has been developed and tested at a number of industrial sites. The system has been designed to have the flexibility of reclaiming a wide variety of industrial solvents while still adhering to EPA's regulations governing the quantities of wastes which remain within the system as residue, and minimizing the amount of cross-solvent contamination. It employs a specially engineered vacuum distillation unit equipped with two unique cleaning systems for continuous cleaning of the side walls and dome head. The paper will discuss the current progress of this project including the design and 
construction of the system and its operation. Results will be given from a field test verification study conducted on various solvent-containing wastes, generated from a number of industrial sources. The wastes tested have consisted of sludges with solvents such as toluene, trichloroethane, n-propyl acetate, MEK, xylene, acetone, methylene chloride and others. The results to date have been very promising and indicate that from 50-90\% of the initial volume of these wastes may be reduced and that reusable solvent may be obtained, thereby providing both an economic and a waste management incentive for on-site reclamation.

Kennedy, W.E. Jr., Parkhurst, M.A., Aaberg, R.L., Rhoads, K.C., Hill, R.L., and Martin, J.B., Evaluation of Exposure Pathways to Man from Disposal of Radioactive Materials into Sanitary Sewer Systems, Report No(s). NUREG/CR-5814 and PNL--7892, Order No. TI92015758, 217 pp. (May 1992).

In accordance with 10 CFR 20, the U. S. Nuclear Regulatory Commission (NRC) regulates licensees' discharges of small quantities of radioactive materials into sanitary sewer systems. This generic study was initiated to examine the potential radiological hazard to the public resulting from exposure to radionuclides in sewage sludge during its treatment and disposal. Eleven scenarios were developed to characterize potential exposures to radioactive materials during sewer system operations and sewage sludge treatment and disposal activities and during the extended time frame following sewage sludge disposal. Two sets of deterministic dose calculations were performed; one to evaluate potential doses based on the radionuclides and quantities associated with documented case histories of sewer system contamination and a second, somewhat more conservative set, based on theoretical discharges at the maximum allowable levels for a more comprehensive list of 63 radionuclides. The results of the stochastic uncertainty and sensitivity analysis were also used to develop a collective dose estimate. The collective doses for the various radionuclides and scenarios range from 0.4 person-rem for sup 137Cs in Scenario No. 5 (sludge incinerator effluent) to 420 person-rem for sup 137Cs in Scenario No. 3 (sewage treatment plant liquid effluent). None of the 22 scenario/radionuclide combinations considered have collective doses greater than 1000 person-rem/yr. However, the total collective dose from these 22 combinations was found to be about 2100 person-rem.

LaJeunesse, C.A., Rice, S.F., Hanush, R.G., Aiken, J.D., (Sandia National Laboratories) Salt Deposition Studies in a Supercritical Water Oxidation Reactor, Report No. SAND-94-8201, Order No. DE94001708, 18 pp. (October 1993).

Supercritical water oxidation (SCWO), a method for destroying aqueous organic waste, is a relatively new technology discovered about fifteen years ago. SCWO occurs at moderate temperatures and pressures where the ability of water to dissolve hydrocarbons and other organic chemicals is greatly enhanced. Depending on the feed stream and residence time, the dissolved organic waste reacts with an oxidizer to produce innocuous combustion products. However, oxidation of organic material containing heteroatoms, such as sulfur or phosphorous, forms sulfuric or phosphoric acid in the absence of metal ions. In situ neutralization with sodium hydroxide then forms salts that are insoluble at supercritical conditions. These salts deposit in the reactor affecting the processing of the organic material. To design a system that can accommodate the formation of these salts, it is important to understand the deposition process quantitatively. This paper is an interim report on an experimental program designed to understand the salt deposition phenomena. 
Lussiez, G.W., (Los Alamos National Laboratory) Decontaminating Lead Bricks and Shielding, presented at the Second International Mixed Waste Symposium, Baltimore, Maryland, 17-20 August 1993, Report No(s). LA-UR-93-1203 and CONF-930873--4, Order No. DE93012662, 8 pp. (1993).

Lead used for shielding is often surface contaminated with radioisotopes and is therefore a RCRA D008 mixed waste. The technology-based standard for treatment is macroencapsulation. However, decontaminating and recycling the clean lead is a more attractive solution. Los Alamos National Laboratory decontaminates material and equipment contaminated with radioisotopes. Decontaminating lead poses special problems because of the RCRA hazard classification and the size of the inventory, now about 50 tons and likely to grow substantially because of planned decommissioning operations. This lead, in the form of bricks and other shield shapes, is surface contaminated with fission products. One of the best methods for decontaminating lead is removing the thin superficial layer of contamination with an abrasive medium trader pressure. For lead, a mixture of alumina with water and air at about 40 psig rapidly and effectively decontaminates the lead. The abrasive medium is sprayed onto the lead in a sealed-off area. The slurry of abrasive and particles of lead falls through a floor grating and is collected in a sump. A pump sends the slurry mixture back to the spray gun, creating a continuous process. The process generates small volumes of contaminated lead slurry that can be solidified and, because it passes the TCLP, is not a mixed waste. The decontaminated lead can be released for recycling.

Link, H. and Turchi, C.S., National Renewable Energy Laboratory, "Cost and Performance Projections for Solar Water Detoxification Systems," Solar Engineering 1991, Mancini, T.R., Watanabe, K, Klett, D.E., eds. Presented at the American Society of Mechanical Engineers (ASME)/Japan Solar Energy Society (JSES)/Japan Society of Mechanical Engineers (JSME) International Solar Energy Conference, Reno, Nevada, 17-22 March, 1991, New York: American Society of Mechanical Engineers, Report No. CONF-910318, pp. 289-294 (1991).

Laboratory and small-scale field experiments show that concentrated solar flux can be used to detoxify water contaminated with a variety of hazardous chemicals. Studies reported in this paper extrapolate laboratory and field test data to predict the cost and performance of a representative commercial water-detoxification system. The system kinetics are modeled using a modified form of the Lanmuir-Hinshelwood rate equation to predict the exposure time required to reduce contaminant concentrations to below those required by the 1986 amendment to the Safe Drinking Water Act. Although current costs for solar water detoxification systems are higher than those for conventional treatment technologies, improvements demonstrated in the laboratory are expected to result in competitive field systems by the mid-1990s.

"Microorganisms May Play Role in Waste Management," (Oak Ridge National Laboratory), Oak Ridge National Laboratory Review, v 23:1, pp. 92-93 (1990).

Oak Ridge National Laboratory (ORNL) researchers study microorganisms that remove metals from water for possible use in managing radioactive and hazardous wastes at ORNL and elsewhere. These organisms, including bacteria, fungi, and algae, selectively absorb metals from water. Thus, in high concentrations, they could be used to treat wastewater containing radioactive or toxic metals. 
Mohr, G.V., Metrology Process Waste Assessment: Fluorinert Bath Temperature Calibration Z951-421-1, Report No. KCP-613-5216, Order No. DE94001378, 31 pp. (September 1993).

Fluorinert, FC-40 and FC-72, was chosen for this pilot Process Waste Assessment because it is the most frequently used chemical in Metrology. Fluorinert has been used since 1986 as a substitute for trichloroethylene. Although it is much safer than trichloroethylene, it still has disadvantages. If Fluorinert is taken above its boiling point it will produce toxic chemicals, creating a health hazard rating of 4 . To prevent this occurrence, over-temperature controls are installed on the bath and a fume hood is provided for the vapors. Fluorinert is used in a Rosemount Temperature Bath, CE 64138, as a stirred temperature medium which provides a stable temperature environment to compare readings of a Standard Platinum Resistance Thermometer to readings obtained from thermocouples, thermistors, and other types of thermometers. Fluorinert is used primarily to provide a safe liquid medium that can be varied from $-120^{\circ}$ to $200^{\circ} \mathrm{F}$. When temperature devices are removed from the bath, the excess Fluorinert is removed by wiping with a KayDry. Contaminated KayDrys are disposed of as step can waste.

Powell, M.R. and Mahalingam, R., (Pacific Northwest Laboratory), "Continuous Solidification/ Stabilization Processing of Hazardous Wastes Through Polymeric Microencapsulation," Industrial and Engineering Chemistry Research, v 31:2, pp. 543-548 (February 1992).

This paper reports that the continuous solidification/stabilization of a simulated aqueous hazardous waste steam through microencapsulation in a polyester matrix was evaluated in a static mixer/reactor and found to be feasible. For the emulsion formation step, the Sauter mean droplet size of the emulsion formed was found to vary with the stream total flow rate to the -0.87 power, the number of mixing elements to the -0.63 power, and the volume fraction of waste to the 0.2 power. Next, numerical simulation of the polymerization reaction step for the conditions investigated predicted that the degree of polymerization occurring inside the mixer/reactor was only on the order of a safe and desirable $0.2 \%$ of the total conversion, thus ensuring the absence of any premature gelling within the mixer/reactor; also, this resulted in only a negligible fluid temperature rise, these being verified by experimental observations and measurements. On these bases, exothermicity and solidification of the stream inside the mixer/reactor are hence not expected to be processing problems.

Release of Radioactive Scrap Metal/Scrap Metal (RSM/SM) at Nevada Test Site (NTS), presented at the conference on the Release of Radioactive Scrap Metal/Scrap Metal (RSM/SM) at Nevada Test Site (NTS) Salt Lake City, Utah, 20-21 April 1993, Report No. CONF-9304169-Summ., Order No. DE93016219, 11 pp. (1993).

Reynolds Electrical and Engineering Company, Inc. (REECo) is the prime contractor to the US Department of Energy (DOE) in providing service and support for NTS operations. Mercury Base Camp is the main control point for the many forward areas at NTS, which covers 1,350 square miles. The forward areas are where above-ground and underground nuclear tests have been performed over the last 41 years. No metal (or other material) is returned to Mercury without first being tested for radioactivity. No radioactive metals are allowed to reenter Mercury from the forward areas, other than testing equipment. RAMATROL is the monitor check point. They check material in various ways, including swipe tests, and have a large assortment of equipment for testing. Scrap metal is also checked to address Resource Conservation and Recovery Act concerns. After addressing these issues, the scrap metals are categorized. Federal Property Management Regulations are followed by REECo. The nonradioactive scrap material is sold through the GSA on a scheduled basis. Radioactive scrap metal are presently held in forward areas where they were used. REECo has gained approval of their Nevada Test Site Defense Waste Acceptance Criteria, Certification, and Transfer Requirements, NVO-325 application, which will allow disposal on site, 
when RSM is declared a waste. The guideline that REECo uses for release limits is DOE Order 5480.11, Radiation Protection for Occupational Works, Attachment 2, Surface Radioactivity Guides, of this order, give release limits for radioactive materials. However, the removal of radioactive materials from NTS require approval by DOE Nevada Operations Office on a case-by-case basis. Requirements to consider before removal are found in DOE Order 5820.2A, Radioactive Waste Management.

Sauer, N.N. and Smith, B.F., (Los Alamos National Laboratory) Metal-Ion Recycle Technology for Metal Electroplating Waste Waters, Report No. LA-12532-MS, Order No. DE93016006, 55 pp. (June 1993).

As a result of a collaboration with Boeing Aerospace, the authors have begun a program to identify suitable treatments or to develop new treaments for electroplating baths. The target baths are mixed-metal or alloy baths that are being integrated into the Boeing electroplating complex. These baths, which are designed to replace highly toxic chromium and cadmium baths, contain mixtures of two metals, either nickel-tungsten, nickel-zinc, or zinc-tin. This report reviews the literature and details currently available on emerging technologies that could affect recovery of metals from electroplating baths under development by Boeing Aerospace. This literature survey summarizes technologies relevant to the recovery of metals from electroplating processes. The authors expanded the scope to investigate single metal ion recovery technologies that could be applied to metal ion recovery from alloy baths. This review clearly showed that the electroplating industry has traditionally relied on precipitation and more recently on electrowinning as its waste treatment methods. Despite the almost ubiquitous use of precipitation to remove contaminant metal ions from waste electroplating baths and rinse waters, this technology is clearly no longer feasible for the electroplating industry for several reasons. First, disposal of unstabilized sludge is no longer allowed by law. Second, these methods are no longer adequate as metal-removal techniques because they cannot meet stringent new metal discharge limits. Third, precious resources are being wasted or discarded because these methods do not readily permit recovery of the target metal ions. As a result, emerging technologies for metal recovery are beginning to see application to electroplating waste recycle. This report summarizes current research in these areas. Included are descriptions of various membrane technologies, such as reverse osmosis and ultrafiltration, ion exchange and chelating polymer technology, and electrodialysis.

Seeberger, D.A., Household Batteries: Evaluation of Collection Methods, Report No. DOE/IR/05106-6, Order No. DE93005627, 33 pp. (1992).

While it is difficult to prove that a specific material is causing contamination in a landfill, tests have been conducted at waste-to-energy facilities that indicate that household batteries contribute significant amounts of heavy metals to both air emissions and ash residue. Hennepin County, Minnesota, used a dual approach for developing and implementing a special household battery collection. Alternative collection methods were examined; test collections were conducted. The second phase examined operating and disposal policy issues. This report describes the results of the grant project, moving from a broad examination of the construction and content of batteries, to a description of the pilot collection programs, and ending with a discussion of variables affecting the cost and operation of a comprehensive battery collection program. Three out-of-state companies were found that accept spent batteries; difficulties in reclaiming household batteries are discussed. 
Seeberger, D.A., Household Hazardous Waste Management Planning, Report No. DOE/IR/05106-T157, DE91013452, 66 pp. (1991).

In 1985, Hennepin County entered into an agreement with Hennepin Energy Resource Co., Ltd. for the construction and operation of a 1000-ton/day waste-to-energy facility. In an effort to ensure that the new incinerator operated as safely as possible, Hennepin County examined various methods of removing unacceptable materials from the waste stream; household hazardous wastes (HHW) were one stream considered for diversion. As with any new program, a number of policy and design issues were addressed prior to implementing a permanent HHW collection system. In an effort to address these questions and share information from its experiences, Hennepin County applied for and was awarded a grant from the Urban Consortium Energy Task Force. The grant research plan detailed a three-phase approach for developing and implementing a HHW collection. In phase one, the County examined planning issues affecting program design and drafted a set of recommendations that included establishing a pilot collection program in Phase 2. This report describes the results from the first phase of the project grant, moving from a broad examination of what HHW is to detailed findings from surveys and focus groups addressing county residents' needs and opinions about a specialized HHW disposal system.

Sigmon, C.F. and Sharples, F.E., "Hazardous Waste Regulatory Update," (Oak Ridge National Laboratory) Proceedings of the International Topical Meeting on Nuclear and Hazardous Waste Management, presented at Conference Spectrum '88: International Topical Meeting on Nuclear and Hazardous Waste Management, Pasco, Washington, 11-15 September 1988, Report No. CONF-880903, pp. 127-129 (1988).

Environmental regulations strongly influence both current hazardous waste management and remedial activities for past waste management practices at U.S. Department of Energy (DOE) facilities. Of particular importance are the Resource Conservation and Recovery Act (RCRA) and its 1984 Hazardous and Solid Waste Amendments and the Comprehensive Environmental Response Compensation and Liability Act (CERCLA) and its reauthorization through the Superfund Amendments and Reauthorization Act of 1986. Both RCRA and CERCLA are undergoing changes that might affect DOE activities. This paper highlights recent or upcoming changes in RCRA and CERCLA with particular emphasis on areas of importance to DOE.

Spencer, R.L., "Local Governments Take on Hazardous Waste Collection," BioCycle (USA) v 30:3, pp. 42-43 (March 1989).

Diversion of toxic chemicals from solid waste disposal facilities is one major reason communities conduct collection programs for household hazardous wastes (HHW). By keeping wastes like old cans of paint thinner, pesticides, waste oil and car batteries out of the trash collection, the hypothesis is that leachate, air emissions and compost quality will be improved. While special HHW collection days are the most common technique used by local communities, there are varied perspectives and issues about the effort, which include low average participation rates, high cost of collection, liability of sponsoring communities, and environmental benefits from diverting a small portion of waste from the solid waste facility. The major benefits are clearly educational. As community recycling programs and material reclamation facilities develop, the public is becoming increasingly aware of the presence of HHW in their waste stream. This is a natural spinoff of source separation. The increased interest in solid waste composting facilities is also forcing communities to evaluate ways of producing compost with acceptable levels of contaminants. 
Thornton, J.P., Solar Thermal Technologies in Support of an Urgent National Need: Opportunities for the Photon-Enhanced Decomposition of Concentrated and Dilute Hazardous Wastes, Report No. SERI/SP-250-3359, Order No. DE89000840, 33 pp. (December 1988).

Toxic waste cleanup is a national concern that affects every citizen. Experimental data taken at the National Renewable Energy Laboratory indicate that solar thermal technologies can directly destroy a wide variety of dilute and concentrated organic wastes. Photons contained in the ultraviolet portion of the solar spectrum enhance the decomposition process. Potential benefits include shorter processing times, complete destruction of organic toxins, lower processing temperatures, fewer noxious by-products that need secondary treament, and smaller plants to handle given capacities. These unique qualities offer substantial promise to help solve the national problem of hazardous waste cleanup and disposal.

Wentz, C.A., (Argonne National Laboratory) "The Risk Associated with the Research of an Innovative Process for the Thermal Destruction of Hazardous Substances-A Case Study," Proceedings of the International Conference on Incineration of Hazardous, Radioactive and Mixed Wastes, presented at the International Conference on Incineration of Hazardous, Radioactive, and Mixed Wastes, San Francisco, California, 3-6 May 1988, Irvine, California, Report No. CONF-880526, pp. 1-10 (1988).

High-temperature gasification is an innovative thermal process that offers considerable potential for highly efficient destruction of hazardous waste. Destruction and removal efficiencies (DREs) of at least $99.999999 \%$, and possibly $99.9999999 \%$, should be achieved in the gasification of hazardous substances. Recognizing the commercial potential of such an innovative process, Union Carbide Corporation contracted with the University of North Dakota Energy Research Center at Grand Forks, North Dakota, to demonstrate this technology by destroying polychlorinated biphenyls (PCBs) in the Center's existing pilot-plant lignite gasifier. After Union Carbide and the Energy Research Center agreed on the scope of the experimental program, the Center applied for and received the necessary state and federal environmental permits. Shortly after these permits were granted a group of local citizens came out against the PCB program. The project came under intense public scrutiny, the state operating permit was revoked, and the project was terminated. The authors present their analysis of this situation. 


\section{Landfills}

Bogner, J.E., (Argonne National Laboratory) Energy Potential of Modern Landfills, presented at the Eighteenth Annual Illinois Energy Conference: Energy Aspects of Solid Waste Management, Chicago, Illinois, 29-30 October, 1990, Report No. CONF-9010176-1, Order No. DE91006490, 14 pp. (1990).

Methane produced by refuse decomposition in a sanitary landfill can be recovered for commercial use. Landfill methane is currently under utilized, with commercial recovery at only a small percentage of U. S. landfills. New federal regulations mandating control of landfill gas migration and atmospheric emissions are providing impetus to methane recovery schemes as a means of recovering costs for increased environmental control. The benefits of landfill methane recovery include utilization of an inexpensive renewable energy resource, removal of explosive gas mixtures from the subsurface, and mitigation of observed historic increases in atmospheric methane. Increased commercial interest in landfill methane recovery is dependent on the final form of Clean Air Act amendments pertaining to gaseous emissions from landfills; market shifts in natural gas prices; financial incentives for development of renewable energy resources; and support for applied research and development to develop techniques for increased control of the gas generation process in situ. This paper discusses the controls on methane generation in landfills. In addition, it addresses how landfill regulations affect landfill design and site management practices which, in turn, influence decomposition rates. Finally, future trends in landfilling, and their relationship to gas production, are examined.

Bogner, J., Brubaker, K., Tome, C., Vogt, M., and Gartman, D. (Argonne National Laboratory), Bidirectional Gas Movement Through Landfill Cover Materials, Volume 1: Instrumentation and Preliminary Site Investigations at Mallard North Landfill, Dupage County, Illinois, Report No. ANL/CNSV-TM-193, Order No. DE88007132, 35 pp. (February 1988).

Since the first commercial landfill gas recovery system was installed in 1975 at the Palos Verdes Landfill in southern California (Zimmerman et al., 1983), there have been few systematic research efforts aimed at understanding gas dynamics in the landfill and, in particular, gas exchange between the landfill and the atmosphere through the cover materials. To maximize the amount of landfill gas available to a recovery system, the impact of processes by which gas is vented or consumed in near-surface zones must be minimized. This report describes a project undertaken to monitor the flow of gas in a landfill. Data from the observations are presented.

Bogner, J.E., Rose, C., and Piorkowski, R., (Argonne National Laboratory) Modified Biochemical Methane Potential (BMP) Assays to Assess Biodegradation Potential of Landfilled Refuse, presented at the Fifth International Conference on Solid Wastes, Sludges and Residual Materials: Characterization, Technology, Management, Public Policy, Rome, Italy, 26 April 1989, Report No. CONF-890440-1, Order No. DE89009840, p. 16 (1989).

Modified Biochemical Methane Potential (BMP) assays were used to assess the biogas production potential of solid landfill samples. In landfill samples with visible soil content, moisture addition alone was generally as effective at stimulating biogas production as the addition of a comprehensive nutrient media. In a variety of samples from humid and semiarid landfills, the addition of an aqueous nutrient media was the most effective stimulant for biogas production; however, moisture addition was almost as effective for most samples, suggesting that water addition would be the most cost-effective field approach. The onset of methanogenesis was slower in fresh refuse samples (even when inoculated with anaerobic digester sludge) than in landfill samples, indicating that the soil into which materials are landfilled is a major source of microorganisms. High volatile solids loading in fresh refuse and landfill assays retarded 
methanogenesis. A comparison of anaerobic and aerobic sample handling techniques showed no significant differences with regard to the onset of methanogenesis and total gas production. The technique shows initial promise with regard to replication and reproducibility of results and could be a meaningful addition to landfill site evaluations where commercial gas recovery is anticipated. The BMP technique could also be adapted to assess anaerobic biodegradability of other solid waste materials for conventional anaerobic digestion applications.

Bogner, J. and Spokas, K., (Argonne National Laboratory), Landfill $\mathrm{CH}_{4}:$ Rates, Fates, and Role in Global Carbon Cycle, presented at the North Atlantic Treaty Organization (NATO) Advanced Research Workshop, Mount Hood, Oregon, 6-11 October 1991, Report No(s). ANL/CP-75733, CONF-9110220--2, Order No. DE92010906, 20 pp. (1991).

Published estimates for worldwide landfill methane emissions range from 9 to $70 \mathrm{Tg} \mathrm{yr}^{-1}$. Field and laboratory studies suggest that maximum methane yields from landfilled refuse are about 0.06 to 0.09 $\mathrm{m}^{-3}$ (dry Kg) ${ }^{-1}$ refuse, depending on moisture content and other variables, such as organic loading, buffering capacity, and nutrients in landfill microevnironments. Methane yields may vary by more than an order of magnitude within a given site. Fates for landfill methane include direct or delayed emission to the atmosphere through landfill cover materials or surface soils; oxidation by methanotrophs in cover soils, with resulting emission of carbon dioxide; or recovery of methane followed by combustion to produce carbon dioxide. The percent methane assigned to each pathway will vary among field sites and, for individual sites, through time. Nevertheless, a general framework for a landfill methane balance can be developed by consideration of landfill age, engineering and management practices, cover soil characteristics, and water balance. Direct measurements of landfill methane emissions are sparse, with rates between $10^{-6} 10^{-8} \mathrm{~g} \mathrm{~cm}^{-2} \mathrm{~s}^{-1}$; very high rates of $400 \mathrm{~kg} \mathrm{~m}^{-2} \mathrm{yr}^{-1}$ were measured at a semiarid unvegetated site. The proportion of landfill carbon that is ultimately converted to methane and carbon dioxide is problematical; the literature suggests that, at best, $25 \%$ to $40 \%$ of refuse carbon can be converted to biogas carbon. Cellulose contributes the major portion of the methane potential. Routine excavation of nondecomposed cellulosic materials after one or two decades of landfill burial suggests that uniformly high conversion rates are rarely attained at field sites.

Bogner, J.E., Vogt, M., and Miller, R.M., (Argonne National Laboratory) Studies of Soil Gas, Gas Generation, and Shallow Microbial Activity at Mallard North Landfill, presented at the Thirteenth International Landfill Gas Symposium, Lincolnshire, Ilinois, 27-29 March 1990, Report No. CONF-9003147-1, Order No. DE90010102, 18 pp. (1990).

Three types of investigations at the Mallard North Landfill led to the development of useful field and laboratory techniques for better understanding gas generation, gas migration, and shallow microbial processes at any landfill. This paper summarizes the techniques with reference to representative results from Mallard North and discusses their general applicability to landfill site investigations.

City of Chicago, Evaluation of Landfill Gas as an Energy Source, Management Report, Report No. DOE/IR/05106-T47, 45 pp. (December 1980).

Consideration of the benefits and problems of landfill gas recovery by the City of Baltimore, Maryland, resulted in the structuring and testing of a realistic gas-recovery evaluation procedure for use by local governments. This management report summarizes the Baltimore methodology and presents results of its application to a large landfill in the Baltimore area. 
Croft, B., "Field-Scale Landfill Gas Enhancement: The Brogborough Test Cells," Klass, D.L., ed., Energy from Biomass and Wastes XV, presented at the Fifteenth Annual Conference on Energy from Biomass and Wastes, Washington, D.C., 25-29 March 1991, Chicago, Illinois, Report No. CONF-910339, pp. 129-157 (1991).

This paper reviews the design, construction, instrumentation and results for the first year of monitoring of an experiment comprising six cells, each containing approximately 15,000 tonnes of waste. The primary objective is to examine the effects of various practical propositions for enhancement of landfill gas yield from municipal solid waste, including variation of in-place density, temperature elevation by air injection, water/leachate recirculation, addition of sewage sludge and addition of commercial/industrial wastes. The sixth cell is a control. Monitored variables include gas flow and quality (major gases), leachate generation rate and quality, within-waste temperatures and pressures, and settlement rates. Studies of landfill microbiology, trace composition of gas and influence of meteorology have also been incorporated. Initial results suggest that the effects of sewage sludge addition on gas quality and flow are pronounced but short-lived, while commercial/industrial waste addition currently demonstrates the greatest specific yield. Commencement of temperature elevation and leachate recirculation will occur when these cells are at equilibrium gas production. Density variation has, perhaps surprisingly, shown no detectable effect to date. Settlement and gas yield appear to be closely related. Leachate composition and gas quality/flow show a complex but intimate relationship. Meteorological effects may be significant, particularly atmospheric pressure variation.

Data Summary of Municipal Solid Waste Management Alternatives, (National Renewable Energy Laboratory), Report No. NREL/TP-431-4988H, Order No. DE93008309, 75 pp. (October 1992).

While the preceding appendices have focused on the thermochemical approaches to managing municipal solid waste (MSW), this appendix and those that follow on composting and anaerobic digestion address more of the bioconversion process technologies. Landfilling is the historical baseline MSW management option central to every community's solid waste management plan. It generally encompasses shredfills, balefills, landfill gas recovery, and landfill mining. While landfilling is virtually universal in use, it continues to undergo intense scrutiny by the public and regulators alike. Most recently, the U.S. Environmental Protection Agency (EPA) issued its final rule on criteria for designing, operating, monitoring, and closing municipal solid waste landfills. While the Federal government has established nationwide standards and will assist the states in planning and developing their own practices, the states and local governments will carry out the actual planning and direct implementation. The states will also be authorized to devise programs to deal with their specific conditions and needs. While the main body of this appendix and corresponding research was originally prepared in July of 1991, references to the new RCRA Subtitle D, Part 258 EPA regulations have been included in this resubmission (908). By virtue of timing, this appendix is, necessarily, a "transition" document, combining basic landfill design and operation information and reference to new regulatory requirements. Given the speed with which landfill practices are and will be changing, the reader is encouraged to refer to Part 258 for additional details. As states set additional requirements and schedules and owners and operators of MSW landfills seek to comply, additional guidance and technical information, including case studies, will likely become available in the literature.

District of Columbia Department of Environmental Services, 1-95 Landfill Gas Recovery and Utilization Feasibility Study, Report No. DOE/RA50314-1, 179 pp. (February 1983).

This feasibility study was to determine the viability of a landfill gas (LFG) recovery and utilization system at the I-95 Sanitary Landfill in Lorton, Virginia. Specific objectives included estimating the 
quantity and quality of recoverable LFG, evaluating alternatives for LFG use, developing a phased LFG-recovery program, and assessing the environmental, health, safety, and socioeconomic impacts of such a program.

EMCON Associates, Feasibility Study: Utilization of Landfill Gas for a Vehicle Fuel System-Rossman's Landfill, Clackamas County, Oregon, Report No. DOE/RA/50366-1, 216 pp. (February 1983).

The areas addressed in this feasibility study include: (1) landfill gas yield and collection, including an estimate of production rates, a prediction of methane yield versus time, and development of a conceptual gas-gathering system; (2) gas processing, compressing, and storage, including a review of current state of the art and relevant case histories, development of alternative processing options, selection of an optimum system, and conceptual design; and (3) methane-fueled vehicle systems, including a review of the state of the art and evaluation of case histories, development of alternative fuel systems, and final selection of the optimum system. Cost estimates are included as an integral part of each area of study. Presented also is a summary of total project costs and economic feasibility.

EMCON Associates, Effects of Water, Buffer, and Sludge Addition on Gas Production in Large-Scale Landfill Cells: Controlled Landfill Project, Mountain View, California, Report No. ANL/CNSV-TM-110, 244 pp. (July 1982).

To verify previous findings and to establish a data base for facilitating selection of operational conditions for controlled management of landfill-gas generation and recovery, a field demonstration project on gas-generation enhancement was started at the Mountain View Landfill in Mountain View, California. This demonstration project was designed to address the effects of such enhancement parameters as final water, buffer, and seed/nutrient content. Beginning in Nov. 1980, a six-cell cluster was constructed to study the effects of water content on gas enhancement, as well as to verify the suggested synergism between water, buffer and seed/nutrient content. All cells were constructed in an identical manner. A 5-ft clay base liner was placed to control the downward movement of liquids and gases, as well as to isolate the test cells from ground-water intrusion. Cell walls were constructed of clay to ensure control over lateral movement. A 30-mil reinforced Hypalon cell cover effectively isolates the cells from infiltration of precipitation, as well as serving to contain the gas produced within the cells. This report describes construction of the cells and presents data obtained during the first 200 days of monitoring.

EMCON Associates, State of the Art of Methane Gas Enhancement in Landfills, Report No. ANL/CNSV-23, 70 pp. (August 1981).

The rate of landfill-gas production is a function of many factors. Theoretical and empirical findings are reported for the effects of these factors on gas-extraction rates at large municipal landfills with somewhat uniform refuse composition. Moisture is the most important enhancement factor. Management of bacteria through sludge seeding and proper proportions of nutrients are also important. Experimental evidence indicates that methane production is optimized when the substrate utilized by the methanogenic bacteria has a biodegradable carbon/nitrogen ratio of 30 . Environmental considerations such as temperature and $\mathrm{pH}$ also affect enhancement. 
Engineering-Science, Inc., Design and Operation of a Demonstration Sanitary Landfill Developed to Optimize the Generation and Capture of Combustible Gas, Report No. ANL/CNSV-TM-112, 74 pp. (March 1983).

This report discusses a project to demonstrate the influences of selected factors on the generation and recovery of methane gas from sanitary landfills. The factors selected were (1) encapsulation, (2) shredding, (3) air classifying, (4) moisture content, and (5) pH. Six model sanitary landfill cells, each with a capacity of approximately 450 cubic yards of municipal waste, and auxiliary subsystems were constructed in the San Fernando Valley, north of Los Angeles, California. Municipal waste in each cell was contained in a 30-mil-thick polyvinyl chloride (PVC) plastic sheeting, forming a virtually gas-tight envelope. Three pairs of cells were filled with waste: two cans with as-collected urban waste, two with shredded waste, and two with shredded and air-classified waste. One cell from each pair was used as a control cell; the other cell was used as an experimental cell. Systems were provided for adding measured amounts of water, removing and recirculating leachate, extracting gas, and measuring gas flow. During the demonstration period, the rate of gas production, quantity and composition of gas produced, and internal cell characteristics were measured to determine the effects of mechanical processing (shredding and air classifying), moisture content, and leachate $\mathrm{pH}$.

Fingleton, D.J., Habegger, L., Peters, R., Tomasko, D., Liengcharemsit, W., Hastings, P., Boonraksa, C., Phantumvanit, D., Smith, K and Carpenter, R., (Argonne National Laboratory) Siting Industrial Waste Land Disposal Facilities in Thailand: A Risk Based Approach, presented at the Pacific Basin Conference on Hazardous Waste, Singapore, China, 2-7 April 1989, Report No. CONF-8904232-2, Order No. DE90002271, 26 pp. (1989).

The Thailand Industrial Works Deparment (IWD) has established a toxic industrial waste Central Treatment and Stabilization Center (CTSC) for textile dyeing and electroplating industries located in the Thonburi region of the Bangkok metropolitan area. Industrial waste is treated, stabilized, and stored at the CTSC. Although the IWD plans to ship the stabilized sludge to the Ratchaburi Province in western Thailand for burial, the location for the land disposal site has not been selected. Assessing the relative health risks from exposure to toxic chemicals released from an industrial waste land disposal site is a complicated, data-intensive process that requires a multidisciplinary approach. This process is further complicated by the unique physical and cultural characteristics exhibited by the rapidly industrializing Thai economy. The purpose of this paper is to describe the research approach taken and to detail the constraints to health risk assessments in Thailand. Issues discussed include data availability and quality, effectiveness of control or mitigation methods, cultural differences, and the basic assumptions inherent in many of the risk assessment components.

Francis, C.W., (Oak Ridge National Laboratory) Land Disposal of Solid Waste: Foreign Trip Report, March 13-21, 1988, Report No. ORNL/FTR-2833, Order No. DE89017408, 26 pp. (31 March 1988).

The traveler participated in the Swiss Workshop on Land Disposal of Solid Waste. This workshop was financially supported by a variety of Swiss enterprises and public authorities whose objective was to assemble a select group of engineers, natural scientists, and economists from various European countries and the United States and Canada to discuss the criteria essential to qualify anthropogenic solid waste as being acceptable for final storage. The Workshop was structured to enhance informal discussions within four working groups of 10 to 12 participants, each group addressing specific questions relating to the landfill as a reactor and the landfill as a final storage facility. Conclusions of the workshop participants were (1) the landfill as a reactor could not be depended on to generate a waste of final storage quality and (2) if a landfill was to be used as a final storage facility, only wastes of final storage quality should be 
disposed of in such facilities. The most controversial items of debate were the criteria necessary to meet final storage quality. The major criteria for final storage quality agreed upon by the participants were that composition of the waste should be defined (within 95\%), total organic carbon of wastes should not exceed 5\%, and leachate concentrations emanating from the landfill should not be significantly different from natural concentrations in groundwaters and surface water adjacent to the landfill.

Geotechnics, Inc., Applications Manual for Analyzing Landfill Methane Recovery Data Using the Computer Analysis of Field Data (CAFD) Interactive Graphics System, Report No. ANL/CNSV-TM-114, 100 pp. (July 1982).

This applications guide describes how the CAFD (Computer Analysis of Field Data) computer software system can be applied to the analysis and display of data obtained during field monitoring studies associated with recovery of methane from landfills. The software is written in Basic for use on a Tektronix 4054 dynamic graphics minicomputer and display terminal. Required peripherals include a single floppy disk drive, a digitizing tablet, a hard-copy unit, and an $x-y$ plotter. The analysis portion of the software compares and statistically correlates data sets and performs interpolation and filtering of data as a function of time. The display portion of the software presents data at particular sampling points as a function of time and presents contour and oblique plots of data at sampling points located in a two-dimensional grid pattern.

Harrington, K and Kaszynski, G., An Annotated Bibliography: Environmental Impacts of Sanitary Landfill and Associated Gas Recovery Systems, Report No. ANL/CNSV-27, 122 pp. (July 1981).

Many references associated with the environmental impacts of landfill gas-extraction systems are assembled in this comprehensive annotated bibliography.

Kaszynski, G., et al., The Environmental Impacts, Institutional Problems, and Research Needs of Sanitary Landfill Methane Recovery, Report No. ANL/CNSV-TM-86, 60 pp. (August 1981).

More than two dozen impacts and constraints related to landfill gas are discussed in this report, and projects are proposed for high-priority research efforts. Foremost research needs are disposal and treatment of condensates and leachate; hazard control related to landfill-gas composition; emissions from equipment fueled by landfill gas; and determination of cost-benefit relationships on the basis of institutional factors. Appendix $\mathrm{A}$ is a case-study analysis of 10 landfill sites.

Leaching Characteristics of Resource Recovery Ash in Municipal Waste Landfills, Final Report, prepared by Oak Ridge National Laboratory, Report No. DOE/OR/21400-T96, 87 pp. (December 1984).

The purpose of the research described in this report is to evaluate trends in leachate concentrations of resource-recovery ashes landfilled under mono- and codisposal conditions. Monodisposal implies disposal of a resource-recovery ash in a separate landfill, while codisposal implies disposal of the resource-recovery ash in a landfill in which untreated municipal wastes are also disposed of. Leachates from four resource-recovery ashes were generated using: (1) distilled water as the leaching medium to simulate monodisposal conditions and (2) municipal waste leachate as the leaching medium to simulate codisposal of a resource-recovery ash in a municipal waste landfill. The approach is to measure the concentration of potential contaminants in leachates from resource-recovery ashes under field-simulated conditions. The intent is to determine if significantly greater quantities of these contaminants are leached 
under codisposal conditions than under monodisposal conditions and to decide if the contaminant concentrations in leachates of codisposed resource-recovery ashes are significantly different from those leachates from typical municipal waste landfills.

Lofy, R.J., Study of Zones of Vacuum Influence Surrounding Landfill Gas Extraction Wells, prepared by Lockman and Associates, Report No. ANL/CNSV-TM-113, 114 pp. (March 1982).

Optimum recovery of the available gas is an essential aspect of the profitability of any commercial landfill gas project. Paramount in the design of a well-field-collection system is an understanding of the zone of vacuum influence and synergistic interactions of such key variables as depth of well and well screen in relation to total landfill depth, extent of wellhead vacuum, degree of refuse compaction, porosity of refuse with respect to cover material and interim cover material, and spacing of wells. This study was designed (1) to expand available knowledge, (2) to provide basic research data that could be used to verify computer models of the extraction process, (3) to confirm or disprove various design concepts, and (4) to clearly establish basic physical principles. This report indicates that many of the previously held hypotheses about steady state, isotropic, homogenous, symmetrical conditions occurring in a landfill are erroneous. The zone of vacuum influence surrounding a well is neither necessarily symmetrical nor constant. Instead, it is apparently in a continual state of flux in response to one or more external variables. There is strong evidence to suggest that barometric pressure is one of the external variables responsible for the transitory fluctuations in the zone of vacuum influence surrounding a well and the resultant intrusion of air into a landfill.

Lofy, R.J., Feasibility of Direct On-Site Conversion of Landfill Gas to Electrical Energy at Scholl Canyon Landfill, Glendale, Calif., Final Report, Report No. DOE/CE/20237-1, 55 pp. (June 1981) [available in microfiche only].

The report documents the Phase I study on the technical and economic feasibility of direct on-site conversion of landfill gas to electricity for distribution through a municipal power grid. The landfill, which is on a large parcel of land owned by the city of Glendale, California, and dedicated to recreational use, would contribute a small (less than 1\%) but reliable supply of low-cost power to its grid. Installation of the well-field collection system must precede the construction of a golf course. Three conversion technologies are evaluated. Internal-combustion engine-driven generator sets are chosen over gas turbines (which are not commercially available) and steam turbines (which are not cost-effective). Anticipated initial gas yield is $750 \mathrm{ft}^{3} / \mathrm{min}$ of $400-\mathrm{Btu} / \mathrm{ft}^{3}$ gas, enough to generate about $1,662 \mathrm{~kW}$ electrical power. Comparison of cost versus loss of $\$ 473,040 / \mathrm{yr}$ in methane sales is the basis for a recommendation that the project continue into the final design stage.

Lytwynyshyn, G., et al., Landfill Methane Recovery, Part II: Gas Characterization, Final Report, December 1981 to December 1982, Report No. ANL/CNSV-TM-118, 151 pp. (December 1982).

This is the second part of a study of the environmental impacts of landfill methane recovery (LMR). Part I reviewed the state-of-the-art and environmental effects of LMR and developed a research plan for the subject area. Four high-priority research projects were recommended in Part 1. Part II addresses two of the four recommended projects: to standardize the sampling and analysis procedures and to establish a nationwide survey of the trace components in both inlet (raw) and processed (product) landfill gas. 
Managing Municipal Solid Waste: A Comparative Risk Analysis of Landfill and Resource Recovery Facilities: Final Report, Report No. DOE/OR/21389-12, Order No. DE89007193, pp. 70 (November 1988).

This report offers policy guidance to state and local officials in comparing the health, safety and environmental risks of state-of-the-art resource recovery and landfill facilities, the two disposal options which will be necessary even after aggressive source reduction and recycling. The study objectives are to: (1) inform decision-makers and the public on what is known and not known about the relative health and environmental risks of these two disposal options; and (2) suggest how such information can be used in formulating local and regional MSW management strategies. To compare risks, we synthesize a small but growing body of studies which provide quantitative and qualitative analyses of the nature and magnitude of various risk sources. Because so many uncertainties remain even in the most rigorously structured risk assessment, it is generally agreed that the only valid use of such assessments is to estimate relative risks. This means, for example, that absolute numbers such as ten excess cancer deaths per million population exposed from operation of a resource recovery facility or landfill should not be used as a precise predictor of health outcomes. Instead, its value lies only when 10 is compared to 5,15 or any other number derived from a risk assessment of a different facility.

Massman, J.W., et al., Development of Computer Simulations for Landfill Methane Recovery, Report No. ANL/CNSV-26, 110 pp. (December 1981).

Two- and three-dimensional finite-difference computer programs simulating methane recovery systems in landfills have been developed. These computer programs model multicomponent combined pressure and diffusional flow in porous media. Each program and the processes it models are described in this report. Examples of the capabilities of each program are also presented. The two-dimensional program was used to simulate methane recovery systems in a cylindrically shaped landfill. The effects of various pump locations, geometries, and extraction rates were determined. The three-dimensional program was used to model the Puente Hills landfill, a field test site in southern California. The biochemical and microbiological details of methane generation in landfills are also given. Effects of environmental factors, such as moisture, oxygen, temperature, and nutrients, on methane generation are discussed, and an analytical representation of the gas generation rate is developed.

Massman, J.W., and Moore, C.A., Computer Optimization of Landfill Cover Design, Report No. ANL/CNSV-TM-109, 90 pp. (December 1982).

A finite-difference computer program to aid in optimizing landfill cover design is discussed in this report. The report compares the methane yield from sand-covered and clay-covered landfills equipped with methane recovery systems. The results of this comparison indicate a clay cover can restrict air inflow into the landfill system, thus preventing oxygen poisoning of the methane-producing organisms. The practice of monitoring methane-to-air ratios in the pipelines of the recovery system in order to wam of oxygen infiltration into the fill material was shown to be ineffective in some situations. More reliable methods to forewam of oxygen poisoning are suggested.

Metropolitan Service District of Portland, Oregon, Feasibility of Methane Gas Recovery at the St. John's Landfill, Report No. DOE/RA/50367-1, 244 pp. (March 1983).

This report discusses a study to determine the feasibility of a commercial landfill-gas recovery system at the St. John's Landfill in Portland, Oregon. Included are the landfill operational history, 
descriptions and results of field testing, landfill-gas production and recovery predictions, results of the preliminary market research, cost matrixes for primary utilization modes, and conclusions and recommendations based on analysis of the data gathered.

New York State Energy Research and Development Administration, Landfill Gas to Electricity Demonstration Project, Report No. DOE/CS/20292-1, 128 pp. (October 1982).

Medium-Btu methane gas is a naturally occurring by-product of anaerobic digestion of landfilled municipal solid waste. The energy potential of landfill gas in New York State is estimated to be $61 \times 10^{12} \mathrm{Btu} / \mathrm{yr}$, or the equivalent of $10 \%$ of the natural gas used annually in the state. The 18-month landfill-gas-to-electricity demonstration project conducted at the Fresh Kills Landfill in Staten Island, New York, demonstrated that landfill gas is an acceptable fuel for producing electricity using an internalcombustion engine/generator set. Landfill gas proved to be a reliable and consistent fuel source during a six-month field test program. Engine exhaust emissions were determined to be comparable with those from natural gas, and no unusually high corrosion rates on standard pipeline material were found. This report documents the project findings.

Pacific Gas and Electric Co., Development of the Utilization of Combustible Gas Produced in Existing Sanitary Landfills: Effects of Corrosion at the Mountain View, CA, Landfill Gas Recovery Plant, Report No. DOE/CS/ 20291-3, 72 pp. (October 1982).

This report is part of a program to determine how to most efficiently utilize combustible gases from landfills. Specifically, this report presents information obtained from an investigation of corrosion of equipment at the Mountain View, California, Landfill Gas Recovery Plant. Corrosion was most severe on compressor valve seats and cages, tubes in the first and second stages of the interstage gas cooler, and first- and second-stage piping and liquid separators. Corrosion occurs because the raw landfill gas contains water, carbon dioxide, and oxygen. Some corrosion may also result from trace concentrations of organic acids present in the landfill gas. Corrosion of the third-stage compressor, cooler, and piping does not occur, because the gas is dehydrated immediately prior to the third stage. Controlling corrosion is necessary to maintain the mechanical integrity of the plant and to keep the cost of the gas competitive with that of natural gas. Attempts to reduce corrosion rates by injecting a chemical inhibitor have proven only partially successful. Recommendations for dealing with corrosion include earlier dehydration of the gas, selection of special alloys in critical locations, chemical inhibition, and regular plant inspections.

Pacific Gas and Electric Co. and Dynatech R\&D Co., Development of the Utilization of Combustible Gas Produced in Existing Sanitary Landfills: Investigation of Effects of Air Inclusion, Report No. DOE/CS/20291-4, 60 pp. (January 1983).

A combustible gas mixture composed of methane and carbon dioxide is generated in municipal solid waste landfills. A practical consequence of the collection of this fuel gas is the inclusion of some air in the collected product. This report discusses the effects of such included nitrogen and oxygen on landfill gas operations. The effects include increased collection and purification costs, reduction in the quality of the fuel gas produced, corrosion, explosion hazards, and interference with odorant systems. The scope of such effects was determined using data and experience from the Mountain View, California, landfill-gas recovery site. Useful supplemental fuel gas may be recovered despite the inclusion of air. Recommendations are given for establishing limits for nitrogen and oxygen content and minimizing the costs associated with their presence. 
Public Service Gas and Electric Co., Development of a Case Study for the Cinnaminson Landfill Methane Recovery Operation, Report No. ANL/CNSV/TM-73, 67 pp. (February 1981).

This report presents a case history of landfill gas extraction and use from project inception in 1976 to gas testing, use, and sales in 1979-81. Landfill gas that had caused migration problems at the 64-acre Cinnaminson, New Jersey, landfill was sold and piped to Hoeganaes Corp., a subsidiary of Interlake, Inc. The report summarizes initial negotiations, permits and testing of the raw gas, construction and testing of the collection system, and Phase I and II operational tests. Gas pricing and return on investment are discussed.

Science Applications, Inc., and Pacific Gas and Electric Co., Trace Chemical Characterization of Pollutants Occurring in the Production of Landfill Gas from the Shoreline Regional Park Sanitary Landfill, Mountain View, California, Report No. DOE/CS/20291-2, 126 pp. (October 1982).

This report summarizes the results of sampling and analysis of ambient and process gas streams, as well as liquid and solid samples taken at different locations from the Pacific Gas and Electric Co.'s Landfill Gas Recovery Plant in Mountain View, California. This study was to identify environmental pollutants and characterize the trace chemistry of landfill gas recovered from the Mountain View Sanitary (Class II) Landfill. Gaseous samples, liquid condensate, and other plant products were analyzed for their trace chemical constituents. The results indicate that certain organic and inorganic pollutants inherent to the landfill are emitted into the ambient environment and also become involved in the methane-recovery process. Incorporation of condensate traps, molecular sieves, and charcoal filtration was found to significantly reduce both the organic and inorganic component burdens in the product gas. The environmental significances of the landfill-gas recovery to the surrounding area and to worker safety are presented.

SCS Engineers, Inc., Feasibility Study of Landfill Gas Recovery at Seven Landfill Sites, Adams County/Commerce City, Colorado, Final Report, Report No. DOE/CS/20235-1, 104 pp. (July 1984).

This report documents the findings of a major landfill-gas-recovery study conducted in Adams County, Colorado. The study was performed during the period from Aug 1979 through Sept. 1980. The study was broad in scope, involving a technical, economic, and institutional feasibility analysis of recovering landfill-generated methane gas from seven sanitary landfills in southwestern Adams County.

SCS Engineers, Impact of the Resource Conservation and Recovery Act on Landfill Gas Utilization, Report No. ANL/CNSV-TM-117, 224 pp. (June 1983).

This report was prepared to assess the impact that the Resource Conservation and Recovery Act (RCRA) requirements for gas controls may have on implementing landfill-gas-utilization systems. Conclusions presented are based on surveys and personal interviews with solid-waste personnel and regional U.S. Environmental Protection Agency staff members. Conclusions are categorized into landfill numbers, landfill-gas migration-control systems, cost-effectiveness of hybrid systems, RCRA gas criteria impact on landfills, and present constraints on hybrid system implementation. 
SCS Engineers, Work Plan for Development of a Data Base on Potential Landfill Gas Utilization Sites in the United States, Report No. ANL/CNSV-TM-116, 44 pp. (February 1982).

This report describes a project that quantified the gas utilization potential for landfills of various types and sizes in the United States. The survey sought the following information: size, age, and type of each landfill; status of gas control and utilization projects; and location of landfill-gas problem sites. In addition, the quality of information in each state's files and the accessibility of those files were evaluated. This information is included in this report, as well as a methodology for developing a detailed data base of landfill-gas-utilization sites.

SCS Engineers, City of Industry Landfill Gas Recovery Operation, Report No. ANL/CNSV-TM-91, 42 pp. (November 1981).

This is a case study of landfill-gas recovery and use at the City of Industry, California, an industrial and commercial community east of downtown Los Angeles. Bordered by residential and commercial development, the 600-acre site is in the Little Puente Hills. A portion of the site (150 acres) was used for the disposal of solid wastes from 1951 to 1970. City of Industry developed civic, recreation, and conservation facilities throughout the site as part of an overall urban development project. The facilities include two golf courses, a golf service and conference center, 17 tennis courts, a swimming pool, a laundry facility, and an 11-story, 284-room hotel. The landfill-gas recovery system provides fuel for use in boilers to meet space heating and/or hot water demands for site development.

Surface, J.M., Peverly, J.H., Steenhuis, T.S., and Sanford, W.E., (Oak Ridge National Laboratory), Effect of Season, Substrate Composition, and Plant Growth on Landfill Leachate Treatment in a Constructed Wetland, presented at the Conference on Constructed Wetlands for Water Quality Improvement, Pensacola, Florida, 21-24 October 1991; Report No. CONF-9110402-1, Order No. DE92018250, 22 pp. (1991).

In 1989 the United States Geological Survey (USGS), in cooperation with Tompkins County, New York, Departments of Planning and Solid Waste, began a 3-year study at a municipal solid waste landfill near Ithaca, New York, to test the efficiency of leachate treatment by constructed wetlands and to examine the associated treatment processes. Specific objectives of the study were to examine: treatment efficiency as a function of substrate composition and grain size, degree of plant growth, and seasonal changes in evapotranspiration rates and microbial activity; the effects of leachate and plant growth on the hydraulic characteristics of the substrate; and the chemical, biological, and physical processes by which nutrients, metals, and organic compounds are removed from leachate as it flows through the substrate. This report addresses the first two of these objectives and briefly discusses the third. It describes the substrate plots, leachate-distribution system, sampling methods, and analytical procedures; and it presents the results in terms of percent removal rates of selected constituents between inflow- and outflow-sampling points, seasonal effects on constituent-removal rates, and the effect of substrate composition on constituent removal and plant growth.

Walsh, J., et al., Demonstration of Landfill Gas-Enhancement Techniques in Landfill Simulators, Report No. ANL/CNSV-TM-103, 114 pp. (September 1982).

Sixteen landfill test cells (lysimeters) were constructed at the U.S. Environmental Protection Agency (EPA) Center Hill Laboratory in Cincinnati, Ohio, each to hold approximately $0.80 \mathrm{~m}^{3}\left(1 \mathrm{yd}^{3}\right.$ of shredded refuse. The lysimeters were constructed in late January 1980 and were located aboveground on a concrete slab in an enclosed, temperature-controlled room. The purpose of the project was to evaluate 
environmental variables that have been proposed to enhance methane production. The four variables investigated were accelerated moisture addition, leachate recirculation, $\mathrm{pH}$ control/buffer addition, and nutrient addition.

Wilkey, M.L., et al., Methane from Landfill: Preliminary Assessment Workbook, Report No. ANL/CNSV-31, 34 pp. (June 1982).

This workbook provides basic information for assessing the potential of a landfill-gas-recovery project at a given site. Commercialization technology is currently available for the various developmental options described. The balance of the workbook provides basic technical information about the production, recovery, and utilization of landfill gas-including production and recovery rates and basic economic information about various modes of operation. Worksheets are appended to enable a reader to make a cursory assessment of landfill-gas utilization at a particular site.

Young, S.C. and Clapp, R.B., (Oak Ridge National Laboratory) The Importance of Climatological Variability and the Rate at which Waste is Added to Modeling Water Budget of Landfills, presented at the Fourth International Conference on Solving Ground Water Problems with Models, Indianapolis, Indiana, 7 February 1989, Report No. CONF-890262-2, Order No. DE89008917, p. 20 (1989).

A transient one-dimensional wetting front model was developed to predict water budgets for landfills. The model simulates the moisture profile by a series of blocks, each of which has a uniform soil moisture content. The model can simulate the continual stacking of waste by adding blocks, which represent new waste layers. The model can be programmed to build up a landfill at a given rate and to cap the landfill with a liner once a specific height has been reached. The wetting front model has been compared with models that solve the Richards Equation directly. In past studies the results between the two types of models compared well, but the wetting front model solved problems with a fraction of the computer time. Because of its efficient algorithms, the wetting front model is well suited for Monte Carlo simulation of different meteorological conditions in order to produce probability density functions for runoff, evapotranspiration, and leachate generation. In order to simulate different meteorological conditions, the TVA developed RGEN, which generates hourly rainfall, and EGEN which generates daily potential evaporation rates. The results of the numerous runs with the wetting front model were used to determine the potential importance of climatological variability and the effects of the rate at which new waste is added on the water budget of dry-stack fly ash landfills.

Zimmerman, R.E., et al., Landfill Gas Recovery: A Technology Status Report, Report No. ANL/CNSV-TM-121, 98 pp. (August 1983).

This is one of nine assessment reports prepared for Argonne National Laboratory to document the current state of development of energy from municipal-waste disposal/recovery technologies. This report focuses on the landfill-gas-recovery industry and technologies and the 14 commercial landfill-gas-recovery facilities in the United States. The report discusses various techniques that can be used to enhance gas production and yield, collection systems and processing issues, economic aspects, and research and development under way and needed. 


\section{Recycling (Materials Separation)}

Alexandratos, S.D., Trochimczuk, A., Crick, D.W., Horwitz, E.P., Gatrone, R.C., and Chiarizia, R., (Argonne National Laboratory) "Synthesis of a Novel Diphosphonate-Based Ion Exchange Resin with Enhanced Metal Ion Selectivity," Emerging Separation Technologies for Metals and Fuels, Lakshmanan, V.I., Bautista, R.G., and Somasundaran, P., eds. Presented at the Symposium on Emerging Separation Technologies for Metals and Fuels, Palm Coast, Florida, 13-18 March 1993, Warrendale, PA: Minerals, Metals and Materials Society, Report No. CONF-9303107, pp. 111-117 (1993).

A novel ion exchange resin has been prepared. Diphosphonic acid ligands are responsible for the observed metal ion specificity. The resin displays both ionic selectivity and rapid rates of complexation. Sulfonic acid ligands within the polymer matrix enhance metal ion accessibility into the polymer network. Thus the resin, tradenamed Diphonix, complexes $96.5 \%$ of the Eu(III) present in a solution of $1 \mathrm{~N}$ $\mathrm{HNO}_{3} / 0.4 \mathrm{~N} \mathrm{NaNO}_{3}$ after a 30 minute contact time. Under identical conditions, a commercially available sulfonic acid resin complexes $14.3 \% \mathrm{Eu}(\mathrm{III})$. In another example, Diphonix has a distribution coefficient for $\mathrm{Zn}$ (II) of 130,000 while a sulfonic acid resin has a value of 0.67 and an iminodiacetic acid resin has a value of 17 .

Allen, D.I. and Walton, R.M., (Oak Ridge National Laboratory) Plant Service Award 1992: Oak Ridge Y-12 Recycling Program, Report No. Y/IB-44, Order No. DE93004759, 7 pp.(28 April 1992).

The solid waste recycling program at the Y-12 plant is described. The efforts there to minimize the filling of sanitary landfills are exemplary. Aluminium cans and paper are recycled. Cost recovery information is presented.

Bagalman, P.M., et al., Final Operation and Test Period: Aluminum and Glass Recovery Systems at Recovery 1, Report No. DOE/NBB-0042, 188 pp. (September 1983).

This report documents the final operations and tests of the Recovery Module at Recovery 1, the resource-recovery facility in New Orleans, Louisiana, from May 18 through August 14, 1981. The tests were to document the functioning of the current aluminum and glass recovery systems at Recovery 1 and to obtain data that would provide information needed by the designers of recovery systems. A high priority was assigned to this latter purpose, which resulted in a test plan that would provide specific inputs to the design process. Although this report documents the operations and tests from May 18 through August 14, 1981, data and experiences from previous periods are cited when specifically apropos of future designs. The process flow, mass balance, and product quality for both aluminum and glass recovery systems are described. The process equipment modifications and performances are also described, as well as the tests that were conducted to determine performances.

Beauchamp, B., Establishing a Comprehensive Recycling Process at $K C D$, presented at the Ninth Waste Minimization and Pollution Prevention Conference, San Francisco, California, 13-15 April 1993, Report No. KCP-613-5193, Order No. DE93012885, 19 pp. (April 1993).

An effort is being undertaken at the Kansas City Division to enhance its recycling program by establishing a comprehensive recycling process. The objective of this recycling process is to optimize the use of our resources of people, equipment, time, and money as we search for ways to minimize the amount of waste generated and disposed of at our facility. The comprehensive recycling process that is being developed consists of a checklist that will help the user identify all the steps needed to take a 
recycling opportunity from initial concept to completed program in an effective and efficient manner. The purpose of this presentation is to address the efforts that are made to achieve this objective.

Bemheisel, J.F. and Hickert, M.T., Status of Aluminum and Glass Recovery by Mechanical Separation, Report No. DOE/NBB-0041, 164 pp. (September 1983).

This report presents the status of resource-recovery plants that have implemented systems for removal and cleanup of aluminum, glass, or both, as of the summer of 1981. Nine facilities in the United States and one in England are included.

Burke-Davoud and Associates, Cannon Shredding of Municipal Solid Waste for the Preparation of Biological Feedstock, Final Report, Report No. DOE/CE/20088-1, 44 pp. (April 1981).

This study explores the use of explosive decompression to reduce the size of materials found in municipal solid waste (MSW) and presents preliminary data on the handling and wet separation of exposed material. Steam is emphasized as the pressure source. Municipal refuse is placed in an 8-ft-long steel cannon with an inner diameter of 10.75 in. The cannon is then sealed and pressurized, and the test material is expelled through a constrictive orifice, resulting in explosive decompression. Flash evaporation of pressurized saturated water, expansion of steam, and strong turbulence at the cannon muzzle reduce the size of the waste. Hydraulic processing is shown to be an effective technique for separating heavy and light fractions of MSW.

Cal Recovery Systems, Composition and Properties of Municipal Solid Waste and Its Components, Report No. DOE/SF/11724-Tl, 105 pp. (May 1984).

This report includes data obtained through waste composition surveys and laboratory analyses. It provides information on generation rates and waste-stream composition and properties. In addition to the results obtained in waste composition surveys conducted in cities in various parts of the United States, the report includes a listing of the mechanical, thermal, and chemical properties of the waste. Among the properties reported are bulk densities, ash contents, ash fusion temperatures, proximate and ultimate analyses, and heating values.

Cal Recovery Systems, Trommel Screen Research and Development for Applications in Resource Recovery, Report No. DOE/CS/20490-1, 275 pp. (February 1982).

This report presents the results of research and development to characterize the operation and performance of trommel screens used in the processing of municipal solid waste (MSW). The primary objective was the definition and quantification of the parameters that govern and describe the trommeling process as applied to the recovery of a high-quality fuel fraction from solid waste. The research addressed the two solid-waste materials commonly considered for usage as fuel (and hence for trommel screening), raw (unprocessed) MSW and the light fraction separated from shredded MSW through air classification. Methodology was developed for defining and characterizing the operation and performance of trommel screens used in the processing. The report serves as a reference regarding the aspects of management and recovery that require the design and utilization of trommel screens. 
Cohen, A.S.; Abert, J., Evaluation of the Integrated Municipal Solid Waste Management Systems Extant in Japan, with Special Emphasis on the Effectiveness of Recycling Activities, Report No. DOE/ FTR-93011812, Order No. DE93011812, 14 pp. (18 November 1992).

Meetings were held with national government officials to discuss the legislative and regulatory structure governing municipal solid waste management in Japan. Additional meetings were held with local officials to learn how these policies are actually implemented. Tours of waste-to-energy, materials-recovery, and materials-processing facilities provided added insights into the actual implementation activities. Finally, meetings were held with officials from various associations and consultants to assess the true level and types of recycling occurring in Japan. Reports and data were obtained that will support the findings and conclusions that will be documented in the final report being prepared by CSI on solid waste management practices in Japan.

Curlee, T.R., (Oak Ridge National Laboratory) Targets of Opportunities for Plastics Recycling and Source Reduction, presented at the Recycling-Plas V Conference, Washington, D.C., 23-24 May 1990, Report No. CONF-9005169-1, Order No. DE90010716, 25 pp. (1990).

This paper summarizes the results of two recent studies to identify and assess targets of opportunity for additional recycling and source reduction of plastic wastes. The targets of opportunity are discussed in terms of the quantities of plastics wastes that might be affected, the relevant supply-side and demand-side constraints that must be overcome before these targets can be met, and the degree to which meeting these targets might be facilitated by government-sponsored incentive programs or other regulatory measures. Several hypothetical scenarios are developed that depict various supply-side and demand-side conditions. In some cases, the supply-side and demand-side assumptions are consistent with current technical, economic, institutional, and regulatory conditions. In other cases, particularly with respect to supply-side constraints, the assumptions represent significant shifts in the ways plastics are collected and processed in the United States. The quantities and types of plastics that could be recycled or source reduced, given the hypothetical conditions, are estimated.

Data Summary of Municipal Solid Waste Management Alternatives, (National Renewable Energy Laboratory), Report No. NREL/TP-431-4988G, Order No. DE93008310, 66 pp. (October 1992).

The enthusiasm for and commitment to recycling of municipal solid waste (MSW) is based on several intuitive benefits: conservation of landfill capacity; conservation of non-renewable natural resources and energy sources; minimization of the perceived potential environmental impacts of MSW combustion and landfilling; minimization of disposal costs, both directly and through material resale credits. In this discussion, recycling refers to materials recovered from the waste stream. It excludes scrap materials that are recovered and reused during industrial manufacturing processes and prompt industrial scrap. Materials recycling is an integral part of several solid waste management options. For example, in the preparation of refuse-derived fuel (RDF), ferrous metals are typically removed from the waste stream both before and after shredding. Similarly, composting facilities, often include processes for recovering inert recyclable materials such as ferrous and nonferrous metals, glass, plastics, and paper. While these two technologies have as their primary objectives the production of RDF and compost, respectively, the demonstrated recovery of recyclables emphasizes the inherent compatibility of recycling with these MSW management strategies. This appendix discusses several technology options with regard to separating recyclables at the source of generation, the methods available for collecting and transporting these materials to a materials recovery facility (MRF), the market requirements for post-consumer recycled materials, and the process unit operations. Mixed-waste MRFs associated with mass bum plants are also presented. 
Dudek, F.J., Daniels, E.J., and Morgan, W.A., (Argonne National Laboratory) Recycling Galvanized Steel: Operating Experience and Benefits, presented at Zinc 93, Hobart, Australia, 10-13 October 1993, Report No. ANL/ES/CP-80360, CONF-9310158--1, Order No. DE93018580, 28 pp. (1993).

In response to the increase in consumption of galvanized steel for automobiles in the last decade and the problems associated with remelting larger quantities of galvanized steel scrap, a process is being developed to separate and recover the steel and zinc from galvanized ferrous scrap. The zinc is dissolved from the scrap in hot caustic using anodic assistance and is recovered electrolytically as dendritic powder. The dezinced ferrous scrap is rinsed and used directly. The process is effective for zinc, lead, and aluminum removal on loose and baled scrap and on all types of galvanized steel. The process has been pilot tested for batch treatment of 900 tonnes of mostly baled scrap. A pilot plant to continuously treat loose scrap, with a design capacity of 48,000 tonnes annually, has been in operation in East Chicago, Indiana, since early in 1993. The first $450 \mathrm{t}$ of scrap degalvanized in the pilot plant have residual zinc below $0.01 \%$ and sodium dragout below $0.01 \%$. Use of degalvanized steel scrap decreases raw materials, environmental compliance, and opportunity costs to steel- and iron-makers. Availability of clean degalvanized scrap may enable integrated steel producers to recycle furnace dusts to the sinter plant and EAF shops to produce flat products without use of high quality scrap alternatives such as DRI, pig iron, or iron carbide. Recycling the components of galvanized steel scrap saves primary energy, decreases zinc imports, and adds value to the scrap. The quantities of zinc available by the year 2000 from prompt and obsolete automotive scrap win approach $25 \%$ of zinc consumed in the major automotive production centers of the world. Zinc recycling from galvanized steel scrap, either before or after scrap melting, will have to be implemented.

Gavette, K.B., The Impact of Source Separation on Municipal Waste-to-Energy Project Feasibility, Report No. DOE/IR/05106-T88, Order No. DE89013853, 70 pp. (1989).

The report is organized to present the methodology, findings, and method of analysis in determining the impact of reducing the waste stream through recycling on a waste-to-energy plant. The report is organized in the following way: Chapter 2 presents an overview of the problem, the purpose of the study, the objectives, and an introduction to some waste-to-energy technologies; Chapter 3 describes the development of the sampling methodology; Chapter 4 discusses the findings of the samples as related to generation rates, composition, moisture content, and Btu content; Chapter 5 describes how the findings of the survey sample may be used to determine the effect on the energy output of a waste-to-energy plant when various amounts of recyclable goods are removed; Chapter 6 discusses the barriers to implementing a recycling program and task force recommendations regarding implementation of such a program; and Chapter 7 provides a summary of the report and its uses.

Greene, W.T., Wood Ash Disposal and Recycling Sourcebook, Report No. DOE/OR/21389-13, Order No. DE89007194, 125 pp. (25 April 1988).

This report presents information on thirteen different methods of using or disposing of wood ash in Section III. Discussion concentrates on agricultural landspreading and landfilling since these two methods account for the disposition of about $95 \%$ of the wood ash produced at present in the Northeast. The thirteen disposal options include spreading on agricultural lands, landfilling, as a sewage sludge composting agent, spreading on forest lands, a fertilizer additive, pretreating landfill leachate, in cement production, as a binding agent in charcoal production, as a hazardous waste absorbing agent, as a hazardous waste solidification agent, in roadbase construction, as a waste water treatment agent, and as an agent in treating potato processing waste. Landfilling of wood ash at a "secure" landfill, i.e., one with a liner to allow recovery and treatment of leachate, costs about $\$ 40$ to $\$ 45$ per ton for tipping fees. This 
is the cost for using the landfill and can vary widely. The quoted range is based on 1987 rates in Maine and New Hampshire. In addition, there are transportation costs that typically run about $\$ 1.50$ per mile for a 10- or 12-ton truck, or about $\$ 0.15$ per ton per mile. Thus a facility producing 5000 tons per year of ash that would have to truck the ash 40 miles to the nearest landfill would have tipping fees of $\$ 200,000$ to $\$ 225,000$ per year and transportation costs of $\$ 30,000$ per year. Regulatory requirements placed on landfills have increased dramatically over the last decade. This is reflected in substantially increased tipping fees.

Harper, T.J., Recycling and Surplus Chemical Programs, presented at the Ninth Waste Minimization and Pollution Prevention Conference, San Francisco, California, 13-15 April 1993, Report No(s). WHC-SA-1904 and CONF-930483--11, Order No. DE93016477, 8 pp. (May 1993).

In 1988, 45 years of defense production came to a close at the US Department of Energy Hanford Site. The mission of the Hanford Site was formally changed to environmental restoration and remediation. Westinghouse Hanford Company is the management and operations contractor leading the cleanup. Within the framework of future Site cleanup, Hanford recycling and surplus chemical programs are making a viable contribution today to waste minimization, diversion of materials from the waste stream, and setting a standard for future operations. This paper focuses on two successful efforts: paper recycling and surplus chemical sales.

Jody, B.J., Daniels, E.J., Bonsignore, P.V., and Brockmeier, N.F., (Argonne National Laboratory) $A$ Process to Recover Plastics from Obsolete Automobiles by Using Solvents at Ambient Pressure, presented at the 206th American Chemical Society (ACS) National Meeting, Chicago, Ilinois, 22-27 August 1993, Report No(s). ANL/ES/CP-79996 and CONF-930802--10, Order No. DE93019513 6 pp. (1993).

Recycling of the metal content of obsolete vehicles has been actively pursued since the 1950s; today, obsolete automobiles are the single largest source of scrap iron. They contribute more than 25\% of the 36 metric tonnes ( 40 million short tons) of ferrous scrap recovered annually by the secondary metals industry and used in the production of finished steel products. They also contribute more than one million metric tonnes (1.1 million short tons) of nonferrous metallic scrap a year for recycling. For each ton of metals recovered, about $500 \mathrm{lb}$ of nonmetallic residue or waste is co-produced. Auto shredder residue (ASR) is a very heterogeneous mixture of solids and liquids. Table I lists most of the materials that are commonly present in the ASR are listed. We have developed and tested in the laboratory a three-step process to separate thermoplastics and other potentially recyclable products from ASR. The process involves a drying step followed by a mechanical separation step to concentrate the thermoplastics by separating the polyurethane foam and the fines, which are mostly metal oxides and other inert materials that are smaller than $0.62 \mathrm{~cm}(0.25 \mathrm{in}$.) in size. The concentrated plastics stream is then treated with organic solvents at anbient pressure and elevated temperatures to dissolve the desired plastics. The salient features of the process are described.

Kawatra, S.K., and Eisele, T.C. Recovery and Utilization of Gypsum and Limestone from Scrubber Sludge, Report No. DOE/PC/92521-T51, Order No. DE93019801, 7 pp. (1993).

Wet flue-gas desulfurization units in coal-fired power plants produce a large amount of sludge that must be disposed of. The sludge is currently landfilled in most cases. Increasing landfill costs are gradually forcing utilities to find other alternatives. In principle, this sludge can be used to make gypsum $\left(\mathrm{CaSO}_{4}-2 \mathrm{H}_{2} \mathrm{O}\right.$ for products such as plaster of Paris and wallboard, but only if impurities such as unreacted limestone and soluble salts are removed, and the calcium sulfite $\left(\mathrm{CaSO}_{3}\right.$ is oxidized to calcium sulfate 
$\left(\mathrm{CaSO}_{4}\right.$. This project is investigating methods for removing the impurities from the sludge so that high-quality, salable gypsum products can be made. Work done in the previous quarter concentrated on developing a low-cost froth flotation process that could remove limestone, unburned carbon, and related contaminants from the sludge while recovering the bulk of the calcium sulfite and gypsum. In the current quarter, experiments to remove impurities from the sludge using a water-only cyclone were conducted. The cyclone has been found to be effective for removing the coarser limestone impurities, as well as removing contaminants such as fine gravel and grinding-ball chips. These results show that the cyclone will be very complementary with froth flotation, which mainly removes the very fine impurities.

Littlejohn, D., and Chang, S.G., (Lawrence Berkeley Laboratory) Oxidative Destruction of Nitrogen Sulfonates in Aqueous Solutions, presented at the 204th American Chemical Society National Meeting, Washington, D.C., 23-28 August 1992, Washington, DC: American Chemical Society, Report No. CONF-920815, p. 467, (1992).

Aqueous solutions are often used to remove sulfur dioxide and nitrogen oxides from exhaust gases, such as power plant flue gases. The absorbed gases form sulfur oxyanions and nitrogen oxyanions, which can react to form nitrogen sulfonates. The nitrogen sulfonates, such as hydroxyimidodisulfate, are generally quite soluble and can be difficult to remove from solution. Some of the nitrogen sulfonates can undergo reactions to product nitrous oxide, which is undesirable. With increasingly stringent wastewater regulations, disposal of solutions containing nitrogen sulfonates can be restricted. The authors have investigated destroying nitrogen sulfonates in solution using ozone, nitrogen dioxide, and phosphorus as oxidants. The rates of destruction of the nitrogen sulfonates and the oxidation products are discussed. A conceptual system for elimination of these compounds is described.

Mayberry, J.L., Municipal Waste Processing Apparatus, Patent No.: US 4867866, Patent Assignee(s): U.S. Department of Energy, Washington, D.C., Priority No.: US 7180879 A, Patent Date Filed: 13 April 1988, 6 pp. (19 September 1989).

This patent describes municipal waste materials processed by crushing the materials so that pieces of noncombustible material are smaller than a selected size and pieces of combustible material are larger than the selected size. The crushed materials are placed on a vibrating mesh screen conveyor belt having openings that pass the smaller, noncombustible pieces of material, but do not pass the larger, combustible pieces of material. Consecutive conveyors may be connected by an intermediate vibratory plate. An air knife can be used to further separate materials based on weight.

Mayberry, J.L., Municipal Waste Processing Apparatus, Patent No.: US 4778116 A, Patent Assignee(s): U. S. Deparment of Energy, Washington, D.C., Priority No.: US 7-003523 A, Patent Date Filed: 15 January 1987, vp. (18 October 1988).

This patent describes an apparatus for processing municipal waste, the waste including ferrous materials, nonferrous noncombustible materials and combustible materials. It comprises the means for crushing most of the nonferrous noncombustible waste materials into noncombustible pieces that are smaller than a first size in which no dimension is greater than a selected length, and crushing most of the combustible materials into combustible pieces that are larger than the first size in at least some dimensions; the means for removing substantially all of the noncombustible pieces from the waste material; the means for removing the noncombustible pieces including a mesh screen conveyor; and the means for vibrating the conveyor. 
Mayberry, J.L., (Idaho National Engineering Laboratory) "Advanced Testing of Pulsed Air Classifier and Evaluation of Shear Shredders," Thermochemical Conversion Program Annual Meeting: Proceedings presented at the Thermochemical Conversion Program Review Meeting, Golden, Colorado, 21 June 1988, Report Nos. SERI/CP-231-3355, CONF-8806176, Order No. DE88001187, pp. 129-140 (July 1988).

Idaho National Engineering Laboratory is currently conducting research in the mechanical processing of Municipal Solid Waste. The research areas for FY 1987 and FY 1988 includes advanced testing of the pulsed air classifier and the evaluation of shear shredders. The research effort on the pulsed air classifier involves testing an active pulsed air classifier and a passive pulsed air classifier at Duke University. The variables tested under the current funding includes determining the effects of feed rate and height of the classifier on the efficiency of operation. A prototype pulsed air classifier is also being designed and built. The research effort on the shear shredders involves testing shear shredders in operation for various design configuration and operational conditions in order to establish a database on shear shredders.

Mayberry, J.L., "Evaluation of Disc Screens," Biofuels and Municipal Waste Technology Research Program Summary: FY 1986, Report No. DOE/CH/10093-6, Order No. DE87001140, p. 100 (July 1987).

The proposed disc screen test evaluation program will determine the performance characteristics of the disc screen, particularly the efficiency of separation in refuse-derived fuel production, and then compare them to those of the trommel. The first task will be to conduct a meeting of personnel from EG and G Idaho and Cal Recovery Systems in order to coordinate the research efforts of the two companies, to develop a test plan for both research efforts to use, and to develop a list of manufacturers and facilities with disc screens. Next, a test evaluation program will be conducted in facilities for which there is funding and that give the widest range of independent variables. After the testing program is completed, the data will be analyzed and summarized into a database. Then the data from disc screens will be compared with data from trommels.

Mayberry, J.L., "Proof of Concept Vibrating Mesh Screen," Biofuels and Municipal Waste Technology Research Program Summary: FY 1986, Report No. DOE/CH/10093-6, Order No. DE87001140, p. 99 (July 1987).

EG and G, over the past year, has been working with manufacturers of agricultural conveyors to adapt their equipment to refuse-derived fuel separation. The task objective is to build and test a prototype one-half width vibrating mesh screen conveyor (VMSC) to determine the operation efficiency. The first task will be to determine the feasibility (technical and economical) of extending the VMSC from $10 \mathrm{ft}$ long to $20 \mathrm{ft}$ long and the ability to change elevation, to establish the particle size distribution for a single shred from a shear shredder and horizontal hammermill, and to develop a bid package with specifications and concept drawings. After the feasibility task is complete, a subcontract will be bid and awarded for the fabrication of the VMSC and the field test of the prototype unit. Following the awarding of the contract(s), a test of the VMSC under a continuous load of coarse RDF under various operating conditions will be run.

Mayberry, J., Kaiser, L., Goldsberry, J.A., and Steverson, E.M., Municipal Solid Waste Small-Scale Mechanical Systems Report, Report No. EGG-PE-6924, 229 pp. (June 1985).

The economic feasibility of operating small-scale, dry, municipal solid waste (MSW) plants in various configurations was studied using the economics computer-software program. Several 
configurations of equipment currently used in MSW processing were determined to be cost-effective, with the intent of possible enhancement of the cost-effectiveness of the identified configurations. Also studied were equipment items currently used in industries other than MSW processing and new equipment concepts.

Muller, D., Recycling and Composting Demonstration Projects for the Memphis Region, Report No. DOE/CE/27504-10, Order No. DE93005617, 214 pp. (May 1992).

This report documents the development and implementation of the project entitled "Recycling and Composting Demonstration Projects for the Memphis Region." The project was funded by the Energy Task Force of the Urban Consortium for Technology Initiatives. This Project was implemented by the staff of the Special Programs Section of the Memphis and Shelby County Division of Planning and Development. The project began November 1, 1990, and was completed December 31, 1991. The purpose of the project was to evaluate the feasibility of a variety of solid waste disposal alternatives.

Multifamily Recycling Programs: Program Data and Implementation Guidelines, Report No. DOE/CE/27504-3, Order No. DE93005609, 130 pp. (September 1992.

Portland, Oregon, and San Diego, California, worked independently, but on similar tracks to implement and study multi-family recycling systems. This report examines the implementation and lessons learned from these programs. Each city adapted the program to fit its local environment. San Diego focused its outreach on garbage haulers as well as property managers. San Diego worked to promote the participation of the private sector in multifamily recycling and to encourage haulers to duplicate the program with their other multifamily customers. Portland focused its outreach on the property owners and managers because a new Oregon law requires that landlords provide recycling service and education to all their tenants. The end product in each city was onsite recycling systems and tenant education serving nearly 9,000 multi-family units combined. Newspapers comprised the largest material by volume and weight collected in each city and accounted for the majority of the estimated energy savings in each program. Although recycling is often thought of as being good from an environmental and resource perspective, results from the energy savings analyses show that there is also a considerable energy savings potential from multifamily recycling.

National Center for Resource Recovery, Inc., Elements of Trommel Dynamics: Determination of the Dynamic Bulk Density—A Working Paper, Report No. DOE/CS/24315-16, 18 pp. (November 1982).

In general terms, the main problem in trommel dynamics is to relate the size and density properties of the feedstock, the geometric and dynamic parameters of the device (rotary screen), and the elementary and cumulative probabilities of screening, so as to allow engineering design and/or predictions of operating performances. This working paper proposes a procedure for the determination of the bulk density of the burden in a trommel, under actual dynamical conditions of use.

National Center for Resource Recovery, Inc., Elements of Trommel Dynamics: Drag Free Case-A Working Paper, Report No. DOE/CS/24315-12, 38 pp. (November 1982).

This working paper addresses the problem of the dynamics of an isolated particle in a trommel under no drag and with an infinitely rough wall. 
National Center for Resource Recovery, Inc., Elements of Trommel Dynamics: The Effect of Drag on Particle Motion-A Working Paper, Report No. DOE/CS/ 24315-17, 62 pp. (November 1982).

This short working paper presents an analytical evaluation of aerodynamic effects on the dynamics of the single particle (either a flake or a sphere) in a lightly loaded trommel.

National Center for Resource Recovery, Inc., Elements of Trommel Dynamics: Notes on Elementary Screening Probability-A Working Paper, Report No. DOE/CS/24315-13, 24 pp. (November 1982).

The objective of this working paper is to document the approach taken in computing a predicted probability of passage for a single particle impinging on a screen (dilute case). It also discusses how the approach was utilized in sizing particles (model feedstocks, tracers in full scale tests, etc.) so that they would have a given probability of passage upon one single impingement; this approach was evaluated by comparing the predicted probability with experimental values determined during screening efficiency tests.

National Center for Resource Recovery, Inc., Interim Report: Prototype Tramp Metal Separator-A Summary of Test Results, Report No. DOE/CS/24317-2, 50 pp. (November 1982).

In March 1981, design and set-up of a prototype tramp metal separator (PTMS) was begun to support the theoretical work previously done on materials separation in a transverse jet. The tests were performed at the National Center for Resource Recovery Laboratory in Marlboro, Maryland. Testing continued through June 1981. The test program can be divided into three stages. First, typical MSW feedstocks that had undergone size reduction (flail or shred) and trommeling were analyzed to determine physical characteristics and to obtain samples of tramp metal. Second, tests were performed on individual particles to determine relevant aerodynamic properties. While testing in these two areas was conducted, the PTMS was installed. The PTMS was used during the third stage to measure the deflections of selected particles and feedstocks dropped through the horizontal airstream. The PTMS was then modified to allow semicontinuous tests, but suspension of work on the contract (July 1981) occurred before tests of this nature could be performed.

National Center for Resource Recovery, Inc., An Interim Report: Some Design Considerations in Particles Separation by a Transverse Jet, Report No. DOE/CS/24317-1, 66 pp. (November 1982).

This report discusses relationships between geometric and dynamic parameters in the aerodynamic separation of municipal solid waste particles by a transverse horizontal jet (or a combination of such jets). It also discusses quantitative predictions regarding the feasibility and effectiveness of binary separation (i.e., for one class of heavies and one class of lights) and the choice of physical variables, such as dimensions of the jets, material drop height, jet velocity, etc.

National Center for Resource Recovery, Inc., New Orleans Full-Scale Trommel Evaluation Interim Test Report, Report No. DOE/CS/24315-14, 158 pp. (November 1982).

This report presents the data from five tests of a full-scale trommel processing unsegregated municipal solid waste at throughputs ranging from $58 \%$ to $175 \%$ of design capacity, or 32 to $98 \mathrm{Mg} / \mathrm{h}$ (36 to 109 tons/h). The tests were conducted between December 1980 and March 1981 at the Recovery 1 solid-waste processing facility in New Orleans. Included in the report are a description of the equipment, discussion of the test procedures, and primary summaries and analysis of data on the trommel and mass 
and volumetric flow rates, separation efficiency, and size reduction (on both weight and number count basis). Heat content and ash analysis of the trommel oversize, recovery results on surrogate aluminum cans and flakes, and residence-time measurement results are also reported.

National Center for Resource Recovery, Inc., Pilot-Scale Trommel: Experimental Test Descriptions and Data-A Working Paper, Report No. DOE/CS/24315-15, 54 pp. (November 1982).

This working paper describes the development of a model for trommel performance. lt also supplements data collected in full-scale testing at Recovery 1 in New Orleans. The pilot trommel was $3.2 \mathrm{~m}-(10.5 \mathrm{ft}-)$ long and had an inside diameter of $0.9 \mathrm{~m}(3.0 \mathrm{ft})$. The drum was driven by a variablespeed motor/reducer and trunion wheel/rim drive. For all tests, it was inclined down from feed to discharge at 4-1/2 . All the experiments on the pilot trommel were conducted using prepared feedstocks of nearly identical size flakes and wooden blocks.

National Center for Resource Recovery, Inc., Research and Development on Rotary Screens: Concept of a Model to Evaluate Cost-Effectiveness of Changes in Trommel Configuration-Activities Report, Report No. DOE/CS/24315-18, 22 pp. (November 1982).

This activity report outlines work done toward developing a computerized economic model of a trommel. Although no computer programs for the model were developed, some computer analyses of trommel reliability to be used by the proposed model were made and are appended to the report.

National Center for Resource Recovery, Inc., Increasing the Energy Yield from Resource Recovery by Use of the Organic Materials in the Air Classifier Heavy Fraction, Report No. DOE/CS/20167-9, 95 pp. (February 1982).

In many resource-recovery plants, a basic unit operation is the separation, based on air classification, of a light stream and a heavy fraction. This study investigates the properties and possible use of this heavy fraction as a combustible and as a source of aluminum. On the basis of representative heavy fraction samples from six recovery plants in the United States, detailed analyses were performed of the combustible fraction, particle size distribution, composition, and other physical or chemical characteristics. Methods of processing and costs were considered.

Ridings, R.L. and Brooks, C., (Argonne National Laboratory) "Low-Technology Resource Recovery: Source Separation," Energy from Municipal Wastes: Opportunities for the Southwest, presented at the Workshop on Energy from Municipal Waste: Opportunities for the Southwest, Austin, Texas, 23 June 1986, Report Nos. ANL/CNSV-TM-173, CONF-8606334-, Order No. DE87014258, pp. 3-5 (May 1987).

The city of Austin, Texas spends more than 14 million dollars a year on solid waste services that include refuse collection and disposal, curbside recycling, dead animal service, street cleaning and litter control. The city has implemented a resource recovery plan to complement its solid waste disposal efforts. The resource recovery plan was designed to burn 600 tons of refuse producing 20 megawatts of electricity. 
Rogers, R.D., Mcllwain, M.E., Losinski, S.J., and Taylor, D.D., Research and Engineering Assessment of Biological Solubilization of Phosphate, Report No. EGG-2698, Order No. DE93010368, 46 pp. (March 1993).

This research and engineering assessment examined a microbial phosphate solubilization process as a method of recovering phosphate from phosphorus containing ore compared to the existing wet acid and electric arc methods. A total of 860 microbial isolates, collected from a range of natural environments were tested for their ability to solubilize phosphate from rock phosphate. A bacterium (Pseudomonas cepacia) was selected for extensive characterization and evaluation of the mechanism of phosphate solubilization and of process engineering parameters necessary to recover phosphate from rock phosphate. These studies found that concentration of hydrogen ion and production of organic acids arising from oxidation of the carbon source facilitated microbial solubilization of both pure chemical insoluble phosphate compounds and phosphate rock. Genetic studies found that phosphate solubilization was linked to an enzyme system (glucose dehydrogenase). Process-related studies found that a critical solids density of $1 \%$ by weight (ore to liquid) was necessary for optimal solubilization. An engineering analysis evaluated the cost and energy requirements for a 2 million ton-per-year-sized plant, whose size was selected to be comparable to existing wet acid plants.

Sham Recycling. Hearing before the Subcommittee on Hazardous Wastes and Toxic Substances of the Committee on Environment and Public Works, United States Senate, One Hundredth Congress, Second Session, April 14, 1988, Original Series S. Hrg. 100-663, Washington, D.C., Government Printing Office, 222 pp. (1988).

Government and state officials and representatives from the Environmental Protection Agency and industry were among those testifying at a hearing on the problems involved in the concept of recycling. To encourage recycling, Congress exempted operations from many of the pollution control laws. However, there are many companies that are using the recycling exemption as an apparent attempt to avoid hazardous waste treatment regulations. Companies engaged in sham recycling are treating hazardous wastes apparently with only minimal controls of air emissions and residual wastes.

Shepherd, P.B., Powers, T.J., Hardy, J., Maloof, R., Patenaude, C., and Zilfi, J., Energy Conservation Through Recycling of Factory Asphalt Roofing Waste, Report No. DOE/ID/12795-1, Order No. DE90006304, 273 pp. (31 December 1989).

Prior U. S. Department of Energy laboratory research showed that it was possible to recover the energy resource represented in factory shingle waste. This waste could be processed and recycled into the asphalt composition used to make new shingles. This bench-scale research concluded that factory experiments were all that were needed to provide a basis for commercial implementation. The project reported here completed that full scale research. Factory fiberglass shingle waste was processed to a form suitable for recycling. The processed waste was then mixed into the asphalt used to make new shingles. Process parameters and shingle quality were measured to provide a basis for commercial implementation.

SPM Group, Inc., Refuse-Derived-Fuel Pre-Separator Process Technology Evaluation, Report No. DOE/CS/20523-1, 106 pp. (March 1982).

This work was to build and test a refuse separator that would produce a high-quality refuse-derived fuel (RDF) by separating materials prior to grinding. This report contains the results of testing and substantiates the theory that the concept is possible. The concept was to agitate the municipal solid waste 
(MSW) stream so effectively by mechanical means that a floating bed was created. This would enable rapid separation of glass, beverage cans, yard waste, abrasives, and moisture and dirt to the potential RDF. The work showed that by varying the design configuration it was possible to remove specific resources (glass, aluminum, etc.) from the separator at desired locations. Test results indicated that the quality of RDF remained consistent, in spite of seasonal changes in the MSW input.

Technical Information Project, Inc., Direct Recycling of Municipal Ferrous Wastes for Local Foundry Application, Final Technical Report, Report No. DOE/R3/06044-Tl, 8 pp. (January 1981).

This project investigated the concept of direct recycling as an appropriate technology or approach to improve resource recovery from wastes in Region III. Direct recycling is the process of bringing waste materials directly to reprocessing facilities, with few or no intermediate processing steps. Municipal ferrous waste was the waste material involved. The Region III states were surveyed for municipal recycling systems incorporating municipal ferrous waste separation and grey-iron foundries where the material could be utilized. Contacts and visits were made with foundry and recycling-group personnel. A handbook, Tin Cans and Trash Recovery, was prepared for distribution to interested persons in Region III. This handbook delineates the direct recycling method for municipal ferrous waste, describes the recycling potential for areas of different populations in the region, and lists foundries, recycling groups, and resource persons for the region.

Torma, A.E. and Raghavan, D., Biodesulfurization of Rubber Materials, presented at the American Society of Mechanical Engineers Winter Annual Meeting, Dallas, Texas, 25-30 November 1990, Report Nos. EGG-M-90382, CONF-901194-11, Order No. DE91006122, 7 pp. (1990).

One of the most challenging problems in municipal waste treatment is recycling polymeric waste materials. This study demonstrates the applicability of biotechnological principles in the desulfurization of rubber using shake flask and Warburg respirometric techniques. In terms of oxygen uptake and specific rate of oxygen uptake, it was found that the mixed culture of Thiobacillus ferrooxidans and Thiobacillus thiooxidans was more efficient in this process than the individual pure cultures of these bacteria. Furthermore, the mixed cultures resulted in ten times higher sulfur removals from rubber relative to those of sterile controls. Additional studies are needed to elucidate the mechanisms of biodesulfurization of rubber. It is expected that the development of this process may provide a solution to recycle car tire materials.

Walter, D.W., Kuusinen, T.L., and Beck, J.E., (Pacific Northwest Laboratory) Advanced Recycling and Research Complexes: A Second Strategic Use for Installations on the Base Closure List, presented at the Second Annual Federal Environmental Restoration Conference and Exhibition, Washington, D.C., 25-27 May 1993, Report No(s). PNL-SA-22461 and CONF-930570--3, Order No. DE93015674, 4 pp. (May 1993).

Obstacles currently facing the solid waste recycling industry are often related to a lack of public and investor confidence, issues of profitability and liability, and insufficient consumer identification with products made from recycled materials. Resolution of these issues may not be possible without major changes in the way the solid waste recycling business is structured. At the same time, we are faced with opportunities that will not likely recur in our lifetimes: access to educated, well trained work forces; and large tracts of land that are contiguous with metropolitan areas and are developed for heavy industry and transportation. Military installations are being converted to civilian use just in time to serve as an important role in our national resource conservation policy. The future of recycling in North America 
converges with the future of selected bases on the closure list and takes the form of converting these bases into Advanced Recycling and Research Complexes. The premise is simple: use these strategically-located facilities as industrial parks where a broad range of secondary wastes are separated, refined, or converted and made into new products on site. The wastes would include municipal solid waste, demolition waste, landscape trimmings, used tires, scrap metal, agricultural waste, food processing waste, and other non-hazardous materials. The park would consist of separation and conversion facilities, research and product standards laboratories, and industries that convert the materials into products and fuels. Energy conversion systems using some waste streams as fuel could be located at the park to supplement energy demands of the industrial operations. The strategic co-location of the resource providers and user industries would minimize transportation costs.

Warren Spring Laboratory, under contract to National Center for Resource Recovery, Inc., Evaluation of Trommels for Waste to Energy Plants, Phase 2: Report of the Warren Spring Laboratory Pilot Test Series, Report No. DOC/CS/24315-19, 56 pp. (February 1983).

This report discusses the results of the second and final phase of the trommel test work carried out in the United Kingdom by Warren Spring Laboratory. The U.K. work forms part of a test program designed to develop and prove mathematical models for use in designing rotary screens and in predicting their performance.

Warren Spring Laboratory, under contract to National Center for Resource Recovery, Inc., Evaluation of Trommels for Waste to Energy Plants, Phase 1: Report of the Doncaster and Byker Test Series, Report No. DOE/CS/24315-1, 72 pp. (March 1982).

This report discusses the performance testing of two commercial-scale trommels used for size separation of bulk municipal waste. The work is to develop and prove mathematical models for use in designing rotary screens and in predicting their performance. The commercial-scale trommels examined during this test work are sited at Doncaster and at Byker, United Kingdom. The former is operated by the South Yorkshire County Council and the latter by the Tyne and Wear County Council. The major difference between the two plants is that raw refuse is processed in the Doncaster plant trommel, and pulverized refuse in the Byker plant trommel. Both plants produce a magnetic ferrous fraction, as well as a refuse-derived fuel prepared by upgrading the intermediate-sized product from the rotary screen using air classification, magnetic separation, further size reduction, and pelletization. However, the plants differ in many respects; the feed to the Byker trommel is preshredded, while at Doncaster it is treated as received. The latter plant also has additional facilities for glass and paper recovery. The contents of this report are intended to provide detailed accounts of the Byker and Doncaster tests and to compare the two screening operations, highlighting the effects of the major variables investigated.

Wolsky, A.M., Katzman, M.T., and Daniels, E.J. (Argonne National Laboratory) Paradoxes of Cleaning Up the Environment: Regulation and Recycling, presented at the Environmental Pollution Control: Advance or Retreat, Arlington, Texas, 4 October 1987, Report No. CONF-8710280-1, Order No. DE88006007, 24 pp. (1987).

One of the major objectives of public policy in the past two decades has been cleaning up the environment. Considerable resources have been expended in reclamation of the environment from past errors as well as reducing effluent flows that can cause harm in the future. Recycling can play a major role in protecting the environment as well as saving energy. In response to market incentives, recycling industries provide a large proportion of raw materials for iron and steel producers. The very regulations 
aimed at cleaning up the environment, particularly RCRA, threaten the viability of recycling industries. In the stream of discarded automobiles, there are signs that the recycling of potentially hazardous substances may diminish rather than increase.

Woodward, J., Koran, L.J., Jr., Stephan, L.M., Wong, KK.Y., and Saddler, J.H. (Oak Ridge National Laboratory), Development of a Novel and Environmentally Friendly Method for the Separation of Non-Inked and Inked Cellulose Fibers in Wastepaper, presented at the Ninth International Biodeterioration and Biodegradation Symposium, Leeds (United Kingdom), 5-10 September 1993, Report No. CONF-9309235-1, Order No DE93040605, 5 pp. (1993).

There is currently no method in existence for the separation of non-inked cellulose fibers from the inked fibers in old newsprint (ONP). Current methods for de-inking involve the pulping of the whole paper in the presence of chemicals (caustic sodium hydroxide, diethylenetriaminepentaacetic acid, sodium silicate, hydrogen peroxide, and a surfactant) followed by washing and flotation operations. The result is a mixture of high- and low-quality de-inked secondary fibers and the production of wastewater that has to be rendered harmless prior to its discharge back to the environment. Water-based inks are a particular problem because of the difficulties in recovering the ink particles after their release from ONP by chemical treatment. Currently, only $15 \%$ to $20 \%$ of the newsprint market in the USA uses water-based inks. The use of such inks is, however, preferable from an environmental point of view. The work reported here solves several problems: a separation of non-inked from inked cellulose fibers in ONP has been accomplished without the use of de-inking chemicals; the ink is not released to any great extent from the inked fibers; the non-inked fibers contain substantial quantities of long fibers ranging from 1 to $3.5 \mathrm{~mm}$ and, as such, are judged to be high-quality secondary fibers that could be recycled without further chemical treatment; and the method is suitable for separating the non-inked and inked fibers in ONP utilizing water- and oil-based inks.

Zalosh, R.G., et al., Assessment of Explosion Hazards in Refuse Shredders, Report No. ERDA-76-71, 181 pp. (June 1976).

A hazard analysis of refuse shredder explosions was performed using two parallel approaches. A survey was conducted of municipal solid waste (MSW) shredding plants to document the number, frequency, and severity of the explosions that have occurred in these plants. In addition, an analysis was performed of the various types of materials that can explode in refuse shredders and of alternative explosion-protection measures. A total of 95 explosions was reported from $45 \mathrm{MSW}$ shredding plants included in the survey. Damage and injuries from these explosions were confined to the plants and to personnel in the immediate vicinity of the shredders. Survey results have been analyzed and are presented in tables and histograms showing explosion severity and frequency for the various types of shredders and protection measures. 


\section{Other}

Air Classification Theory and Design for Municipal Solid Waste Processing, Report No. EGG-EP-10715, Order No. DE93011851, 3 pp. (April 1993).

Research conducted at Duke University over the past 12 years has led to the development of a promising alternative method for processing municipal solid waste (MSW) prior to energy production or resource recovery. Pulsed flow air classification is a laboratory-tested method that successfully separates the combustible from the noncombustible components of MSW. In 1986, Duke subcontracted to EG\&G Idaho to perform research in this area for the U.S. Department of Energy. This document represent the final report of that effort and places this research in the context of all air classification research conducted at Duke University. The goal of this final report is to document the history of pulsed flow air classifier theory and design, while emphasizing test results which confirm success with MSW processing. The three objectives are to summarize the pulsed-flow air classification theory developed at Duke University; document the equipment, procedures, test protocols, and results from research constructed at Duke University, with a focus on the combinations and classifier heights and feed rates which produce the best achievable separations, as well as a focus on the estimated cost of a complete classification system; and draw conclusions on the relative merits of selected air classifiers. The development of the theory and design of pulsed flow air classification is initially presented and experimental results are summarized. Pulsing and non-pulsing classifiers are discussed, and a complete system is designed and costed.

Alternative Schemes for Production of Chilled Water and Cogeneration of Electricity at Ashley Plant, Report No. DOE/CE/26579-T2, Order No. DE91010940, 166 pp. (1989).

William Tao Associates, Inc. (TAO) evaluated altemative systems for the generation of chilled water at Ashley Plant. The generation of chilled water is necessary for several reason; initially as a source of revenue for St. Louis Thermal Energy Corporation (SLTEC), but more importantly as a necessary component of the Trash-to-Energy Plant proposed north of Ashley Plant. The chilled water system provides a base load for steam generated by the Trash-to-Energy Plant. The benefits include reduced tip-fees to the City of St. Louis, lower cost of energy to customers of both the district steam system and the proposed chilled water system, and results in lower energy and operating costs for the system than if individual services are provided. This symbiotic relationship is the main advantage of the Trash-to-Energy system. TAO provided the preliminary engineering of the chilled water line route. The basic assumptions of an initial load of 10,000 tons with an ultimate load of 20,000 tons at a temperature difference of $16^{\circ} \mathrm{F}$ remain. The findings of the pipeline study, although not incorporated into this document, remain valid. Assumptions include the following: an initial design load of 6000 tons, which has the capability of growing to 20,000 tons; the incremental costs of steam generated by Ashley Plant and the Trash-to-Energy plant; the turbine room at Ashley Plant is suitable for gut rehab except for turbines No. 7 and No. 9, which should remain operational; and the daily chilled water flow and annual load profile. The paper describes the findings on eight alternative chiller systems. Additional studies were performed on the following: chilled water storage, low-pressure absorption chiller for balancing plant steam loads, economizer cycle for chiller system; auxiliary equipment energy source, variable flow water pumps, and comparison to satellite chilled water plant study. 
An Assessment of District Heating and Cooling Potential in Joliet, Illinois: Phase I Technical and Economic Feasibility Study, Final Report, Report Nos. DOE/CE/26557-T1, ESI/COJ-87-001, Order No. DE88011555, 79 pp. (November 1987).

A preliminary assessment of the technical and economic feasibility of a district heating and cooling (DHC) system serving a portion of Joliet, nlinois, has been completed. The basic system, which was designed to provide thermal and electrical energy services to the assessment area, was found to be economically feasible while providing energy services at prices that are less than or equal to current costs. The DHC assessment area included the Downtown Business District, the newly-designated Heritage Business Park, and the Joliet Correctional Center. The Heritage Business Park is the site of a former steel wire and rod mill. Approximately one-third of the site is currently occupied by a rod mill operated by American Steel and Wire, while the rest of the Park is essentially undeveloped. In late 1985, plans were formulated to redevelop the site into an industrial park for light industry, offices and research and development facilities. The installation of a DHC system over the next five to ten years would not only complement the redevelopment of the Downtown Business District that was recently begun, but would help to encourage the eventual development of the Heritage Business Park as well.

Atanasio, P. and Brooks, C., (Argonne National Laboratory) "Financing Resource-Recovery Projects," Energy from Municipal Wastes: Opportunities for the Southwest, presented at the Workshop on Energy from Municipal Waste: Opportunities for the Southwest, Austin, Texas, 23 June 1986, Report Nos. ANL/CNSV-TM-173, CONF-8606334, Order No. DE87014258, pp. 142-151 (May 1987).

This paper has been prepared to provide an overview of some major issues involved in financing resource recovery facilities. Each subject discussed could provide a framework for its own detailed presentation and is beyond the scope, and in the intent, of this paper. Rather, its purpose is to prompt the developer of a project to further investigate the issues so as to better understand all of the relevant data involved in this rather complex area of municipal finance. The ultimate goal being to implement the most cost effective project to help solve one's waste disposal problem.

Barrier, J.W., Bulls, M.M., Lambert, R.O., and Broder, J.D., "Production of Ethanol and Coproducts From MSW-derived Cellulosics Using Dilute Sulfuric Acid Hydrolysis," Twelfth Symposium on Biotechnology for Fuels and Chemicals: Program and Abstracts, Scheitlin, F.M., ed., (Oak Ridge National Laboratory). Presented at the 12th Symposium on Biotechnology Fuels and Chemicals, Gatlinburg, Tennessee, 7-11 May, 1990, Report No. CONF-900512-Absts, Order No. DE91000602, Paper 83 (1990).

The Tennessee Valley Authority conducts research to convert the cellulosic portion of municipal solid waste to marketable products. A one-stage dilute sulfuric acid hydrolysis process is evaluated in bench-scale research to produce sugars for the production of ethanol and other chemicals. Preliminary economics of the process are evaluated based on bench-scale results. Capital and operating costs for a base case commercial facility designed to process $500 \mathrm{t} / \mathrm{d}$ of processed MSW (the cellulosic portion) are prepared. Sensitivity analyses evaluate the effect of variables such as tipping fee, plant size, and electricity selling prices on return on investment for a commercial facility.

Barth, W.S., et al., Analysis of Akron, Ohio, Steam-District-Heating Distribution Network, Report No. ORNL/TM-8173, 74 pp. (June 1982).

In 1979, the city of Akron, Ohio, built a refuse-burning steam plant called the Recycle Energy System (RES) to provide steam to customers of the existing downtown district heating system. Technical 
difficulties and maintenance problems made major modifications to the RES necessary. Because the level of revenues was insufficient to cover the cost of the modifications, Akron considered two ways of deriving additional revenue for the RES: (1) by increasing steam sales on the district heating system, and (2) by adding the cogeneration of electricity to the RES. In order to evaluate these options, a thorough understanding of the pressure-flow relationship of the district heating system with the existing customer loads was essential. This study analyzed the options by using an existing steady-state network flow-modeling program that simulates the pressure flow relationship for the district heating system. The results indicated that the Akron system had excessive flow capacity in the existing network, so that additional customers could be served by the system. In addition, with minor modifications the system pressures could be lowered, which would improve the potential for cogeneration. The major concern in lowering the pressures was not the system constraint, but whether the customers would be willing to modify their needs to accommodate lower system pressures.

Battelle Columbus Division, Identification of Technical and Operating Problems of Nashville Thermal Transfer Corporation Waste-to-Energy Plant, Battelle Columbus Division Report No. BMI-1947 (February 1976).

This study evaluates the technical problems associated with the Nashville Thermal Transfer Corp. plant and the applicability of Nashville Thermal Transfer's experience to future installations. The report identifies needs for further research in the area of waterwall refuse combustion.

Bauman, B.D., Scrap Tire Reuse Through Surface-Modification Technology, presented at the AWMA International Specialty Conference on Research Developments for Improved Municipal Solid Waste Management, Cincinnati, Ohio, 5-7 Febnary 1991, Report Nos. EGG-M-91033, CONF-910216--1, Order No. DE91010057, 14 pp. (1991).

Air Products and Chemicals, Inc. is developing a novel approach for reusing scrap tire rubber. The process involves the combination of scrap tire rubber particles with other materials to form higher value and higher performance composites. The process begins by grinding scrap tire to a fine particle size, and removing steel and fabric. The key to this approach is a proprietary surface-modification step that is critical for enhancing the compatibility with and bonding to other continuous phase matrix materials. Of all approaches for scrap tire rubber reuse, this approach offers the potential to recover (or save) the rreatest amount of energy. Furthermore, this is the only approach that is clearly economically viable with current pricing and without a scrap tire tax. The process is environmentally innocuous, and capital requirements for large scale processing plants are projected to be modest.

Bauman, B.D., Scrap Tire Utilization via Surface Modification, presented at the Tire Industry Conference, Greenville, South Carolina, 24-25 October 1990, Report Nos. EGG-M-90456, CONF-9010296--1, Order No. DE91006207, 9 pp. (1990).

Air Products and Chemicals, Inc. is developing a novel approach to reusing scrap tire rubber, which is described in this presentation. In addition to consuming scrap tires, this technology represents a new approach to material engineering. Furthermore, this method of rubber recycle is most efficient in terms of energy recovery. 
Bauman, B.D., Utilization of Waste Tires Employing Novel Surface-Modification Technology, presented at the Scrap Tire Seminar, Philadelphia, Pennsylvania, 4 December 1989, Report No. EGG-M-89481, CONF-8912109--1, Order No. DE90015472, 9 pp. (1989)

Air Products and Chemicals, Inc. is developing unique technology for the recycle of scrap tires. The approach involves surface-modification of ground tire nubber particles to facilitate their incorporation into novel composites. This form of recycling represents the highest value-added and greatest energy conservation potential of all tire recycle technologies. Furthermore, it is environmentally innocuous. Research and development of this unique technology is partially funded through a cost-shared contract with the U.S. Department of Energy.

Beck, M.J., Johnson, R.D., and Baker, C.S., Tennessee Valley Authority, "Fermentation Studies on Sugars Recovered from Waste Cellulosics via Acid Hydrolysis," Twelfth Symposium on Biotechnology for Fuels and Chemicals: Program and Abstracts, Scheitlin, F.M., ed., (Oak Ridge National Laboratory). Presented at the 12th Symposium on Biotechnology Fuels and Chemicals, Gatlinburg, Tennessee, 7-11 May, 1990, Report No. CONF-900512-Absts, Order No. DE91000602, Paper 36 (1990).

Fermentation studies were conducted on sugars recovered from various waste cellulosics, including newsprint and cellulosics from municipal solid wastes. Sugars were recovered by a dilute sulfuric acid hydrolysis of the cellulosics designed to optimize glucose recovery at the expense of more acid-labile sugars. However, the acid processing produced toxins that interfered with fermentation. Toxins were identified and studied to determine inhibitory levels as well as a means to alleviate their inhibition of glucose fermenting yeasts. Several strains of yeasts were evaluated for their ability to produce acceptable ethanol yields from the acid hydrolyzates. Parameters of fermentations, including growth rates, sugar utilization rates, ethanol production rates, fate of inhibitors, and yield data were determined. Results from the fermentation studies of the various waste cellulosics are presented.

Bennett, R.H., Burns, J.T., Li, H., Walker, D., Valent, P.J., Percival, C.M., and Lipkin, J. (Sandia National Laboratories) "Subseabed Disposal Project Experiment Piezometer Probe Measurement Technology," Geotechnical Engineering of Ocean Waste Disposal, Demars, KR. and Chaney, R.C., eds. Presented at the Geotechnical Aspects of Ocean Waste Disposal Symposium, Orlando, Florida, 26 January 1989, Philadelphia, PA: American Society for Testing and Materials, Report No. CONF-890193, pp. 175-189 (1990).

Deep-ocean piezometer probes were developed and extensively tested in the laboratory, hyperbaric chamber, and the Pacific Ocean Basin environment at ambient pressures of 1 to $545 \mathrm{~atm}$. The probes are small diameter $(8 \mathrm{~mm})$ and utilize single sensor differential transducers to measure very slight changes in excess pore-water pressure caused by induced mechanical and thermal stresses in the surrounding sediment. Pore-pressure increases can cause time-dependent changes in the physical and mechanical properties of the sediment and thus affect the integrity of the sediment's isolation capacity. A system design, which exposes the transducers' external and internal (line pressure) components to ambient hydrostatic pressures, permits the measurement of extremely small pressure changes with high sensitivity and precision. The pressure sensors exhibited excellent sensitivity and stability during deep-ocean simulated laboratory tests and in-situ systems performance tests. 
Biofuels Program Summary, (National Renewable Energy Laboratory), Report No. DOE/CH/10093-69, Order No. DE89009484, 240 pp. (January 1990).

The federal government has supported research on biomass technology and energy from municipal waste since 1975. Separate research programs were conducted until 1985 when the two were merged into biofuels and municipal waste technology to take advantage of their many similarities in conversion requirements and research needs. The purpose of the biofuels program is to provide focus, direction, coordination, and funding for the development of technologies that produce tailored energy crops and convert these crops and wastes to fuels. The FY 1989 program includes research on the production (growth) of biomass and its conversion to fuels. Research on biomass production involves the development and use of genetically improved trees and grasses specifically for their energy conversion characteristics (terrestrial energy crops). The Biofuels Program Summary is prepared each year and consists of a two-volume reference set describing the technological advances, current projects, and future research and development (R D) directions of the program. Volume 1 (Overview) contains a brief history of the program and summary descriptions of research activities and significant accomplishments during the year. It also provides information on the management structure and budget of the program. This volume (Volume 2-Research Summaries) is a compilation of detailed descriptions of the $R$ D projects performed by the national laboratories and their subcontractors from industry, universities, and nonprofit research institutions. It is divided into an introduction and three sections.

Boston, H.L., Van Miegroet, H., Larsen, I.L., Walzer, A.E., and Carlton, J.E., (Oak Ridge National Laboratory) The Fate of Radionuclides in Sewage Sludge Applied to Land, presented at the Fourth International Conference on Environmental Contamination, Barcelona, Spain, 1-4 October 1990, Report No. CONF-901036-1, Order No. DE90015159, 6 pp. (1990).

Municipal sewage sludge containing up to $12 \mathrm{pCi} / \mathrm{g}$ sup $137 \mathrm{Cs}, 20 \mathrm{pCi} / \mathrm{g}$ sup $60 \mathrm{Co}$, and $300 \mathrm{ppm}$ $\mathrm{U}$ was injected in a pasture (43 Mg/ha) and sprayed over a young pine plantation ( $34 \mathrm{Mg} / \mathrm{ha})$. In the pasture, radionuclides were largely retained in the upper $15 \mathrm{~cm}$ of the soil, and only about $15 \%$ moved below $15 \mathrm{~cm}$. Sludge rapidly infiltrated the soil on the pine plantation. One year after application, at least $85 \%$ of the sup 137Cs, sup $60 \mathrm{Co}$, and $U$ were found in the upper $7 \mathrm{~cm}$ of the pine plantation, with only about $15 \%$ moving into the 7 - to $15-\mathrm{cm}$ strata. On-site total added radiation dose was 2 to 6 mrem/year. Radionuclides were not detected above background in soil solutions at approximately $50 \mathrm{~cm}$ depth or in shallow down-gradient groundwater wells. Surface runoff from application areas did not have elevated radionuclide concentrations. Concentrations of these radionuclides increased slightly in vegetation on treated sites, and uranium was notably higher in earthworms.

Brandt, C.A. and Hendrickson, P.L., (Pacific Northwest Laboratory) Review of Municipal Sludge Use as a Soil Amendment on Disturbed Lands, Report No. PNL-7425, Order No. DE90015835, 26 pp. (August 1990).

The U.S. Deparment of Energy is examining options of improving soil conditions at Hanford reclamation sites. One promising technology is the incorporation of municipal sewage sludge into the soil profile. This report reviews the potential benefits and adverse consequences of sludge use in land reclamation. Land reclamation comprises those activities instigated to return a mechanically disturbed site to some later successional state. Besides the introduction of suitable plant species to disturbed lands, reclamation generally requires measures to enhance long-term soil nutrient content, moisture retention or drainage, and mitigation of toxic effects from metals and $\mathrm{pH}$. One of the more effective means of remediating adverse soil characteristics is the application of complex organic manures such as municipal sewage sludge. Sewage sludges contain complete macro- and micronutrients necessary to sustain plant 
growth. The application of sewage sludge may reestablish microbial activity in sterile soils. Physical properties, such as water-holding capacity and percentage water-stable aggregates, also improve with the addition of sewage sludge. Sludge applications may also increase the rate of degradation of some hydrocarbon pollutants in soils. Potential adverse impacts associated with the application of sewage sludge to land include negative public perception of human waste products; concerns regarding pathogen buildup and spread in the soils, plants, and water, entrance and accumulation of heavy metals in the food chain; salt accumulation in the soil and ground water, leaching of nitrates into ground water; and accumulation of other potentially toxic substances, such as boron and synthetic hydrocarbons, in the soil, plants, and food chain.

Carpenter, W., AFBC Roadbed Project Groundwater Data, Report No. DOE/FE/61594-T1, Order No. DE93040214, 13 pp. (21 August 1992).

TVA permitted the use of AFBC material in a section of roadbed at Paducah, Kentucky, for the purpose of demonstrating its usability as a roadbed base. To determine if the material would leach and contaminate groundwater, four wells and seven lysimeters were installed beside and in the roadbed base material. In August 1991, TVA Field Engineering visited the AFBC Roadbed Project to collect samples and water quality data. The goal was to collect samples and data from four wells and seven lysimeters. All attempts to collect samples from the lysimeters failed with one exemption. All attempts to collect samples from the groundwater wells were successful. The analytical data from the four wells and one lysimeter are also attached. The well data is typical of groundwater in the Paducah, Kentucky area indicating that it was not affected by the AFBC roadbed material. The analysis of the lysimeter shows concentrations for iron and manganese above normal background levels, however, the data do not reflect significant concentrations of these heavy metals. Also, the difficulty in obtaining the lysimeter samples and the fact that the samples had to be composited to obtain sufficient quantity to analyze would make a qualitative evaluation of the data questionable.

Chang, Shih-Chih, Method of Energy Recovery for Wastewater Treatment: Final Technical Report, Report No. DOE/CE/15210-T5, Order No. DE89007401, 36 pp. (1989).

The principle of using the energy of falling water to compress air was invented in antiquity and largely forgotten until comparatively recently. It was used by the Romans to supply air to their catalan forges and was not used again until around the turn of the century in this country and Canada as an air compressor in mining, lumbering, canal lock operations and other applications. More recently, the principle was studied extensively as part of an ultra low-head hydropower system. The present application of the principle to subsurface aeration is an innovative method for saving energy and reducing costs of water pollution control. The Hydraulic Compression Aerator (HCA) as this application is called, was invented by Innovative Technology Laboratories. Development of the HCA, which is the subject of this report, was sponsored by a grant (No. CE-FG01-85CE15210) from the U.S. Department of Energy.

Chang, Shoou-Yuhand Rivera, A.L., (Oak Ridge National Laboratory) Theory and Evidence of Economies of Scale in the Development of Waste Management Systems, presented at the DOE Model Conference, Oak Ridge, Tennessee, 2-6 October 1989, Report No. CONF-8910193-2, Order No. DE90000702, 54 pp. (1989).

Waste is a cost of doing business. This cost can be considered in terms of the potential adverse health and environmental impacts, or the waste management costs associated with avoiding, minimizing, and controlling those impacts. There is an anticipated increase in the cost of waste management as a 
result of the increasing requirements for regulatory compliance. To meet the total waste management capacity needs of the organization and the compliance requirements, low-level radioactive, hazardous, and mixed waste management will need demonstrated technologies strategically managed as a technology portfolio. The role of the decision maker is to select the optimum mix of technologies and facilities to provide the waste management capacity needed for the next twenty years. The waste management system resulting from this mix includes multiple small-scale fixed facilities, large-scale centralized facilities, and waste management subcontracts. This study was conducted to examine the theory and evidence of economies of scale in the development of waste management systems as as exploratory research on the economic considerations in the process of technology selection and implementation.

Chapman, C.C., (Pacific Northwest Laboratory), Evaluation of Vitrifying Municipal Incinerator Ash, presented at the Ninety-Third Annual Meeting and Exposition of the American Ceramic Society (ACerS), Cincinnati, Ohio, 28 Apr-2 May, 1991, Report Nos. PNL-SA-18990, CONF-910430--20, Order No. DE91017531, 10 pp. (April 1991).

The management of municipal solid waste (MSW) is a national problem. Landfills are being closed and new landfills are not projected to meet future needs. Incineration provides significant volume reduction of MSW, but the resulting ash can concentrate undesirable organics and heavy metals. Vitrification of ash is a very attractive means for treating this ash stream. It provides further volume reduction, destroys any organic residues, and immobilizes heavy metals. In addition, the vitrified ash can become a useful construction material. Thus, vitrification can transform a waste material into a useful product without requiring landfill capacity. The feasibility of vitrifying MSW incinerator ash produced by an existing incineration facility in Whatcom County, Washington, was evaluated technically and economically. Vitrification of the incinerator ash provides an 80 volume percent reduction, forms a homogeneous glass, and is estimated to be economically favored over transportation and disposal of ash for the Whatcom County site by over $\$ 25$ dollars per ton of ash. The vitrification cost per ton of ash is about $\$ 53$. When assigned to the original ton of MSW, the vitrification cost is about $\$ 20$ dollars per to: of MSW. Thus, vitrification of MSW incinerator ash provides an economic treatment method while providing an environmentally sound solution to another potentially troublesome waste stream.

Chemical Technology Division Annual Technical Report, 1990, (Argonne National Laboratory), Report No. ANL-91/18, Order No. DE91014718, 244 pp. (May 1991).

Highlights of the Chemical Technology (CMT) Division's activities during 1990 are presented. In this period, CMT conducted research and development in the following areas: (1) electrochemical technology, including advanced batteries and fuel cells; (2) technology for coal-fired magnetohydrodynamics and fluidized-bed combustion; (3) methods for recovery of energy from municipal waste and techniques for treatment of hazardous organic waste; (4) the reaction of nuclear waste glass and spent fuel under conditions expected for a high-level waste repository; (5) processes for separating and recovering transuranic elements from nuclear waste streams, concentrating plutonium solids in pyrochemical residues by aqueous biphase extraction, and treating natural and process waters contaminated by volatile organic compounds; (6) recovery processes for discharged fuel and the uranium blanket in the Integral Fast Reactor (IFR); (7) processes for removal of actinides in spent fuel from commercial water-cooled nuclear reactors and burnup in IFRs; and (8) physical chemistry of selected materials in environments simulating those of fission and fusion energy systems. The Division also has a program in basic chemistry research in the areas of fluid catalysis for converting small molecules to desired products; materials chemistry for superconducting oxides and associated and ordered solutions at high temperatures; interfacial processes of importance to corrosion science, high-temperature superconductivity, and catalysis; and the geochemical processes responsible for trace-element migration within the earth's crust. The 
Analytical Chemistry Laboratory in CMT provides a broad range of analytical chemistry support services to the scientific and engineering programs at Argonne National Laboratory.

Choudhry, V., Zimmerle, T., Utilization of Illinois Coal Gasification Slags for Production of Ultra-Lightweight Aggregates, Report No. DOE/PC/92521-T49, Order No. DE93019799, 15 pp. (1993).

This research is aimed at testing and developing the expansion potential of gasification solid residues (slag) to manufacture ultra-lightweight aggregates (ULWA). Conventional ULWAs are manufactured by pyroprocessing of perlite or vermiculite ores and have unit weights in the range of 5--15 $\mathrm{lb} / \mathrm{ft} 3$. These materials are sold for approximately $\$ 200 /$ ton (or $\$ 1.00 / \mathrm{ft} 3$ ) and have numerous applications including loose fill insulation, insulating concrete, precast products, filtration media, and agricultural applications. In a previous project, Praxis Engineers demonstrated that lightweight aggregates (LWA) with unit weights of $25--55 \mathrm{lb} / \mathrm{ft} 3$ can be produced from nlinois coal slags and used as substitutes for conventional LWAs. In this program, tests are being undertaken in a pilot-scale vertical shaft furnace to identify operating conditions for the expansion of nlinois slags such that the product can be substituted for ULWA. Upon completion of testing, a large batch of expanded slag will be produced for evaluation in various applications, both in this phase and in subsequent Phase II testing. During the initial pilot plant runs using two nlinois slags, expanded products with unit weights of $12.5--26.5$ and $20--52 \mathrm{lb} / \mathrm{ft} 3$, respectively, were produced. Efforts are under way to generate products with lower unit weights.

Chumey, K.L., et al., Chlorine Content of Municipal Solid Waste from Baltimore County, Maryland, and Brooklyn, New York, Report No. NBSIR-85-3213, 66 pp. (September 1985).

The total chlorine and water-soluble chlorine contents of the components of municipal solid waste were determined from sampling studies carried out at two sites, Baltimore County, Maryland, and Brooklyn, New York, for a five-day period. The component that contributed the largest fraction to the chlorine content in Baltimore County was the paper fraction; in Brooklyn, the plastics fraction provided the major contribution. Chemical analyses for sulfur content were performed on composite samples for each day of sampling at the two sites. American Society for Testing and Materials standard methods for sulfur, total chlorine, and water-soluble chlorine contents, developed for refuse-derived fuel, were used in performing the analyses.

City and County of Honolulu, Hawaii, Evaluation of Technical Proposals for Honolulu Program of Waste Energy Recovery, Report No. DOE/CS/20244-1, 119 pp. (October 1982).

This report presents the results of a technical analysis of four resource-recovery proposals received during the HPOWER project of the City and County of Honolulu. The report discusses the criteria for evaluation and presents a synopsis of each proposal. The results of the evaluation cover three general areas: technical system design, system management, and environmental impact. Three proposals were judged acceptable and one, unacceptable. The technical evaluation was an important part of a two-step resource-recovery procurement approach taken in Honolulu.

City of Huntsville, Alabama, Alternative Fuel Production Facility for City of Huntsville, Alabama, Vols. I-V, Report Nos. DOE/CS/50296-1 through DOE/CS/50296-5 (October 1982).

This study was to determine the feasibility of an alternative fuel production facility using the Huntsville solid-waste stream. A data base applicable to local solid-waste management and resource 
recovery was established, and available options for an alternative best suited to local needs were screened. The series of five volumes describes existing solid-waste practices, local factors affecting solid-waste management and resource recovery, and alternatives for solid-waste management and resource recovery in the study area. The five volumes and their titles are as follows:

Vol. I-Executive Summary, $72 \mathrm{pp}$.

Vol. II-Feasibility Study, 258 pp.

Vol. Ill-Technology Development Summary, 88 pp.

Vol. IV-Preliminary Design and Outline Specifications, $150 \mathrm{pp}$.

Vol. V-Environmental Assessment and Permit Workbook, 50 pp.

City of Kansas City, Missouri, Public Works Department: Solid Waste Management Plan, District Heating and Cooling Plan, and Waste-to-Energy Feasibility Study: Appendix. Report No. DOE/CE/26549-T1App., Order No. DE88016145, 298 pp. (1988).

This paper covers the following topics: Garbage and Trash (Municipal Solid Waste Storage and Ordinance of Kansas City with Proposed Modifications; Contract (Draft Solid Waste Collection Contract); Solid Waste Disposal Services Contract; Electric Power Purchase Agreement; Steam Delivery Agreement; Results of Telecon Survey of Companies Paying for Recycled Materials; Regional Hazardous Waste Processing and Disposal Facilities; Summary of Downtown District Heating Survey; Steam Distribution System Information; Ruling by Missouri Public Service Commission: KCPandL Downtown Steam Heating System for Kansas City, Missouri; and Review of Kansas City Power and Light Waste-to-Energy Study.

City of Tallahassee, Florida, Alternate Fuels and Energy Sources for Electric Department: City of Tallahassee, Florida, Report No. DOE/RA/50318-1, 130 pp. (October 1982).

This study reviewed conventional, renewable, and nonconventional fuels. Because of technology concerns or costs, all alternatives except coal, wood, and solid wastes were eliminated from consideration. A resource-recovery system including solid-waste fuel and wood waste from the five-county area was selected for study and preliminary economic analysis. The study investigated the effect of loadmanagement techniques, conservation, and alternative energy sources on the system and concluded that these would not significantly reduce costs or were not pertinent to this study of alternative fuel supplies.

Clean Water Act (excluding Section 404), (Oak Ridge National Laboratory) Report No. ORNL/M-2263, Order No. DE93013751, 578 pp. (15 January 1993).

This Reference Book contains a current copy of the Clean Water Act (excluding Section 404) and those regulations that implement the statutes and appear to be most relevant to US Department of Energy (DOE) activities. The document is provided to DOE and contractor staff for informational purposes only and should not be interpreted as legal guidance. Updates that include important new requirements will be provided periodically. Questions concerning this Reference Book may be directed to Mark Petts, EH-231 (202/586-2609).

Columbia University, Membrane-Controlled Processes for the Energy-Efficient Conversion of Sludges to Fuels and Marketable Chemicals, Report No. DOE/CS/20400-1, 254 pp. (March 1982).

This report presents the development of a new process involving the membrane-controlled conversion of sludges into fuels and marketable chemicals. The process is energy-efficient and makes 
available more energy than it consumes. It is cost-effective because of the substantial value of the chemical byproducts obtained. The process steps are: (1) concentrate sludges to allow for smaller fermenters; (2) ferment the sludges rapidly under membrane control, converting all the undesirable byproducts into useful chemicals such as liquid ammonia and organic acids; (3) follow with a secondary aerobic fermentation to obtain the virtually complete destruction or conversion of all organic matter to chemical byproducts. The new system is compact and capable of being put into operation at sewage treatment plants to effect a virtual closed-loop operation. The system enhances the rate and extent of aerobic digestion of cellulosic urban solid wastes and sludges, allows for the recovery of organic acids and ammonia as marketable materials, and renders the remaining materials either inert or readily disposable.

Compere, A.L. and Griffith, W.L., (Oak Ridge National Laboratory) Catalytic Sodium Hypochlorite Degradation Using a Kynar Stabilized Catalyst, Report No. ORNLTM-10471, Order No. DE87012520, 28 pp. (June 1987).

Based on bench scale data, the Kynar-cobalt oxide catalyst developed by Pennwalt is able to treat waste hypochlorite streams. The effectiveness of the catalyst rises with decreasing $\mathrm{pH}$ and increasing temperature. At $55^{\circ} \mathrm{C}$ to $70^{\circ} \mathrm{C}$, it is possible to meet discharge requirements using a single pass through an upflow $40 \mathrm{~cm}$ deep catalyst bed. Solution $\mathrm{pH}$ will be reduced somewhat. The size of a Pennwalt unit for a given flow/concentration can be estimated. Based on bench experience, construction and operation of a full scale unit appears economically feasible. Operating problems with the system include attrition, catalyst conditioning and storage. Catalyst attrition is a major problem. In bench tests, catalyst loss from a tared laboratory column across several weeks was about 0.5 gram per gallon of concentrated hypochlorite processed or, using current Pennwalt costs of $\$ 50 / \mathrm{b}$ catalyst, $\$ 55$ per 1000 gal. Attrition may result from explosion of the catalyst by trapped oxygen. Several operating parameters can increase the rate of catalyst breakdown: high hypochlorite concentrations, increased temperature, and decreased $\mathrm{pH}$. Once attrition begins, increased catalyst movement increases breakdown caused by mechanical abrasion. Operations methods can be planned to decrease catalyst breakup by limiting the rate of hypochlorite degradation. Alternatively, a lower efficiency catalyst could be formulated. However, easy catalyst reloading should be part of any equipment design. During the first use, a gradual increase in hypochlorite concentrations for several hours appears necessary. In re-uses of the bed after storage, at least one-half hour of use is required for consistent minimal hypochlorite output. During startup periods, provision for the effluent recycle is recommended. Wet storage of the catalyst is recommended by previous investigators.

Cooper Union Research Foundation, Comprehensive Study on the Feasibility of Energy Recovery from Sewage Sludge, Final Report, Report No. DOE/RA/50358-H, 111 pp. (June 1986).

The feasibility of converting municipal sewage sludge into fuel that can replace or supplement existing fuels was studied. Conclusions are based on a detailed investigation using the design and operational characteristics of a New York City modified-aeration water pollution control plant. Since the selected plant does not achieve secondary treatment, as defined by the Federal Clean Water Act, two design options were considered: an upgraded plant, which utilizes a step-aeration mode; and the existing plant, which will be maintained in the modified or high-rate aeration mode for the indefinite future. The first option is necessary to meet the U.S. Environmental Protection Agency (EPA) secondary-effluent guidelines. The upgraded alternative also serves as a generic case for a typical secondary plant. The second alternative is for use in the event that a secondary level of treatment is not required by the EPA. 
Counce, R.M. and Crawford, D.B., (Oak Ridge National Laboratory) The Depletion of Aqueous Nitrous Acid in Packed Towers, presented at the Fifth Symposium on Separation Science and Technology for Energy Application, Knoxville, Tennessee, 26 October 1987, Report No. CONF-871038-5, Order No. DE88002315, 35 pp. (1987).

The depletion of aqueous nitrous acid was studied at $298^{\circ} \mathrm{K}$ and at slightly greater than atmospheric pressure. Solutions containing nitrous and nitric acids were contacted with nitrogen in towers packed with 6- and 13-mm Intalox saddles. The results indicate the existence of two depletion mechanisms for the conditions studied-liquid-phase decomposition and direct desorption of nitrous acid. Models based on mass-transfer and chemical-kinetic information are presented to explain the experimental results.

CSI Resource Systems, Incorporated, Integrated Solid Waste Management in Japan, Report No. NREL/TP-430-5692, Order No. DE93018825, 141 pp. (October 1993).

The Japanese, through a combination of public policy, private market conditions, and geographic necessity, practice integrated municipal solid waste (MSW) management. The basic concept of refuse treatment in Japan consists of recycling discharged refuse into usable resources, reusing such resources as much as possible, and then treating or disposing of the usable portion into a sanitary condition. Considering the difficulty of procuring land or seaside areas for such purpose as a refuse disposal site, it will be necessary to minimize the volume of refuse collected for treatment or disposal.

CSI Resource Systems, Inc., RECOVER: A Computer Model for Resource Recovery Projects, Report No. DOE/CS/10361-1, 160 pp. (October 1982).

RECOVER, a computer-based model developed by CSI Resource Systems, Inc., was designed to facilitate the analysis of economic impacts on a resource-recovery project of varying technical market, price, and business alternatives. During each stage of project development, from feasibility through financing, the user can determine the impacts of various selected business arrangements on the individual project participants: the waste supplier, the energy buyer, and the system operator. Potential users of the model are the project sponsor, the technical and management consultants, the financial advisor or underwriter, and the legal counsel. RECOVER was structured to accommodate analysis of the impact of a wide range of possible technologies, including mass-buming, waterwall furnace/boilers, modular combustion units, and refuse-derived fuel (RDF) systems. Energy products considered include RDF, steam, electricity, and other products, such as hot and chilled water. Technologies producing more than one energy product (cogeneration) can also be accommodated. The model can analyze a variety of recovered material, including magnetic and nonmagnetic metals, glass, and other recovered products, such as paper pulp. Both preprocessing and postprocessing (postcombustion) material recovery can be considered for each type of material.

CSI Resource Systems, Inc., Energy Resource Recovery Facility for Kent and Sussex Counties, Delaware, Report No. DOE/CS/20234-1, 180 pp. (November 1981).

This report presents two options for solid-waste disposal in Kent and Sussex Counties, Delaware, and outlines factors to be considered in planning a solid-waste facility. Chapter 1 contains the technical findings. Chapter 2 discusses existing waste-disposal facilities, future systems, and waste characteristics. Chapter 3 identifies markets for the waste resources. Chapter 4 presents a rational plan for site evaluation, in which numerical values are assigned to four principal factors in decision making. Chapter 5 describes 
the refuse-derived fuel system and the modular combustion system as the most promising systems, and Chapter 6 identifies risks and implementation issues surrounding these systems.

Data Summary of Municipal Solid Waste Management Alternatives, (National Renewable Energy Laboratory), Report No. NREL/TP-431-4988A, Order No. DE93008360, 194 pp. (October 1992).

This report provides data for use in evaluating the proven technologies and combinations of technologies that might be considered for managing municipal solid waste (MSW). It covers five major methods for MSW management in common use today: landfilling; mass combustion for energy recovery; production of refuse-derived fuel (RDF); collection/separation of recyclables; and composting. It also provides information on three MSW management technologies that are not widely used at present: anaerobic digestion; cofiring of MSW with coal; and gasification/pyrolysis. To the extent possible with available reliable data, the report presents information for each proven MSW technology on: net energy balances; environmental releases; and economics. In addition to data about individual operations, the report presents net energy balances and inventories of environmental releases from selected combined MSW management strategies that use two or more separate operations. The scope of the report extends from the waste's origin (defined as the point at which the waste is set out for collection), through transportation and processing operations, to its final disposition (e.g., recycling and remanufacturing, combustion, or landfilling operations). Data for all operations are presented on a consistent basis: one ton of municipal (i.e., residential, commercial, and institutional) waste at the collection point. Selection of an MSW management plan may be influenced by many factors, in addition to the technical performance and economics of each option.

Data Summary of Municipal Solid Waste Management Alternatives, (National Renewable Energy Laboratory), Report No. NREL/TP-431-4988B, Order No. DE93008311, 163 pp. (October 1992).

The objective of the study in this report was to gather data on waste management technologies to allow comparison of various alternatives for managing municipal solid waste (MSW). The specific objectives of the study were to compile detailed data for existing waste management technologies on costs, environmental releases, energy requirements and production, and coproducts such as recycled materials and compost; identify missing information necessary to make energy, economic, and environmental comparisons of various MSW management technologies, and define needed research that could enhance the usefulness of the technology; and develop a data base that can be used to identify the technology that best meets specific criteria defined by a user of the data base. Volume I contains the report text. Volume II contains supporting exhibits. Volumes III through $\mathrm{X}$ are appendices, each addressing a specific MSW management technology. Volumes XI and XII contain project bibliographies.

Data Summary of Municipal Solid Waste Management Alternatives, (National Renewable Energy Laboratory), Report No. NREL/TP-431-4988I, Order No. DE93008308, 65 pp. (October 1992).

Municipal solid waste (MSW) composting is experiencing a dramatic resurgence in the United States. Several factors are driving this interest in composting, including landfill closures, resistance to siting of new landfills and combustion facilities, public support for recycling, and, in general, the overall costs of waste disposal. Starting with only one demonstration project operating in 1980, the total number of projects in the United States increased to sixteen by July 1991. There are approximately 100 projects in some form of planning or development. One reason some communities are seeking composting as a waste management option is that sewage sludge and MSW can be cocomposted, thereby recycling a major portion of the overall municipal waste stream. In 1991, five of the operating facilities have incorporated 
sludge, with a number of new plants also developing systems with this capability. Generic composting technologies are described followed by a comprehensive discussion of operating facilities. Information is presented on the type of processing system, capital and operating costs, and the status of compost markets. A discussion is also included on the operational problems and challenges faced by composting facility developers and operators. Also presented are facility energy usage and a discussion of the energy implications from the use of compost as a soil and fertilizer replacement. A discussion of cost sensitivity shows how facility costs are impacted by waste handling procedures, regulations, reject disposal, and finance charges. The status of, and potential for, integrating composting into the overall waste management strategy is also discussed, including composting's contribution to municipal recycling goals, and the status of public acceptance of the technology. Finally information and research needs are summarized.

Data Summary of Municipal Solid Waste Management Alternatives, (National Renewable Energy Laboratory), Report No. NREL/TP-431-4988K, Order No. DE93008306, 72 pp. (October 1992).

This appendix contains the alphabetically indexed bibliography for the complete group of reports on municipal waste management alternatives. The references are listed for each of the following topics: mass burn technologies, refuse-derived fuel technologies, fluidized-bed combustion, pyrolysis and gasification of municipal solid waste (MSW), materials recovery and recycling technologies, sanitary landfills, composting, and anaerobic digestion of MSW.

Data Summary of Municipal Solid Waste Management Alternatives, (National Renewable Energy Laboratory), Report No. NREL/TP-431-4988L, Order No. DE93008305, 72 pp. (October 1992).

This appendix contains the numerically indexed bibliography for the complete group of reports on municipal solid waste (MSW) management alternatives. The list references information on the following topics: mass burn technologies, refuse-derived fuel technologies, fluidized bed combustion, pyrolysis and gasification of MSW, materials recovery and recycling technologies, sanitary landfills, composting and anaerobic digestion of MSW.

Data Summary of Municipal Solid Waste Management Alternatives, (National Renewable Energy Laboratory), Report No. NREL/TP-249-4988, Order No. DE92016433, 27 pp. (August 1992).

This study was initiated to compile publicly available data on the five major options commonly used for municipal solid waste management today: landfilling, mass burning for energy recovery, production and combustion of refuse-derived fuel (RDF), and composting. The report also provides some data on energy, environmental releases, and economics for the following less commonly used options: anaerobic digestion, coining of RDF with coal, and gasification/pyrolysis. The data for these options are based on pilot plant results.

DOE Model Conference on Waste Management and Environmental Restoration, (U.S. Department of Energy) presented at the Sixth Annual Department of Energy Model Conference on Waste Management and Environmental Restoration, Oak Ridge, Tennessee, 29 October-2 November 1990, Report No. CONF-9010166, Order No. DE91010951, 343 pp. (1990).

Reports dealing with current topics in waste management and environmental restoration were presented at this conference in six sessions. Session 1 covered the "Hot Topics" including regulations and 
risk assessment. Session 2 dealt with waste reduction and minimization; session 3 dealt with waste treatment and disposal. Session 4 covered site characterization and analysis. Environmental restoration and associated technologies were discussed in sessions 5 and 6 . Individual papers have been cataloged separately.

Doh, Kapsoo and Lee, Keunwon, "Properties and Utilization of Coal Briquette and MSW Ash," Proceedings of the Seventh U.S.-Korea Joint Workshop on Coal Utilization Technology, presented at the Seventh U.S.-Korea Workshop on Coal Utilization Technology, Pittsburgh, Pennsylvania, 26-29 Aug 1990, Report No. CONF-900859, Order No. DE91012801, pp. 526-541 (1990).

A large amount of ash is generated from the combustion of coal. Korean anthracite coal contains clay compounds that help the manufacture of anthracite briquette as a binder, but leave ash after combustion. The briquette ash increases a quantity of municipal solid waste, which has caused the deficit of landfill sites and increased environmental pollution. The investigation of the generation quantity and the physical and chemical properties of anthracite briquette ash shows it to be good material to be used for sanitary landfill site coverage, as a filter aid, and as an adsorbent of heavy metal.

Dutchess County Pyrolysis Project, Report of the Dutchess County Resource Recovery Task Force, Report No. DOE/TIC-11102, 237 pp. (January 1980).

The study concentrates on siting the facility, verifying waste quantities available for processing, and calculating net processing costs on the basis of current projected revenues and facility construction and operating costs. Recommendations made by the Dutchess County Resource Task Force are given. The task force recommends that the proposed resource-recovery facility be reliable and efficient and have a sufficient and controlled waste stream, a recovered-energy customer, and a strategic location.

Elcock, D., (Argonne National Laboratory), Interstate Waste Transport-Emotions, Energy, and Environment, presented at WasteTech '93, Marina del Rey, California, 14-15 January 1993, Report Nos. ANL/EAIS/CP-76727, CONF-930158--1, Order No. DE93004807, 33 pp. (1993).

This report applies quantitative analysis to the debate of waste transport and disposal. Moving from emotions and politics back to numbers, this report estimates potential energy, employment and environmental impacts associated with disposing a ton of municipal solid waste under three different disposal scenarios that reflect interstate and intrastate options. The results help provide a less emotional, more quantitative look at interstate waste transport restrictions.

Eley, M., Watson, J., Beck, M.J., Johnson, R.D., and McCaskey, T., (Oak Ridge National Laboratory), "MSW Volume Reduction, Value Recovery, and Value Addition," Twelfth Symposium on Biotechnology for Fuels and Chemicals: Program and Abstracts, Scheitlin, F.M., ed. Presented at the 12th Symposium on Biotechnology Fuels and Chemicals, Gatlinburg, Tennessee, 7-11 May, 1990, Report No. CONF-900512-Absts, Order No. DE91000602, paper 92 (1990).

Technologies are needed to reduce dependency on landfilling and mass burning as our primary means of disposal of municipal solid wastes (MSW). Source separation and recycling is desirable; however, significant quantities of wastes remain for disposal. This paper describes a number of processing steps which might be included in a technical scheme for volume reduction, value recovery, and value addition in processing paper, MSW, and sewage sludge. The substrates processed are from one 
municipality but appear to be representative of documented MSW analyses. The separation and pulping of cellulosics step is accomplished with steam classification. Non-cellulosics are identified and assigned value based on regional markets for glass, plastics, and metals. Three technologies for the glucose recovery from recovered-cellulosics step are compared: enzymatic hydrolysis and both dilute and concentrated sulfuric acid hydrolysis. The ethanol production step is evaluated by employing a uniform fermentation test of sugars recovered by the three hydrolysis methods. The final processing step of stillage disposal is addressed by evaluation of the stillages for animal feed from both a nutritional and health standpoint. Results of the various processing steps are presented, as well as predictions of success of the scheme for waste reduction, value recovery, and value addition.

Energy and Environmental Analysis, Inc., Resource Recovery and Energy Reclamation Technologies: Potential Applications under a Loan Guarantee Program, Report No. DOE/SF/85006-T1, 79 pp. (1976).

This report identifies developing energy-recovery technologies to justify a full-scale loan-guarantee demonstration program. Section II reviews the waste categories that may be recovered for use as fuel or products. These include crop and wood waste, municipal solid refuse, industrial waste, animal manure, and sewage sludge. Section III reviews the technologies available for recovering energy from the waste categories given in Section II. The technologies are direct combustion, materials recovery, thermochemical conversion, and bioconversion (anaerobic digestion). These processes recover usable materials or convert organic wastes into a number of different energy forms, including gaseous, liquid, and solid fuels as well as steam and electricity. Section IV considers the special issues that affect the integrated energy-recovery system: transportation, resource reliability, marketability of derived fuels, and the conversion technology stage of development. Section $\mathrm{V}$ describes potential and existing applications of the available energyrecovery technologies.

Energy Aspects of Solid Waste Management, Proceedings, presented at the 18th Annual nlinois Energy Conference on Energy Aspects of Solid Waste Management, Chicago, Illinois, 29-30 October 1990, Report No(s). DOE/CH/10461-1, CONF-9010176, Order No. DE92011005; 193 pp. (1990).

The Eighteenth Annual Illinois Energy Conference entitled Energy Aspects of Solid Waste Management was held in Chicago, Illinois on October 29-30, 1990. The conference program was developed by a planning committee that drew upon Illinois energy and environmental specialists from the major sectors including energy industries, environmental organizations, research universities, utility companies, federal, state and local govemment agencies, and public interest groups. Within this framework, the committee identified a number of key topic areas surrounding solid waste management in Ilinois, which were the focus of the conference. These issues included: a review of the main components of the solid waste cycle in the Midwest and what the relative impact of waste reduction, recycling, incineration and land disposal might be on nlinois' and the Midwest's solid waste management program; an investigation of special programs in the Midwest dealing with sewage sludge, combustion residuals and medical/infectious wastes; a review of the status of existing landfills in Illinois and the Midwest and an examination of the current plans for siting of new land disposal systems; a review of the status of incinerators and waste-to-energy systems in Ilinois and the Midwest, and an update on activities to maximize methane production from landfills in the Midwest. 
Enviro Control, Inc., Proceedings of the Conference on Energy Conservation: Retrofit of Municipal Wastewater Treatment Facilities, June 23-25, 1981, Report No. ANL/CNSVTM-95, 268 pp. (February 1982).

The presentations given at the national conference on "Energy Conservation: Retrofit of Municipal Wastewater Treatment Facilities" are documented in these proceedings. The conference focused on reducing energy consumption during municipal wastewater treatment. Topics of discussion included sludge treatment and incineration, methane production and use, mechanical equipment, and control instrumentation. The program emphasized utilization of existing technology and treatment practices to save energy and reduce operating costs, and several case histories documented the advantages of careful planning for energy conservation. The participants included treatment plant operators, consultants, engineers, representatives of government and industry, and other professionals involved with wastewater treatment.

Environmental Assessment-Urban Waste Technology Program, Report No. DOE/CS/0095, 108 pp. (July 1979).

This report assesses the environmental impacts of the U.S. Department of Energy (DOE) Urban Waste Technology Program. Title II, §207(b), of P.L. 95-238 establishes the authority of the Secretary of Energy to implement federal support of demonstration programs for producing alternative fuels from domestic resources. This environmental analysis finds that construction of urban waste projects is similar to that required for a typical industrial processing plant. Land-use effects will be small; no effect on population is foreseen. Positive effects include diversion of municipal solid waste from landfill; materials recovery; and possible tax, employment, and income benefits within a community, depending on facility ownership. Waste combustion may affect climate and meteorology. Dust, particulate matter, and other atmospheric emissions require controls. Plant siting is subject to air-quality regulations. No effects on groundwater are anticipated from in-plant operations; leachate from landfill operations may affect groundwater. Pretreatment of wastewaters discharged to municipal sewage systems may be required. Good housekeeping practices will be required to control odors and noise involved in handling and processing refuse. A cost/benefit analysis concludes that the immediate social benefits to be gained from demonstration facilities outweigh the financial risk associated with the new capital-intensive technologies. Environmental effects differ according to the technologies applied. Appropriate site-specific environmental analysis must be undertaken by each proposed applicant for individual waste-technology projects.

Environmental Restoration and Waste Management (EM) Program: An Introduction, Report No. DOE/EM-0005P, Order No. DE91006061, 91 pp. (December 1990).

This booklet introduces the reader to the mission and functions of a major new unit within the $U$. S. Department of Energy (DOE): the Office of Environmental Restoration and Waste Management (EM). The Secretary of Energy established EM in November 1989, implementing a central purpose of DOE's first annual Environmental Restoration and Waste Management Five-Year Plan, which had appeared three months earlier. The contents of this booklet, and their arrangement, reflect the annual update of the Five-Year Plan. The Five-Year Plan supports DOE's strategy for meeting its 30-year compliance and cleanup goal. This strategy involves focusing DOE's activities on eliminating or reducing known or recognized potential risks to worker and public health and the environment; containing or isolating, removing, or detoxifying onsite and offsite contamination; and developing technology to achieve DOE's environmental goals. 
Eykamp, W., (U.S. Department of Energy), "Microfiltration," Membrane Separation Systems-A Research and Development Needs Assessment, Final report: Volume 2; Baker, R.W., Cussler, E.L., Eykamp, W., Koros, W.J., Riley, R.L., Strathmann, H., eds. Report No. DOE/ER/30133-H1-Vol.2, Order No. DE90011770, pp. 6.1-6.31 (April 1990).

This chapter gives an overview of microfiltration, by far the most widely used membrane process. Definitions and theory are described. Design considerations, namely, dead-end versus crossflow operation, are discussed. The status of the microfiltration industry is also described, including background, suppliers, and trends in membranes, modules, and processes. Current applications are briefly described. More emphasis is placed on future applications in water treatment, sewage treatment, clarification (diatomaceous earth replacement), and fuels. Also described are process economics, energy requirements, and opportunities of further research.

Feindler, K.S., "Commercial Operation of a Codisposal, Composting, Landfilling and Power Generation System at Kaiserslautern, FRG," Energy from Biomass and Wastes XIV, Klass, D.L., ed. Presented at the Fourteenth Annual Conference on Energy From Biomass and Wastes, Lake Buena Vista, Florida, 29 January-2 February, 1990, Chicago, IL: Institute of Gas Technology, Report No. CONF-900117, pp. 981-1008 (1991).

A unique codisposal composting plant operates at Kaiserslautern, West Germany. The design and operating features of this plant are discussed. Special attention is given to a cascading mill that forms the technological core piece. An annual mass balance is presented that allows for a comparison of inputs and outputs. The various products are characterized and estimates are furnished for their potential revenues. Capital and operating costs are projected for a similar plant adapted to conditions in the United States. Both single- and dual-shift operations are considered. Annual budgets are compiled to allow estimates of the annual surplus expected. Synergistic effects between the composting plant and the adjacent landfill are pointed out, together with the usefulness of on-site biogasification.

Field, J.A., Field, T.M., Giger, W., Miller, D.J., and Hawthorne, S.B., "Quantitative Determination of Sulfonated Aliphatic and Aromatic Surfactants in Sewage Sludge by Ion-Pair/Supercritical FluidExtraction and Derivatization Gas Chromatography/Mass Spectrometry," Analytical Chemistry, v 64:24, pp. 3161-3167 (15 December 1992).

Secondary alkanesulfonate (SAS) and linear alkylbenzene-sulfonate (LAS) surfactants were quantitatively ( $>90 \%$ ) extracted from sewage sludges as their tetrabutylammonium ion pairs using 400 atm of supercritical $\mathrm{CO}_{2}$ for $5 \mathrm{~min}$ of static extraction followed by $10 \mathrm{~min}$ of dynamic extraction at $80^{\circ} \mathrm{C}$. Ion pairs of SAS and LAS quantitatively formed butyl esters in the injection port of the gas chromatograph and were determined by gas chromatography/mass spectrometry without class fractionation of the sewage sludge extracts. Concentrations of SAS and LAS in sludges from five different sewage treatment plants ranged from 0.27 to $0.80 \mathrm{~g} / \mathrm{kg}$ of dry sewage sludge and from 3.83 to $7.51 \mathrm{~g} / \mathrm{kg}$, respectively. Good reproducibility was achieved with RSDs of typically 5\% for replicate extractions and analyses. Homologue and isomer distributions of SAS in sewage sludge indicated an enrichment of the more hydrophobic components in sewage sludge during sewage treatment. 
Fifteenth National Industrial Energy Technology Conference: Proceedings, presented at the 15th National Industrial Energy Technology Conference, Houston, Texas, 24-25 March 1993, Report No. CONF-9303108, Order No. DE93016699, 371 pp. (1993).

This year's conference, as in the past, allows upper-level energy managers, plant engineers, utility representatives, suppliers, and industrial consultants to present and discuss novel and innovative ideas on how to reduce costs effectively and improve utilization of resources. Papers are presented on topics that include: Win-win strategies for stability and growth and future success, new generation resources and transmission issues, industry and utilities working together, paper industry innovations, improving energy efficiency, industrial customers and electric utilities regulations, industrial electrotechnologies for energy conservation and environmental improvement, advances in motors and machinery, industrial energy audits, industrial energy auditing, process improvements, case studies of energy losses, and industrial heat pump applications. Individual papers are indexed separately.

Flanders, W.A., Grahmann, N., and Green, G., (U.S. Department of Energy) "Sewer Water: An Alternate Water Source for a $\mathrm{CO}_{2}$, EOR (Enhanced Oil Recovery) Project," SPEDOE Seventh Symposium on Enhanced Oil Recovery: Proceedings, EOR (enhanced oil recovery) in the 1990's: Global Prospects and Perspectives, presented a the Seventh SPE/DOE Symposium on Enhanced Oil Recovery, Tulsa, Oklahoma, 22-25 April 1990, Richardson, TX: Society of Petroleum Engineers, Report No. CONF-900426, p. 944 (1990).

Water is utilized in oil field operations to increase oil recovery by conventional water flood and is increasingly being used in enhanced oil recover (EOR) technology. In many areas there is not a sufficient supply of water from subsurface salt water formations. Shallow fresh water sands have been used in the past as an alternative source when the fresh water was compatible with the reservoir water and formation. Use of the fresh water is not practical in many areas. An extreme strain has been placed on the limited fresh water supply by its use for the general population and agricultural irrigation. Effluent from municipal sewer plants can be used as an alternate source of water for the oil field. Sewer water is being utilized successfully as the water source for the water injection requirements in the Hansford Marmaton $\mathrm{CO}_{2}$ EOR project. The source of water for the project is a portion of the 10,000 barrels of water per day available from the effluent of the water treatment plant in the small city of Spearman, Texas, population 3,800. Prior to injection, the water must be deoxidized, bacteria must be killed, and the suspended oil and grease must be removed. This paper reviews how these processes are being accomplished for the Hansford Marmaton Project. Additionally, the problems encountered in installing the system, how they were resolved, the cost to implement and operate the water injection system are reviewed.

Fourteenth National Industrial Energy Technology Conference: Proceedings, presented at the 14th National Industrial Energy Technology Conference, Houston, Texas, 22-23 April 1992, Report No. CONF-9204250, Order No. DE93016698, 251 pp. (1992).

Presented are many short articles on various aspects of energy production, use, and conservation in industry. The impacts of energy efficient equipment, recycling, pollution regulations, and energy auditing are discussed. The topics covered include: New generation sources and transmission issues, superconductivity applications, integrated resource planning, electrotechnology research, equipment and process improvement,environmental improvement, electric utility management, and recent European technology and conservation opportunities. Individual papers are indexed separately. 
Franklin Associates, Ltd., A Study to Develop a Predictive Technique for the Estimation of Collectible Solid Waste in the United States, Report No. ANL/CNSV-TM-171, 144 pp. (January 1985).

This study was to gather waste-generation-rate data from several cities throughout the United States to test the reliability of the estimating equations developed in a similar study in 1979. A second purpose of the study was to examine other parameters (specifically, seasonality, temperature, and precipitation) and to determine if they have a predictable effect on the waste-generation rate. Only municipal solid waste generation rates were examined in this study. On the basis of an analysis of residential waste data from the cities surveyed, it was concluded that the addition of an income-related factor (household income) to the population factor does not significantly improve the accuracy of the waste-estimation process. It appears that the best predictor of residential waste generation on a national level is population. The analysis of commercial waste data showed no consistent seasonal pattern from city to city. The average per capita generation of commercial waste for the cities surveyed is $2.06 \mathrm{lb} / \mathrm{d}$. The average residential waste generation per person was about $2.2 \mathrm{lb} /$ person.

Franklin Associates, Ltd., Preliminary Development of a Technique for Estimating Municipal Solid Waste Generation, Report No. DOE/CE/24390-1, 84 pp. (June 1981).

Accurate data on waste generation are required for proper design and scaling of resource-recovery facilities. In this report a simple predictive method for estimating residential and commercial waste within any defined urban center is suggested as an improvement over current predictive methods (per capita averaging). Base data on refuse collection by area are obtained from five urban areas: San Francisco; Garland, Texas; Milwaukee, Wisconsin; Lawrence, Kansas; and Kansas City, Missouri. These data are then correlated with land-use patterns, population density, median household income, and retail sales totals for each area, and an equation is developed to predict solid-waste generation in pounds of waste per person per day. Correlations are developed from U.S. Census Bureau data on population and income updated by growth ratios found in Statistical Abstracts of the United States. Retail sales figures are obtained from the local Chambers of Commerce. Median household income proved to be the most reliable indicator. In the range from $\$ 14,000$ to $\$ 30,000$ per year, a proportionate daily increase of $0.05 \mathrm{lb} /$ person increase in solid waste is shown for every $\$ 10^{3}$ increase in household income. Per capita generation appears to decrease slowly with increased population density, although this result is still speculative. A rate of change of $0.06 \mathrm{lb} /$ person daily appears to occur for every 10-person-per-acre increase in population. Land use does not contribute to predictability. Total retail dollar sales appears to be a good predictor of solid waste in cities or regions with a diversity of waste mixture (wholesale, retail, and office).

General Electric Co., Household Energy Conservation System Study, Report No. COO4058-1, 30 pp. (April 1978).

The areas investigated and the procedures used to develop the preliminary design for a cost-effective household energy conservation and reclamation system for waste-product energies are discussed. The selected design recovers sufficient energy from household wastes to provide up to 50\% of the heating energy for a domestic hot water system. In addition, it ameliorates energy expenditures associated with trash collection and disposal, as well as sewage collection and processing, and conserves fresh water usage and the energy associated with providing it. Secondary benefits include the increased potential for the use of marginal lands for residential construction. The design is shown to be compatible with existing life styles and to be cost-competitive when compared with competing systems. In accomplishing the study, household energy and water use patterns were reviewed and a baseline model established. Solid-waste generation and sewage and wastewater flows were determined for the model. The areas of solid-wastes and liquid-wastes processing were examined for potential techniques and systems 
applicable to energy reclamation for a household. A number of household energy-reclamation systems were then conceptualized using the most attractive elements of the individual waste processing systems. These systems were then evaluated and screened for further analysis and development. An integrated solid- and liquid-waste energy-recovery and -conservation concept was subsequently selected and a design baseline established and evaluated. Barriers to implementation have been assessed, and market penetration has been analyzed. Recommendations for phased development and dissemination are included.

Gershman, H.W. and Brooks, C., (Argonne National Laboratory) "Finding Markets and Negotiating a Successful Project," Energy from Municipal Wastes: Opportunities for the Southwest, presented at the Workshop on Energy from Municipal Waste: Opportunities for the Southwest, Austin, Texas, 23 June 1986, Report Nos. ANL/CNSV-TM-173, CONF-8606334, Order No. DE87014258, pp. 124-141 (May 1987).

Locating and securing an energy market and completing successful contractual negotiations are two critical factors to timely, cost-effective facility implementation and operation. The success with which markets are developed from the start of project planning will be the key to their eventual involvement and the overall economic viability of any forthcoming project. This discussion addresses the necessary steps to establish a successful, long-term relationship with an energy and/or materials market. Also discussed wil be techniques used to negotiate contracts with a project's selected vend and to keep other important aspects of the development process going simultaneously. It must be remembered that local political support and leadership must be present during every phase of project development and an informed project sponsor is a vital asset to successful negotiations and project implementation.

Geyer, H.K. and Grammel, S.J., Municipal Solid Waste Processing Systems Computer Model, Report No. ANL/ENG-TM-03, 140 pp. (March 1985).

This report documents a computer code, GARB, developed for analyzing municipal solid waste processing systems. It is a modular code in which arbitrary system configurations may be analyzed using computer models of hammermills, trommels, air classifiers, etc. These component models are an implementation of models developed by Cal Recovery Systems. GARB can also perform parameter sweeps and optimization studies using a nonlinear constrained optimization method. The GARB code has been written in Fortran for use on an IBM PC.

Goodman, B.J. and Texeira, R.H., (National Renewable Energy Laboratory) Assessment of Municipal Solid Waste for Energy Production in the Western United States, Report No. SERITP-231-3622, Order No. DE90000361, 95 pp. (August 1990).

Municipal solid waste (MSW) represents both a significant problem and an abundant resource for the production of energy. The residential, institutional, and industrial sectors of this country generate about 250 million tons of MSW each year. In this report, the authors have compiled data on the status of MSW in the 13-state western region, including economic and environmental issues. The report is designed to assist the members of the Western Regional Biomass Energy Program Ad Hoc Resource Committee in determining the potential for using MSW to produce energy in the region. 
Gordian Associates, Inc., DOE Resource Recovery Project Financing Workshop, Report No. CONF-7801143, 40 pp. (June 1978).

This report is the proceedings of a workshop held 17 January 1978 to discuss barriers to financing and implementing MSW resource-recovery projects and to identify workable policies and programs to overcome these barriers. Participants included legal and financial experts, managers of resource-recovery system companies, and representatives of the federal government.

Grandfield, C.H., Rueppel, D.W., and Sims, J.M., (Lawrence Livermore National Laboratory) $A$ Comprehensive Upgrade of LLNL's Wastewater Control Program, Report No. UCRL-ID-105001, Order No. DE91002579, 13 pp. (September 1990).

The sewage from Lawrence Livermore National Laboratory (LLNL) and from Sandia National Laboratories, Livermore (Sandia) is combined in the LLNL sewer system and discharged through a common sewer outfall into the city of Livermore's community sewer system. The sewage flows to the Livermore Water Reclamation Plant (LWRP) where it is mixed with city wastewater. LLNL sewage is about $10 \%$ of the total. The mixed waters are treated and the effluent is either released through a pipeline to San Francisco Bay or used as irrigation water for the municipal golf course adjacent to the LWRP. A comprehensive approach to control sewer discharges is essential for facilities the size and diversity of LLNL and Sandia. The upgrades at LLNL in sewer monitoring, diversion, and source location enhance the controls and provide greater assurance to the Laboratory and the Livermore community because any unacceptable sewer discharges can be kept onsite for appropriate handling. The sewer-monitoring system is a unique state-of-the-art system, and the Laboratory will continue to upgrade its sewer-monitoring capabilities with both commercial systems and LLNL-developed systems to meet its special requirements.

Hamm, B.A., West, W.L.; Tatterson, G.B., "Sludge Suspension in Waste Storage Tanks," AIChE Journal, v 35:8, pp. 1391-1404 (August 1989).

In large storage tanks, jets rather than impellers are used for mixing and solid suspension. Jets often are formed by submerged rotating pumps, commonly referred to as slurry pumps. In sludge suspension applications, the jets from the slurry pumps form circular sludge-free cavities. The radius of these circular cavities, called the cleaning radius, is used often as a measure of the suspension capability of slurry pumps to suspend solid sludges. Although there is considerable technical literature on mixing and solid suspension in impeller-agitated tanks, studies on jet-induced suspension of a paste or sludge in large storage tanks using slurry pumps are unavailable in the open published literature. The objective of this paper is to determine how the cleaning radius and suspension rate change with time for a typical sludge material and to provide a phenomenological model which explains the results in a general fashion.

Harkness, J.B.L., Doctor, R.D., and Daniels, E.J., (Argonne National Laboratory), Plasma-Chemical Conversion of Hydrogen Sulfide into Hydrogen and Sulfur, presented at the Third World Congress on Engineering and Environment, Beijing (China), 12-14 October 1993, Report No. ANL/ES/CP-80089 and CONF-9310171--1, Order No, DE93041167 8 pp. (1993).

A waste-treatment process that recovers both hydrogen and sulfur from hydrogen-sulfidecontaminated industrial wastes is being developed to replace the Claus technology, which recovers only sulfur. The proposed process is based on research reported in the Soviet technical literature and uses microwave (or radio-frequency) energy to initiate plasma-chemical reactions that dissociate hydrogen sulfide into elemental hydrogen and sulfur. In the plasma-chemical process, the gaseous stream would 
be purified and separated into streams containing the product hydrogen, hydrogen sulfide for recycle to the plasma reactor, and the process purge containing carbon dioxide and water. Since unconverted hydrogen sulfide is recycled to the plasma reactor, the plasma-chemical process has the potential for sulfur recoveries in excess of $99 \%$ without the additional tail-gas clean-up processes associated with the Claus technology. Laboratory experiments with pure hydrogen sulfide have confirmed that conversions of over 90\% per pass are possible. Experiments with impurities typical of petroleum refinery and natural gas production acid gases have demonstrated that these impurities are compatible with the plasma dissociation process and do not appear to create new waste-treatment problems. Other experiments show that the cyclonic-flow pattern hypothesized by the Russian theoretical analysis of the plasma-chemical process can substantially decrease energy requirements for hydrogen sulfide dissociation while increasing conversion. This process has several advantages over the current Claus-plus-tail-gas-cleanup technology. The primary advantage is the potential for recovering hydrogen more cheaply than the direct production of hydrogen. The difference could amount to an energy savings of $40 \times 10^{15}$ to $70 \times 10^{15} \mathrm{~J} / \mathrm{yr}$ in the refining industry, for an annual savings of $\$ 500$ million to $\$ 1,000$ million.

Harkness, J.B.L., Gorski, A.J., and Daniels, E.J., Hydrogen and Sulfur Recovery from Hydrogen Sulfide Wastes, Patent No. US 5211923 A, Patent Assignee: Univ. of Chicago, 101 pp. (18 May 1993).

A process is described for generating hydrogen and elemental sulfur from hydrogen sulfide waste in which the hydrogen sulfide is [dis]associated under plasma conditions and a portion of the hydrogen output is used in a catalytic reduction unit to convert sulfur-containing impurities to hydrogen sulfide for recycle, the process also including the addition of an ionizing gas such as argon to initiate the plasma reaction at lower energy, a preheater for the input to the reactor and an internal adjustable choke in the reactor for enhanced coupling with the microwave energy input.

Holter, G.M., Pennock, K.A., and Shaver, S.R., (Pacific Northwest Laboratory) Macro Material Flow Modeling for Analyzing Solid Waste Management Options, presented at the 86th Annual Meeting and Exhibition of the Air and Waste Management Association, Denver, Colorado, 13-18 June 1993, Report No(s). PNL-SA-21415 and CONF-930647--7, Order No. DE93017661, 12 pp. (June 1993).

A Macro Material Flow Modeling (MMFM) concept and approach are being adopted to develop a predictive modeling capability. This capability is intended to provide part of the basis for evaluating potential impacts from various solid waste management system configurations and operating scenarios, as well as evaluating the impacts of various policies on solid waste quantities and compositions. The MMFM capability, as part of a broader Solid Waste Initiative at Pacific Northwest Laboratory, is intended to provide an increased understanding of solid waste as a disposal, energy, and resource problem on a national and global scale, particularly over the long term. This model is a macro-level simulation of the flows of the various materials through the solid waste management system, and also through the associated materials production and use system. Inclusion of materials production and use within the modeling context allows a systems approach to be used, providing a much more complete understanding of the origins of the solid waste materials and also of possible options for materials recovery and reuse than if a more traditional end-of-pipe view of solid waste is adopted. The MMFM is expected to be useful in evaluating longer-term, broader-ranging solid waste impacts than are traditionally evaluated by decision-makers involved in implementing solutions to local or regional solid waste management problems. This paper discusses the types of questions of interest in evaluating long-term, broad-range impacts from solid waste. It then identifies the basic needs for predictive modeling capabilities like the MMFM, and provides a basic description of the conceptual framework for the model and the associated data. Status of the MMFM implementation is also discussed. 
Holter, G.M., Shay, M.R., and Stiles, D.L., (Pacific Northwest Laboratory) Planning for Future Waste Storage and Transport Requirements, presented at the Eighty-Third Annual Meeting and Exhibition of the Air and Waste Management Association, Pittsburgh, Pennsylvania, 24-29 June 1990, Report Nos. PNL-SA-17985, CONF-900676-12, Order No. DE90016357, 7 pp. (March 1990).

Waste management is becoming an ever more important topic. Increasing regulatory requirements are being placed on waste management activities. There is also an expanding public awareness of and attention to waste management topics, with increased public participation in decisions affecting waste management. Although much of the current waste management focus is on remediating problems resulting from past practices, we are also faced with the significant challenge of planning for management of current and future wastes. This planning must take into account the storage and transport capabilities that will be required to properly manage the wastes, from the point of generation through to their ultimate disposal. Planning to provide adequate and appropriate storage and transport capabilities for wastes to be generated or received in the future is a difficult but critical undertaking. Storage and transport capabilities need to be provided in appropriate amounts and types to match the amounts and characteristics of the wastes to be handled. For example, wastes containing flammable components are required to have different storage conditions than other types of hazardous wastes, and are required to be kept separate. Storage overcapacity for flammable wastes will generally not substitute for undercapacity for wastes containing, for example, acute toxins. There are a number of similarly exclusive requirements that severely limit options for storage of multiple waste types. This paper examines several key factors in developing reliable projections of future waste storage and transport requirements and subsequently using these projections to develop specific plans. The paper then discusses application of these factors in the development of solid waste projection capabilities for a large, complex facility with a number of distinct waste types.

Holter, G.M., Stapp, D.C., and Beck, J.E., (Pacific Northwest Laboratory), A Comprehensive Definition and Approach to Waste Minimization, presented at the Eighth International Conference on Solid Waste Management and Secondary Materials, Philadelphia, Pennsylvania, 15-18 November 1992, Record Nos. PNL-SA-20888, CONF-9211150 -1, Order No. DE93005036, 8 pp. (November 1992).

This report describes important concepts and needs related to waste minimization.

Hull, D.E.; Bieniewski, T.M., (Los Alamos National Laboratory) Method of Processing Materials Using An Inductively Coupled Plasma, Application Priority No. US 6-037898, Report No. PATENTSUS-A6037898, 13 pp. (13 April 1987).

The invention, a method of processing materials, enables ultrafine, ultrapure powders to be formed from solid ingots in a gas free environment. A plasma is formed directly from an ingot, which ensures purity. The vaporized material is expanded through a nozzle and the resultant powder settles on a cold surface. An inductively coupled plasma may also be used to process waste chemicals. Noxious chemicals are directed through a series of plasma tubes, breaking molecular bonds and resulting in relatively harmless atomic constituents.

Humber Associates, Definition and Analysis of the Barriers to the Implementation of Urban Energy Recovery Systems, Report No. ANL/CNSV-TM-2, 17 pp. (May 1979).

Major barriers to the implementation of urban resource-recovery systems are identified through interviews with 40 experts from the private and public sectors. Data are weighed and incorporated into 
the U.S. Department of Energy's program planning efforts in urban waste utilization. Federal programs are ranked for their effectiveness in implementing urban energy recovery.

Hunter, R.M., The FlumeterTM: A New Tool for Wastewater Management (in Small Sewers), Report No. DOE/CE/15298-T1, Order No. DE88010302, 134 pp. (May 1988).

Wastewater system managers and engineers are often faced with the problem of measuring flows in closed conduits (e.g., small sewers) that operate both under open channel conditions and under full pipe flow conditions. Solutions to the problem developed previously have had serious limitations. The Flumeter ${ }^{\mathrm{TM}}$ technology described in this report has few limitations and shows great promise as a simple and reliable means of measuring such flows.

Implications of Pollution Prevention Experience for Environmental Management, (Oak Ridge National Laboratory), presented at the 18th National Association of Environmental Professionals (NAEP) Annual Conference on Current and Future Priorities for Environmental Management, Raleigh, North Carolina, 24-26 May, 1993, Report No. CONF-930523-7, Order No. DE93013512, 14 pp. (1993).

Conventional wisdom in the United States is that firms face a trade-off between environmental efforts and profit because of the belief that environmental protection invariably involves costs that reduce profits. Firms, therefore, generally perceive environmental protection as an impediment to their goal of profit maximization. Environmental efforts are viewed as an added hurdle in producing a product, rather than an as intrinsic part of well-designed operations. From this perspective, firms have no incentive to engage in environmental protection efforts, and will do so only if they are forced (or are given incentives) by government or if they perceive in advance potential profits from their efforts (e.g., a market for environmental products). The concept of a trade-off between the environment and profit, however, has been challenged recently. A common argument raised for questioning this trade-off is that efforts directed at environmental protection will lead to the development of new technologies and will give US firms a competitive advantage in the emerging environmental industry. It is argued that opportunities available within this growth field outweigh costs of entry and research. Recent publications (World Wildlife Fund, 1992; Resources for the Future, 1993) have proposed that government actions, may encourage the development of the environmental industry and, thus, improve both economic and environmental performance. Suggested governmental actions include using market incentives rather than command and control regulation to achieve environmental goals, integrating environmental values into govemmental policy analysis, and supporting investments in environmental technologies. This paper details the economics and benefits of various waste management efforts.

Industrial Waste Reduction and Utilization, Report No. NMAB-466, 96 pp. (April 1993).

An independent assessment was conducted of the programs and plans of the Industrial Waste Reduction and Utilization program of the Department of Energy's Office of Industrial Technologies. Procedures for identifying and selecting projects were examined to identify potential improvements in planning and program initiation. Recommendations made include greater interaction with industry in program planning, greater interaction with other federal agencies and universities and funding of innovative ideas in chemicals, refining, and related industries. Opportunities for innovative industrial and academic research projects are identified. 
Inhibition of Respiration in Activated Sludge by High Carbon Dioxide Concentration: A Laboratory Study, Report No. DOE/IR/05106-T67, Order No. DE89013831, 41 pp. (February 1988).

This research project investigated the degree to which the activated sludge wastewater treament process is inhibited by high carbon dioxide concentration. This report presents the specific methods utilized in the performance of this research and the results obtained. Experiments were done in a $\mathrm{CO}_{2}$-rich environment, using a modified large volume respirometer. Because of operating difficulties encountered when the respirometer was modified for elevated $\mathrm{CO}_{2}$ concentrations, inhibition was measured by comparing rate of substrate removal in the experimental respirometer with that of the control. After calibrating the experimental method with known substrates and inhibitors, a number of experiments with high $\mathrm{CO}_{2}$ concentrations were conducted.

Jody, B.J. and Daniels, E.J., (Argonne National Laboratory) An Energy-Conserving Process to Treat and Recycle Wastewater and Sludges, presented at the Twenty-Fifth Intersociety Energy Conversion Engineering Conference, Reno, Nevada, 12-17 August 1990, Report No. CONF-900801-28, Order No. DE90017671, 5 pp. (May 1990).

This paper describes a process that combines the energy-conserving features of a multiple effect evaporator with a chemical reactor to treat wastewater and sludges containing heavy metals, suspended solids, and organic compounds. Temperatures and pressures can be controlled such that the organic species can be made to evaporate with the steam, which could be superheated to promote the destruction of the organic species via hydrolysis and thermal decomposition. The product stream can be passed over a catalyst bed where a reagent such as oxygen, ozone, or hydrogen can be introduced to clean up the product stream further. As a result, the residual (thickened) wastewater or sludge is reduced in mass and volume. The treament of its heavy-metals content will thus be less expensive. The process employs a combination of commercially available equipment. The evaporator may require a slight modification to be able to handle sludges containing high levels of solids. The process nuns continuously and requires minimal human interaction.

Kaiser Engineers, Inc., Industrial Utilization of Waste-Derived Energy, Vol. II (Apps. 1 and 2), Report No. DOE/CS/20030-2, 198 pp. (September 1981).

Kaiser Engineers, Industrial Utilization of Waste-Derived Energy, Vol. I, Report No. DOE/CE/20030-1 (June 1981).

A technical and economic feasibility study of a partial oxidation unit (Union Carbide Corporation's PUROX $^{\circledR}$ System) was conducted. Major objectives of the program were disposal of both urban (municipal refuse and sewage sludge) and agricultural (dairy) wastes and the production of a medium-Btu fuel gas. The investigated waste-disposal area includes portions of western San Bernardino County, eastern Los Angeles County, and northwestern Riverside County in California. Section 2 summarizes the study, Section 3 discusses the available waste supply (municipal refuse, sewage sludge, and dairy wastes), Section 4 covers transportation of these waste materials, and Section 5 discusses product quantities and energy products of fuel gas, steam, and electricity. Markets for energy, slag, and recovered materials, such as ferrous and nonferrous metals (e.g., aluminum), are studied. 
Kirklin, D.R., et al., Test Procedures for the Determination of the Gross Calorific Value of Refuse and Refuse-Derived Fuel of Kilogram-Size Samples Using Constant-Pressure Flow Calorimeter: Summary of the 1980 Fiscal Year Results, Report No. NBSIR-822491, 90 pp. (June 1982).

This report describes the systematic approach used at the National Bureau of Standards to design, construct, and place into operation a constant-pressure flow calorimeter that can accommodate kilogram-size samples. The contents of the report are divided into three parts: Part A, The Variability of Municipal Solid Waste and Its Relationship to the Determination of the Calorific Value of Refuse-Derived Fuels; Part B, 25-Gram-Capacity Combustion Flow Calorimeter; and Part C, Municipal Solid Waste. The primary objective of this effort is to develop a procedure for the determination of accurate calorific values for minimally processed MSW and to correlate these calorific values with those obtained on RDF samples that have been processed to a small particle size.

Kirklin, D.R., et al., Test Procedures for the Determination of the Gross Calorific Value of Refuse and Refuse-Derived Fuel by Conventional Bomb and Large-Bomb Calorimetry, Report No. NBSIR-81-2278 (June 1981).

This report provides the results of investigations during fiscal year 1979 to develop test procedures for the determination of the calorific value of refuse and refuse-derived fuel by means of oxygen bomb calorimetry. The results of 138 calorimetric measurements are discussed, along with 32 calorimeter calibration measurements for 20 different refuse-derived fuel (RDF) samples. In addition, determinations have been camied out on the RDF samples for air dry loss, residual moisture, furnace ash, bomb ash, and sulfur content to correct the calorimetric datafor their presence: the latter group of measurements amounts to 283 experiments.

Kirklin, D.R., et al., Determination of the Calorific Value of Refuse-Derived Fuels by Large-Bomb Calorimetry: Summary of the 1978 Fiscal Year Results (Interim Report), Report No. NBSIR-80-1968, 38 pp. (January 1980).

An oxygen bomb calorimeter that can accommodate a $25-\mathrm{g}$ sample of refuse or a refuse-derived fuel (RDF) has been designed and constructed at the National Bureau of Standards (NBS) for the purpose of studying the effects of sample processing on the measured calorific value of such material. This large calorimeter is an enlarged and modified version of a conventional-size calorimeter also in use at NBS. The large calorimeter can handle samples 10 times larger than the conventional-size calorimeter and, therefore, can be used to investigate RDF samples with either minimal or no processing. Calorimetric results are presented for calorific value measurements carried out on densified RDF (d-RDF) in both calorimetric systems. The results of this investigation indicate that the calorific value of $d-R D F$ is unaffected by the sample processing technique used at NBS.

Kirklin, D.R., et al., Test Procedures for the Determination of the Gross Calorific Value of Refuse and Refuse-Derived Fuels by Oxygen Bomb Calorimetry: Summary of the 1977 Fiscal Year Results, Report No. NBSIR-78-1494, 34 pp. (December 1978).

Gross calorific values were determined for refuse-derived fuels from two manufacturers, Teledyne National and Combustion Equipment Associates. Test procedures used were modifications of those used for coal and coke. Results of 23 laboratory samples are presented at various stages of sample preparation derived from single field samples from each of the two sources. Calorimetric results based on an equilibrated laboratory sample are presented along with some semiquantitative spectrochemical results. 
The results indicate that the techniques of oxygen bomb calorimetry can be successfully applied to a nonhomogeneous refuse stream after considerable processing to prepare a homogeneous refuse-derived fuel.

Kjeldgaard, E.A., Stermer, D.L., Saloio, J.H. Jr., and Lorton, G.A., (Sandia National Laboratories) Waste Minimization/Pollution Prevention at R\&D Facilities: Implementing the SNLNM Process Waste Assessment Program, presented at the Ninth Waste Minimization and Pollution Prevention Conference, San Francisco, California, 13-15 April 1993, Report No(s). SAND-93-0466C, CONF-930483-8, and TIC-1253, Order No. DE93012860, 12 pp. (1993).

The Sandia National Laboratories, New Mexico (SNL/NM) Process Waste Assessment (PWA) program began formally on November 2, 1992. This program represents the first laboratory-wide attempt to explicitly identify and characterize SNL/NM's waste generating processes for waste minimization purposes. This paper describes the major elements of the SNL/NM PWA program, the underlying philosophy for designing a PWA program at a highly diverse laboratory setting such as SNL/NM, and the experiences and insights gained from five months of implementing this living program. Specifically, the SNL/NM PWA program consists of four major, interrelated phases: process definition; process characterization; waste minimization opportunity assessment; and project evaluation, selection, implementation, and tracking. This phased approach was developed to provide a flexible, yet appropriate, level of detail to the multitude of different "processes" at SNL/NM. Using a staff infrastructure of approximately 60 Waste Minimization Network Representatives (MinNet Reps) and consulting support, the SNL/NM PWA program has become the linchpin of even more progressive and proactive environment, safety, and health (ES\&H) initiatives such as: cradle-to-grave material/waste tracking, centralized ES\&H reporting, and detailed baselining and tracking for measuring multi-media waste reduction goals. Specific examples from the SNLNM PWA program are provided, including the results from process definition, process characterization, and waste minimization opportunity assessments performed for a typical SNL NM process.

Kunkle, R., Gray, R., and Delzel, D., Wastewater Treatment Facilities: Energy Efficient Improvements and Cogeneration, Report No. WSEO-92-093, Order No. DE93003587, 54 pp. (October 1992).

The Washington State Energy Office (WSEO) has worked with both the Bonneville Power Administration and the U.S. Department of Energy to provide technical and financial assistance to local governments. Based on a recent study conducted by Ecotope for WSEO, local govermments spend an estimated $\$ 45$ million on utility bills statewide. Water and wastewater facilities account for almost onethird of this cost. As a result, WSEO decided to focus its efforts on the energy-intensive water and wastewater sector. The ultimate goal of this project was to develop mechanisms to incorporate energy efficiency improvements into wastewater treatment facilities in retrofits and during upgrades, remodels, and new construction. Project activities included the review of the existing regulatory environment for treatment system construction, a summary of financing options for efficiency improvements in treatment facilities, a literature review of energy efficiency opportunities in treatment plants, survey and site visits to characterize existing facilities in Washington State, estimates of the energy efficiency and cogeneration potential in the sector, and a case study to illustrate the implementation of an efficiency improvement in a treatment facility.

Kuusinen, T.L., Beck, J.E., and Holter, G.M., (Pacific Northwest Laboratory), Regional Secondary Resource Utilization Parks: The Industrial Parks of the Future, presented at the Eighth International Conference on Solid Waste Management and Secondary Materials, Philadelphia, Pennsylvania, 
15-18 November 1992, Report Nos. PNL-SA-20892, CONF-9211150--2, Order No. DE93005098, 9 pp. (November 1992).

Obstacles currently facing the solid waste recycling industry are often related to lack of public and investor confidence, issues of profitability and liability, and insufficient consumer identification with products made from recycled materials. Resolution of these issues may not be possible without major changes in the way the solid waste recycling business is structured. One potential solution takes the form of the secondary resource utilization park. The premise is simple: provide a strategically located facility where a broad range of secondary resources are separated, refined or converted, and made into new products on the site. The secondary material resources would come from municipal solid waste, demolition waste, landscape trimmings, used tires, scrap metal, agricultural waste, food processing waste, and other non-hazardous forms. The park would consist of separation and conversion facilities, research and product standards laboratories, and industries that convert the materials into products and fuels. Energy conversion systems using some waste streams as fuel could be located at the park to supplement energy demands of the industrial operations. The strategic co-location of the resource providers and user industries would also minimize transportation costs and could provide a test case for an "industrial ecology" approach to sustainable economic development.

Laguna, G.R., Peter, F.J., Stuart, A.D., and Loyola, V.M., (Sandia National Laboratories) Volatile Organic Monitor for Industrial Effluents, Report No. SAND-93-1044, Order No. DE93018692, 59 pp. (July 1993).

1990 amendments to the Clean Air Act have created the need for instruments capable of monitoring volatile organic compounds (VOCS) in public air space in an unattended and low cost manner. The purpose of the study was to develop and demonstrate the capability to do long term automatic and unattended ambient air monitoring using an inexpensive portable analytic system at a commercial manufacturing plant site. A gas chromatograph system personal computer hardware, meteorology tower instruments, and custom designed hardware and software were developed. Comparison with an EPA approved method was performed. The system was sited at an aircraft engines manufacturing site and operated in a completely unattended mode for 60 days. Two VOCs were monitored every 30 minutes during the 24-hr day. Large variation in the concentration from $800 \mathrm{ppb}$ to the limits of detection of about

Land, M.D., Brothers, R.R., and McGinn, C.W., (Oak Ridge National Laboratory), Canyon Waste Dump Case Study, Presented at the Agency for Toxic Substance and Disease Registry (ATSDR) workshop for the Pan American Health Organization (PAHO), El Paso, Texas, 5-9 August, 1991, Report No. CONF-9108138-1, Order No. DE91017698, 55 pp. (1991).

This data packet contains the Canyonville Canyon Waste Dump results of the various physical environmental sampling. Core samples were taken from the on site waste material. Vertical grab samples were made from these borings. The waste samples were screened for volatile organic compounds (VOC) and logged for lithology. Soil samples were also tested for VOC. Composite sediment samples were taken using a coring device known as a clam gun. No surface water was available for testing from the intermittent Canyon Wash. The hydrogeology of the Canyon Waste Dump was inferred from lithologic logs and hydraulic data from the five monitoring wells located along the canyon floor. Groundwater was monitored through five wells. The soil vapor and air screening techniques used were adaptations of the EPA ERT and NIOSH methodologies. 
Logan County Commission, Logan, West Virginia, Solid Waste Management Study: Logan County, West Virginia, Report No. DOE/CS/20169-1, 216 pp. (March 1983).

This report presents a review of the eight chapters contained in the Logan County feasibility study. It discusses technical findings and cost estimates needed to select an alternative for solid-waste disposal. The main goals of the solid-waste-generation and resource-recovery marketing study for Logan County were the determination of a solid-waste generation rate in pounds per capita per day and the selection of a potential customer of a resource-recovery fuel, energy, or material.

MacViro Consultants, Inc., 3RS Action Plan, Report No. MIC-91-01181/XAB 111 pp. (1990) .

The goal of the Solid Waste Interim Steering Committee (SWISC) process is to develop a long-term waste management system for the Greater Toronto Area (GTA), to be in place by 1996, which is environmentally, socially, economically and technically sound. This background report is being released to the public and member Regional Councils to facilitate input to the SWISC planning process. The report documents current reduction, reuse and recycling initiatives in the GTA, identifies opportunities for coordination and collaboration among the GTA communities, and develops an action plan for improving the effectiveness of the reduction, reuse and recycling efforts within the GTA.

Marsee, KW. and Pierce, A.L., Pilot Process Waste Assessment: R-11 Chiller Refrigeration, Report No. KCP-613-5120, Order No. DE93016584, 106 pp. (June 1993).

This report represents a comprehensive assessment of the process of chilling water through the use of CFC R-11. The assessment investigates the following: wastes generated by the process, mass balances, pollution prevention options, benefit analysis of the options, and recommendations.

Mathematica Policy Research, Energy from Urban Wastes: Report on a Focus Group Discussion, Report No. DOE/TIC-10022, 42 pp. (November 1978).

This report presents opinions expressed during a group discussion on the commercialization potential of urban waste technologies. The group generally agreed that energy production from urban wastes is technically feasible and, in certain situations, commercially viable but probably will not provide more than a small fraction of the national energy supply. Barriers to commercialization of the urban-waste energy-production systems that were discussed include problems serving long-term contracts, uncertainty about environmental laws, refuse supply, disposal and use of residue, uncertainties about future tax laws, legal obstacles, technical reliability, and citizen dissent. The general feeling was that these barriers would be overcome as experience with production systems is gained. Potential government policies that received expressions of support include long-term sales commitments, grandfather clauses in new environmental laws, and legal aid to municipalities. However, the group gave little indication of the need or desirability of large-scale direct government action in this area.

Mazurkiewicz, M., Development of a Liquid Jet for Disintegration of Organic and Inorganic Materials: Final Technical Report, September 15, 1986 September 14, 1987, Report No. DOE/CE/15299-T1, Order No. DE88003813, 28 pp. (November 1987).

The work completed for this project includes the development of three working prototypes for disintegrating materials and testing the systems to determine performance characteristics. The material 
used was waste newsprint, books and fiberboard. This report describes the systems tested, the method of testing and presents results of the testing.

Menkes Municipal Services, Inc., Portable Hopper/Conveyor for Processing Glass Cutlet and Aluminum, Final Report, Report No. DOE/R3/06083-T1, 16 pp. (July 1980).

Energy comparisons and savings using a portable hopper/conveyor to process municipal solid wastes in Pennsylvania are described. The equipment was demonstrated in several municipalities in Bucks and Montgomery Counties, as well as in Philadelphia. Glass was processed and upgraded and sold at the highest prices for cullet by the recycling programs. Metals were also successfully marketed.

Middlesex County Department of Solid Waste Management, Resource Recovery Codisposal Demonstration Project, Middlesex County, New Jersey: Feasibility Study and Recommendation for Implementation-Final Report, Report No. DOE/CS/20230-1, 210 pp. (November 1983).

This study was to evaluate a proposed solid-waste and sewage sludge codisposal system for the Middlesex County Department of Solid Waste Management that could be coordinated with the Department's existing and planned solid-waste management programs. The proposed system had to be technically sound, environmentally and economically feasible, and beneficial for the county as a whole. The study included: characterizing existing and future conditions, including solid-waste and sludge data and potential energy markets; determining the regulatory and procedural requirements imposed on codisposal programs by state and federal agencies; and evaluating resource-recovery and codisposal systems in relation to the needs and objectives of Middlesex County.

Mishkin, A.E. and Brooks, C. (Argonne National Laboratory) "Resource Recovery for Municipalities in the Southwest: Major Legal Issues and Their Impacts," Energy from Municipal Wastes: Opportunities for the Southwest, presented at the Workshop on Energy from Municipal Waste: Opportunities for the Southwest, Austin, Texas, 23 June 1986, Report Nos. ANL/CNSV-TM-173, CONF-8606334, Order No. DE87014258, pp. 105-123 (May 1987).

The legal framework for resource recovery reflects the novelty and unusual nature of these projects for municipalities. This paper provides an overview of significant legal issues relating to procurement, taxes, financing, environmental regulation, and energy sale. It also describes a number of programs that favor or hinder the development of resource recovery. Emphasis is given to statutes and programs affecting the southwestern states. The paper also identifies interest groups affected by the legal issues, and the potential impacts of the issues on those groups. Key legal issues should be studied early so that needed state legislation can be identified and obtained on a timely basis.

MITRE Corp., Resource Recovery Research Development and Demonstration Plan, Report No. DOE/CS/20178-1, 426 pp. (October 1979).

This volume summarizes results of a comprehensive assessment of the near-term technical research needed to accelerate commercialization of resource-recovery technologies. The assessment is based on the premise that delays in technical development may be tied to lack of a structured development within the industry, and it focuses on actions that can begin over the period from 1980 to 1983. Technologies assessed cover mass-burning, modular units, prepared fuel, pyrolysis, cocombustion, and bioconversion (anaerobic digestion; landfill-gas recovery; and alcohol, alkane, and other chemical processes). Separate 
discussions cover mechanical separation processes, source separation programs in communities, and generic research needs common to all technologies. The report is divided by topics. The status of each technology is briefly reviewed, followed by a synopsis of current research on each process and those research needs which, if addressed, could accelerate near-term commercialization. A proposed research program addresses the specific needs of each technology, emphasizing nearterm actions. Resource recovery is retarded by both technological uncertainties and institutional impediments. Therefore, some proposed recommendations are for nontechnical barriers, which range from procurement and contracts through finances and taxation to waste-stream control.

Molton, P.M., Fassbender, A.G., Robertus, R.J., Sullivan, R.G., and Brown, M.D., (Battelle, Pacific Northwest Laboratories) "Production of Fuel Oil From Sewage Sludge by the STORS Process," Energy from Biomass and Wastes XII, Klass, D.L., ed. Presented at the Twelfth Energy from Biomass and Wastes, New Orleans, Louisiana, 15-19 February 1988, Chicago, IL: Institute of Gas Technology, Report No. CONF-880215, pp. 1153-1186 (1989).

The authors have been performing liquefaction research since 1971. They discuss how this research is being applied to the thermochemical conversion of primary sewage sludge in what is known as STORS, an acronym representing Sludge To Oil Reactor System. A prototype STORS was built and operated in 1985, and performed well. The next generation unit is intended to allow use of the experience gained during operation of the prototype, and in particular to allow for the generation of more accurate mass balance data, longer continuous operating periods, and more accurate economic assessment. The new unit, designated STORS-II, is in the design stage and is scheduled to be completed by the summer of 1988.

Moretti, C.J., Development of Fly Ash-Based Slope Protection Materials for Waste Disposal Ponds, Report No. DOE/MC/10637-3376, Order No. DE93000294, 31 pp., February 1993.

A research project was conducted to develop a cost-effective slope protection material for a 100-acre scrubber sludge disposal pond located at the Sherco power plant. The technical objective of the project was to formulate and evaluate the performance of a slope protection material produced using self-cementing coal combustion by-products. The material was to have sufficient durability and erosion resistance to protect the underlying bottom ash fill and clay liner from wave erosion for at least 5 years when it was placed on the interior side slopes of the pond. The two coal combustion by-products that were considered for use in the slope protection material were 1) a spray dryer waste and 2) a subbituminous coal fly ash. The spray dryer waste was approximately a 50:50 mixture of subbituminous coal fly ash and reacted, lime-based scrubber sorbent. The subbituminous coal fly ash was produced from a cyclone-fired boiler. Both by-products displayed self-cementing behavior when mixed with water. The results of the field tests indicated that a slope protection slab prepared from Sherco spray dryer waste placed with a $20 \%$ moisture content showed almost no deterioration after 20 months in the field. A slab prepared from a mixture of $25 \%$ Riverside fly ash and $75 \%$ bottom ash with a moisture content of $18 \%$ showed a slight loss of material from the surface of the slab, but no substantial deterioration after 20 months in the field. Two other materials containing Riverside fly ash that were prepared with higher moisture contents showed somewhat more deterioration after 20 months, although none of the field test slabs appeared to have failed in that time period.

Municipal Waste Disposal Crisis. Hearings before the Subcommittee on Transportation, Tourism, and Hazardous Materials of the Committee on Energy and Commerce, House of Representatives, One 
Hundredth Congress, First Session, March 19, May 6, and June 5, 1989, Original Series Serial No. 100-38, 404 pp. (1987).

Members of Congress and other government officials were among those testifying at a hearing to discuss the problems involved in municipal waste disposal. According to a number of studies the municipal solid waste problem in this country is growing rapidly. As of 1985 , we as a nation were generating nearly 200 million tons of municipal waste each year, and this figure is growing at an estimated rate of between 25 and 75 million tons per year. Cities across the country are now struggling with many issues relating to municipal waste disposal. One of the key issues is the safe disposal of municipal incinerator ash. The toxicity of the ashes, particularly the fly ash has been acknowledged under certain circumstances by EPA. An attempt should be made to concentrate on finding treatment solutions that will detoxify residues which are determined to be toxic.

Nanyang Technological Institute, Singapore (China), "Ultimate Disposal of Sludge," Heavy Metals in the Environment: Volume 1, Tay, J.H., Lindberg, S.E., Hutchinson, T.C., eds., (Oak Ridge National Laboratory). Presented at the Sixth Intemational Conference on Heavy Metals in the Environment, New Orleans, Louisiana, 15 September 1987, Report No. ORNL/M-463, CONF-870937-Vol.1, pp. 91-95 (1987).

Sludge is an unavoidable consequence of waste water treatment and creates the problem of disposal. Most of the sludge is disposed of either by spreading on the land, landfilling in selected locations, dumping into the sea, or incineration. This paper presented the use of dewatered sludge as brick-making material and cement substitute as an alternative solution for sludge disposal. The effects of various percentages of sludge on the properties of brick and concrete were highlighted.

National Center for Resource Recovery, Inc., Recapitulative Analysis of Model, Laboratory and Full-Scale Trommel Performance Investigations by NCRR, 1980-1981, Report No. DOE/CS/24315-20, 72 pp. (October 1983).

The report reviews work performed by the National Center for Resource Recovery (NCRR) from April 1980 to July 1981 to further understanding and obtain reliable data on the design, operation, and performance of rotary screens (trommels) using municipal solid waste (MSW) or its fractions as feedstocks. Contents are described and comments are made on each of eight reports written as interim documents or final test reports by NCRR and its subcontractor, the Warren Spring Laboratory of the U.K. Department of Industry in Stevenage, Great Britain. Full-scale tests at New Orleans, Louisiana, and Doncaster, Byker, and Stevenage, U.K, conducted on trommels of different geometric or dynamic characteristics, are analyzed. The report states that a fair degree of correlation exists between the modeling and theoretical work pursued under the contract and experimental observations. The same comment applies to the corroboration of theory with experimental data obtained at the laboratory scale at the NCRR Laboratory in Marlboro, Maryland. The report introduces a number of suggested calculation procedures that could be helpful in the design of trommels and the prediction of their performance as screening devices operating on municipal waste and its processed fractions.

National Center for Resource Recovery, Inc., Resource Recovery Analysis Briefing Workbook, Report No. DOE/CS/20167-11, 194 pp. (February 1982).

This workbook is intended to aid public officials in the implementation of resource-recovery facilities. Chapters deal with methods of analysis, resource-recovery systems, solid-waste management 
systems, disposal costs at landfill, potential for resource recovery, resource-recovery facility costs, projecting future costs and revenues, and landfill-gas recovery and utilization.

National Center for Resource Recovery, Inc., Review of the Literature on the Use of Trommels in Waste Processing and Resource Recovery, Report No. DOE/CS/20167-6, 60 pp. (March 1981).

Published and unpublished literature on the use of trommels (rotary screens) for waste processing and resource recovery is presented in the format of a review essay. The appendix gives design and operating data for 13 trommels in the United States.

National Center for Resource Recovery, Inc., Use of RDF to Dry Recovered Froth-Floated Glass, Final Report, Report No. DOE/CS/20167-2, 122 pp. (October 1980).

Glass particles are recovered from the heavy fraction of municipal solid waste during wet processing for resale as cullet. Drying the glass product with fossil fuels costs $\$ 2 /$ ton for a product selling for $\$ 20-30 /$ ton. This study assesses the technical feasibility and economic effect of using waste or refuse-derived fuels to dry recovered glass at the resource-recovery site. The potential effects of increasing cullet recovery, oil conservation, and indirect fuel savings to the glass manufacturing industry are examined.

National Renewable Energy Laboratory, $R D \& D$ Priorities for Energy Production and Resource Conservation from Municipal Solid Waste, Report No. NREL/TP-431-4982, Order No. DE92016406, 268 pp. (August 1992).

This report identifies research, development, and demonstration (RD\&D) needs and priorities associated with municipal solid waste (MSW) management technologies that conserve or produce energy or resources. The changing character of MSW waste management and the public's heightened awareness of its real and perceived benefits and costs creates opportunities for RD\&D in MSW technologies. Increased recycling, for example, creates new opportunities for energy, chemicals, and materials recovery. New technologies to control and monitor emissions from MSW combustion facilities are available for further improvement or application. Furthermore, emerging waste-to-energy technologies may offer environmental, economic, and other advantages. Given these developments, the U.S. Department of Energy (DOE) identified a need to assess the RD\&D needs and priorities and carefully target RD\&D efforts to help solve the carbon's waste management problem and further the National Energy Strategy. This report identifies and documents RD\&D needs and priorities in the broad area of MSW resource recovery, focusing on efforts to make MSW management technologies commercially viable or to improve their commercial deployment over a 5- to 10-year period. Panels of technical experts identified 279 RD\&D needs in 12 technology areas, ranking about one-fifth of these needs as priorities. A "Peer Review Group" identified mass-burn combustion, "systems studies," landfill gas, and ash utilization and disposal as high priority areas for RD\&D based on cost and the impacts of further RD\&D. The results of this assessment are intended to provide guidance to DOE concerning possible future RD\&D projects.

National Renewable Energy Laboratory, Five Year Research Plan, 1988-1992: Biofuels: Renewable Fuels for the Future, Report No. DOE/CH/10093-25, Order No. DE88001181, 37 pp. (July 1988).

This five-year research plan sets forth the research activities of the U.S. Department of Energy's (DOE) Biofuels and Municipal Waste Technology Program for 1988 through 1992. These research 
activities are necessary to provide versatile, renewable substitutes for oil and natural gas, the fossil fuels that power much of the world. In developing and implementing this plan, DOE and several of its laboratories are working closely with university, industrial, and other federal and local government research organizations. The Biofuels and Municipal Waste Technology Program focuses on the production of liquid fuels such as alcohol fuels, biocrude-derived gasoline, and plant-oil-drived diesel fuel, and gaseous fuels such as biogas and syngas. These fuels can be produced from many plant materials and from certain waste products such as municipal waste. These raw materials, or feedstocks, together are called biomass.

New York City Department of Sanitation, A Model Request for Proposals: The Brooklyn Navy Yard Resource Recovery Facility, Report No. DOE/CS/20170-1, 179 pp. (July 1981).

This document is a Request for Proposals (RFP) issued by the City of New York soliciting proposals for the construction of the city's first resource-recovery plant. The city conducted the legal, financial, and technical investigations necessary to develop a comprehensive and definitive RFP. The information provided in this RFP is designed to guide the proposer in the preparation and submission of a proposal. Section 2 of the document provides information on the city's solid-waste management system and its approach to resource recovery, as well as general background information necessary to respond to this RFP.

O'Connell, R.A., Northeast Regional Biomass Energy Program, Report No. DOE/OR/21389-29, Order No. DE91014531, 7 pp. (October 1990).

This final report summarizes the actions of the past year (7th year), an overview of the Northeast Regional Biomass Program (NRBP), the biomass energy challenge, and future direction. Attached to this report are the four quarterly reports previously submitted, which provide specific details. The management structure and program objectives for the Northeast Regional Biomass Program remain unchanged from previous years. The funding for this year, however, was considerably reduced permitting the issuance of grants to states to be held to $\$ 15,000$ per state. It also meant that fewer projects could be undertaken in the technical subcontract area. To alleviate this condition, $\$ 120,000$ of unobligated state grant funds was transferred to the technical subcontract area. Technical projects were selected by the NRBP Steering Committee.

O'Connell, R.A., Northeast Regional Biomass Energy Program Progress Report, April 1990-June 1990, Report No. DOE/OR/21389-27, Order No. DE90015062, 7 pp. (July 1990).

This document discusses activities during this reporting period. The management structure and program objectives for the Northeast Regional Biomass Program remain unchanged from previous years. The funding for this year however has been considerably reduced permitting the issuance of grants to states to be held to $\$ 15,000 /$ State. It also meant that fewer projects could be undertaken in the technical subcontract area. To alleviate this condition, $\$ 120,000$ of unobligated state agent funds has been transferred to the technical subcontract area. Technical projects have been selected by the Steering Committee. Work statements are in preparation. The Biofuels and Municipal Waste Technology Division has advised that the Northeast Regional Biomass Program (NRBP) will receive $\$ 610,000$ of fiscal year 1990 funds to contract future programs. Also discussed are research and management highlights, Technical grants, Technical subcontracts, and Technology Transfer. 
O'Connell, R.A., Northeast Regional Biomass Energy Program, Report No. DOE/OR/21389-25, Order No. DE90015074, 6 pp. (April 1990).

In 1990, the management structure and program objectives for the Northeast Regional Biomass Program remained unchanged from previous years. The funding, however, was considerably reduced, causing the issuance of grants to states to be held to $\$ 15,000 /$ state. To alleviate this condition, $\$ 120,000$ of unobligated state grant funds was transferred to the technical subcontract area. Technical projects were selected by the Steering Committee. The final report entitled Energy Implications of Alternative Solid Waste Management Systems was prepared and distributed to NRBP states. An overview of the findings are as follows: all but three states (DE, ME, MA) show positive waste management systems balance, incinerator goals are the single largest contributor to systems balance, significant projected energy savings through waste recycling operations, recycling waste leads to reduced energy use for operations, recycling yields a higher value fuel and less ash, infrastructure to handle planned recyclables will require major improvements, and several cases of inconsistency in state MSW Plans.

O'Connell, R.A., Northeast Regional Biomass Energy Program, Report No. DOE/OR/21389-22, Order No. DE90001915, 15 pp. (October 1989).

The Northeast Regional Biomass Program (NRBP) was initiated in August 1983 with a grant to the Coalition of Northeastem Governors Policy Research Center, Inc. from the U. S. Department of Energy's Oak Ridge Operations Office. The program is designed to promote the responsible use of biomass energy in the Northeast region which encompasses eleven states (Connecticut, Delaware, Maine, Maryland, Massachusetts, New Hampshire, New Jersey, New York, Pennsylvania, Rhode Island and Vermont). The Program conducted by NRBP has three basic features: (1) a state grant component that provides funds (within a 50 percent matching requirement) to each of the state agencies involved in biomass energy; (2) a series of technical reports and studies in areas that have been identified as being of critical importance to the development of biomass energy in the region; and (3) a continuous long range planning component with heavy private sector involvement that helps to identify activities necessary to spur greater development and use of biomass energy in the Northeast.

O'Connell, R., Northeast Regional Biomass Energy Program: Progress Report, April 1989-June 1989, Report No. DOE/OR/21389-21, Order No. DE89015927, 11 pp. (July 1989).

The Northeast Regional Biomass Program (NRBP) was initiated in August 1983 with a grant to the Coalition of Northeastern Governors (CONEG), Policy Research Center, Inc. from the U.S. Department of Energy's Oak Ridge Operations Office. The program is designed to promote the responsible use of biomass energy in the Northeast region which encompasses eleven states (Connecticut, Delaware, Maine, Maryland, Massachusetts, New Hampshire, New Jersey, New York, Pennsylvania, Rhode Island and Vermont). The Program conducted by NRBP has three basic features: (1) a state grant component that provides funds (with a 50\% matching requirement) to each of the state agencies involved in biomass energy; (2) a series of technical reports and studies in areas that have been identified as being of critical importance to the development of biomass energy in the region; and, (3) a continuous long range planning component with heavy private sector involvement that helps to identify activities necessary to spur greater development and use of biomass energy in the Northeast. 
O'Connell, R., Northeast Regional Biomass Energy Program: Progress Report, January 1989-March 1989, Report No. DOE/OR/21389-16, Order No. DE89012956, 14 pp. (April 1989).

The program conducted by Northeast Regional Biomass Program has three basic features: (1) a state grant component that provides funds (with a 50 percent matching requirement) to each of the state agencies involved in biomass energy; (2) a series of technical reports and studies in areas that have been identified as being of critical importance to the development of biomass energy in the region; and (3) a continuous long range planning component with heavy private sector involvement that helps to identify activities necessary to spur greater development and use of biomass energy in the Northeast. The state grant program provides states with an opportunity to strengthen and integrate the work of energy, forestry, air quality. Until recently, most state efforts to promote biomass involved various aspects of this energy source. The state grant projects required interagency cooperation and fall into several general categories: industrial conversion assistance; resource availability and use assessments; technical information development and dissemination; and conversion of state facilities.

O'Connell, R., Northeast Regional Biomass Energy Program: Quarterly Report, October 1988-December 1988, Report No. DOE/OR/21389-15, Order No. DE89007369, 20 pp. (January 1989).

This abstract has three basic features: (1) a state grant component that provides funds (with a $50 \%$ matching requirement) to each of the states in the region to strengthen and integrate the work of state agencies involved in biomass energy; (2) a series of technical reports and studies in areas that have been identified as being of critical importance to the development of biomass energy in the region; and, (3) a continuous long range planning component with heavy private sector involvement that helps to identify activities necessary to spur greater development and use of biomass energy in the Northeast. The state grant program provides states with an opportunity to strengthen and integrate the work of energy, forestry, air quality and other appropriate offices in promoting biomass energy use. Until recently, most state efforts to promote biomass energy have been fragmented among a wide range of agencies involved in various aspects of this energy source. The state grant projects require interagency cooperation and fall into several general categories: industrial conversion assistance; resource availability and use assessments; technical information development and dissemination; and conversion of state facilities.

One America, Inc., Urban Waste Program Research and Development 1978-1981: An Overview, Report No. DOE/CS/24312-3, 110 pp. (August 1982).

This report documents the U.S. Department of Energy Urban Waste Program's research and development investments between Fiscal Year 1978 and the end of Fiscal Year 1981.

Pacheco, J., Prairie, M., and Yellowhorse, L., (Sandia National Laboratories) "Photocatalytic Destruction of Chlorinated Solvents With Solar Energy," Solar Engineering 1991, Mancini, T.R., Watanabe, K., Klett, D.E., eds. Presented at the American Society of Mechanical Engineers (ASME)/Japan Solar Energy Society (JSES)/Japan Society of Mechanical Engineers (JSME) International Solar Energy Conference, Reno, Nevada, 17-22 March, 1991, New York: American Society of Mechanical Engineers, Report No. CONF-910318, pp. 275-282 (1991).

Sandia National Laboratories and the National Renewable Energy Laboratory are developing a photocatalytic process to destroy organic contaminants in water. Tests with common water pollutants are being conducted at Sandia's Solar Thermal Test Facility using a near commercial-scale single-axis tracking parabolic trough system with a glass pipe reactor mounted at its focus. Experiments at this scale provide 
verification of laboratory studies and allow examination of design and operation issues as a real-life scale. The catalyst, titanium dioxide $\left(\mathrm{TiO}_{2}\right)$, is a harmless material found in paint, cosmetics and toothpaste. Experiments were conducted to determine the effect of key process parameters on destruction rates of two chlorinated organic compounds that are common water pollutants: trichloroethylene and trichloroethane. In this paper the authors summarize the engineering-scale results of these experiments and analyses.

Paulsen, G., Epps, J.A., Shepherd, P.B., Powers, T.J., and Albers, J.L., Recovery and Reuse of Asphalt Roofing Waste: Incorporation of Roofing Waste in Asphalt Paving. Volume 1. Analysis, Report No. DOE/ID/12560-2-Vol.1, Order No. DE87000618, 100 pp. (15 September 1986).

A prior U. S. Department of Energy study on ten candidate methods for recovering the energy resource represented in asphalt roofing waste showed that incorporating this waste in asphalt paving was a potentially viable commercial means for recovering a large portion of the annual $7 \times 10^{13} /$ Btus in this waste resource. Laboratory tests were designed to investigate this potential and study such variables as waste preparation and amount of roofing waste which might be added to asphalt paving. These laboratory studies reported in Volume II of this report showed that paving mixes can be prepared using hammer milled, worn-out shingles up to about $181 / 2 \%$ by weight ( $30 \%$ by volume). The laboratory tests, limited to field waste, showed that the source of waste, size of waste and amount of waste will influence the test response of paving mixes. Preliminary economic projections were made based on the laboratory test results. Adding roofing waste to asphalt paving should prove to be a financially viable means for recovering the energy resource in asphalt roofing waste. Pavement mix cost reductions in the range of $5 \%$ to $20 \%$ were estimated for the ranges of waste addition tested.

Pearson, C.V., (Argonne National Laboratory) "Effluent Dewatering Research for MSW and Wastewater Treatment Sludges," FY 1987 Anaerobic Digestion: Annual Report, Report No. SERI/SP-231-3331, Order No. DE88001172, pp. 201-212 (July 1988).

Since 1983 the program to investigate methods to achieve near energy independence in wastewater treatment plants has focused on two areas that have the greatest possibility for energy reduction and subsequent energy production in the processing of municipal wastewater. Development of a low energy process to produce combustor-fuel-quality sludge has been the primary focus of the program. Two processes have been investigated-the BMI electro-acoustic process and the low-grade energy, contact-drier process being developed at Clemson University. Both processes have achieved solids concentrations of from $37 \%$ to $45 \%$ using no more energy than is required by conventional equipment to achieve $15 \%$ to $22 \%$ solids. The end-product is autogenous and appears to be capable of being burned for energy production as a single fuel and is able to achieve the desired $1500^{\circ} \mathrm{F}$ to $1700^{\circ} \mathrm{F}$ flame temperature required for odor control.

Pearson, C.V., (Argonne National Laboratory) Effluent Dewatering Research for MSW (Municipal Solid Waste) and Wastewater Treatment Sludges, presented at the Anaerobic Digestion Program Review Meeting, Golden, Colorado, 1 December 1987, Report No. CONF-871269-2, Order No. DE88005991, 12 pp. (1987).

Since 1983 the program to investigate methods to achieve near energy independence in wastewater treatment plants has focused on two areas that have the greatest possibility for energy reduction and subsequent energy production in the processing of municipal wastewater. Development of a low energy process to produce combustor-fuel-quality sludge has been the primary focus of the program. Two processes have been investigated-the BMI electro-acoustic process and the low-grade energy, 
contact-drier process being developed at Clemson University. Both processes have achieved solids concentrations of from $37 \%$ to $45 \%$ using no more energy than is required by conventional equipment to achieve $15 \%$ to $22 \%$ solids. The end-product is autogenous and appears to be capable of being bumed for energy production as a single fuel and is able to achieve the desired $1500^{\circ} \mathrm{F}$ to $1700^{\circ} \mathrm{F}$ flame temperature required for odor control.

Pierson, F.W. and Pearson, C.V., Energy from Municipal Waste: Assessment of Energy Conservation and Recovery in Municipal Wastewater Treatment, Report No. ANL/CNSVTM-124, 124 pp. (October 1984).

This is a qualitative report on the status of a program for energy conservation in wastewater treatment. Analyzing the nation's energy requirements for wastewater treatment by process has shown that the wastewater and sludge stabilization processes accounted for more than $56 \%$ of the energy used for wastewater treatment in 1978. Advanced processes are projected to have the largest increase in energy of all treatment processes between 1978 and the year 2000. To promote energy conservation in wastewater treatment, the U.S. Department of Energy has sponsored a number of projects including the demonstration of the Anaerobic Upflow Bioreactor at Knoxville, Tennessee; the assessment of digester-gas production and use in anaerobic-digestion facilities; the study of the enhancement of anaerobic digestion by carbon addition; the demonstration of water-hyacinth wastewater treatment at Lake Buena Vista, Florida; and the demonstration of unheated anaerobic contact stabilization of sludge. This report describes these programs.

Proceedings of the U.S. Department of Energy, Energy Optimization of Water and Wastewater Management for Municipal and Industrial Applications Conference, Vols. 1 and 2, held in New Orleans, Louisiana, December 10-13, 1979, Report No. ANLEES-TM-96, Vol. 1, 570 pp; Vol. 2, 576 pp. (August 1980).

The conference focused on energy use and conservation in water and wastewater. Volume 1 covers the General Session and Sessions 1-5; Volume 2 covers Sessions 6-12. Session 1 papers discuss energy in the planning process, including energy audits, alternative technologies, multipurpose reservoirs, and digester gas utilization. Session 2 papers focus on research and development. Topics include the anaerobic upflow fixed-film process, energy efficiency of deep U-tube aeration, digestion of treatment plant side-streams, rotating biological contactors, the binary cooling tower process, activated biofiltration, use of solar power, and use of brewery wastes as an alternative to methanol denitrification. Session 3 , on energy use in design considerations, includes case studies of filters, aeration systems, hydrograph controlled release, digester design, solar sludge drying, and heat recovery. Session 4 covers industrial applications, including synfuel options, recycling waste through forages, ultrasonics and electrostatics, enhanced separation methods for oil recovery, a hydraulically operated helical-flow reactor, and methane generation from whey. Session 5 addresses conservation in operations and maintenance; topics include monitoring, fine-tuning, tracer measurement of oxygen transfer, two-stage gas-liquid dissolution for an activated sludge process, sequencing batch treatment of wastewater, and cost-effective methods for small communities.

Volume 2 contains Session 6 papers on water supply, covering such topics as water flow controls, groundwater production, time-of-use electricity rates, and case studies of water savings in operating wastewater plants. The unit processes reviewed in Session 7 include the rotating biological contractor, shallow-bed low-head filtration, rapid infiltration, and fluid-bed regeneration of granular activated carbon. In Sessions 8 and 9, case studies are reported on sludge management and energy recovery, respectively. The Session 10 topic was transmission pumping systems, pipeline maintenance, and pressure sewer systems. Alternative conservation technologies surveyed in Session 11 include plastic media for rock 
trickling filters, fixed-film reactors, self-propelled aerators for lagoons, and trace contaminant removal from secondary domestic effluent by vascular aquatic plants. The focus of papers from the final session of the conference, Session 12, was public and private cooperation for energy-conserving design and operation.

Renard, M., Review of Comparative Energy Use in Materials Potentially Recoverable from Municipal Solid Waste, Report No. DOE/CS/20167-12, 79 pp. (March 1982).

This study reviews published literature on the energy savings that might be realized from manufacturing four materials present in municipal solid waste (MSW), using recycled rather than virgin materials. The four materials examined are glass, paper, steel, and aluminum. An attempt is made to assess this energy savings, reported by diverse sources, on a consistent basis or at least by pointing out the conceptual bases on which the results were obtained. The review indicates that significant savings in manufacturing energy are achievable for aluminum, steel, glass, and certain grades of paper. These materials are all potentially recoverable from the MSW stream, but they must be of a purity and in a form acceptable to the respective industries for reuse in manufacturing.

Renewable Energy, A Glossary, Report No. DOE/TIC-11617, 21 pp. (March 1985).

This report provides current specialized terminology associated with the development of renewable energy resources to U.S. Department of Energy (DOE) administrators and program managers. Included are definitions of terms associated with solar heating and cooling, photovoltaic conversion, solar thermal technology, biomass production and conversion, wind and wave energy, and geothermal energy conversion. Brief descriptions of some of the major projects supported by DOE are also included.

Richerson, F.B., "MSW to Ethanol Process," Biofuels and Municipal Waste Technology Research Program Summary: FY 1986, Report No. DOE/CH/10093-6, Order No. DE87001140, p. 124 (July 1987).

The objectives of this project are to evaluate alternative pretreatments for municipal solid waste (MSW), and to determine the digestibility of MSW after the pretreatment, the capital and operating costs of the pretreatments, and whether the pretreatments are cost effective. Three mechanical pretreatment methods and one thermochemical pretreatment method have been identified for testing at the pilot scale: Draiswerke Perl (ball) Mill; C.E. Bauer double and single disk refiners; SBM Wegeneder double rotor hammermill; and Stake Technology, Ltd. steam explosion process. Each of these pretreatment equipment types is used to process several thousand pounds of material in order to ascertain the operating characteristics, throughput, and power consumption. Samples of the pretreated material are then sent to the University of Arkansas where they are tested for enzymatic digestibility. The samples will also be used to test the ability of the enzyme-producing fungi to grow on the pretreated MSW feedstock. From these data, capital and operating cost estimates will be made to determine the economic and technical feasibility of each pretreatment.

Richlen, S.L., Corrosive Resistant Heat Exchanger, Patent No.: US 4840226, Patent Assignee(s): U. S. Department of Energy, Washington, D.C., Patent Date Filed: 10 August 1987, 10 pp. (27 June 1989).

A corrosive and errosive resistant heat exchange is described that recovers heat from a contaminated heat stream. The heat exchanger uses a boundary layer of innocuous gas, which is continuously replenished, to protect the heat exchanger surface from the hot contaminated gas. The 
innocuous gas is conveyed through ducts or perforations in the heat exchanger wall. Heat from the heat stream is transferred by radiation to the heat exchanger wall. Heat is removed from the outer heat exchanger wall by a heat recovery medium.

Richmond, P., and Brooks, C. (Argonne National Laboratory) "Tulsa Resource-Recovery Project: From Start to Start-Up," Energy from Municipal Wastes: Opportunities for the Southwest, presented at the Workshop on Energy from Municipal Waste: Opportunities for the Southwest, Austin, Texas, 23 June 1986, Report Nos. ANL/CNSV-TM-173, CONF-8606334, Order No. DE87014258, pp. 206-211 (May 1987).

To deal with the problem of limited landfill space available for municipal waste disposal, the city of Tulsa began looking for a successful, cost effective resource recovery project. The authors discuss the problems encountered, the decisions that had to be made and the risks that were involved with the project.

Ridzon, G.J., et al., Institutional Issues Concerning Energy from Municipal Waste: A Status Report, Report No. ANL/CNSV-TM-123, 168 pp. (June 1983).

This report describes the institutional issues affecting the successful recovery of energy and material from MSW. Within the institutional area falls a range of less technical topics that directly affect the opportunities to implement MSW projects. These topics include economics, market, financing, risks, contracts, environmental impacts, and operation. The objective here is to complement existing technical reports with an analysis of nontechnical considerations critical to the successful use of MSW technologies. Although much is understood and has been written regarding the various EMW technologies-their availabilities, assets and liabilities-many projects have experienced significant setbacks as a result of inadequate preliminary planning and concern with the less technical or institutional aspects of a project's development and implementation.

Rivera, A.L. and Ferrada, J.J., (Oak Ridge National Laboratory) Progress on Developing Expert Systems in Waste Management and Disposal, Joint ANS/ASME Nuclear Engineering Conference, Newport, Rhode Island, 16-20 September 1990, Report No. CONF-9009110-2, Order No. DE90012174, 6 pp. (1990).

The concept of artificial intelligence (AI) represents a challenging opportunity in expanding the potential benefits from computer technology in waste management and disposal. The potential of this concept lies in facilitating the development of intelligent computer systems to help analysts, decision makers, and operators in waste and technology problem solving similar to the way that machines support the laborer. Because the knowledge of multiple human experts is an essential input in the many aspects of waste management and disposal, there are numerous opportunities for the development of an expert system using software products from AI. The spectrum of opportunities for expert systems development ranges from identification of waste and technology research needs to real-time control of waste management and disposal operations. This paper presents systems analysis as an attractive framework for the development of intelligent computer systems of significance to waste management and disposal, and it provides an overview of limited prototype systems and the commercially available software used during prototype development activities. 
Sabate, J., Anderson, M.A., Kikkawa, H., Edwards, M., and Hill, C.G. Jr., "A Kinetic Study of the Photocatalytic Degradation of 3-chlorosalicylic Acid Over $\mathrm{TiO}_{2}$ Membranes Supported on Glass," Joumal of Catalysis, v 127:1, pp. 167-177 (January 1991).

The photocatalytic degradation of 3-chlorosalicylic acid to $\mathrm{HCI}$ and $\mathrm{CO}_{2}$ on glass-supported $\mathrm{TiO}_{2}$ has been investigated in a photoreactor designed to permit both continuous throughput of gaseous and liquid feed streams and frequent exchange of the catalyst. The data for the photodegradation reaction can best be correlated in terms of the rate expression: $r=k^{1}\left(\mathrm{O}_{2}\right) \mathrm{K}_{2}(\mathrm{~S}) /\left(\left(1+\mathrm{K}^{1}\left(\mathrm{O}_{2}\right)\right)\left(1+\mathrm{K}_{2}(\mathrm{~S})\right)\right)$, where $\left(\mathrm{O}_{2}\right)$ and $(S)$ represent the concentrations of oxygen and 3-chlorosalicylic acid, respectively.

Sassi Corp., Process Selection and Investment Analysis Methanation Facility for PUROX Off-Gas, Report No. DOE/CS/20449-1, 186 pp. (August 1981).

This report discusses a part of a study to determine the viability of converting refuse (trash and garbage) to synthetic natural gas. This conversion would be accomplished by (1) shredding and preparing the refuse for conversion, producing a gas of low calorific value from the refuse using the Union Carbide PUROX $^{\circledR}$ Process, and methanating the PUROX ${ }^{\circledR}$ off-gas to a quality suitable for sale in the existing gas-distribution system. The last step of this conversion process, the PUROX ${ }^{\circledR}$ off-gas methanation (covered in this report) comprises a process study and investment analysis.

Savage, G.M., Glaub, J.C., and Diaz, L.F., Models of Unit Operations Used for Solid-Waste Processing, Report No. ANL/CNSV-TM-152, 229 pp. (September 1984).

This report documents the unit operations models that have been developed for typical refusederived-fuel processing systems. These models, which represent the mass balances, energy requirements, and economics of the unit operations, are derived, where possible, from basic principles; empiricism has been invoked where a governing theory has yet to be developed. Field test data and manufacturers' information, where available, supplement the analytical development of the models. A literature review has also been included.

Sawyer, H.T., Apparatus and Method for Deliquifying Material, Report No. DOE/CH/10380-1, Order No. DE90009058, 11 pp. (17 January 1990).

Dewatering toxic wastes comprised of industrial, municipal sanitation treatment sludges, food, pulp and paper, industrial wastes, processed material, and effluent waste discharges, is a very expensive operation that is achieved by commercially available equipment such as rotating vacuum drum filters, centrifuges, pressurized belt filters, and vacuumed moving screens. The U.S. Department of Energy funded a feasibility study, based on the subject new technology, to determine if it may be possible to apply the necessary amount of energy in the form of cavitation to the liquid-mass on a screen to disengage the liquid from the material and to release and recover the liquid that has passed through a screen. A subcontract purchase order was delivered to the Loyola Marymount University of Los Angeles to test the prototype dewatering apparatus and to determine the extraction characteristics of the apparatus when used with a variety of industrial test samples and screen mesh sizes. Various test samples were scheduled and delivered to the university from the pulp and paper, food, municipal, and sanitation industries etc. for the test program. This document describes the test program and results. 
Science Applications International Corporation, Who's Who in Energy Recovery from Waste, Report No. DOE/CE/30784-1, 54 pp. (October 1985).

This directory provides names, addresses, and affiliations of persons in the resource-recovery field, including representatives from government; researchinstitutes and universities; associations; public interest groups; trade joumals and publications; system vendors, operators, and equipment manufacturers; investment bankers and bond counselors; and engineering, management, and technical consultants.

Shepherd, P.B. and Powers, T.J., Recovery and Reuse of Asphalt Roofing Waste: Recycling Roofing Waste to New Roofing, Report No. DOE/ID/12560-4, Order No. DE87012421, 92 pp. (July 1987).

A prior U. S. Department of Energy study on ten candidate methods for recovering the energy resource represented in asphalt roofing waste showed that incorporating fresh factory waste in new roofing was a potentially viable means for recovering some of the annual $7 \times 10^{13} / \mathrm{Btu}$ in this waste resource. The project reported here involved measuring the effect of adding factory waste to the asphalt coating compound (called filled coating asphalt). The influence of waste type, size, and quantity on coating asphalt properties such as viscosity, impact resistance, pliability, and service life was measured. In addition, experiments were made to determine if there was a possibility of using field waste (worn-out asphalt roofing) in a similar manner.

Sladek, T.A. and Demos, E.K., Disposal Techniques with Energy Recovery for Scrapped Vehicle Tires, Report No. DOE/IR/05106-T83, Order No. DE89013847, 99 pp. (June 1987).

The scrap tire disposal problem is serious and widespread. However, there are a number of promising management options, especially using the rubber as a supplemental fuel for existing combustors. The most cost-effective approach to dealing with Denver's tire stockpile appears to be shredding to a coarse size range, storing the shreds in a secure area, and marketing the rubber to nearby cement kilns, lime kilns, and boilers. This interim step would greatly reduce the volume of the pile, facilitate the Superfund evaluation, reduce fire and disease hazards, and simplify subsequent materials handling. Further processing to obtain rubber chips or crumbs may also be practical. However, the industry and the markets would have to emerge over time. New power plants or pyrolysis facilities would be impeded by the low energy prices in Denver and the need for elaborate pollution controls. Landfilling could be considered as a last resort. Landfilling costs would be minimized if the tires are shredded. Chapter 2 discusses the tire disposal problem and the general options for tire management. Chapter 3 describes the methodology used to analyze Denver's situation and presents the results and conclusions obtained. This includes evaluating strategies to implement the more promising resource recovery options in the Denver area. Chapter 4 summarizes the lessons learned and identifies impediments and uncertainties that need to be addressed in any future studies. The Appendix contains additional acknowledgments, a list of references, definitions for the acronyms and units used in the text, the agenda for the tire workshop, and a brief description of a stockpile fire near Denver in June 1987.

Solid Waste Integrated Cost Analysis Model: 1991 Project Year Report, Report No. DOE/CE/27504-13-Pt.2, Order No. DE93005621, 102 pp. (1991).

The purpose of the City of Houston's 1991 Solid Waste Integrated Cost Analysis Model (SWICAM) project was to continue the development of a computerized cost analysis model. This model is to provide solid waste managers with the tools to evaluate the dollar cost of real or hypothetical solid waste management choices. Those choices have become complicated by the implementation of Subtitle D 
of the Resources Conservation and Recovery Act and the U.S. Environmental Protection Agency's Integrated Approach to managing municipal solid waste; that is, minimize generation, maximize recycling, reduce volume (incinerate), and then bury (landfill) only the remainder. Implementation of an integrated solid waste management system involving all or some of the options of recycling, waste to energy, composting, and landfilling is extremely complicated. Factors such as hauling distances, markets, and prices for recyclable, costs and benefits of transfer stations, and material recovery facilities must all be considered. A jurisdiction must determine the cost impacts of implementing a number of various possibilities for managing, handling, processing, and disposing of waste. SWICAM employs a single Lotus 123 spreadsheet to enable a jurisdiction to predict or assess the costs of its waste management system. It allows the user to select his own process flow for waste material and to manipulate the model to include as few or as many options as he or she chooses. The model will calculate the estimated cost for those choices selected. The user can then change the model to include or exclude waste stream components, until the mix of choices suits the user. Graphs can be produced as a visual communication aid in presenting the results of the cost analysis. SWICAM also allows future cost projections to be made.

Sproull, R.D., Premuzic, E.T., Lin, M.S., Kukacka, L.E., (Brookhaven National Laboratory) "Metal Detoxification of Wastewater by Bioaccumulation," Proceedings of the 1987 Pacific Northwest Metals and Minerals Conference (abstracts), presented at the Pacific Northwest Metals and Minerals Conference, Portland, Oregon, 26--28 April 1987, Report No. CONF-8704166, p. 43 (1987).

This paper reports a study of the feasibility of using microorangisms for the detoxification of a 720,000-GPD industrial wastewater stream containing low levels of $\mathrm{Cu}, \mathrm{Mn}, \mathrm{Ni}, \mathrm{Zn}$ and $\mathrm{Cr}$ (as chromate). Batch experiments were characterized by short contact times ( $30 \mathrm{~min}$ or less) between the metal solution and biomass, low $\mathrm{pH}$ (2.5 to 6), and the absence of agitation. Of the microorganisms investigated, E. coli was found to be the most efficient. However, to reduce chromium to drinking water standards, the chromate ions had to be reduced to chromic ions. The major units in the proposed bioaccumulation process include: a chromate reduction facility, a metals adsorption vessel, a biomass growth fermentor, a biomass-water separations facility, a shot pond and a back neturalizer. An economic analysis of this process indicates that the industrial waste stream can be traced to one cent per gallon of waste, which is on the same order as conventional chemical treatment processes.

SRI International, A Technoeconomic Evaluation of the NYU Acid-Hydrolysis Process for Producing Ethanol from Municipal Solid Waste, Report No. DOE/CS/24318-1, 60 pp. (October 1982).

This report describes a technoeconomic analysis of the New York University (NYU) acid-hydrolysis process using a consistent set of economic and design bases developed previously. The technoeconomic analysis includes: consideration of facilities capable of producing sufficient quantities of $\mathrm{C}_{6}$ sugars from typical municipal solid waste for use in production of $25 \times 10^{6} \mathrm{gal} / \mathrm{yr}$ of ethanol; consideration of production of ethanol by both batch and continuous fermentation; preparation of a process description to include feedstock characteristics; process design considerations and block flowsheet; mass flows and utility and operating requirements; calculation of process efficiency; estimation of plant investment cost; estimates of revenue requirements for three types of ventures; a cost sensitivity analysis to demonstrate the effects of feedstock cost (or tipping fee), operating hours, and plant facilities investment cost on product prices; and discussion of the current status of the technology and the availability of the process for commercialization. The process information sources for this study included articles available in the open literature on the NYU process and similar processes and nonproprietary data released by NYU and Werner and Pfleiderer to SRI International. 
Stanley Consultants, Federal Involvement in Municipal Wastewater Treatment Plant Sludge Energy Recovery and Conservation, Report No. CONS/2482-1, 42 pp. (June 1977) [available in microfiche only].

This study examines federal involvement in municipal wastewater treatment plants. The report summarizes major agency programs and related projects, coordination mechanisms, and recommendations for future involvement of the U.S. Department of Energy in sludge energy recovery and conservation projects.

Stanton, S.L., Alam, M.K., Hebner, G.A., (Sandia National Laboratories) High Quality Garbage: A Neural Network Plastic Sorter in Hardware and Software, presented at the GOMAC 93: Government Microcircuit Application Conference, New Orleans, Louisiana, 1-4 November 1993, Report No.(s): SAND-93-0521C and CONF-9311101--2, Order No. DE93041143, 5 pp. (1993).

In order to produce pure polymer streams from post-consumer waste plastics, a quick, accurate and relatively inexpensive method of sorting needs to be implemented. This technology has been demonstrated by using near-infrared spectroscopy reflectance data and neural network classification techniques. Backpropagation neural network routines have been developed to run real-time sortings in the laboratory, using a laboratory-grade spectrometer. In addition, a new reflectance spectrometer has been developed which is fast enough for commercial use. Initial training and test sets taken with the laboratory instrument show that a network is capable of leaming 100\% when classifying 5 groups of plastic (HDPE and LDPE combined), and up to $100 \%$ when classifying 6 groups. Initial data sets from the new instrument have classified plastics into all seven groups with varying degrees of success. One of the initial networks has been implemented in hardware, for high speed computations, and thus rapid classification. Two neural accelerator systems have been evaluated, one based on the Intel 80170NX chip, and another on the AT T ANNA chip.

Stapp, D.C. and Holter, G.M., (Pacific Northwest Laboratory) Solid Waste Research and Development: A Perspective from Pacific Northwest Laboratory, presented at the Eighth International Conference on Solid Waste Management and Secondary Materials, Philadelphia, Pennsylvania, 15-18 November 1992, Report No. PNL-SA-20905, Order No. DE93005101, 8 pp. (November 1992).

The need for research and development (R\&D) of technologies and approaches for sound, effective solid waste management is unquestionable. While many advances have been made by the government and private sectors, still more are needed. Resources for conducting R\&D, even at the federal level, are limited however, and thus it is critical that resources be distributed as wisely as possible. The U.S. Department of Energy (DOE) has a vested interest in developing technologies and approaches for managing solid waste because solid waste management is strongly linked to energy use and environmental impacts. This federal role is needed to address the national and international impacts that can result from the cumulative effects of decisions being made at local, county, state, and regional levels. At Pacific Northwest Laboratory (PNL), one of DOE's R\&D laboratories, is developing an integrated solid waste $\mathrm{R} \& \mathrm{D}$ program to assist DOE in defining its role and in providing the required federal leadership. This paper presents the elements and major thrust areas of PNL's program. 
Steinberg, M., (Brookhaven National Laboratory), Treatment of Municipal Solid Waste (MSW) by the Hydrocarb Process, presented at the National Meeting of the American Chemical Society (ACS)

New York, New York, 25-30 August 1991, Report Nos. BNL-46477, CONF-910812--12, Order No. DE91016996, 5 pp. (May 1991).

This report describes the application of the hydrocarb process to management of municipal solid waste and discusses the economics of a waste processing plant.

Steinberg, M., (Brookhaven National Laboratory) "The HYDROCARB Process-Conversion of Carbonaceous Materials to Clean Carbon and Gaseous Fuel," Energy from Biomass and Wastes XII, Klass, D.L., ed. Presented at the Twelfth Energy from Biomass and Wastes, New Orleans, Louisiana, 15-19 February 1988, Chicago, IL: Institute of Gas Technology, Report No. CONF-880215, pp. 787-804 (1989).

A process (HYDROCARB) is described for converting raw carbonaceous materials to a clean carbon fuel and a coproduct clean gaseous fuel. The process consisting of two major process steps is highly mass and energy efficient. The value of an ash-free and sulfur-free carbon black as a heat engine fuel is described. Estimates indicate that, on an energy basis, the clean carbon fuel produced from U. S. coal can compete with present costs of oil and gas derived fuels in the order of $\$ 2$ to $\$ 4 / \mathrm{MMBTU}$. With biomass and municipal solid waste as feedstocks, conversion costs are in the order of $\$ 4$ to $\$ 5 / \mathrm{MMBTU}$.

Stevenson, G.G., (Oak Ridge National Laboratory), Renewable Energy Data Requirements: A Review of User Opinions and Data Collection Efforts, Report No. ORNL/TM-11869, Order No. DE92002389, 100 pp. (November 1991).

Interest in the contribution of renewable energy to the U.S. energy supply is growing. This interest stems from environmental and energy security concerns and the desire to develop domestic resources. In order to plan for the use of renewable energy, data are essential to a variety of users both inside and outside the government. The purpose of this study is to identify priorities and requirements for gathering different types of renewable energy data. Results of this study are to be used by the U.S. Department of Energy/Energy Information Administration in planning and evaluating its ongoing and future renewable energy information programs. The types of renewable energy addressed in this study include biomass (wood, agricultural residues, and crops grown for energy), municipal solid waste, geothermal energy, solar energy, and wind. To assess the relative importance of different types of information, we reviewed existing renewable energy data collection efforts and asked the opinions of renewable energy data users. Individuals in government, private industry, research organizations, industry trade associations, and public interest research groups were contacted and questioned about particular renewable energy data items. An analysis of their responses provides the basis for the conclusions in this report. The types of information about which we asked each respondent included resource stock and flow information; quantities of energy inputs (e.g., wood) and outputs (e.g., electricity, heat); energy input and output costs and prices; numbers, location, and production capacities of energy conversion facilities; quantities and costs of energy conversion equipment; and quantities of pollutant emissions from energy conversion. 
Steverson, E.M., Semler, T.T., and Goldsberry, J.A. Evaluation of Densification Technologies, Report No. EGG-EA-6775, 204 pp. (June 1985).

The purpose of this work is to assess and evaluate the state of the art of densification technology as it is applied to the production of densified refuse-derived fuels (d-RDF). Such aspects of the technology as performance, economics, pacing problems, operational practice, and available equipment are addressed. The first part of this report describes the chemical, physical, handling, storage, and combustion properties of d-RDF. Data from the various studies and commercial plants that produced d-RDF were obtained and collated to present an assessment of d-RDF as a fuel. The next section presents an evaluation of pellet mills in d-RDF production applications. The majority of d-RDF production processes have involved pellet mills. Data from various tests and visits with pellet mill manufacturers served to provide the information presented. An in-depth technical description of the extrusion process is included and is also applicable to the cubing and extruding processes. A life-cycle economic analysis of a d-RDF production plant, using cost information on the pellet mill, is also presented. This report then presents an assessment of the cuber and other densification techniques. Operating experience on RDF using these techniques is limited, compared with experience using pellet mills, and much of the information presented is speculation by the manufacturers and consultants in the field. The final section presents an assessment of the state of the d-RDF production industry.

Strickland, R.C., Tuten, D.S., and Hardy, M.D., "Conversion of Newsprint- and MSW-cellulosics to Sugar by Dilute Sulfuric Acid Hydrolysis," Twelfth Symposium on Biotechnology for Fuels and Chemicals: Program and Abstracts, Scheitlin, F.M., ed., (Oak Ridge National Laboratory). Presented at the Twelfth Symposium on Biotechnology Fuels and Chemicals, Gatlinburg, Tennessee, 7-11 May, 1990, Report No. CONF-900512-Absts, Order No. DE91000602, Paper 39 (1990).

The Tennessee Valley Authority is developing a two-stage dilute sulfuric acid hydrolysis process to produce sugar from hardwood hemicellulose (first stage) and cellulose (second stage). The objective of this work is to maximize the possible process changes and reduce costs associated with using hydrolysis. To compare sugar production using autohydrolysis or dilute acid, tests are performed at temperatures between $130^{\circ} \mathrm{C}$ and $210^{\circ} \mathrm{C}$, several liquid-to-solid ratios, retention times from $1 \mathrm{~min}$ to 180 min and a sulfuric acid concentration of $0.75 \%$ for the tests with acid. This paper presents data on sugar production, sugar degradation, residue composition, and nonsugar hydrolyzate components resulting from the two types of hemicellulose hydrolysis.

Strickland, R.C., Tuten, D.S., and Hardy, M.D., "Evaluation of Dilute Sulfuric Acid Hydrolysis and Autohydrolysis for Sugar Production from Hardwood Hemicellulose," Twelfth Symposium on Biotechnology for Fuels and Chemicals: Program and Abstracts, Scheitlin, F.M., ed., (Oak Ridge National Laboratory). Presented at the Twelfth Symposium on Biotechnology Fuels and Chemicals, Gatlinburg, Tennessee, 7-11 May, 1990, Report No. CONF-900512-Absts, Order No. DE91000602, Paper 38 (1990).

The Tennessee Valley Authority is evaluating dilute sulfuric acid hydrolysis for sugar production from newsprint and the cellulosic fraction of municipal solid waste (MSW). The objective of this work is to provide information essential for the assessment of the technical and economic feasibility of a process to produce ethanol from these waste cellulosics. A one-step hydrolysis process to maximize glucose production from cellulose coupled with zero or negative feedstock cost could be a viable alternative to the landfilling and mass burning of a significant portion of MSW. Tests have been performed at temperatures between $150^{\circ} \mathrm{C}$ and $210^{\circ} \mathrm{C}$, retention times of 1 to $180 \mathrm{~min}$, and acid concentrations between $1 \%$ and $4 \%$ $(w / w)$. This paper discusses the effect of different hydrolysis variables on glucose production and examines the use of the hydrolysis residue as an acceptable boiler fuel. 
Suffern, J.S. and Vogel, R.A., (Oak Ridge National Laboratory) Waste Minimization Case Histories at Three U.S. Air Force Air Training Command Bases, presented at the Thirteenth Annual Environmental Quality R and D Symposium, Williamsburg, Virginia, 16 November 1988, Report No. CONF-8811122-3, Order No. DE89004929, 36 pp. (1988).

Waste minimization audits are being carried out at three U.S. Air Force Air Training Command bases: Randolph Air Force Base (AFB) near San Antonio, Texas; Lowry AFB near Denver, Colorado; and Keesler AFB near Biloxi, Mississippi. These audits include detailed surveys of base operations and processes, detailed analytical reports that contain recommendations for waste minimization actions, guidelines to allow bases to maintain and change their own waste minimization programs, and training programs for base personnel. The operations and processes are described in detail, as are the recommendations for waste minimization actions. The cost savings and efficiency increases associated with each recommended action are discussed. The cost savings identified vary in amount from base to base, depending on base size and mission, and range from $\$ 42,000$ to $\$ 644,000$ per year. The annualized return on investment for the audits varies between 0.4 and 6.4 , making them an extremely attractive investment for the sponsoring agency. Payback period for recommended waste minimization options varies from immediate to 10 years, the average being less than 1 year. The institutional factors affecting the success of waste minimization programs are discussed, especially the need for involvement of supply and logistics functions.

Surface-Modification Technology for Scrap Tire Reuse, (National Renewable Energy Laboratory), Report No. DOE/CH/10093-123, Order No. DE92001179, 15 pp. (September 1992).

This technical briefing report describes the DOE-Air Products project to develop the surface-modification technology for scrap tire rubber. It introduces the technology; discusses the project history, status, and feasibility studies; and reviews the potential benefits of the technology with respect to energy use and economics. Preliminary analyses indicate energy savings of approximately 60,000 Btu/lb by substituting surface-modified rubber in polyurethane systems.

Swift, G.W., (Los Alamos National Laboratory) Malone Refrigeration, presented at the Oak Ridge National Laboratory Refrigeration and Air Conditioning Technology Workshop, Breckenridge, Colorado, 23-25 June 1993, Report No(s). LA-UR-93-1890 and CONF-9306166--1, Order No: DE93014468, 6 pp. (1993).

Malone refrigeration is the use of a liquid near its critical points without evaporations as working fluid in a regenerative or recuperative refrigeration cycle such as the Stirling and Brayton cycles. Its potential advantages include compactness, efficiency, an environmentally benign working fluid, and reasonable cost. One Malone refrigerator has been built and studied; two more are under construction. Malone refrigeration is such a new, relatively unexplored technology that the potential for inventions leading to improvements in efficiency and simplicity is very high.

Systems Technology Corp., Systems Analysis for the Development of Small Resource Recovery Systems: Description of Solid Waste Modular Simulator, Final Report, Report No. DOE/CS/20026-01-V2, 39 pp. (October 1980).

This report, the second in a series of four, describes the Solid Waste Modular Simulator, a computer program for simulating the performance of solid-waste processing and resource-recovery systems. The current program can simulate systems with design throughput rates of 100 and 200 tons of 
solid waste per day. Systems with larger throughput capacities can also be simulated by supplying the program with their performance data. The main line of this program is an accounting routine that totals costs, revenues, and mass balances for all components in a simulated waste processing line. In addition, the main line controls the input of all information required to execute the program and the output of the resultant system performance data.

Systems Technology Corp., Systems Analysis for the Development of Small Resource Recovery Systems: Executive Summary, Report No. DOE/CS/20026-01-V1, 24 pp. (October 1980).

The report identifies the technologies that should be developed to make small-scale solid-waste facilities attractive to and viable for small municipalities that generate 50-250 tons of solid waste per day. In addition to identifying candidate technologies, the report applies a set of criteria to determine which technologies could best satisfy the existing market conditions. The criteria include costs of alternative landfill disposal, material and energy prices, developmental status of the technology, and environmental impact of the systems.

Systems Technology Corp., Systems Analysis for the Development of Small Resource Recovery Systems: Research and Development Needs, Final Report, Report No. DOE/CS/20026-01-V3, 37 pp. (October 1980).

This systems analysis identifies the research and development (R\&D) needed to advance small-scale resource recovery. A quantitative sensitivity analysis was used to determine which systems warrant the investment of R\&D funds and to identify which system components and operating components could be modified to substantially improve system performance. The R\&D needs presented are classified according to process type.

Systems Technology Corp., Systems Analysis for the Development of Small Resource Recovery Systems: System Performance Data, Final Report, Report No. DOE/CS/2002601-V4, 155 pp. (October 1980).

Intended primarily as a reference document, this volume describes systems and presents performance data. Unique systems are referred to by the manufacturer's name, rather than by a generic system type, to facilitate identification. The inclusion or exclusion of specific systems does not reflect the relative viability of the systems studied. Because the information in this report is intended as a basis for a generalized systems analysis, it should not be used to determine the viability of any system in a specific application.

Thompson, D.T., Process Waste Assessment for Spray Cleaning with Trichloroethylene, Report No. KCP-613-5154, Order No. DE93016583, 23 pp. (June 1993).

A Process Waste Assessment (PWA) was performed on the trichloroethylene (TCE) spray cleaning operation. This process is used on field-returned parts sent to the Kansas City Plant (KCP) for rework, reacceptance, and reuse. Trichloroethylene is a chlorinated hydrocarbon that is number two on the KCP list of Priority Pollution Prevention Issues. This solvent is a frequently used cleaner. Because of the volume used in the department, and the KCP list of Priority Pollution Prevention Issues, the trichloroethylene spray cleaning operation was chosen as the most immediate process requiring review. As a result of the PWA on the TCE spraying cleaning process, several ideas and options were discussed to eliminate TCE usage and waste generation. The goal of the PWA team and the process/product 
engineers is to eliminate TCE usage and waste generation by October 1992. This will be done by using an alternate solvent or by an alternate cleaning method. Parts that require TCE by definition will be studied to determine a suitable replacement solvent. All activities of this nature will be coordinated with the proper Design Agency and KCD product engineer. Future factory order routings on active parts will not require the use of TCE as a cleaning solvent, unless drawing definitions require it.

Ward, P.P., (Sandia National Laboratories) Plasma Cleaning for Waste Minimization, presented at the Workshop on Regulatory Compliance: Waste Minimization, Laramie, Wyoming, 17-19 June 1993, Report No(s). SAND-93-1452C and CONF-9306197--1, Order No. DE93017498, 8 pp. (1993).

Although plasma cleaning is a recognized substitute for solvent cleaning in removing organic contaminants, some universal problems in plasma cleaning processes prevent wider use of plasma techniques. Lack of understanding of the fundainental mechanisms of the process, unreliable endpoint detection techniques, and slow process times make plasma cleaning processes less than desirable. Our approach to address these plasma cleaning problems is described. A comparison of plasma cleaning rates of oxygen and oxygen/sulfur hexafluoride gases shows that fluorine-containing plasmas can enhance etch rates by $400 \%$ over oxygen alone. A discussion of various endpoint indication techniques is discussed and compared for application suitability. Work toward a plasma cleaning database is discussed. In addition to the global problems of plasma cleaning, an experiment in which the specific mixed-waste problem of removal of machine oils from radioactive scrap metal is discussed.

Waste Reduction and Recycling: A Strategy for New Brunswick, Report No. MIC-91-00570/XAB, 32 pp. (1990).

This program has been developed to address the broader issues of waste management. Specifically, it looks at ways government can be influential both in reducing the volume of waste generated and in encouraging and sustaining recycling within the context of the Solid Waste Management Program. In order to ensure that waste reduction and recycling become significant components of regional waste management strategies, several initiatives in each area are proposed.

Waste Distillation Technology, Inc., Evaluation and Test Program of a 50-Ton-per-Day Waste Distillator, Report No. DOE/CE/15126-T4, 170 pp. (June 1985).

The subject of the testing program covered in this report was a 50-ton/d waste distillator manufactured by Waste Distillation Technology, Inc., of Irvington, New York. This distillator produces a volatile gas product, suitable as a boiler fuel, and a carbon char residue via the destructive distillation of municipal solid waste. Actual testing was performed on a demonstration unit located at Marcal Paper Mills, Inc., in Elmwood Park, New Jersey. The results of the final testing and evaluation indicate that the distillation has the ability to provide substantial energy savings in an environmentally safe manner, utilizing municipal solid waste as its sole source of fuel. The technology, dry distillation, should be able to convert a wide variety of potentially hazardous waste products into useable energy without polluting the atmosphere. These waste products include garbage, pharmaceutical waste, printer's ink, paper, plastics, railroad ties, bamyard waste, oil, paint, grease, rubber, solvents, agricultural waste, and other organic material. 
Weyand, T.E., Pyrolyzer Slag Reuse Evaluation, Report No. DOE/CE/30839-T5, Order No. DE91012740, 26 pp. (7 December 1990).

Westinghouse Electric Waste Technology Services Division has evaluated the feasibility of processing municipal incinerator ash in its pyrolyzer to produce a nonhazardous slag product. The scoping work reported here evaluates the potential reuse applications for such a glassy slag in various high-volume reuse markets. The specific evaluations requested involved physical property testing of three slags identified as Combined Ash, Air Cooled; Fly Ash, Water Cooled; and Fly Ash, Air Cooled. Pittsburgh Mineral and Environmental Technology, Inc. was requested to evaluate reuse potential and general economics for the use of such material as Portland cement aggregate, asphalt paving aggregate, and as feedstock for the production of structural clay products and in the production of glass fiber and felt products.

White, A.L., Becker, M.B., and Schatzki, S.T., Energy Implications of Alternative Solid Waste Management Systems, Report No. DOE/OR/21389-26, Order No. DE90015073, 100 pp. (February 1990).

This study examines the energy implications of alternative solid waste management systems. As state and local governments move away from traditional single facility strategies to more integrated waste management systems, energy use and recovery patterns are substantially altered. The direct and indirect effects of such trends result in major shifts in the volumes and composition of waste handled at incineration, recycling, composting and landfill facilities. In addition, second order energy savings result from the substitution of recycled materials for virgin materials in the manufacturing sector. As such shifts occur, the energy balance-the difference between energy recovered and energy used-undergoes major adjusments. Such repercussions occur at the regional, state, local and facility-specific level. Energy balances defined in this study cover seven use points, three recovery points and, separately, energy saved in production processes. For each of eleven Northeastern states, we estimate current balances based on existing waste management systems. State-specific profiles of recycling, composting, resource recovery and landfill activities provide the starting point for these base year estimates. Using the same estimating procedure, and taking into account each state's policy and planning objectives during the 1990's, we proceed to estimate the energy balances that result if such objectives are met. By comparing current balances against future balances, we project the percentage change over a specified planning horizon.

White, D.H., et al., Fundamentals of Direct Liquefaction of Municipal Solid Waste in a Semicontinuous, Microprocessor-Controlled Autoclave, Report No. ANL/CNSV-TM-180, 136 pp. (July 1986)

This report documents work performed at the University of Arizona on two aspects of direct liquefaction of municipal solid waste (MSW) to oils: the role of the water-gas shift reaction, and some mechanisms of the chemical reactions that occur during liquefaction. The work consisted of modifying an existing autoclave and a real-time digital microprocessor control system to allow operation in a semicontinuous mode. The various components of MSW were studied. It was found that these MSW components could be converted to liquid oils and a high-heating-value residual solid at temperatures of $325^{\circ} \mathrm{C}$ to $400^{\circ} \mathrm{C}$ and pressures of 1,000 to 3,000 psi.

White, A.L., et al., Co-Utilization of Municipal Solid Waste and Wood Residues for Small-Scale Resource Recovery: A Preliminary Assessment, Report No. DOE/CS/30149-5, 32 pp. (December 1982).

The availability of municipal solid waste (MSW) and wood residues in the Northeast region is assessed. General statements are supported by specific quantitative data gathered from published sources. 
Included are a number of observations with respect to the geographical interrelationships of the two resources. The technologies and equipment for converting each feed stock into usable energy and for combining the two in a co-utilization mode are discussed, emphasizing equipment appropriate to small-scale applications. It is assumed that MSW technologies are more amenable to the addition of wood wastes than is wood equipment to the addition of MSW. Energy markets are examined for the major energy products from waste recovery-steam and electricity. A single idealized model of a typical market and its sources of feed stock is derived on the basis of patterns of energy demand and resource availability. Case studies of two Vermont projects are presented. One is designed to use MSW as its primary feed stock, whereas the second seeks to use MSW as a supplement to industrial wood residue.

Who's Who in Energy Recovery from Waste, Report No. DOE/CE/39844-H1, Order No. DE89007702, 33 pp. (February 1989).

Who's Who in Energy Recovery from Waste is a directory of organizations and individuals actively involved in the energy from municipal waste field. The purpose of this directory is to facilitate technology and information transfer within the industry and to provide a resource for those communities that are developing or considering municipal waste-to-energy projects.

Wisconsin University, Energy Conservation Manual for Water and Wastewater Facilities, Report No. DOE/TIC-10211-75, 134 pp. (December 1980).

The manual provides water and wastewater managers with an overview of energy conservation activities in Wisconsin and gives specific recommendations for improving programs already in place. Chapter titles are Energy Conservation Management, Water Supply System Energy Conservation, Wastewater Treatment System Energy Conservation, and General Measures for Energy Conservation. The appendixes contain detailed information on energy audits and papers on energy conservation and renewable energy sources.

Wolfe, A.K., (Oak Ridge National Laboratory) Societal Acceptance of Controversial Facilities: The Role of Two Public Participation Strategies-Negotiation and Risk Communication, presented at the Annual Meeting of the Society for Risk Analysis, Washington, D.C., 31 October 1988, Report No. CONF-8810249-3, Order No. DE89007521, p. 18 (1988).

Public participation in decision making about the siting of controversial facilities is viewed in contradictory ways by different groups of people. Some see public participation as an impediment, while others think it is an important mechanism in gaining societal acceptance for eventual siting. This paper discusses two strategies for obtaining societal acceptance-negotiation and risk communication-in light of the extent to which they involve members of the public; focus on risk-related issues; and contribute to decisions to site controversial facilities. The paper presents an integrated conceptual model for public participation in siting decisions that incorporates risk as well as social, political, and historical contexts. 
Yourong, L. and Ju, C., (Oak Ridge National Laboratory), "Study on BOD Microbial Sensor for Wastewater Treatment Control," Twelfth Symposium on Biotechnology for Fuels and Chemicals: Program and Abstracts, Scheitlin, F.M., ed. Presented at the Twelfth Symposium on Biotechnology Fuels and Chemicals, Gatlinburg, Tennessee, 7-11 May, 1990, Report No. CONF-900512-Absts, Order No. DE91000602, paper 110 (1990).

A microbial sensor consisting of immobilized yeast or bacterial cells and an oxygen electrode is used for the estimation of BOD in this study. The structure of the biosensor is delicately designed and a flow-through system was set up. The response time of the biosensor is within $20 \mathrm{~min}$. A linear relationship is observed between the relative current decrease and the BOD of the sample solution in the range of 1 to $45 \mathrm{mg} / 1$. The operation life of the biosensor is more than one year. The reproducibility of the sensor is quite good, and the relative standard deviation is less than $6 \%$ FS at a concentration of 210 $\mathrm{mg} / \mathrm{l}$ BOD. The BOD biosensor is applied to the determination of BOD in a brewery plant and a glutamic acid plant wastewater. Satisfactory agreement is observed between the $\mathrm{BOD}_{5}$ value (by conventional 5-d method) and the value determined by the BOD biosensor.

Zygmunt, S.J., (Los Alamos National Laboratory) Development of Cylinder Gas Disposal Plant: Phase 1, Detailed Project Planning and Concept Development Report, Report No. LA-UR-88-1306, Order No. DE88009179, 17 pp. (February 1988).

The purpose of this program is to develop, test, and document a process for the safe disposal of the contents of leaking, unknown, or damaged gas cylinders. During fiscal year 1988 (FY 1988), the Los Alamos National Laboratory will prepare the equivalent of a Title 1 design for a process to contain problem gas cylinders. Completion of the Title 1 design will allow construction of the prototype process in FY 1989 and testing in FY 1990. Preparation of test run and technology transfer documentation will occur in FY 1991. 


\section{Appendix A}

Pricing Schedule for U.S.

Department of Energy Reports

\begin{tabular}{|c|c|c|c|}
\hline \multirow[b]{2}{*}{$\begin{array}{l}\text { Price } \\
\text { Code }\end{array}$} & \multirow[b]{2}{*}{$\begin{array}{l}\text { Page } \\
\text { Range }\end{array}$} & \multicolumn{2}{|c|}{ Standard Price $(\$)$} \\
\hline & & Domestic & Foreign \\
\hline A01 & Note $^{a}$ & 9.00 & 18.00 \\
\hline A02 & $1-25$ & 12.50 & 25.00 \\
\hline A03 & $26-50$ & 17.50 & 35.00 \\
\hline A04 & $51-75$ & 19.50 & 39.00 \\
\hline A05 & $76-100$ & 19.50 & 39.00 \\
\hline A06 & $101-125$ & 27.00 & 54.00 \\
\hline A07 & $126-150$ & 27.00 & 54.00 \\
\hline A08 & $151-175$ & 27.00 & 54.00 \\
\hline A09 & $176-200$ & 27.00 & 54.00 \\
\hline A10 & $201-225$ & 36.50 & 73.00 \\
\hline A11 & $226-250$ & 36.50 & 73.00 \\
\hline A12 & $251-275$ & 36.50 & 73.00 \\
\hline A13 & $276-300$ & 36.50 & 73.00 \\
\hline A14 & $301-325$ & 44.50 & 89.00 \\
\hline A15 & $326-350$ & 44.50 & 89.00 \\
\hline A16 & $351-375$ & 44.50 & 89.00 \\
\hline A17 & $376-400$ & 44.50 & 89.00 \\
\hline A18 & $401-425$ & 52.00 & 104.00 \\
\hline A19 & $426-450$ & 52.00 & 104.00 \\
\hline A20 & $451-475$ & 52.00 & 104.00 \\
\hline A21 & $476-500$ & 52.00 & 104.00 \\
\hline A22 & 501-525 & 61.00 & 122.00 \\
\hline A23 & 526-550 & 61.00 & 122.00 \\
\hline A24 & $551-575$ & 61.00 & 122.00 \\
\hline A25 & $576-600$ & 61.00 & 122.00 \\
\hline A99 & Note $^{b}$ & -- & -- \\
\hline
\end{tabular}

${ }^{a} \mathrm{All} A 01$ (microfiche) documents are priced at $\$ 9.00$ (domestic) or $\$ 18.00$ (foreign), without regard to page range.

${ }^{\mathrm{b}}$ For documents longer than 600 pp., please ask for a price quote. 


\section{Appendix B-Alphabetical Listing of Titles}

Title

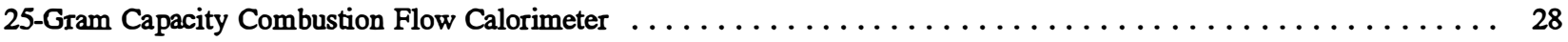

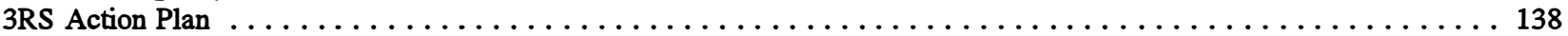

A Glossary . . . . . . . . . . . . . . . . . . . . . . . . . . . . . . . . . 148

Accounting for Dry Deposition in Incinerator Risk Assessment . . . . . . . . . . . . . . . . . 63

Advanced Recycling and Research Complexes: A Second Strategic Use for Installations on the Base Closure List . . . . 107

Advanced System Experimental Facility-Solid Waste to Methane Gas: Background and Process Description . . . . . . . 4

Advanced Testing of Pulsed Air Classifier and Evaluation of Shear Shredders . . . . . . . . . . . . . . . 102

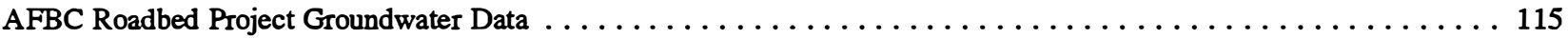

Air Classification Theory and Design for Municipal Solid Waste Processing $\ldots \ldots \ldots \ldots \ldots$

Air Pollution Control Technology for Municipal Solid-Waste-to-Energy Conversion Facilities: Capabilities

and Research Needs . . . . . . . . . . . . . . . . . . . . . . . . . . . . . 41

Alternate Fuels and Energy Sources for Electric Department: City of Tallahassee, Florida . . . . . . . . . . . . 118

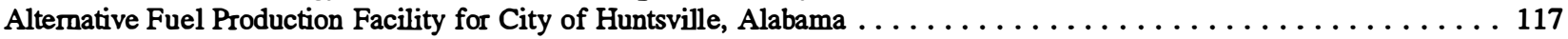

Alternative Schemes for Production of Chilled Water and Cogeneration of Electricity at Ashley Plant . . . . . . . . 110

Anaerobic Biological Treatment of Liquid Wastes for Pyrolysis Processes, Final Report . . . . . . . . . . . . 2

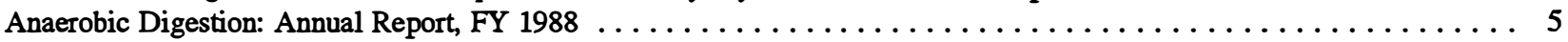

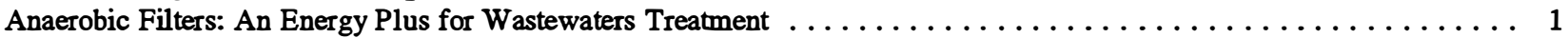

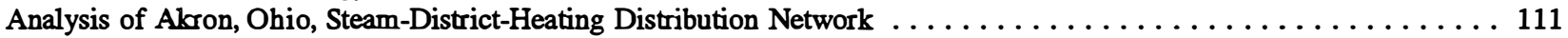

Analysis of Applications of Solar Technology for the Treatment of Chlorinated Organic Waste . . . . . . . . 76

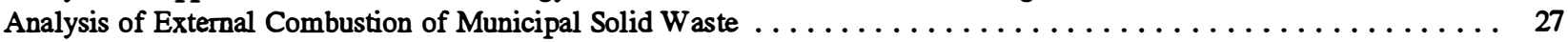

Analysis of Removal of Ash Components from Refuse-Derived Fuel during Pneumatic Transport, An . . . . . . . . . 46

Analysis of the Financial Impacts to the Industrial Energy User of Using Coal or Municipal Solid Waste in a New

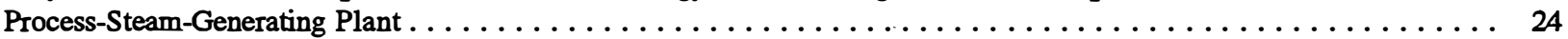

Annotated Bibliography: Environmental Impacts of Sanitary Landfill and Associated Gas Recovery Systems, An . . . . . 89

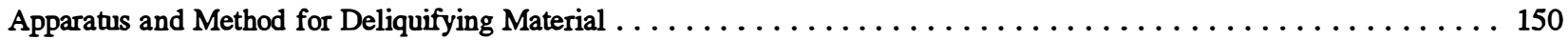

Applications Manual for Analyzing Landfill Methane Recovery Data Using the Computer Analysis of Field

Data (CAFD) Interactive Graphics System . . . . . . . . . . . . . . . . . . . . . . . . . . . 89

Assessing the Credibility of the Calorific Value of Municipal Solid Waste . . . . . . . . . . . . . . . . 20

Assessment of District Heating and Cooling Potential in Joliet, Illinois: Phase I Technical and Economic

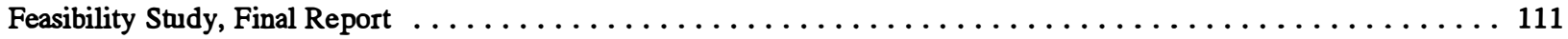

Assessment of Explosion Hazards in Refuse Shredders $\ldots \ldots \ldots \ldots \ldots \ldots \ldots \ldots$

Assessment of Municipal Solid Waste for Energy Production in the Western United States . . . . . . . . . . . . . . . 129

Assessment of the Present Status of Burning Refuse-Derived Fuel as a Fuel Supplement in the Cement Kiln Industry . . 47

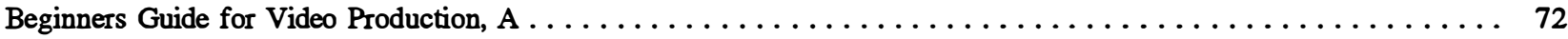

Bench-Scale Reactor Tests of Low Temperature, Catalytic Gasification of Wet Industrial Wastes . . . . . . . . . . . 30

Bidirectional Gas Movement Through Landfill Cover Materials, Volume 1: Instrumentation and Preliminary Site

Investigations at Mallard North Landfill, Dupage County, Illinois $\ldots \ldots \ldots \ldots \ldots$

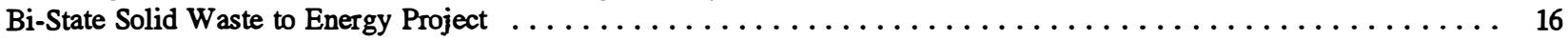

Biochemical Conversion of Municipal Solid Waste: A Technology Status Report . . . . . . . . . . . . . 6

Bioconversion: A New Technology for Waste and Sludge Disposal—Workshop Proceedings . . . . . . . . . . . 2

Bioconversion of MSW (Municipal Solid Waste) and Recovery of Organic Acids . . . . . . . . . . . . . . 1

Bioconversion of Municipal Solid Waste and Recovery of Short-Chain Organic Acids for Liquid Fuels Production . . . . 1

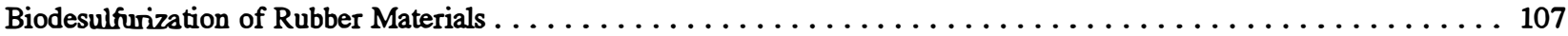

Biofuels and Municipal Waste Research Program of the U.S. Department of Energy, Biofuels and Municipal Waste

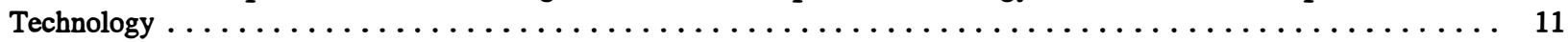

Biofuels and Municipal Waste Technology Research Program Summary: FY $1986 \ldots \ldots \ldots$. . . . . . . . . . 42,65

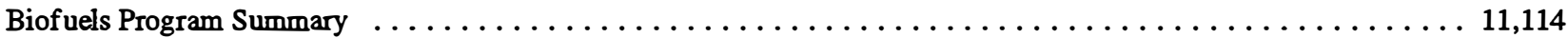

Biofuels Program Summary: Volume 1, Overview Fiscal Year $1988 \ldots \ldots \ldots \ldots \ldots \ldots$

Biotechnological Advances in Processing Municipal Wastes for Fuels and Chemicals . . . . . . . . . . . . . 1

Cannon Shredding of Municipal Solid Waste for the Preparation of Biological Feedstock, Final Report . . . . . . . 97

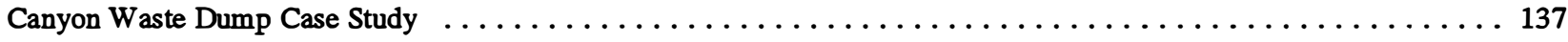

Canyonville Case Study . . . . . . . . . . . . . . . . . . . . . . . . . . . . 72

Catalytic Sodium Hypochlorite Degradation Using a Kynar Stabilized Catalyst . . . . . . . . . . . . . . . . 119

CFB Technology Demonstrates Medical Waste Combustion $\ldots \ldots \ldots \ldots \ldots \ldots \ldots$

Chemical Processing in High-Pressure Aqueous Environments. 2. Development of Catalysts for Gasification ....... 30

Chemical Technology Division Annual Technical Report, $1990 \ldots \ldots \ldots \ldots \ldots \ldots$

Chlorine Content of Municipal Solid Waste from Baltimore County, Maryland, and Brooklyn, New York . . . . . . . 117

City of Columbia, Missouri: Development of a Waste-to-Energy Plan $\ldots \ldots \ldots \ldots \ldots$ 


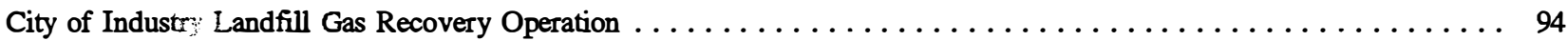

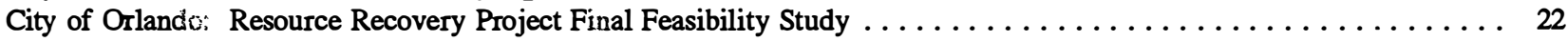

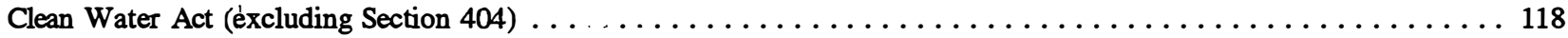

Cleaning up With the Sun: Industry's Opportunities in the DOE Initiative on Solar Detoxification of

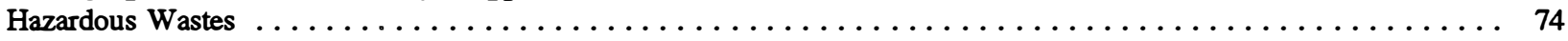

Co-Combustion of Refuse-Derived Fuel and Coal in a Cyclone Furnace at the Baltimore Gas \& Electric Company,

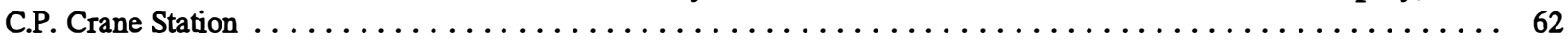

Cofiring of Pelletized Refuse-Derived Fuel with Coal to Achieve Sulfur Dioxide Emissions Requirements . . . . . . 50

Co-Utilization of Municipal Solid Waste and Wood Residues for Small-Scale Resource Recovery: A

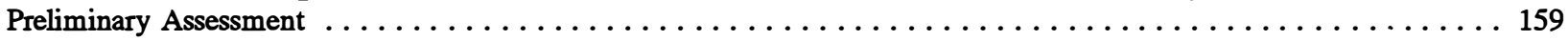

Combustion Characteristics of Refuse-Derived Fuels, Final Report $\ldots \ldots \ldots \ldots \ldots \ldots \ldots \ldots \ldots \ldots \ldots \ldots \ldots$

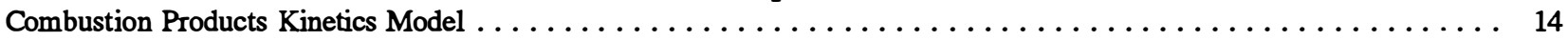

Commercial Operation of a Codisposal, Composting, Landfilling and Power Generation System at

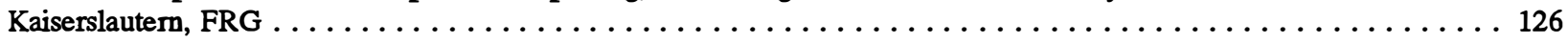

Communicating With the Public About Environmental Health Risks: A Case Study of Waste-To-Energy . . . . . . . . 41

Composition and Properties of Municipal Solid Waste and Its Components $\ldots \ldots \ldots \ldots \ldots \ldots \ldots \ldots \ldots$ 19,97

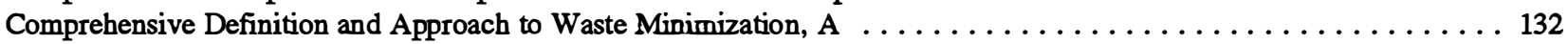

Comprehensive Study on the Feasibility of Energy Recovery from Sewage Sludge, Final Report . . . . . . . . . 119

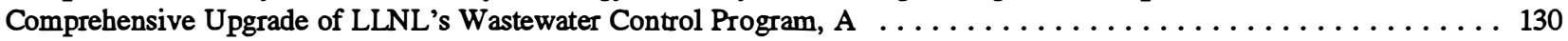

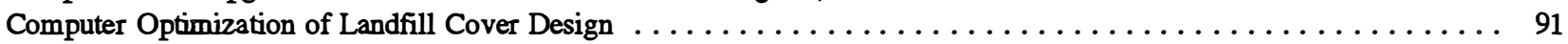

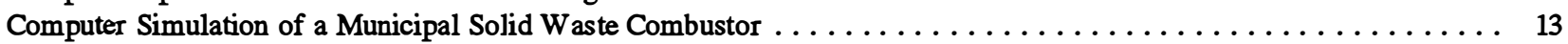

Continuous Solidification/Stabilization Processing of Hazardous Wastes Through Polymeric Microencapsulation $\ldots \ldots .80$

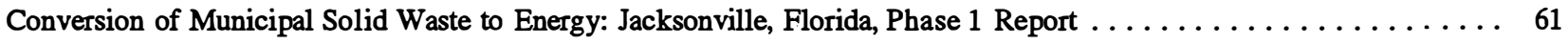

Conversion of Newsprint- and MSW-cellulosics to Sugar by Dilute Sulfuric Acid Hydrolysis $\ldots \ldots \ldots \ldots \ldots \ldots \ldots 155$

Corrosion of Materials Used in Steam-Generating Boiler Systems, Final Report $\ldots \ldots \ldots \ldots \ldots \ldots \ldots \ldots \ldots \ldots .31$

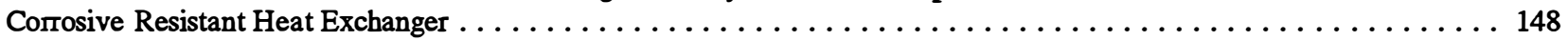

Cost and Performance Projections for Solar Water Detoxification Systems $\ldots \ldots \ldots \ldots \ldots \ldots \ldots \ldots \ldots \ldots$

Data Summary of Municipal Solid Waste Management Alternatives $\ldots \ldots \ldots$ 2,25,25,26,26,86,98,121,121,121,122,122,122

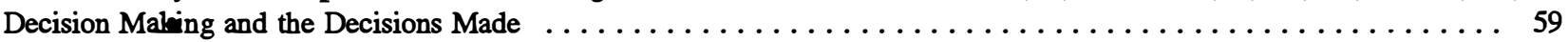

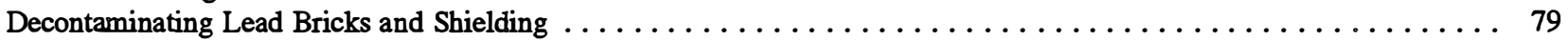

Definition and Analysis of the Barriers to the Implementation of Urban Energy Recovery Systems $\ldots \ldots \ldots \ldots \ldots 132$

Demonstration of Landfill Gas-Enhancement Techniques in Landfill Simulators . . . . . . . . . . . . . . . 94

Demonstration of Synergistic Industrial Energy/Municipal Solid Waste Disposal Facility, Volume $1 \ldots \ldots \ldots \ldots \ldots 26$

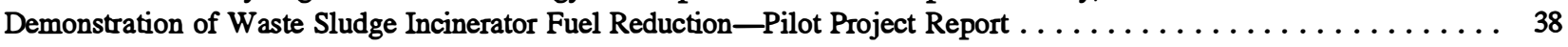

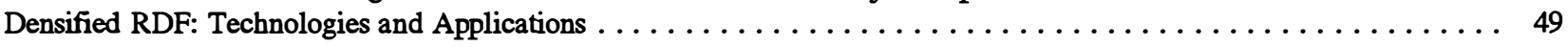

Densified Refuse Derived Fuel: An Alternative Energy Source $\ldots \ldots \ldots \ldots \ldots \ldots \ldots \ldots \ldots \ldots \ldots \ldots . \ldots 4$

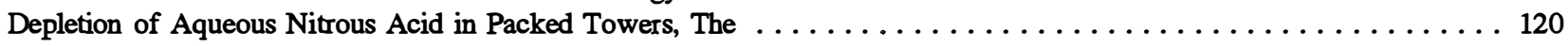

Design and Operation of a Demonstration Sanitary Landfill Developed to Optimize the Generation and Capture of

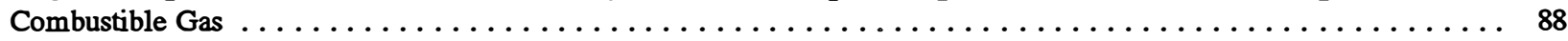

Design and Operation of the World's Largest RDF-to-Energy Plant $\ldots \ldots \ldots \ldots \ldots \ldots \ldots \ldots \ldots \ldots \ldots \ldots 43$

Determination of the Calorific Value of Refuse-Derived Fuels by Large-Bomb Calorimetry: Summary of the

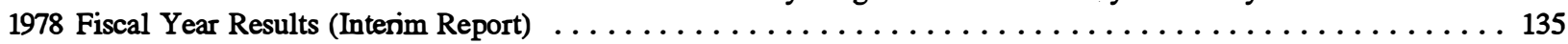

Development of a Case Study for the Cinnaminson Landfill Methane Recovery Operation . . . . . . . . . . 93

Development of a Liquid Jet for Disintegration of Organic and Inorganic Materials: Final Technical Report,

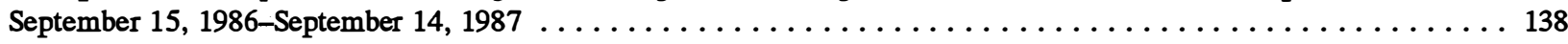

Development of a Novel and Environmentally Friendly Method for the Separation of Non-Inked and Inked

Cellulose Fibers in Wastepaper . . . . . . . . . . . . . . . . . . . . . . . . . . . . . . 109

Development of Computer Simulations for Landfill Methane Recovery $\ldots \ldots \ldots \ldots \ldots \ldots \ldots \ldots \ldots \ldots$

Development of Cylinder Gas Disposal Plant: Phase 1, Detailed Project Planning and Concept Development Report . . 161

Development of Fly Ash-Based Slope Protection Materials for Waste Disposal Ponds . . . . . . . . . . . . . . . 140

Development of the Utilization of Combustible Gas Produced in Existing Sanitary Landfills: Effects of Corrosion

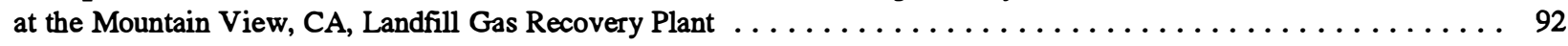

Development of the Utilization of Combustible Gas Produced in Existing Sanitary Landfills: Investigation of

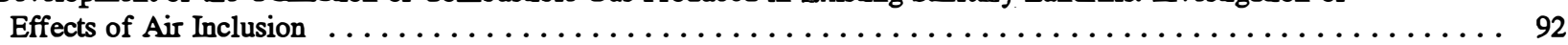

Dioxin Emissions from Municipal Solid Waste Incinerators and the Potential for Human Exposure . . . . . . . . . 69

Direct Recycling of Municipal Ferrous Wastes for Local Foundry Application, Final Technical Report . . . . . . . . 107

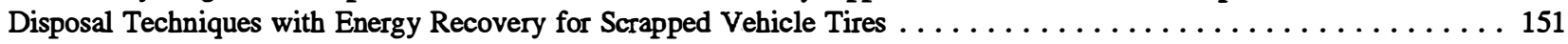

District Heating and Cooling for the City and Port of Tacoma: Phase 1, Feasibility Study $\ldots \ldots \ldots \ldots \ldots \ldots \ldots$. 10

DOE Feasibility Report on Lake Calumet Area Refuse-to-Energy Facility $\ldots \ldots \ldots \ldots \ldots \ldots \ldots \ldots \ldots \ldots .49$ 
DOE Model Conference on Waste Management and Environmental Restoration . . . . . . . . . . . . 122

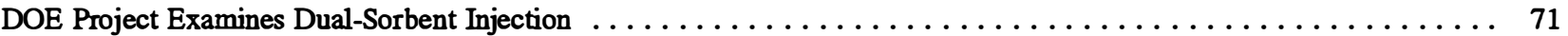

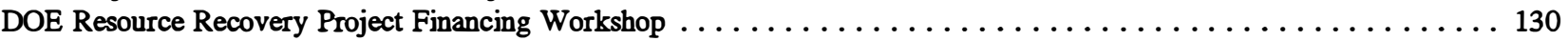

Dutchess County Resource Recovery Task Force Report: Dutchess County Pyrolysis Program . . . . . . . . . . . . . 64

Dynamic Computer Model for Heat Transfer and Incineration in the Oak Ridge TSCA (Toxic Substances Control Act)

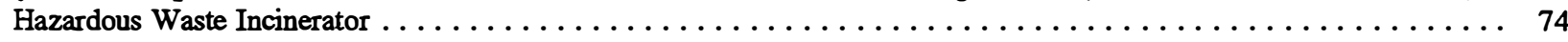

Economical Disposal of Municipal Solid Waste with Minimal Discharges to the Atmosphere and Maximum

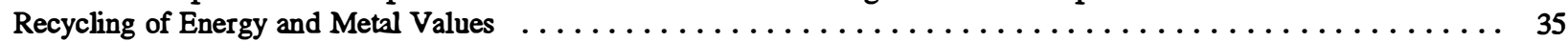

Effect of Season, Substrate Composition, and Plant Growth on Landfill Leachate Treatment in a Constructed Wetland . . 94

Effects of Proposed Environmental Legislation and Rulemaking on Waste-to-Energy Facilities . . . . . . . . . . . . 22

Effects of Water, Buffer, and Sludge Addition on Gas Production in Large-Scale Landfill Cells: Controlled

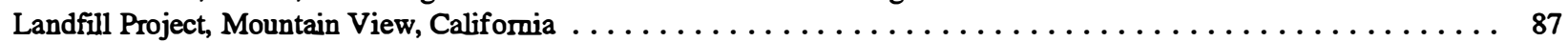

Effluent Dewatering Research for MSW (Municipal Solid Waste) and Wastewater Treatment Sludges . . . . . . . . . 146

Effluent Dewatering Research for MSW and Wastewater Treatment Sludges . . . . . . . . . . . . . . . 146

Electric Power from Biofuels: Planned and Existing Projects in the U.S. . . . . . . . . . . . . . . . . . . . 43

Elements of Trommel Dynamics: Determination of the Dynamic Bulk Density-A Working Paper . . . . . . . . . 103

Elements of Trommel Dynamics: Drag Free Case-A Working Paper . . . . . . . . . . . . . . . . . . 103

Elements of Trommel Dynamics: Notes on Elementary Screening Probability-A Working Paper . . . . . . . . . . . 104

Elements of Trommel Dynamics: The Effect of Drag on Particle Motion-A Working Paper . . . . . . . . . . . . . 104

Emission Studies of Full-Scale Cofiring of Pelletized RDF/Coal at Argonne National Laboratory . . . . . . . . . . . 68

Energy and Cost Impact of Materials Separation on Municipal Waste Combustors $\ldots \ldots \ldots 6$

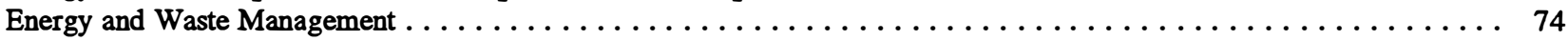

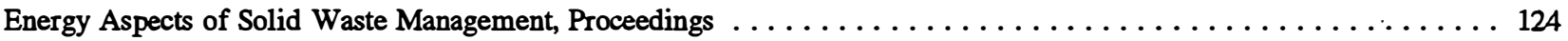

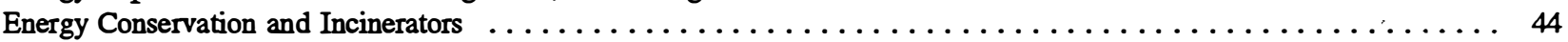

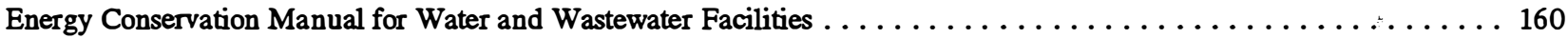

Energy Conservation Through Recycling of Factory Asphalt Roofing Waste . . . . . . . . . . . . . . . 106

Energy-Conserving Process to Treat and Recycle Wastewater and Sludges, An . . . . . . . . . . . . . . 134

Energy from Municipal Solid Waste Mechanical Equipment and Systems Status Report . . . . . . . . . . . . . 35

Energy from Municipal Waste_Assessment of Control Technologies for Stack Gas Emissions . . . . . . . . . . . 70

Energy from Municipal Waste: Assessment of Energy Conservation and Recovery in Municipal Wastewater Treatment . 147

Energy from Municipal Waste_Preliminary Assessment of External Combustion $\ldots \ldots \ldots \ldots$

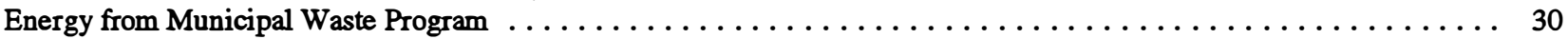

Energy from Municipal Waste Program, Chemical Technology Division, Annual Technical Report, 1982 . . . . . . . 31

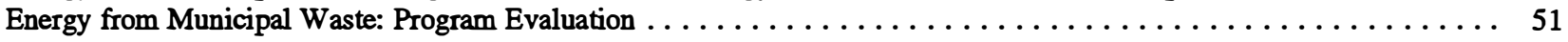

Energy from Municipal Waste Research: A Technical Review of Thermochemical Systems-Workshop Proceedings ... 18

Energy from Municipal Waste: State-of-the-Art and Emerging Technologies-Workshop Proceedings . . . . . . . . 18

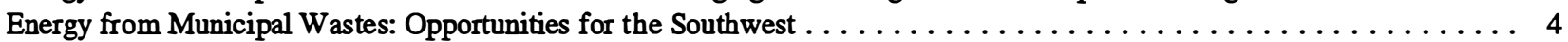

Energy from Urban Wastes: Report on a Focus Group Discussion . . . . . . . . . . . . . . . . . . 138

Energy Implications of Alternative Solid Waste Management Systems $\ldots \ldots \ldots \ldots \ldots \ldots$

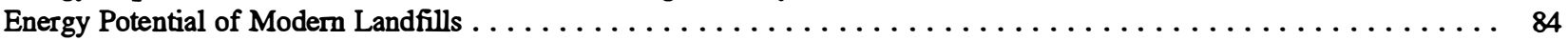

Energy Recovery and Cogeneration from an Existing Municipal Incinerator: Phase IIA, Progress Report on Final Design 20

Energy Recovery for Kent and Sussex Counties, Delaware, Phase II Study Report . . . . . . . . . . . . . . . 27

Energy Recovery from Municipal Solid Waste and Sewage Sludge Using Multi-Solid Fluidized-Bed

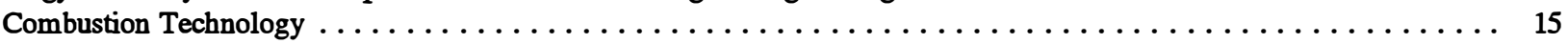

Energy Recovery from Municipal Waste Development Program for Idaho Falls, Idaho, Final Report . . . . . . . . . . 30

Energy Recovery from the Effluent of Plants Anaerobically Digesting Urban Solid Waste . . . . . . . . . . . . . 7

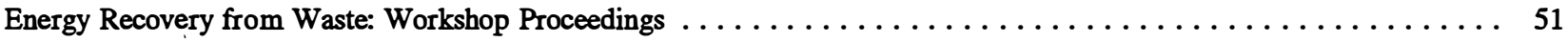

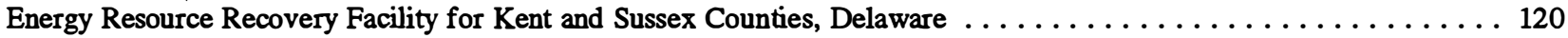

Energy Utilization: Municipal Waste Incineration, Final Report . . . . . . . . . . . . . . . . . . . 59

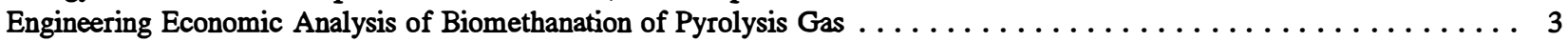

Enhancement of Methane Production in the Anaerobic Digestion of Municipal Sewage Sludge . . . . . . . . . . 6

Environmental Assessment_Urban Waste Technology Program . . . . . . . . . . . . . . . . . 125

Environmental Impacts, Institutional Problems, and Research Needs of Sanitary Landfill Methane Recovery, The . . . . 89

Environmental Restoration and Waste Management (EM) Program: An Introduction . . . . . . . . . . . . . 125

Environmentally Conscious Manufacturing Integrated Demonstration $\ldots \ldots \ldots \ldots \ldots$

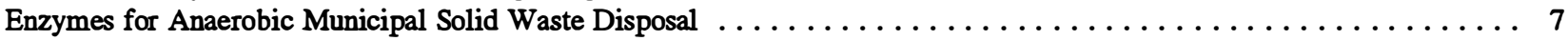

Establishing a Comprehensive Recycling Process at KCD $\ldots \ldots \ldots \ldots \ldots \ldots$

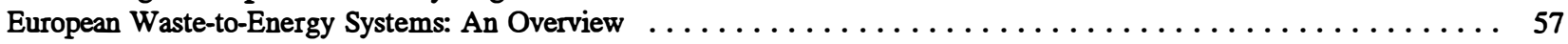

European Waste-to-Energy Systems: Case Study of Geneve, Cheneviers (Switzerland) . . . . . . . . . . . . 57 
European Waste-to-Energy Systems: Case Study of Ivry-sur-Seine, France . . . . . . . . . . . . . . . 56

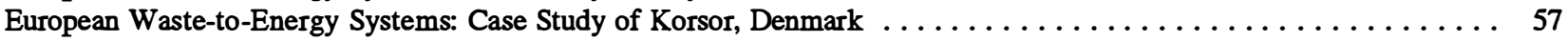

European Waste-to-Energy Systems: Case Study of Landshut, West Germany $\ldots \ldots \ldots \ldots$

European Waste-to-Energy Systems: Case Study of Munich-Munich North 1A \& 1B, Munich North II, Munich

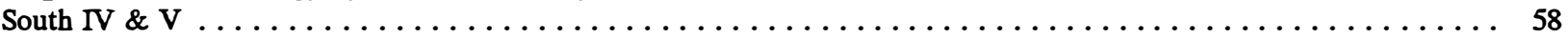

European Waste-to-Energy Systems: Case Study of Rennes, France . . . . . . . . . . . . . . . . . 57

European Waste-to-Energy Systems: Case Study of the Thermal Complex of Brive, France . . . . . . . . . . . . 57

European Waste-to-Energy Systems: Case Study of the Thermal Complex of Toulouse-le Mirail, France . . . . . . . . 58

Evaluation and Comparison of Selected Household Hazardous Waste Collection Facilities . . . . . . . . . . . 73

Evaluation and Test Program of a 50-Ton-per-Day Waste Distillator $\ldots \ldots \ldots \ldots \ldots \ldots$

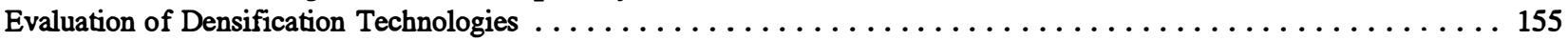

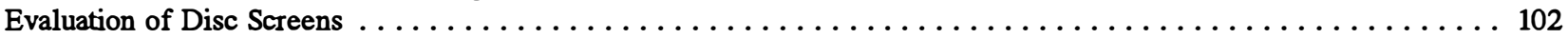

Evaluation of Dilute Sulfuric Acid Hydrolysis and Autohydrolysis for Sugar Production from

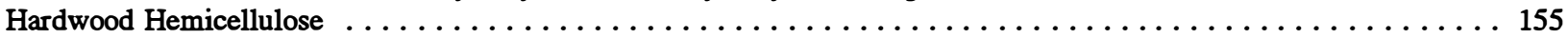

Evaluation of Exposure Pathways to Man from Disposal of Radioactive Materials into Sanitary Sewer Systems . . . . . 78

Evaluation of Landfill Gas as an Energy Source, Management Report . . . . . . . . . . . . . . . . 85

Evaluation of Mixing Systems for Biogasification of Municipal Solid Waste $\ldots \ldots \ldots \ldots \ldots$

Evaluation of Technical Proposals for Honolulu Program of Waste Energy Recovery . . . . . . . . . . . . 117

Evaluation of the Feasibility of Co-Producing Sewage Sludge with Municipal Solid Waste, Final Report . . . . . . . . 24

Evaluation of the Integrated Municipal Solid Waste Management Systems Extant in Japan . . . . . . . . . . . 98

Evaluation of Trommels for Waste to Energy Plants, Phase 1: Report of the Doncaster and Byker Test Series . . . . . 65

Evaluation of Trommels for Waste to Energy Plants, Phase 2: Report of the Warren Spring Laboratory Pilot

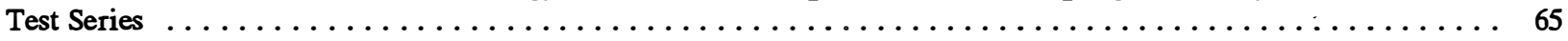

Evaluation of Trommels for Waste to Energy Plants, Phase 1: Report of the Doncaster and Byker Test Series, . . . . 108

Evaluation of Trommels for Waste to Energy Plants, Phase 2: Report of the Warren Spring Laboratory

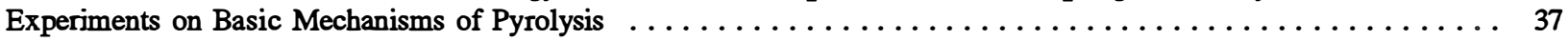

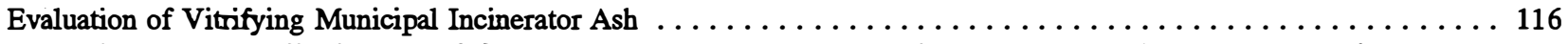

Evaluation Program Effectiveness of Household Hazardous Waste Collection: The Seattle-King County Experience . . . 75

Fast Production of Methane by Anaerobic Digestion, Volumes 1 and $2 \ldots \ldots \ldots \ldots$

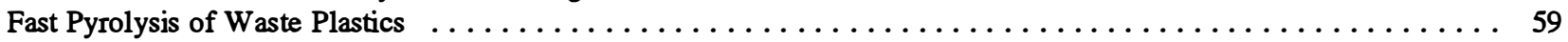

Fate of Radionuclides in Sewage Sludge Applied to Land, The . . . . . . . . . . . . . . . . . 114

Feasibility Analysis and Conceptual Design for the Demonstration of Energy Recovery from Municipal Waste . . . . 64

Feasibility of Burning Refuse-Derived Fuel in Institutional-Size Oil-Fired Boilers, Final Report . . . . . . . . . . . 48

Feasibility of Direct On-Site Conversion of Landfill Gas to Electrical Energy at Scholl Canyon Landfill,

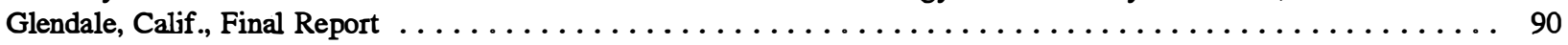

Feasibility of Implementing a Municipal Waste-to-Energy System to Supply Youngstown Thermal with a

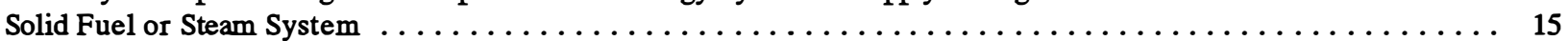

Feasibility of Methane Gas Recovery at the St. John's Landfill . . . . . . . . . . . . . . . . . . . 91

Feasibility Study: Codisposal with Energy Recovery from Wastewater Sludge and Municipal Refuse, Phase II . . . . . . 33

Feasibility Study_Energy Recovery and Cogeneration from an Existing Municipal Incinerator, Phase 1, Final Report . . 20

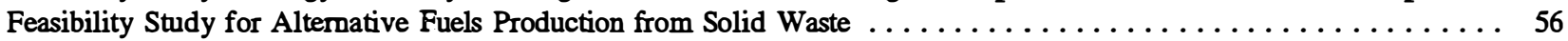

Feasibility Study for Small-Scale Waste-to-Energy System in Caguas, Puerto Rico . . . . . . . . . . . . . . . . . 46

Feasibility Study of Landfill Gas Recovery at Seven Landfill Sites, Adams County/Commerce City, Colorado,

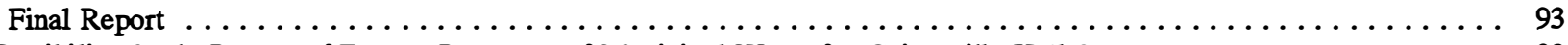

Feasibility Study Report of Energy Recovery of Municipal Waste for Gainesville-Hall County . . . . . . . . . . . . 32

Feasibility Study: Utilization of Landfill Gas for a Vehicle Fuel System-Rossman's Landfill, Clackamas County,

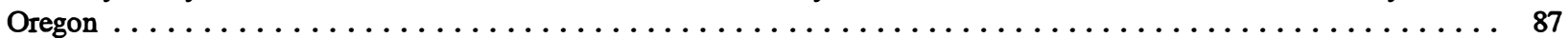

Federal Involvement in Municipal Wastewater Treatment Plant Sludge Energy Recovery and Conservation . . . . . . . 153

Fermentation Studies on Sugars Recovered from Waste Cellulosics via Acid Hydrolysis . . . . . . . . . . . . 113

Field Evaluation of Natural Gas and Dry Sorbent Injection for MWC Emissions Control . . . . . . . . . . . . . 67,71

Field-Scale Landfill Gas Enhancement: The Brogborough Test Cells $\ldots \ldots \ldots \ldots \ldots$

Fifteenth National Industrial Energy Technology Conference: Proceedings $\ldots \ldots \ldots \ldots \ldots$

Final Operation and Test Period: Aluminum and Glass Recovery Systems at Recovery $1 \ldots \ldots \ldots$

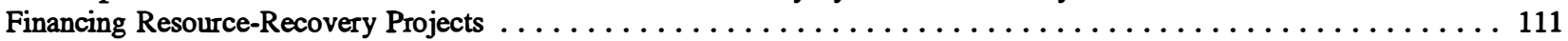

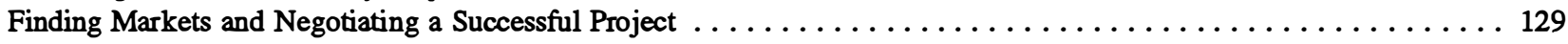

Five Year Research Plan, 1988_1992: Biofuels: Renewable Fuels for the Future . . . . . . . . . . . . . . 142

Fluidized-Bed Boilers: An Emerging Alternative Technology $\ldots \ldots \ldots \ldots \ldots \ldots$

Flumeter ${ }^{\mathrm{TM}}$ : A New Tool for Wastewater Management (in Small Sewers), The . . . . . . . . . . . . . . 133

Fly Ash Utilization in McLean County, North Dakota $\ldots \ldots \ldots \ldots \ldots \ldots \ldots$ 
Fourteenth National Industrial Energy Technology Conference: Proceedings . . . . . . . . . . . . . . 127

From Grave to Cradle: Trends in Hazardous Waste Management $\ldots \ldots \ldots \ldots \ldots \ldots$

Fundamentals of Direct Liquefaction of Municipal Solid Waste in a Semicontinuous, Microprocessor-Controlled

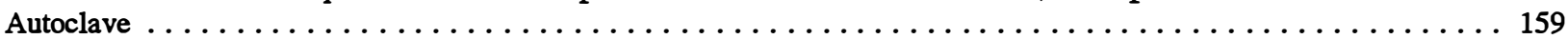

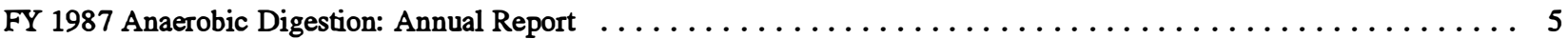

Gasification of Municipal Solid Waste in an Oxygen-Blown Fluidized-Bed Reactor, Final Report . . . . . . . . . . 35

Gasification of Refuse Derived Fuel in the Battelle High Throughput Gasification System . . . . . . . . . . . . . 52

Geotechnical/Geochemical Characterization of Advanced Coal Process Waste Streams: Task $2 \ldots \ldots$. . . . . . . 45

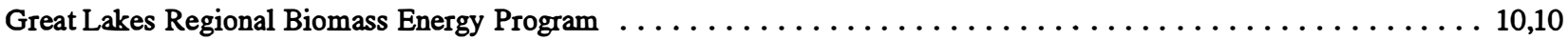

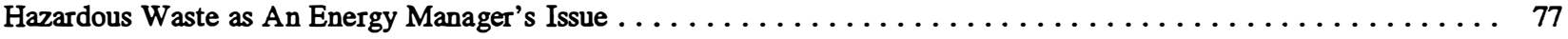

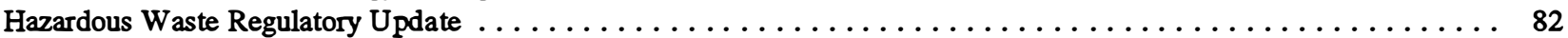

High Efficiency Mixed Solid Waste-Fossil Fuel Combustion Power System, A . . . . . . . . . . . . . . 38

High Quality Garbage: A Neural Network Plastic Sorter in Hardware and Software . . . . . . . . . . . . . 153

Hospital Waste Shredder Test Series at the DONLEE Pilot Test Facility $\ldots \ldots \ldots \ldots \ldots \ldots$

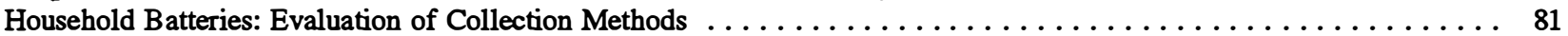

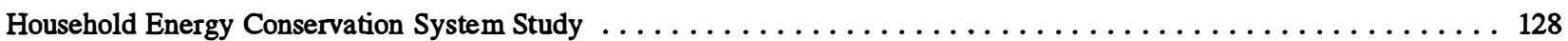

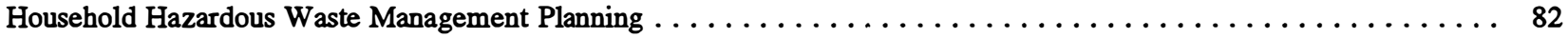

Human Exposure to Dioxin from Combustion Sources . . . . . . . . . . . . . . . . . . . . . . . 69

HYDROCARB Process-Conversion of Carbonaceous Materials to Clean Carbon and Gaseous Fuel, The . . . . . . . 154

Hydrogen and Sulfur Recovery from Hydrogen Sulfide Wastes . . . . . . . . . . . . . . . . . . . 131

Identification of Technical and Operating Problems of Nashville Thermal Transfer Corporation Waste-to-Energy Plant . . 112

Impact of RDF Cofiring on Power Plant Operation and Economics $\ldots \ldots \ldots \ldots \ldots$

Impact of Source Separation on Municipal Waste-to-Energy Project Feasibility, The . . . . . . . . . . . . . 33,99

Impact of the Resource Conservation and Recovery Act on Landfill Gas Utilization . . . . . . . . . . . . . . 93

Implications of Pollution Prevention Experience for Environmental Management $\ldots \ldots \ldots \ldots$

Importance of Climatological Variability and the Rate at which Waste is Added to Modeling Water Budget of

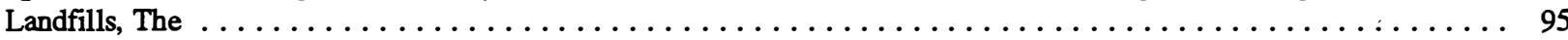

Increasing the Energy Yield from Resource Recovery by Use of the Organic Materials in the Air Classifier

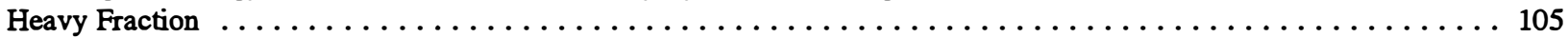

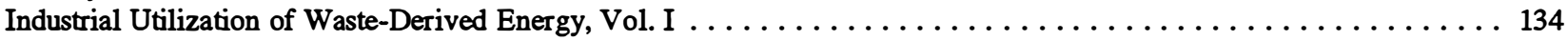

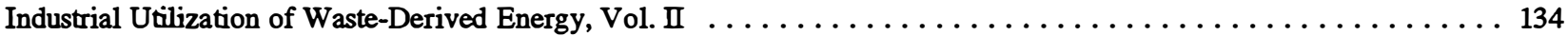

Industrial Waste Reduction and Utilization . . . . . . . . . . . . . . . . . . . . . . . $\ldots 133$

Inhibition of Respiration in Activated Sludge by High Carbon Dioxide Concentration: A Laboratory Study . . . . . . . 134

Institutional Issues Concerning Energy from Municipal Waste: A Status Report . . . . . . . . . . . . . . . 149

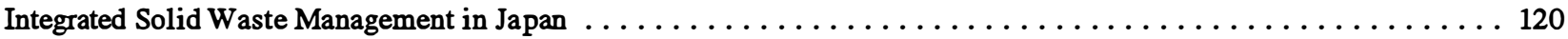

Interim Report: Prototype Tramp Metal Separator-A Summary of Test Results, . . . . . . . . . . . . . . . . 104

Interim Report: Some Design Considerations in Particles Separation by a Transverse Jet, An . . . . . . . . . . . . . 104

Interstate Waste Transport-Emotions, Energy, and Environment $\ldots \ldots \ldots \ldots \ldots \ldots$

Kinetic Study of the Photocatalytic Degradation of 3-chlorosalicylic Acid Over $\mathrm{TiO}_{2}$ Membranes Supported

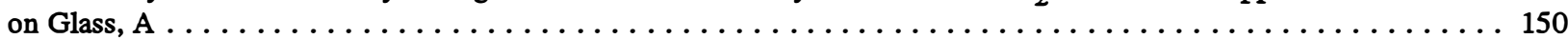

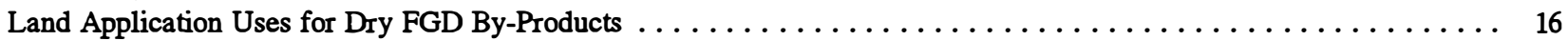

Land Application Uses of Pressurized Fluidized-Bed Combustion (PFBC) Ash . . . . . . . . . . . . . . 16

Land Disposal of Solid Waste: Foreign Trip Report, March 13-21, $1988 \ldots \ldots \ldots \ldots$

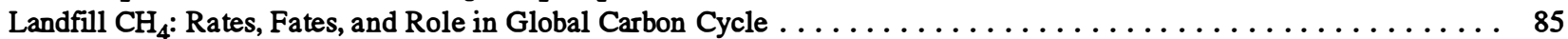

Landfill Gas Recovery and Utilization Feasibility Study . . . . . . . . . . . . . . . . . . . 86

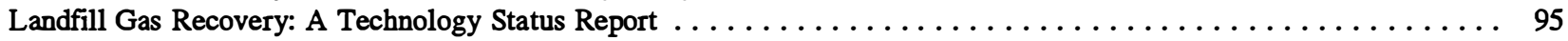

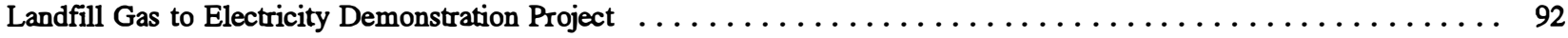

Landfill Methane Recovery, Part II: Gas Characterization, Final Report, December 1981 to December 1982 . . . . . . . 90

Large-Scale Commercial Combustion Systems for Producing Energy from Municipal Solid Waste . . . . . . . . . . 24

Leaching Characteristics of Resource Recovery Ash in Municipal Waste Landfills, Final Report . . . . . . . . . . . 89

Liquid-Liquid Extraction of Short-Chain Organic Acids from Anaerobic Digesters . . . . . . . . . . . . . 9

Liquid Fuels from the Pyrolysis of Municipal Solid Waste and Its Components $\ldots \ldots \ldots \ldots$

Local Govemments Take on Hazardous Waste Collection . . . . . . . . . . . . . . . . . . . . 82

Low-Technology Resource Recovery: Source Separation . . . . . . . . . . . . . . . . . . . . . . 105

Macro Material Flow Modeling for Analyzing Solid Waste Management Options . . . . . . . . . . . . . 131

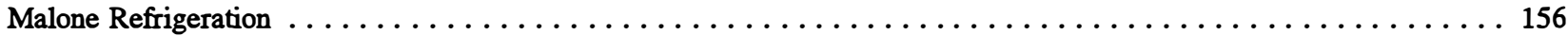

Managing Municipal Solid Waste: A Comparative Risk Analysis of Landfill and Resource Recovery Facilities:

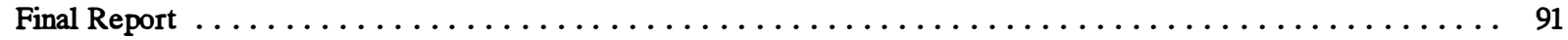

Markets and Economics of Mixed Waste Paper as a Boiler Fuel $\ldots \ldots \ldots \ldots \ldots \ldots$ 


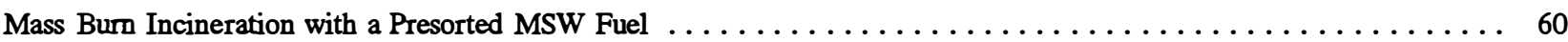

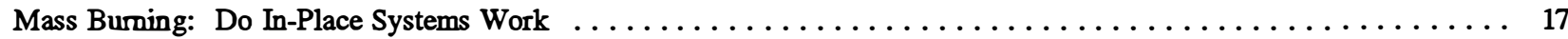

Maximization of Revenues for Power Sales From a Solid Waste Resources Recovery Facility . . . . . . . . . . . 42

Mechanisms of Pyrolysis of Municipal Solid Waste: Annual Report $\ldots \ldots \ldots \ldots \ldots \ldots$

Membrane-Controlled Processes for the Energy-Efficient Conversion of Sludges to Fuels and Marketable Chemicals ... 118

Mercury Emissions From Municipal Solid Waste Combustors: An Assessment of the Current Situation in

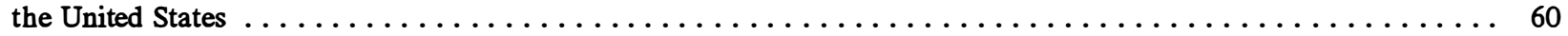

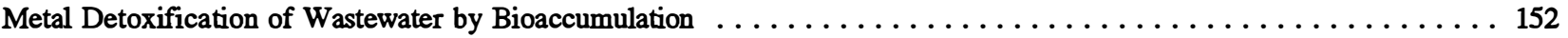

Metal-Ion Recycle Technology for Metal Electroplating Waste Waters . . . . . . . . . . . . . . . . 81

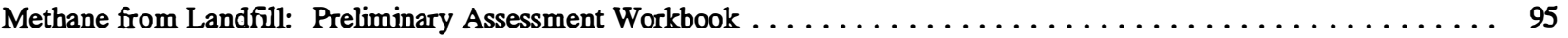

Method of Energy Recovery for Wastewater Treatment: Final Technical Report . . . . . . . . . . . . . . 115

Method of Processing Materials Using An Inductively Coupled Plasma . . . . . . . . . . . . . . . . . 132

Metrology Process Waste Assessment: Fluorinert Bath Temperature Calibration Z951-421-1 . . . . . . . . . . 80

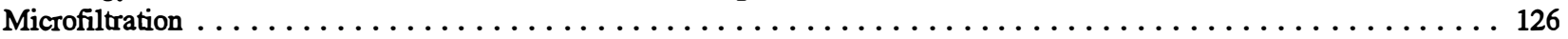

Microorganisms May Play Role in Waste Management $\ldots \ldots \ldots \ldots \ldots \ldots \ldots \ldots \ldots$

Mid-Connecticut Project on Resource Recovery from Municipal Solid Wastes, Final Status Report . . . . . . . . . 23

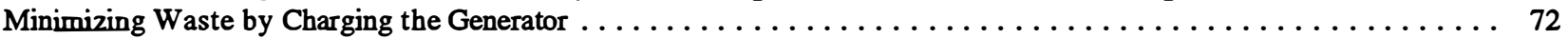

Mobilizable RDF/d-RDF Buming Program 49

Model Contract for a Full-Service Resource Recovery Program, A . . . . . . . . . . . . . . . . . . 46

Model Request for Proposals: The Brooklyn Navy Yard Resource Recovery Facility, A . . . . . . . . . . . . . . . 143

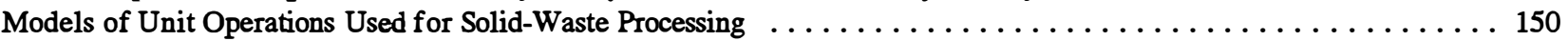

Modified Biochemical Methane Potential (BMP) Assays to Assess Biodegradation Potential of Landfilled Refuse . . . . 84

Monitoring the Fate of Chlorine from MSW Sampling through Combustion: Part 1, Analysis of the Waste

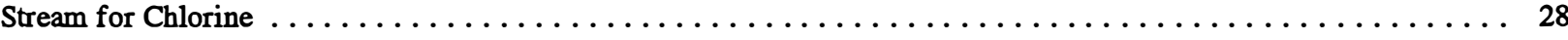

Monitoring the Fate of Chlorine from MSW Sampling through Combustion: Part 2, Combustion Studies . . . . . . . . 28

MSW (Municipal Solid Waste) Emissions and Characterization Research and Destruction of Aromatics by

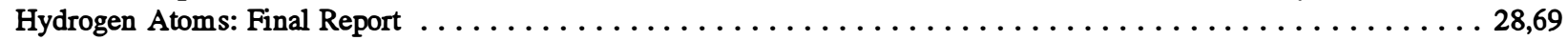

MSW (Municipal Solid Waste) Subscale Rotary Combustor R\&D Support Program . . . . . . . . . . . . . . 14

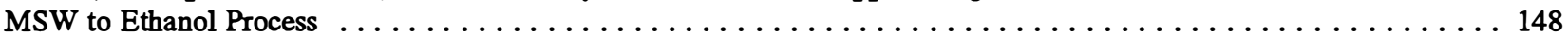

MSW Volume Reduction, Value Recovery, and Value Addition $\ldots \ldots \ldots \ldots \ldots \ldots$

Multifamily Recycling Programs: Program Data and Implementation Guidelines . . . . . . . . . . . . . . 103

Municipal Hazardous Materials Management Programs in Califormia $\ldots \ldots \ldots \ldots \ldots \ldots$

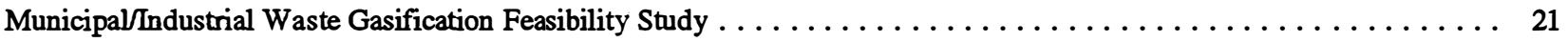

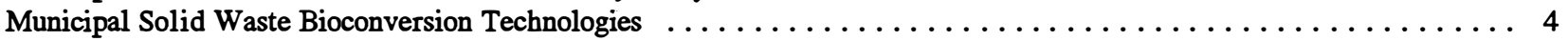

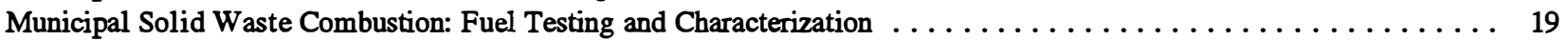

Municipal Solid Waste Processing Systems Computer Model . . . . . . . . . . . . . . . . . . . . . 129

Municipal Solid Waste Small-Scale Mechanical Systems Report . . . . . . . . . . . . . . . . . . . . . 102

Municipal-Waste Combustion: Background Information for Materials Separation, Final Report . . . . . . . . . . . 45

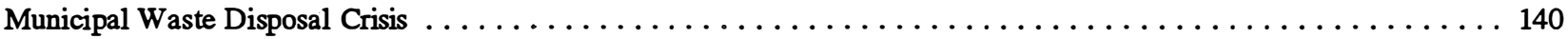

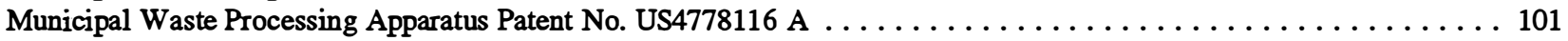

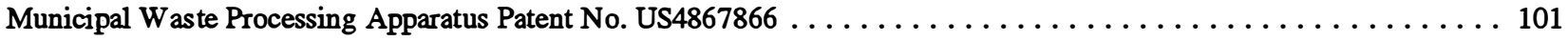

Municipal Waste to Energy, An Annotated Bibliography of U.S. Department of Energy Contractor Reports . . . . . . . 17

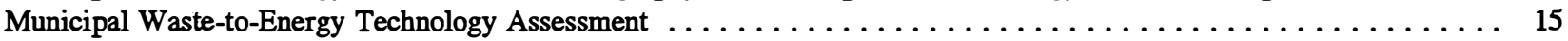

National Survey of Industrial Markets for Steam Produced from Burning Municipal Solid Waste . . . . . . . . . 53

New Orleans Full-Scale Trommel Evaluation Interim Test Report . . . . . . . . . . . . . . . . . . . . . 104

Northeast Regional Biomass Energy Program . . . . . . . . . . . . . . . . . . . . . . . . . . . . 143,144,144

Northeast Regional Biomass Energy Program: Progress Report, January 1989-March 1989 . . . . . . . . . . . . . . 145

Northeast Regional Biomass Energy Program: Progress Report, April 1989-June 1989 . . . . . . . . . . . . . . . . . 144

Northeast Regional Biomass Energy Program Progress Report, April 1990-June 1990 . . . . . . . . . . . . . . . . . . 143

Northeast Regional Biomass Energy Program: Quarterly Report, October 1988-December 1988 . . . . . . . . . . . . 145

Oil/Refuse Homogenization: An Approach to Cocombustion of Refuse in Existing Oil-Fired Boilers . . . . . . . . . . 44

Opelika Resource Recovery Project: Report on the Technological and Economic Evaluation . . . . . . . . . . . . 14

Operational Characteristics of Anaerobic Digesters at Selected Wastewater-Treatment Facilities in the United States . . . . 6

Overview of RDF Processing Systems: Current Status, Design Features, and Future Trends, An . . . . . . . . . 50

Overview of Thermochemical Conversion of Municipal Solid Waste $\ldots \ldots \ldots \ldots \ldots \ldots$

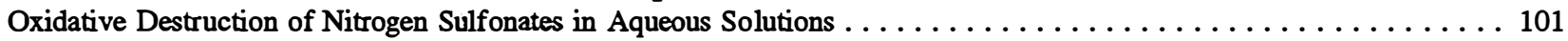

Paradoxes of Cleaning Up the Environment: Regulation and Recycling . . . . . . . . . . . . . . .

Phase 1, Background Study Results Under the Council of Great Lakes Governors Program to Perform Stack

Sampling and Analysis of Emissions from Densified Refuse Derived Fuels (d-RDF) . . . . . . . . . . . . . 53 
Photocatalytic Destruction of Chlorinated Solvents With Solar Energy . . . . . . . . . . . . . . . . . 145 Pilot Process Waste Assessment: R-11 Chiller Refrigeration138

Pilot-Scale Trommel: Experimental Test Descriptions and Data_A Working Paper $\ldots \ldots \ldots \ldots \ldots \ldots \ldots \ldots$

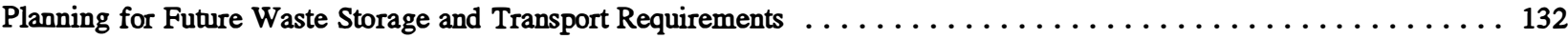

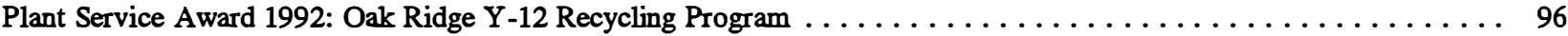

Plasma-Chemical Conversion of Hydrogen Sulfide into Hydrogen and Sulfur $\ldots \ldots \ldots \ldots \ldots \ldots \ldots \ldots \ldots \ldots . \ldots \ldots$

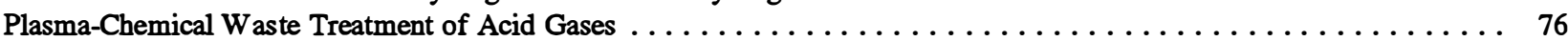

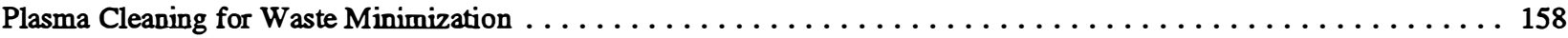

Pollution Control Applications of Pulsed Power Technology $\ldots \ldots \ldots \ldots \ldots \ldots \ldots \ldots \ldots \ldots \ldots \ldots \ldots \ldots$

Polyvinyl Chloride Plastics in Municipal Solid Waste Combustion $\ldots \ldots \ldots \ldots \ldots \ldots \ldots \ldots \ldots \ldots \ldots \ldots$

Portable Hopper/Conveyor for Processing Glass Cutlet and Aluminum, Final Report . . . . . . . . . . . . . . . . . 139

Potential for Converting MSW to Useful Fuels Through Pyrolysis $\ldots \ldots \ldots \ldots \ldots \ldots \ldots \ldots \ldots \ldots \ldots \ldots . \ldots 2$

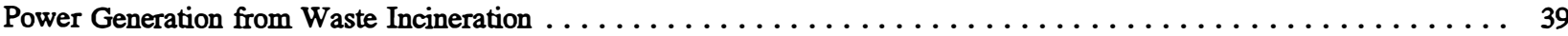

Preliminary Development of a Technique for Estimating Municipal Solid Waste Generation . . . . . . . . . . 128

Preliminary Engineering for Advanced System Experimental Facility (ASEF) Solid Waste to Methane Gas . . . . . . 8

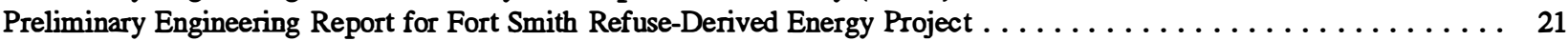

Preliminary Investigation of the Application of Modified Soil Compaction Technologies to Densify Prepared

Municipal Wastes into Fuel Nodules $\ldots \ldots \ldots \ldots \ldots \ldots \ldots \ldots \ldots \ldots \ldots \ldots \ldots \ldots \ldots \ldots \ldots$

Pretreated High-Solids MSW for Anaerobic Digestion to Methane $\ldots \ldots \ldots \ldots \ldots \ldots \ldots \ldots \ldots \ldots \ldots \ldots$

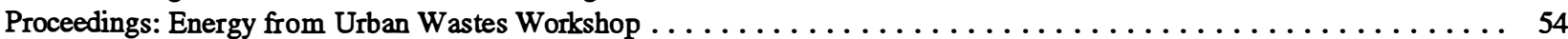

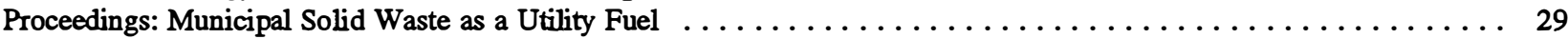

Proceedings: 1991 Conference on Waste Tires as a Utility Fuel $\ldots \ldots \ldots \ldots \ldots \ldots \ldots \ldots \ldots \ldots \ldots \ldots \ldots$

Proceedings of the Conference on Energy Conservation: Retrofit of Municipal Wastewater Treatment Facilities,

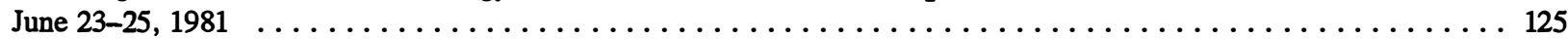

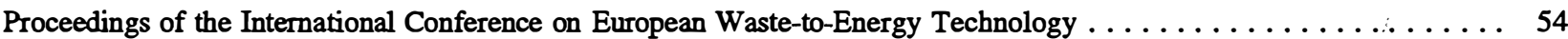

Proceedings of the International Conference on Prepared Fuels and Resource Recovery Technology ............ 55

Proceedings of the U.S. Department of Energy/Argonne National Laboratory Contractors' Research and

Development Workshop: Converting Waste to Energy $\ldots \ldots \ldots \ldots \ldots \ldots \ldots \ldots \ldots \ldots \ldots \ldots \ldots \ldots \ldots$

Proceedings of the U.S. Department of Energy, Energy Optimization of Water and Wastewater Management

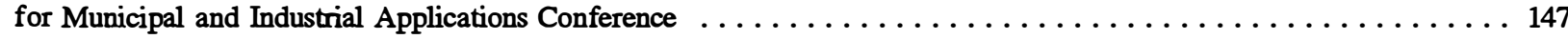

Proceedings of the Waste-to-Energy Workshop on Small-Scale Combustion Systems $\ldots \ldots \ldots \ldots \ldots \ldots \ldots \ldots \ldots$. 18

Process for Removal of Hydrogen Halides or Halogens from Incinerator Gas $\ldots \ldots \ldots \ldots \ldots \ldots \ldots \ldots \ldots \ldots$

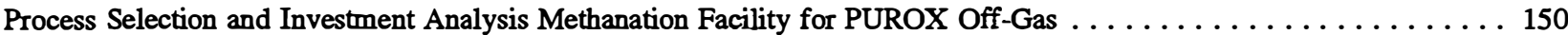

Process to Recover Plastics from Obsolete Automobiles by Using Solvents at Ambient Pressure, A . . . . . . . . 100

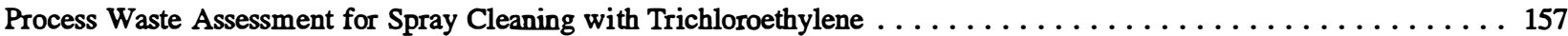

Production and Characterization of Pyrolysis Liquids from Municipal Solid Waste . . . . . . . . . . . . . 36

Production and Utilization of Methane from Anaerobic Sludge Digestion in U.S. Wastewater-Treatment Plants . . . . . . 6

Production of Ethanol and Coproducts From MSW-derived Cellulosics Using Dilute Sulfuric Acid Hydrolysis . . . . . . . 111

Production of Fuel Oil From Sewage Sludge by the STORS Process $\ldots \ldots \ldots \ldots \ldots \ldots \ldots \ldots \ldots \ldots \ldots \ldots \ldots$

Production of Oxygenated Fuels from Municipal Solid Waste Components $\ldots \ldots \ldots \ldots \ldots \ldots \ldots \ldots \ldots \ldots \ldots$

Program to Develop MSW-Fired Fluidized-Bed Boilers $\ldots \ldots \ldots \ldots \ldots \ldots \ldots \ldots \ldots \ldots \ldots \ldots \ldots \ldots \ldots$

Progress on Developing Expert Systems in Waste Management and Disposal . . . . . . . . . . . . . . . . . 149

Promise of Resource Recovery: Lessons from the New York Experience in Gaining Public Approval . . . . . . . . 61

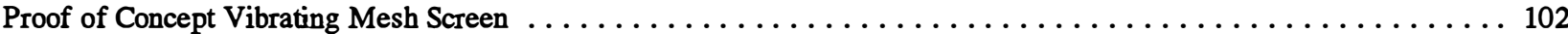

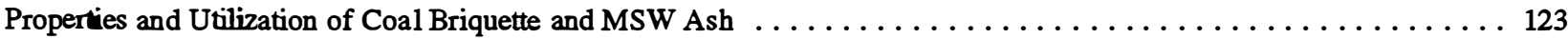

Proposed Draft Document for GSA Office Waste Removal and Procurement of Densified Refuse-Derived Fuel

for Use as a Supplemental Fuel in GSA-Operated Boilers $\ldots \ldots \ldots \ldots \ldots \ldots \ldots \ldots \ldots \ldots \ldots \ldots \ldots . \ldots \ldots$

Public Works Department: Solid Waste Management Plan, District Heating and Cooling Plan, and Waste-to-Energy

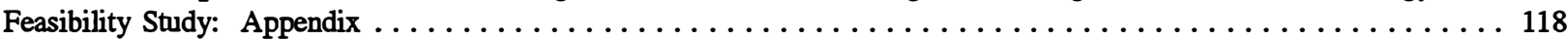

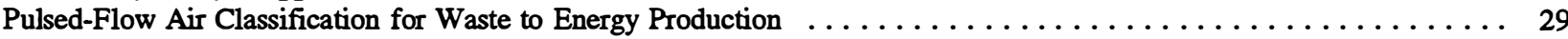

Pyrolysis Experiments with Municipal Solid Waste Components $\ldots \ldots \ldots \ldots \ldots \ldots \ldots \ldots \ldots \ldots \ldots \ldots \ldots$

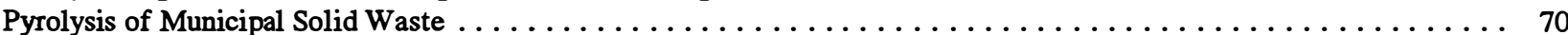

Pyrolysis of Municipal Solid Waste, Annual Report, July 1983-June $1984 \ldots \ldots \ldots \ldots \ldots \ldots \ldots \ldots \ldots \ldots \ldots 5$

Pyrolysis of Municipal Solid Waste: Annual Report, July $1985-J u n e ~ 1986 \ldots \ldots \ldots \ldots \ldots \ldots \ldots \ldots \ldots \ldots . \ldots 6$

Pyrolyzer Slag Reuse Evaluation . . . . . . . . . . . . . . . . . . . . . . . . . . . . . 159

Quantitative Determination of Sulfonated Aliphatic and Aromatic Surfactants in Sewage Sludge by Ion-Pair/Supercritical

Fluid Extraction and Derivatization Gas Chromatography/Mass Spectrometry $\ldots \ldots \ldots \ldots \ldots \ldots \ldots \ldots \ldots \ldots$

Questions and Answers about Energy Recovery from Waste $\ldots \ldots \ldots \ldots \ldots \ldots \ldots \ldots \ldots \ldots \ldots \ldots \ldots$

RD\&D Priorities for Energy Production and Resource Conservation from Municipal Solid Waste $\ldots \ldots \ldots \ldots \ldots \ldots 142$ 
Recapitulative Analysis of Model, Laboratory and Full-Scale Trommel Performance Investigations by NCRR,

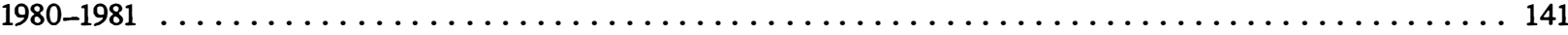

Reclamation with Recovery of Radionuclides and Toxic Metals from Contaminated Materials, Soils, and Wastes .... 75

RECOVER: A Computer Model for Resource Recovery Projects, A . . . . . . . . . . . . . . . . . . . . 120

Recovery and Reuse of Asphalt Roofing Waste Burning of Asphalt Roofing Waste . . . . . . . . . . . 67

Recovery and Reuse of Asphalt Roofing Waste: Incorporation of Roofing Waste in Asphalt Paving.

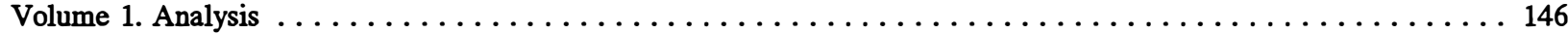

Recovery and Reuse of Asphalt Roofing Waste: Recycling Roofmg Waste to New Roofing . . . . . . . . . . . . . 151

Recovery and Utilization of Gypsum and Limestone from Scrubber Sludge . . . . . . . . . . . . . . . 100

Recovery of Anaerobic Digestion after Exposure to Toxicants, Final Report . . . . . . . . . . . . . . . . 3

Recycling and Composting Demonstration Projects for the Memphis Region $\ldots \ldots \ldots \ldots$

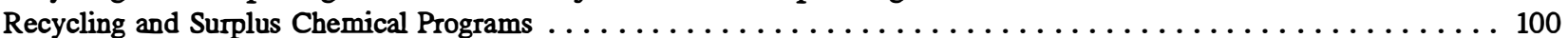

Recycling Galvanized Steel: Operating Experience and Benefits $\ldots \ldots \ldots \ldots \ldots \ldots \ldots$

Reduction of Hazardous Solvent Wastes Through the Application of a Mobile Solvent Recovery System . . . . . . . 77

RefCoM Research Project: Monthly Technical Report, July $1984 \ldots \ldots \ldots \ldots$. . . . . . . . . . . . . . . . . . . 8

Refuse Conversion to Methane (RefCoM): Design and Modification Rationale for Proof-of-Concept Facility . . . . . . . 9

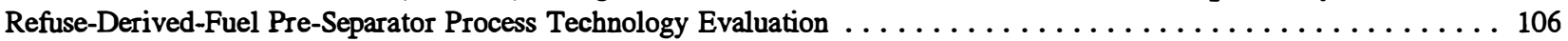

Refuse Incinerator Electrostatic Precipitator Installation, Final Report $\ldots \ldots \ldots \ldots \ldots \ldots$

Regional Secondary Resource Utilization Parks: The Industrial Parks of the Future . . . . . . . . . . . . . . 136

Release of Radioactive Scrap Metal/Scrap Metal (RSM/SM) at Nevada Test Site (NTS) . . . . . . . . . . . . 80

Removal of Acidic Gases from Incinerator Flue Gas in a Fluidized Bed Scrubber . . . . . . . . . . . . . 17,68

Renewable Energy Data Requirements: A Review of User Opinions and Data Collection Efforts . . . . . . . . . 154

Report of the Dutchess County Resource Recovery Task Force $\ldots \ldots \ldots \ldots \ldots \ldots \ldots \ldots$

Research and Development on Rotary Screens: Concept of a Model to Evaluate Cost-Effectiveness of Changes

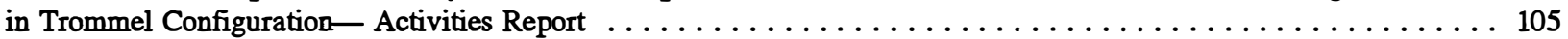

Research and Engineering Assessment of Biological Solubilization of Phosphate $\ldots \ldots \ldots \ldots$

Resource Recovery Analysis Briefing Workbook . . . . . . . . . . . . . . . . . . . . . 141

Resource Recovery and Energy Reclamation Technologies: Potential Applications under a Loan Guarantee Program . . . 124

Resource Recovery Codisposal Demonstration Project, Middlesex County, New Jersey: Feasibility Study and

Recommendation for Implementation-Final Report $\ldots \ldots \ldots \ldots \ldots \ldots \ldots \ldots \ldots$

Resource-Recovery Facility Development: Steps to Successful Implementation . . . . . . . . . . . . . . . . 40

Resource Recovery for Municipalities in the Southwest: Major Legal Issues and Their Impacts . . . . . . . . . . . . 139

Resource Recovery Options in Solid-Waste Management: A Review Guide for Public Officials . . . . . . . . . . . . 14

Resource Recovery Research Development and Demonstration Plan . . . . . . . . . . . . . . . . . . 139

Results of Emissions and Ash Testing in Full-Scale Co-Combustion Tests of Binder-Enhanced dRDF Pellets

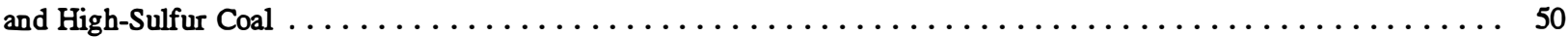

Review and Evaluation of a Bioconversion Process Demonstration Plant and Its Related Technologies 7

Review of Comparative Energy Use in Materials Potentially Recoverable from Municipal Solid Waste . . . . . . . . 148

Review of Municipal Sludge Use as a Soil Amendment on Disturbed Lands . . . . . . . . . . . . . . 114

Review of the Literature on the Use of Trommels in Waste Processing and Resource Recovery . . . . . . . . . . 142

Risk Assessment Department of Energy Kansas City Plant (DOE/KCP) PCB Discharge to Blue River

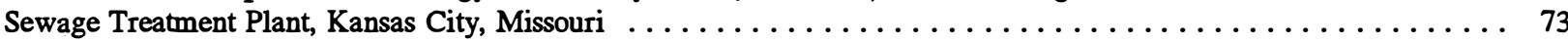

Risk Associated with the Research of an Innovative Process for the Thermal Destruction of Hazardous

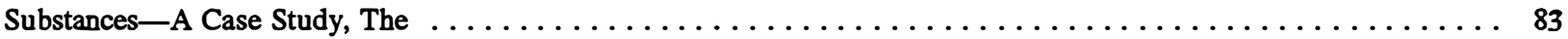

Risks Involved in Commercialization of Multiple Hearth Furnaces for Sludge Disposal Using Refuse-Derived Fuels . . . 23

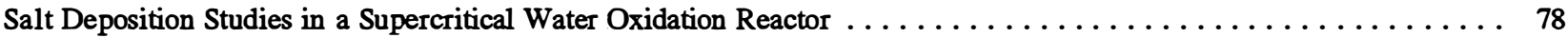

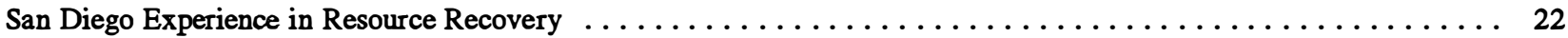

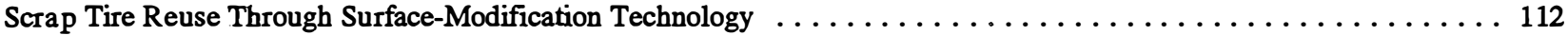

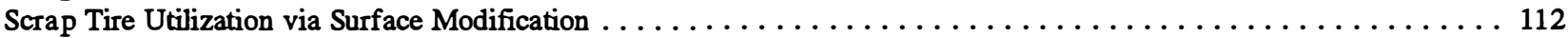

Severity of Institutional Barriers Affecting Energy-from-Municipal-Waste Technologies, The . . . . . . . . . . . 41

Sewage Sludge as a Supplementary Utility Boiler Fuel, Vol. $1 \ldots \ldots \ldots \ldots \ldots$

Sewer Water: An Alternate Water Source for a $\mathrm{CO}_{2}$, EOR (Enhanced Oil Recovery) Project . . . . . . . . . . . 127

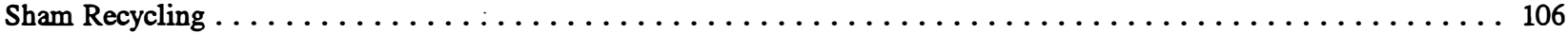

Siting a Waste-to-Energy Facility: the First Acceptance Test $\ldots \ldots \ldots \ldots \ldots \ldots$

Siting Industrial Waste Land Disposal Facilities in Thailand: A Risk Based Approach . . . . . . . . . . . . . 88

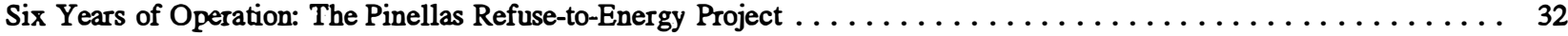

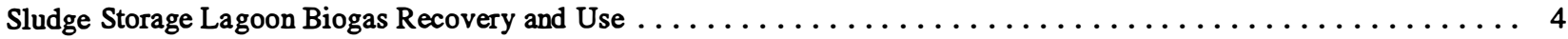

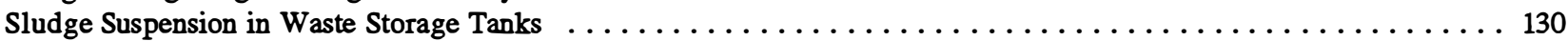


Societal Acceptance of Controversial Facilities: The Role of Two Public Participation Strategies-Negotiation and

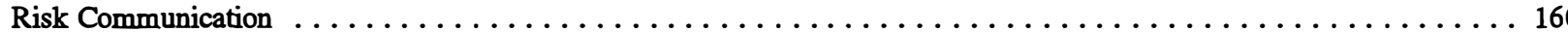

Solar Thermal Technologies in Support of an Urgent National Need: Opportunities for the Photon-Enhanced

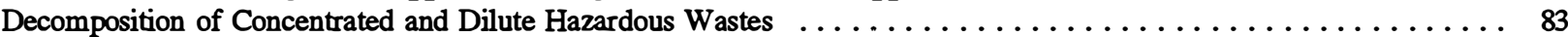

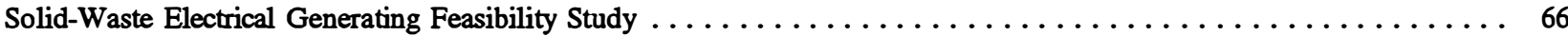

Solid-Waste Energy Recovery Project, Galax, Virginia: Feasibility Analysis . . . . . . . . . . . . . . . . . . . 27

Solid Waste Integrated Cost Analysis Model: 1991 Project Year Report . . . . . . . . . . . . . . . . . . . . . . . 151

Solid Waste Management Program, City and County of San Francisco, Final Report . . . . . . . . . . . . . . . 22

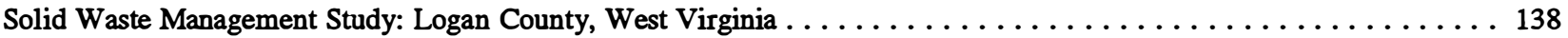

Solid Waste Research and Development: A Perspective from Pacific Northwest Laboratory . . . . . . . . . . . . 153

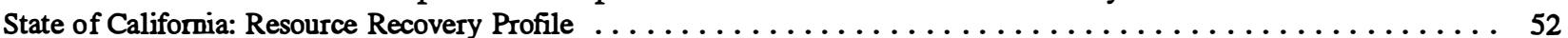

State of New Jersey: Resource Recovery Profile . . . . . . . . . . . . . . . . . . . . . . . 52

State of the Art of Methane Gas Enhancement in Landfills . . . . . . . . . . . . . . . . . . . . . 87

Status of Aluminum and Glass Recovery by Mechanical Separation $\ldots \ldots \ldots \ldots \ldots$

Studies of Soil Gas, Gas Generation, and Shallow Microbial Activity at Mallard North Landfill . . . . . . . . . . . 85

Study of Existing RDF-Cofiring Experience, Vol. 1: Phase I Final Report; Vol. 2: Appendixes to the Phase I

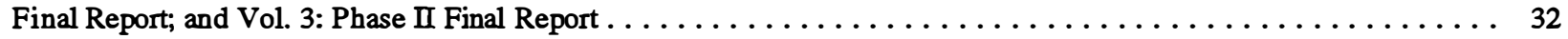

Study of Zones of Vacuum Influence Surrounding Landfill Gas Extraction Wells . . . . . . . . . . . . . . 90

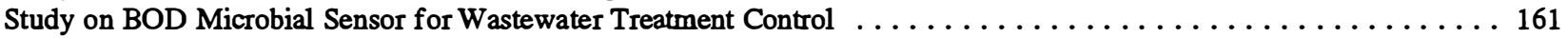

Study to Develop a Predictive Technique for the Estimation of Collectible Solid Waste in the United States, A . . . . . 128

Subseabed Disposal Project Experiment Piezometer Probe Measurement Technology . . . . . . . . . . . . 113

Summary of the Oak Ridge ANFLOW Pilot Plant Project $\ldots \ldots \ldots \ldots \ldots \ldots \ldots$

Sumner County Solid-Waste Energy Recovery Facility, Volume 1, Feasibility Studies, Design, and Construction,

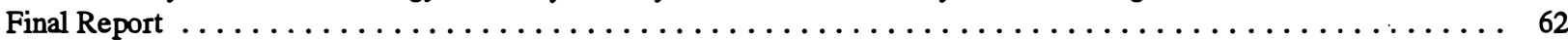

Sumner County Solid-Waste Energy Recovery Facility, Volume 2, Performance and Environmental Evaluation,

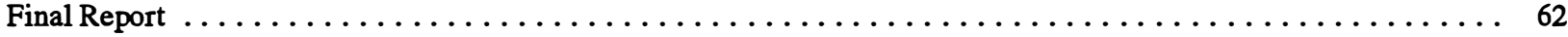

Surface-Modification Technology for Scrap Tire Reuse . . . . . . . . . . . . . . . . . . . . . . 156

Survey of Waste Fuel Storage, Metering, Transport, and Feed Systems . . . . . . . . . . . . . . . 47

Synthesis of a Novel Diphosphonate-Based Ion Exchange Resin with Enhanced Metal Ion Selectivity . . . . . . . . . 96

Systems Analysis for the Development of Small Resource Recovery Systems: Description of Solid Waste

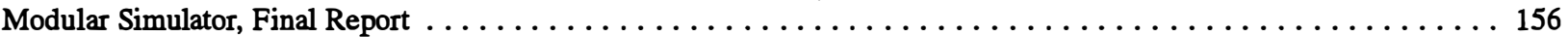

Systems Analysis for the Development of Small Resource Recovery Systems: Executive Summary . . . . . . . . . . . 157

Systems Analysis for the Development of Small Resource Recovery Systems: Research and Development Needs . . . . . 157

Systems Analysis for the Development of Small Resource Recovery Systems: System Performance Data, Final Report . . 157

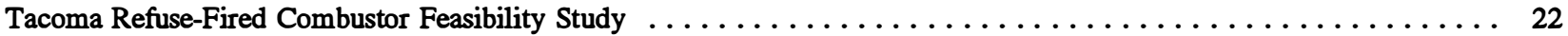

Targets of Opportunities for Plastics Recycling and Source Reduction . . . . . . . . . . . . . . . . 98

Technoeconomic Evaluation of the NYU Acid-Hydrolysis Process for Producing Ethanol from Municipal

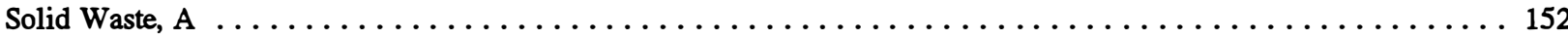

Test Procedures for the Determination of the Gross Calorific Value of Refuse and Refuse-Derived Fuel by

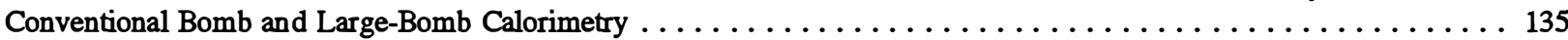

Test Procedures for the Determination of the Gross Calorific Value of Refuse and Refuse-Derived Fuels by

Oxygen Bomb Calorimetry: Summary of the 1977 Fiscal Year Results . . . . . . . . . . . . . . . . 135

Test Procedures for the Determination of the Gross Calorific Value of Refuse and Refuse-Derived Fuel of Kilogram-Size

Samples Using Constant-Pressure Flow Calorimeter: Summary of the 1980 Fiscal Year Results . . . . . . . . . . . 135

Theory and Evidence of Economies of Scale in the Development of Waste Management Systems . . . . . . . . 115

Thermal and Biochemical Options for Advanced RDF Technologies $\ldots \ldots \ldots \ldots \ldots \ldots$

Thermal Systems for Conversion of Municipal Solid Waste, Volume $1 \ldots \ldots \ldots \ldots \ldots$

Thermal Systems for Conversion of Municipal Solid Waste, Volume 2, Mass Burning of Solid Waste in

Large-Scale Combustors: A Technology Status Report . . . . . . . . . . . . . . . . . . . . . . 64

Thermal Systems for Conversion of Municipal Solid Waste, Volume 3, Small-Scale Systems: A Technology

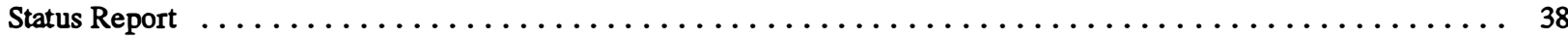

Thermal Systems for Conversion of Municipal Solid Waste, Volume 4, Burning Refuse-Derived Fuels in Boilers: A

Technology Status Report . . . . . . . . . . . . . . . . . . . . . . . . . . . . .

Thermal Systems for Conversion of Municipal Solid Waste, Volume 5, Pyrolytic Conversion: A Technology

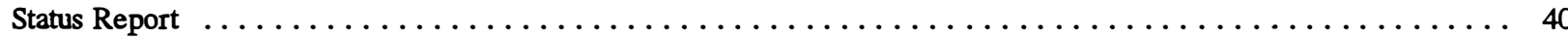

Thermal Systems for Conversion of Municipal Solid Waste, Volume 6, Fluidized-Bed Combustion: A Technology

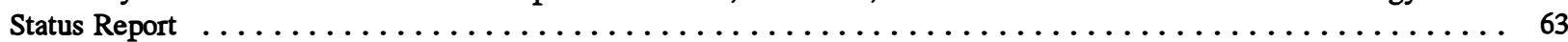

Thermochemical Conversion of Municipal Waste: Pyrolysis, Gasification, and/or Liquefaction . . . . . . . . . . 40

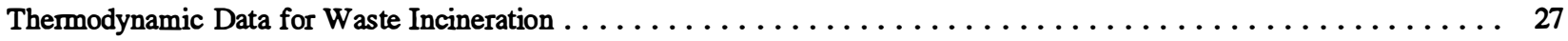


Trace Chemical Characterization of Pollutants Occurring in the Production of Landfill Gas from the Shoreline

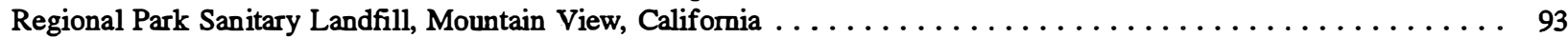

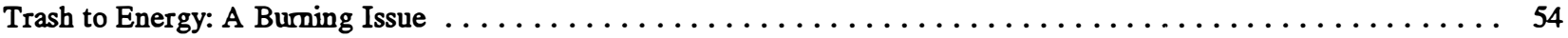

Treatment of Municipal Solid Waste (MSW) by the Hydrocarb Process . . . . . . . . . . . . . . . . 154

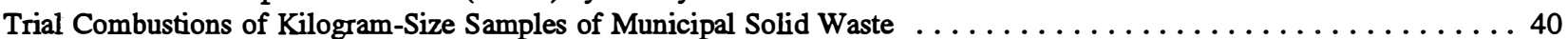

Tri-County Solid-Waste-to-Fuel Production Project Feasibility Study . . . . . . . . . . . . . . . . . . . . . 29

Trommel Screen Research and Development for Applications in Resource Recovery . . . . . . . . . . . . . . . . . 97

Tulsa Resource-Recovery Project: From Start to Start-Up . . . . . . . . . . . . . . . . . . . . . . . . . . . . . 149

Two-Phase Procurement Procedure for Selection of a Resource Recovery System Contractor . . . . . . . . . . . 24

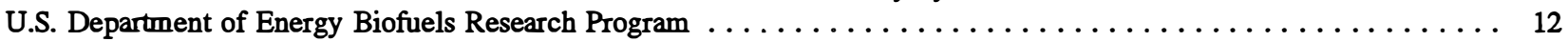

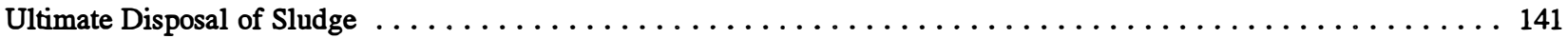

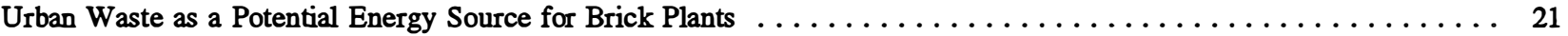

Urban Waste Program Research and Development 1978-1981: An Overview . . . . . . . . . . . . . . . . . . . . 145

Use of Municipal Solid Waste for District Heating in St. Paul, Minnesota . . . . . . . . . . . . . . . . 39

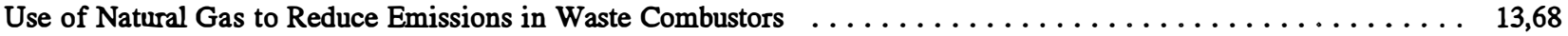

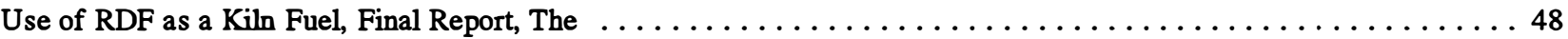

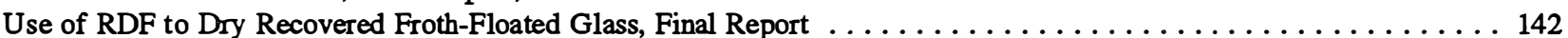

Use of Waste Oils to Improve Densified Refuse-Derived Fuels, Final Report . . . . . . . . . . . . . . . 48

Utilization of Dlinois Coal Gasification Slags for Production of Ultra-Lightweight Aggregates . . . . . . . . . . . 117

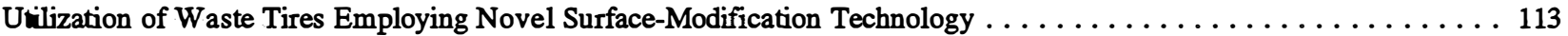

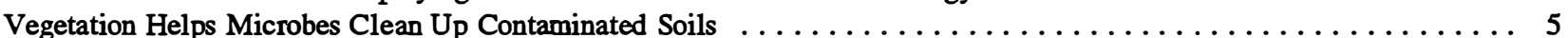

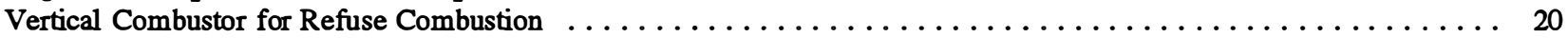

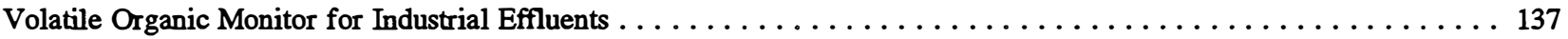

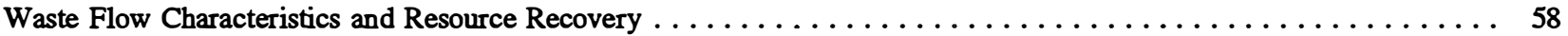

Waste Minimization Case Histories at Three U.S. Air Force Air Training Command Bases . . . . . . . . . . . . . 156

Waste Minimization/Pollution Prevention at R\&D Facilities: Implementing the SNLNM Process Waste

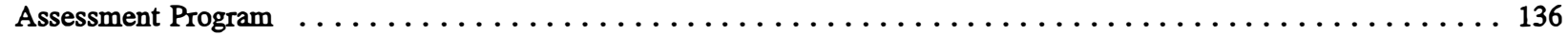

Waste Reduction and Recycling: A Strategy for New Brunswick $\ldots \ldots \ldots \ldots \ldots \ldots \ldots \ldots$

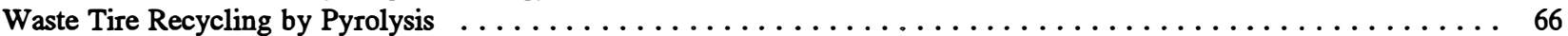

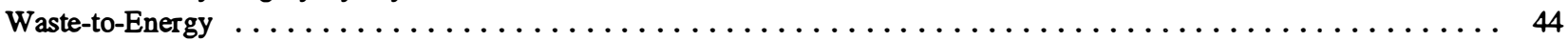

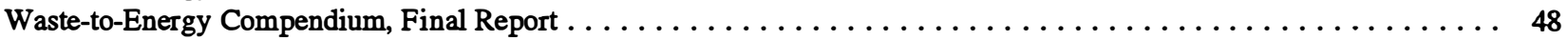

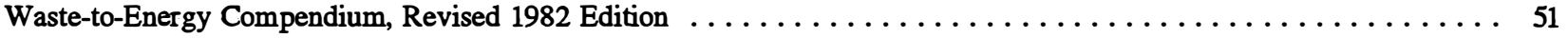

Waste-to-Energy Compendium: Revised 1988 Edition $\ldots \ldots \ldots \ldots \ldots \ldots \ldots$

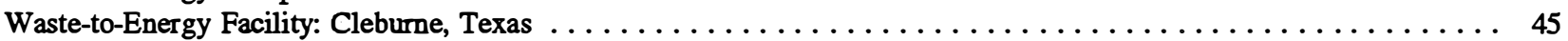

Waste-to-Energy in the United States: Socioeconomic Factors and the Decision-Making Process . . . . . . . . . 25

Waste-to-Energy Projects in Texas: Selecting Systems to Meet Permitting Requirements . . . . . . . . . . . 38

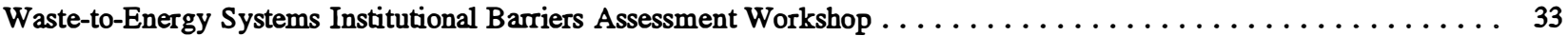

Wastewater Treatment Facilities: Energy Efficient Improvements and Cogeneration . . . . . . . . . . . . . . . . . 136

Water-Related Environmental Control Requirements at Municipal Solid-Waste-to-Energy Conversion Facilities . . . . . 39

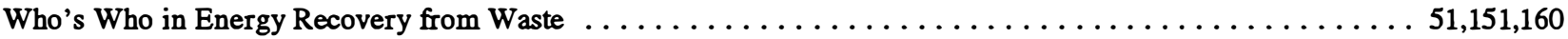

Wood Ash Disposal and Recycling Sourcebook . . . . . . . . . . . . . . . . . . . . . . . . 99

Work Plan for Development of a Data Base on Potential Landfill Gas Utilization Sites in the United States . . . . . . 94

Workshop on Municipal Waste Combustion, Cincinnati, Ohio, June 6-11, $1989 \ldots \ldots \ldots$ 


\section{Appendix C-Alphabetical Listing of Authors}

Author Name

Page

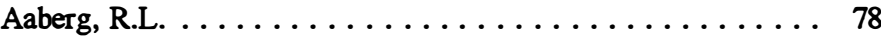

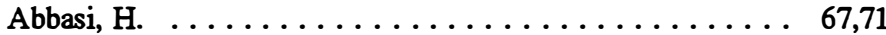

Abbasi, H.A. . . . . . . . . . . . . . . . . . 13,68

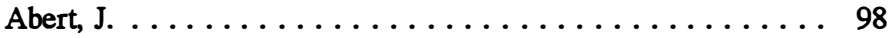

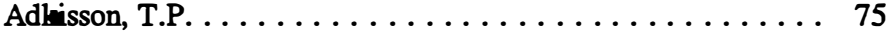

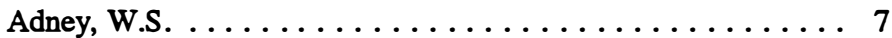

Agrawal, R.K. . . . . . . . . . . . . . . . . 13,36,36,70

Ahmed, S. . . . . . . . . . . . . . . . 13,14

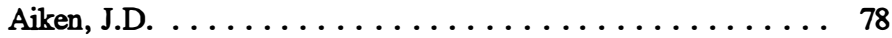

Alam, M.K. . . . . . . . . . . . . . . . . . 153

Albers, J.L. . . . . . . . . . . . . . . . . . . . . 146

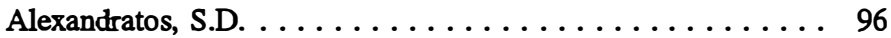

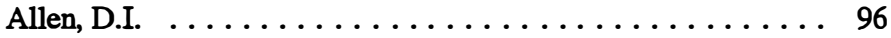

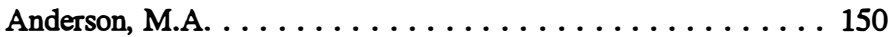

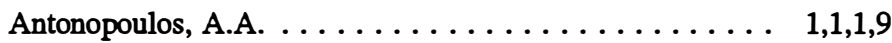

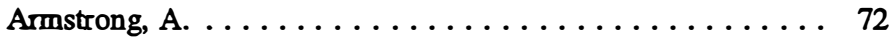

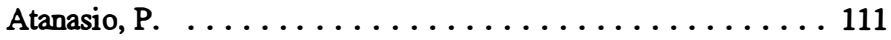

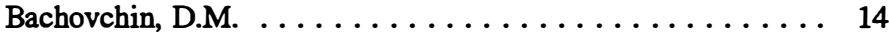

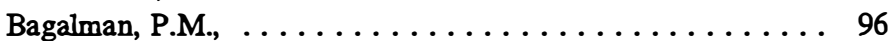

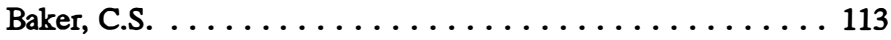

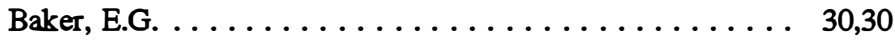

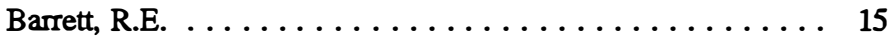

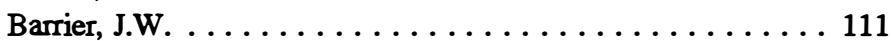

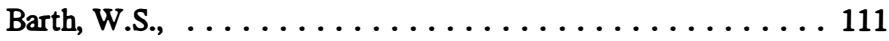

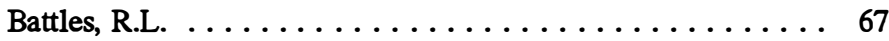

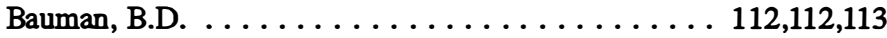

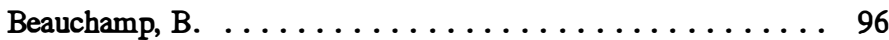

Beck, J.E. . . . . . . . . . . . . . . . . . . . . 107,132,136

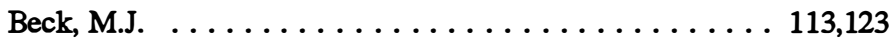

Becker, M.B. . . . . . . . . . . . . . . . . . 159

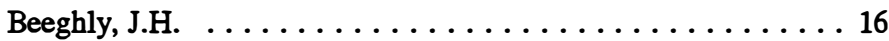

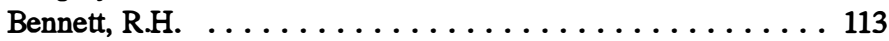

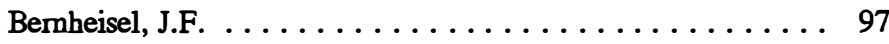

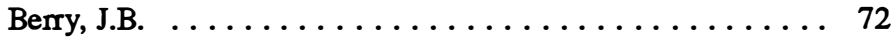

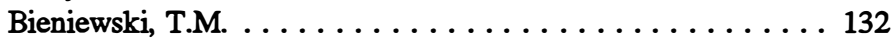

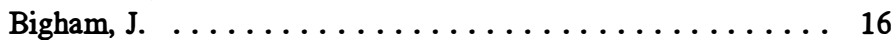

Bloomquist, R.G. . . . . . . . . . . . . . 10

Bogner, J. . . . . . . . . . . . . . . . . 84,85

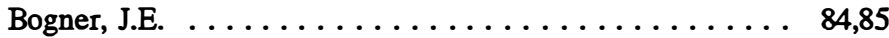

Bonsignore, P.V. . . . . . . . . . . . . . . . 100

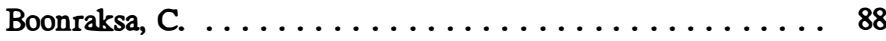

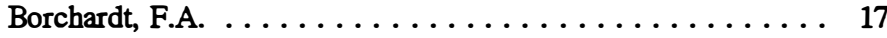

Boston, H.L. . . . . . . . . . . . . . . . . . 114

Bradshaw, W.M. . . . . . . . . . . . . . . . 17,68

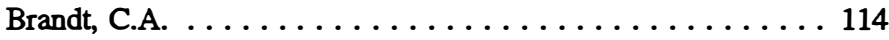

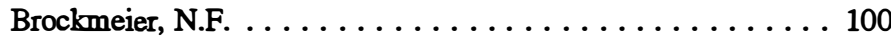

Broder, J.D. . . . . . . . . . . . . . . . . . . 111

Brogan, J.A. . . . . . . . . . . . . . . . . . . 73

Brooks, C. . . . . . 2,4,17,17,18,18,19,22,38,40,40,45,61,64,

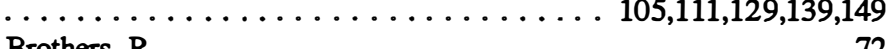

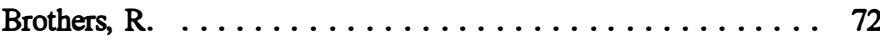

Brothers, R.R. . . . . . . . . . . . . . . . 137

Brown, M.D. . . . . . . . . . . . . . . . . . . . . 140

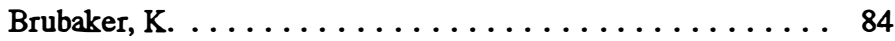

Bruce, S.S. . . . . . . . . . . . . . . . 28,69

Buckley, T.J. . . . . . . . . . . . . . . . . . . 28,69

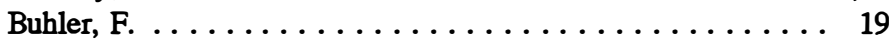

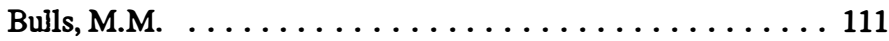

Author Name P:

Burke, M.

Bums, J.T.

Bushnell, D.J.

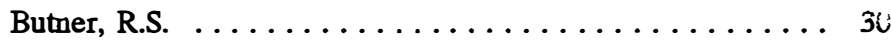

Campbell, J. .................... 49

Canova, J.H. . . . . . . . . . . . . . . . . . . 19

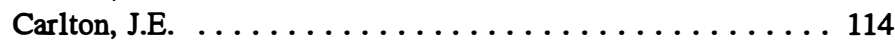

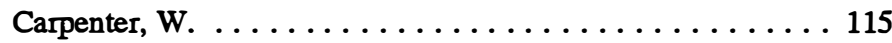

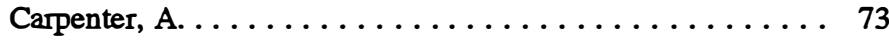

Carpenter, R. . . . . . . . . . . . . . . 88

Chamberlin, R.M. . . . . . . . . . . . . . . 14

Chang, S.G. $\ldots \ldots \ldots \ldots \ldots \ldots \ldots \ldots \ldots \ldots \ldots \ldots \ldots \ldots$

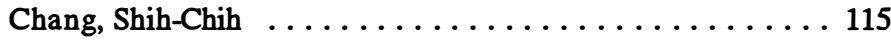

Chang, Shoou-Yuh . . . . . . . . . . . . . . 115

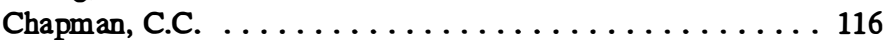

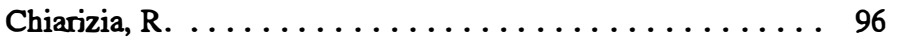

Chidambariah, Venkatesh $\ldots \ldots \ldots \ldots \ldots \ldots \ldots \ldots$

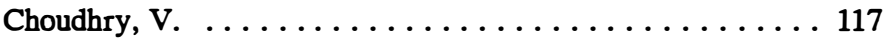

Chung, P. ....................... 20

Chumey, K.L. . . . . . . . . . . . . . . . . . 20,28,69,117

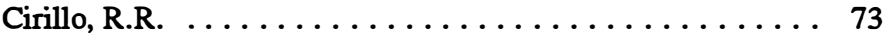

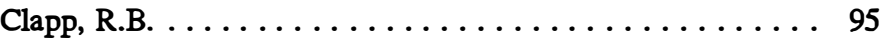

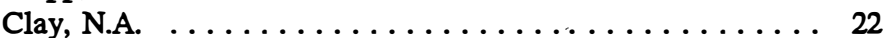

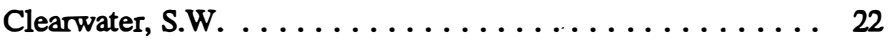

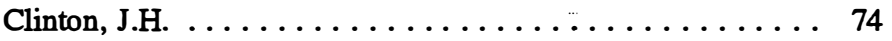

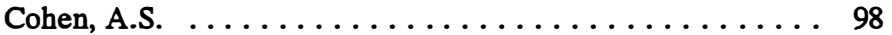

Compere, A.L. . . . . . . . . . . . . . . . . . . . 119

Couithard, J. . . . . . . . . . . . . . . . . 58

Counce, R.M. . . . . . . . . . . . . . . . . 120

Crawford, D.B. . . . . . . . . . . . . . . . 120

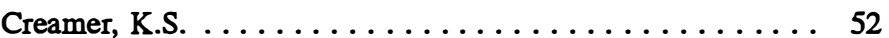

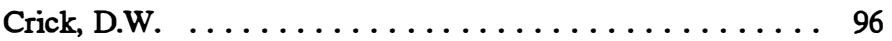

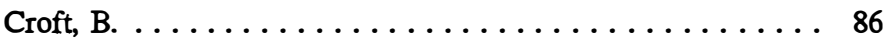

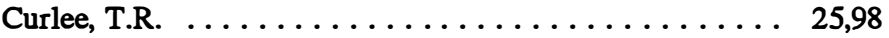

Cygan, D. . . . . . . . . . . . . . . . . . . . . 67,71

Czernik, S.R. . . . . . . . . . . . . . . . 59

D'Amico, N. . . . . . . . . . . . . . . . 14

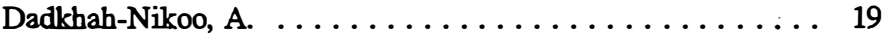

Dague, R. . . . . . . . . . . . . . . . . 2

Daniels, E.J. . . . . . . . . . . . . . 76,99,100,108,130,131,134

Daugherty, K. . . . . . . . . . . . . . . 68

Daugherty, K.E. . . . . . . . . . . . . . 49,50

Delzel, D. . . . . . . . . . . . . . . . . . . . . . 136

Demos, E.K. . . . . . . . . . . . . . . . . 74,151

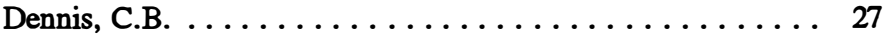

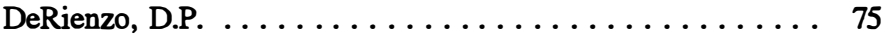

Diaz, L.F. . . . . . . . . . . . . . . . . . . . 150

Dick, W. . . . . . . . . . . . . . . . 16

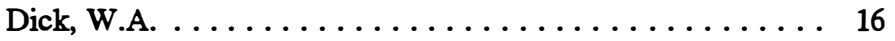

Doctor, R.D. . . . . . . . . . . . . . . 76,130

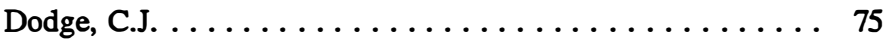

Doh, Kapsoo . . . . . . . . . . . . . . . . . 123

Domalski, E.S. . . . . . . . . . . . . . 27,28,28,28,69

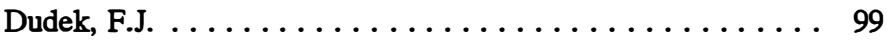

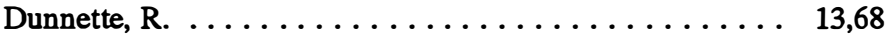

Edwards, M. . . . . . . . . . . . . . . 150

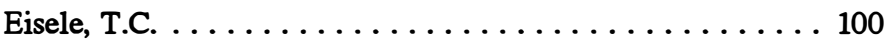

Elcock, D. . . . . . . . . . . . . . . . . . 123 
Nor Name

Page

M. ...................... 123

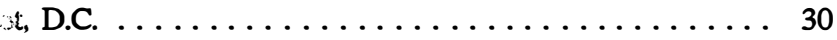

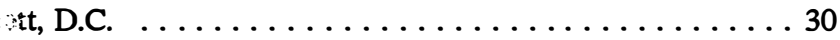

dahl, R.B. . . . . . . . .

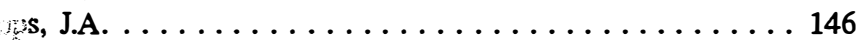

calante, E. . . . . . . . . . . . . . . . 31

Erans, R.J. . . . . . . . . . . . . . . . 31,32

Eykamp, W. . . . . . . . . . . . . . . . 126

Fagan, M. ...................... 54

Fassbender, A.G. . . . . . . . . . . . . . . . . . 140

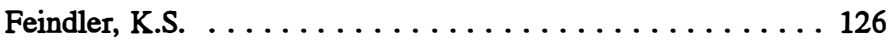

Feldman, D.L. . . . . . . . . . . . . . . . 25

Ferrada, J.J. . . . . . . . . . . . . . . . . . . 149

Field, J.A. . . . . . . . . . . . . . . . . . 126

Field, T.M. . . . . . . . . . . . . . . . . . 126

Fingleton, D.J. . . . . . . . . . . . . . . . . 88

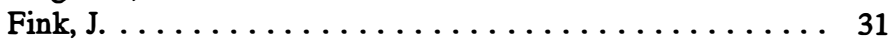

Finney, C. ..................... 3

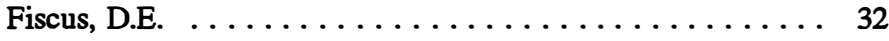

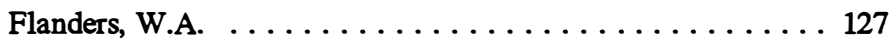

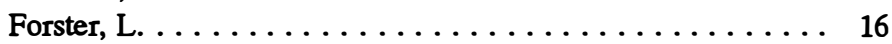

Francis, A.J. . . . . . . . . . . . . 75

Francis, C.W. ..................... 88

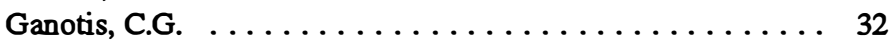

Garrett, J.K. . . . . . . . . . . .

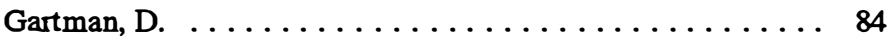

Gatrone, R.C. ..................... 96

Gavette, K.B. . . . . . 33,99

Gentry, D.E. . . . . . . . . . . 76

Genung, R.K. . . . . . . . . . . . 3

Gershman, H.W. ........................ 129

Gesell, G.H. . . . . . . . . . . . . . . . . 17

Geyer, H.K. . . . . . . . . . . . . . . . . 129

Giger, W. ........................ 126

Glatzmaier, G.C. . . . . . . . . . . . . . . . . 76

Glaub, J.C. ......................... 150

Goldbach, G. . . . . . . . . . . . . . . . . 34

Goldsberry, J.A. . . . . . . . . . . . . . . 102,155

Goodman, B. . . . . . . . . . . . . . . . . . . . 34

Goodman, B.J. . . . . . . . . . . . . . . . . . . 34,50,129

Gorski, A.J. . . . . . . . . . . . . . . . . 131

Goswami, D.Y. . . . . . . . . . . .

Grahmann, N. . . . . . . . . . . . . . . . . 127

Grammel, S.J. . . . . . . . . . . . . . . . . . . . 129

Grandfield, C.H. . . . . . . . . . . . . . . 130

Gray, R. . . . . . . . . . . . . . . . . 136

Braziano, G.J. . . . . . . . . . . . . . . . 67

Greene, W.T. . . . . . . . . . . . . . . . . 99

reen, G. . . . . . . . . . . . . . . . . . . . 127

sriffith, W.L. . . . . . . . . . . . . . . . . . 119

srohse, E.W. . . . . . . . . . . . . . . . 35

villory, J.L. . . . . . . . . . . . . . . . . 35

Habegger, L. . . . . . . . . . . . . . . . . 88

Gaefner, R. . . . . . . . . . . . . . . . . . 16

Hainsworth, E. $\ldots \ldots \ldots \ldots \ldots \ldots \ldots \ldots \ldots \ldots \ldots \ldots \ldots \ldots \ldots$

Hamm, B.A. . . . . . . . . . . . . . . 130

Hanush, R.G. $\ldots \ldots \ldots \ldots \ldots \ldots \ldots \ldots \ldots \ldots \ldots \ldots \ldots$

Hardy, J. . . . . . . . . . . . . . . . . . . . . 106

Hardy, M.D. . . . . . . . . . . . . . . 155,155
Author Name Page

Harkness, J.B.L. . . . . . . . . . . . . . . 76,130,131

Harper, T.J. . . . . . . . . . . . . . . . . . . . 100

Harrington, K. . . . . . . . . . . . . 89

Hasselriis, F. . . . . . . . . . . . . . . . . 36

Hastings, P. . . . . . . . . . . . . . 88

Hattemer-Frey, H.A. . . . . . . . . . . . . . . . . . 69,69

Hawthome, S.B. . . . . . . . . . . . . . 126

Hebner, G.A. . . . . . . . . . . . . . . . 153

Helt, J.E. $\ldots \ldots \ldots \ldots \ldots \quad 13,13,14,36,36,37,37,37,42,70,70$

Hendrickson, B. . . . . . . . . . . . . . . 38

Hendrickson, P.L. . . . . . . . . . . . . . . . 114

Hickert, M.T. . . . . . . . . . . . . . . . . 97

Hickman, H.L., Jr. . . . . . . . . . . . . . . . 38

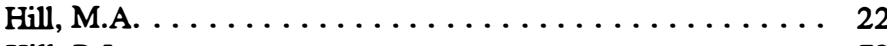

Hill, R.L. . . . . . . . . . . . . . . . . 78

Hill, C.G. Jr. . . . . . . . . . . . . . . . 150

Himmel, M.E. . . . . . . . . . . . . . . . . 7

Hitzhusen, F. . . . . . . . . . . . . . . 16

Holcomb, R.S. . . . . . . . . . . . . . . 38

Holter, G.M. . . . . . . . . . . . . . 131,132,132,136,153

Homan, F.J. . . . . . . . . . . . . . . . . 72

Hopper, R. . . . . . . . . . . . . . 38

Horwitz, E.P. . . . . . . . . . . . . . . 96

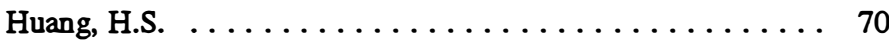

Hull, D.E. . . . . . . . . . . . . . . . 132

Hunter, R.M. . . . . . . . . . . . . . . 133

Isaacson, $R . \ldots \ldots \ldots \ldots \ldots \ldots \ldots \ldots \ldots \ldots \ldots \ldots \ldots, 4,6$

Jody, B.J. . . . . . . . . . . . . . . . . 100,134

Johnson, R.D. . . . . . . . . . . . . . . . . 113,123

Ju, C. ......................... 161

Kaiser, L. . . . . . . . . . . . . . . . . . . . . 102

Kaszynski, G. . . . . . . . . . . . . . . 89,89

Katzman, M.T. . . . . . . . . . . . . . . . . 108

Kawatra, S.K. . . . . . . . . . . . . . . . 100

Keairns, D.L. . . . . . . . . . . . . . . . . 14

Kearley, J.A. . . . . . . . . . . . . . . . . . . . 60

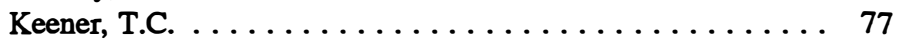

Kelsay, M.P. . . . . . . . . . . . . . . . 25

Kennedy, W.E. Jr. . . . . . . . . . . . . 78

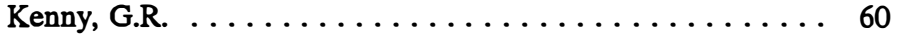

Kerstetter, J.D. $\ldots \ldots \ldots \ldots \ldots \ldots \ldots \ldots \ldots \ldots$. 41

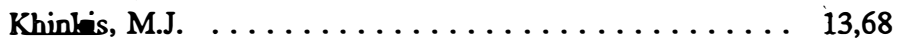

Kikkawa, H. . . . . . . . . . . . . . . . 150

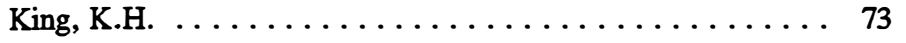

Kirklin, D.R. . . . . . . . . . . . 135,135,135,135

Kjeldgaard, E.A. . . . . . . . . . . . . . . . . . 136

Klass, D.L. . . . . . . . . . . . . . . . . 13,32

Kolb, J.O. . . . . . . . . . . . . . . . . . 39,39

Koppel, P.E. . . . . . . . . . . . . . . . . . . 35

Koran, L.J., Jr. . . . . . . . . . . . . . . . . . . . 109

Korenberg, J. . . . . . . . . . . . . . . . . 58

Krause, H.H., Jr. . . . . . . . . . . . . . . . . 15

Krishnan, R.P. . . . . . . . . . . . . . 17,68

Kuester, J.L. . . . . . . . . . . . . . . . . 40,40

Kukacka, L.E. . . . . . . . . . . . . . . . . . . . 152

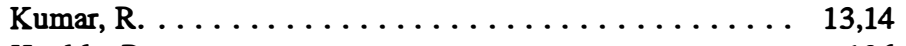

Kunkle, R. ........................ 136

Kuusinen, T.L. . . . . . . . . . . . . . 107,136

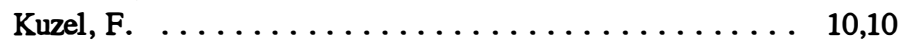




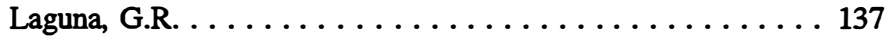

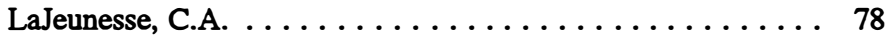

Lambert, R.O. . . . . . . . . . . . . . . . . . 111

Land, M.D. . . . . . . . . . . . . . . . . . 137

Larsen, I.L. . . . . . . . . . . . . . . . . . . . 114

Lazar, J. . . . . . . . . . . . . . . . . . 49,50

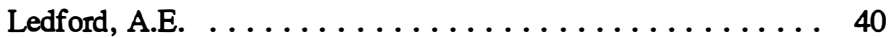

Ledford, A.E., Jr. . . . . . . . . . . . . . . . . . . . 28 28,69

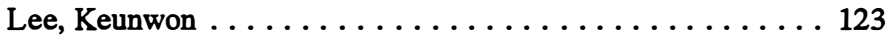

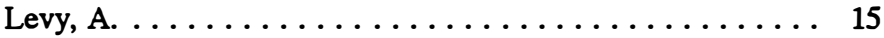

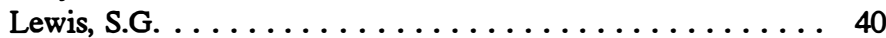

Liengcharernsit, $W . \ldots \ldots \ldots \ldots \ldots$

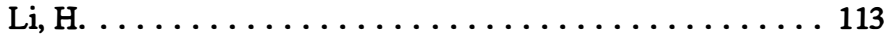

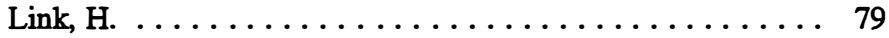

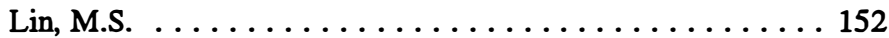

Liplin, J. . . . . . . . . . . . . . . . . 113

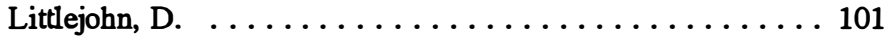

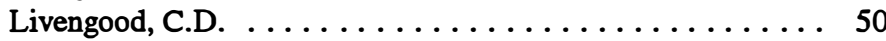

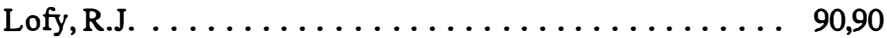

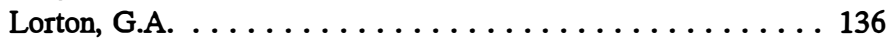

Losinski, S.J. . . . . . . . . . . . . . . 106

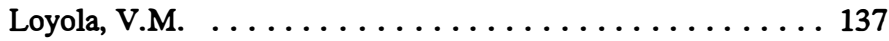

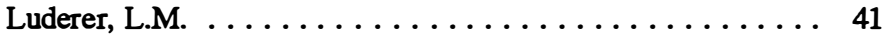

Lussiez, G.W. . . . . . . . . . . . . . . . . . . 79

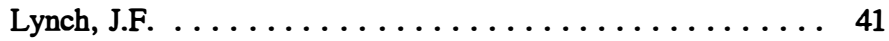

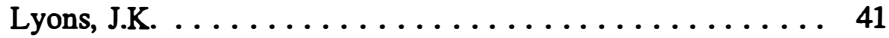

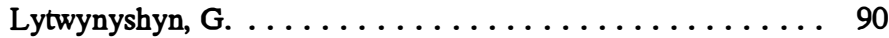

Mahalingam, R. .................. 80

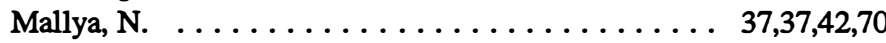

Maloof, R. . . .................. 106

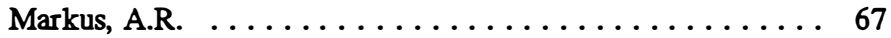

Marsee, K.W. . . . . . . . . . . . . . 138

Martin, J.B. . . . . . . . . . . . . . . . 78

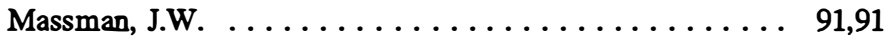

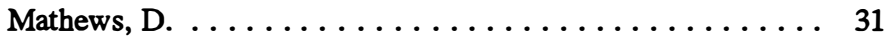

Mayberry, J. . . . . . . . . . . . . . . . . . . 35,102

Mayberry, J.L. . . . . . . . . . . . . . . 42,101,101,102,102,102

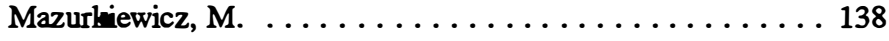

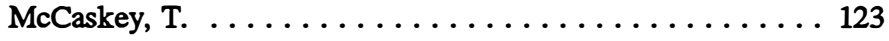

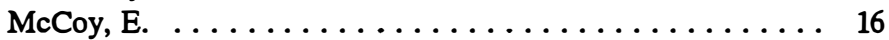

McGinn, C.W. . . . . . . . . . . . . . . . . 137

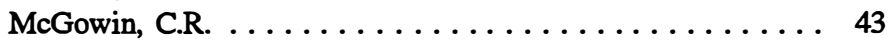

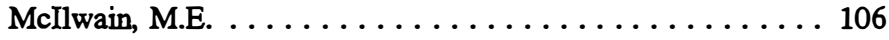

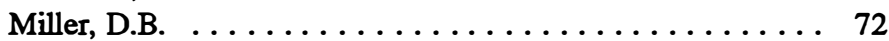

Miller, D.J. . . . . . . . . . . . . . . . . 126

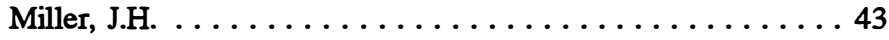

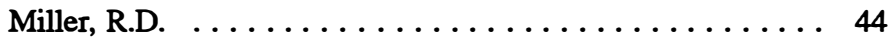

Miller, R.M. . . . . . . . . . . . . . . . 85

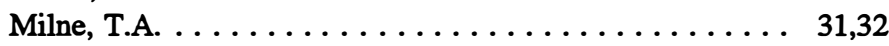

Mishlin, A.E. . . . . . . . . . . . . . . . . . 139

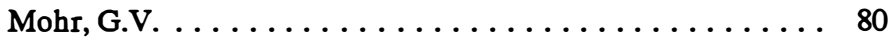

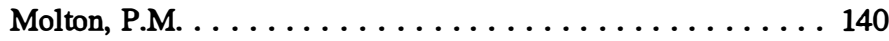

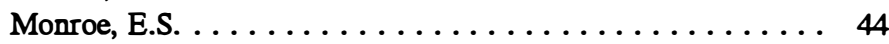

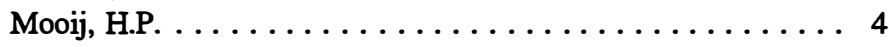

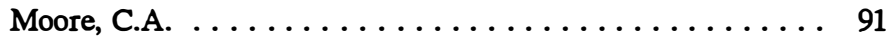

Moretti, C.J. . . . . . . . . . . . . . . 44,45,140

Morgan, W.A. . . . . . . . . . . . . . . . . . . . 99

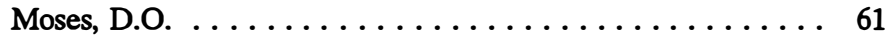

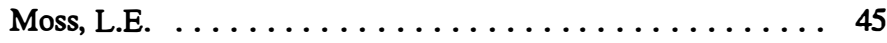

Muller, D. . . . . . . . . . . . . . . 4,

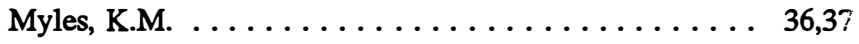

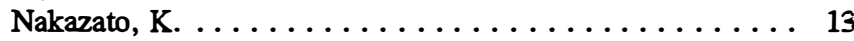

Newby, R.A. . . . . . . . . . . . . . . .

Niemann, K. ................

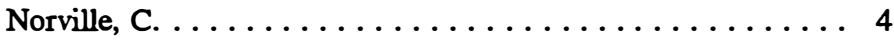

O'Connell, R. . . . . . . . . . . . . . . . . . 144,145,145

O'Connell, R.A. . . . . . . . . . . . . . . 143,143,144,144

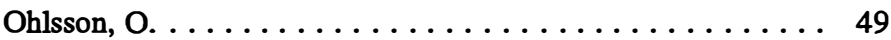

Ohlsson, O.O. . . . . . . . . . . . . 49,50,50,50,68

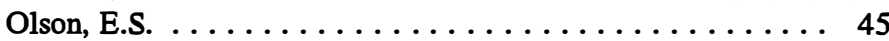

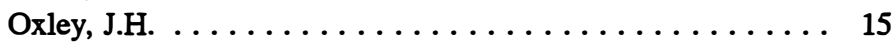

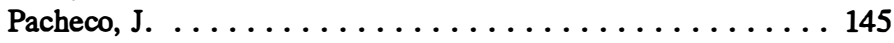

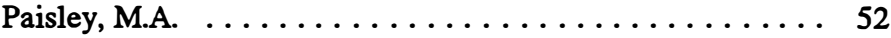

Parkhurst, M.A. . . . . . . . . . . . . 78

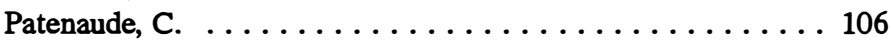

Paulsen, G. . . . . . . . . . . . . . . . . . 146

Pearson, C.V. . . . . . . . . . . . . . 50,53,146,146,147

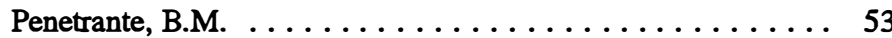

Pennock, K.A. . . . . . . . . . . . . . . . . . 131

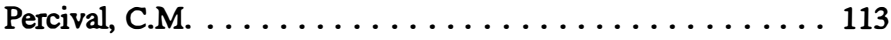

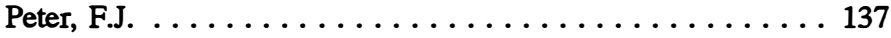

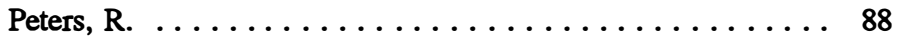

Peverly, J.H. . . . . . . . . . . . . . . . . . . . 94

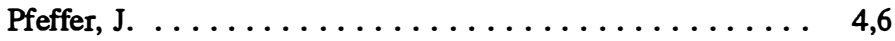

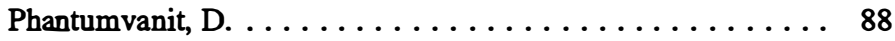

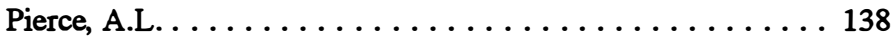

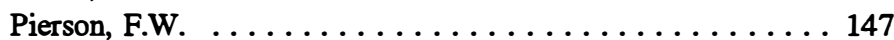

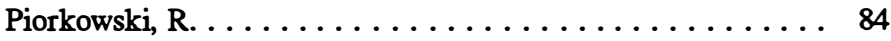

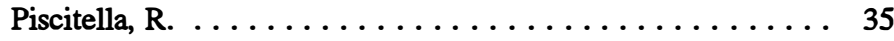

Podolak, P. .................... 54

Powell, M.R. . . . . . . . . . . . . . . . . . . . 80

Powers, T.J. . . . . . . . . . . . . . . . 67,106,146,151

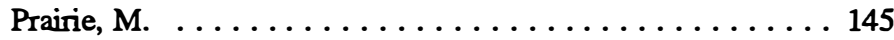

Premuzic, E.T. . . . . . . . . . . . . . . 152

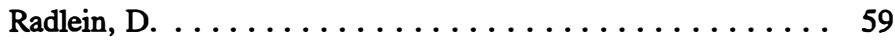

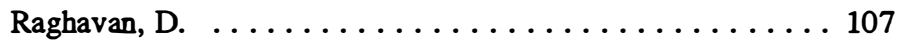

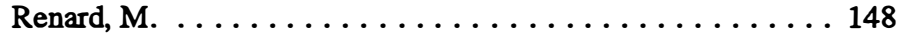

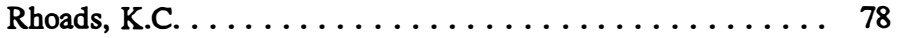

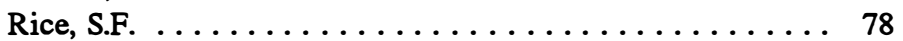

Richerson, F.B. . . . . . . . . . . . . . . . . 148

Richlen, S.L. . . . . . . . . . . . . . . . . . 148

Richmond, P. . . . . . . . . . . . . . . . . . 149

Ridings, R.L. . . . . . . . . . . . . . . . . . . 105

Ridzon, G.J. . . . . . . . . . . . . . . . . . . . . 149

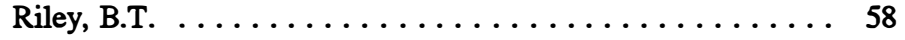

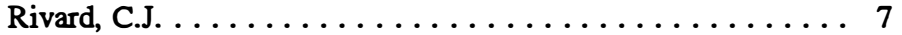

Rivera, A.L. . . . . . . . . . . . . . . . . . 115,149

Robertus, R.J. . . . . . . . . . . . . . . . . . . . . 140

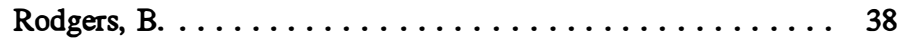

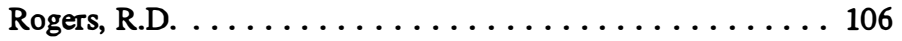

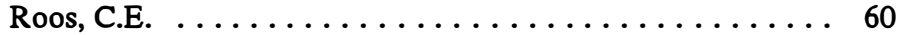

Rose, C. .................... 84

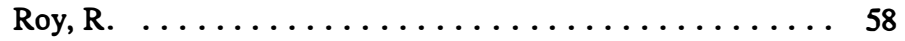

Rueppel, D.W. . . . . . . . . . . . . . . . 130

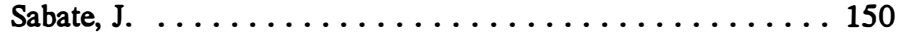

Saddler, J.H. . . . . . . . . . . . . . . . . . . . . . . 109

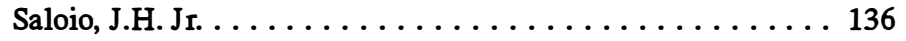

Sanford, W.E. . . . . . . . . . . . . . . . . 94 


\section{Namer Name}

Page

, N.F. . . . . . .

N.N. . . . . . . . . . . . . . . . 81

ge, G.M. $\ldots \ldots \ldots \ldots \ldots \ldots \ldots \ldots \ldots \ldots \ldots \ldots \ldots \ldots \ldots$

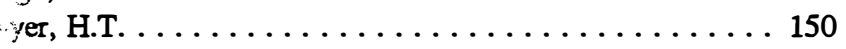

satzki, S.T. . . . . . . . . . . . . . . 159

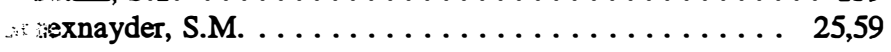

scott, D.S. . . . . . . . . . . . . . . 59

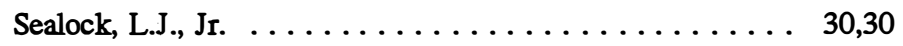

Seeberger, D.A. . . . . . .

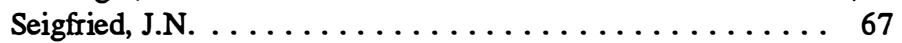

Semler, T.T. . . . . . . . . . . . . . . . . . 155

Sepanski, L.M. $\ldots \ldots \ldots \ldots \ldots \ldots \ldots \ldots \ldots \ldots \ldots \ldots \ldots$

Sharples, F.E. . . . . . . . . . . . . . 82

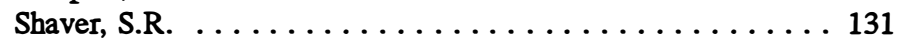

Shay, M.R. . . . . . . . . . . . . . . 132

Shepherd, P.B. . . . . . . . . . . . 67,71,106,146,151

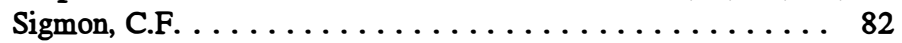

Simpson, S.J. . . . . . . . . . . . . . 10

Sims, J.M. . . . . . . . . . . . . . . 130

Sladek, T.A. . . . . . . . . . . . . . . . 151

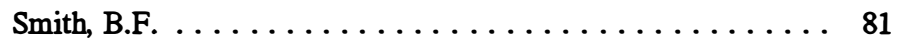

Smith, K. . . . . . . . . . . 68

Sommer, E.J., Jr. . . . . . . . . . . . . . . . . . 60

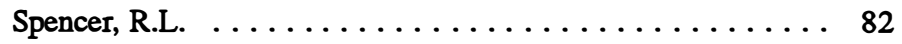

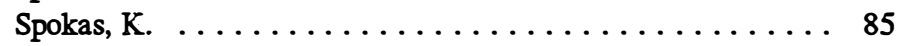

Sproull, R.D. . . . . . . . . . . . . . . . . . 152

Stanton, S.L. . . . . . . . . . . . . . . . 153

Stapp, D.C. . . . . . . . . . . . . . . . . 132,153

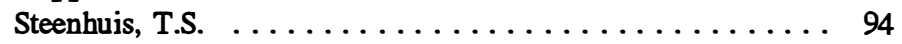

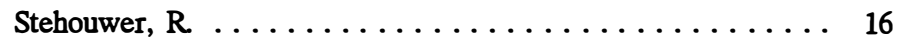

Steinberg, M. . . . . . . . . . . . . . 35,154,154

Steisel, N. . . . . . . . . . . . . . . . 61

Stephan, L.M. . . . . . . . . . . . . . . . . . . 109

Stermer, D.L. . . . . . . . . . . . . . . 136

Stevenson, G.G. . . . . . . . . . . . . . . . 154

Steverson, E.M. . . . . . . . . . . . . . . . 102,155

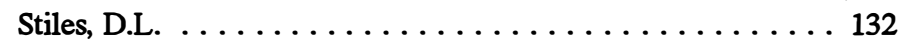

Stodolsky, F. . . . . . . . . . . . . . . . 61

Strickland, R.C. . . . . . . . . . . . . 155,155

Stuart, A.D. . . . . . . . . . . . . . . 137

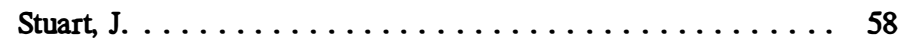

Suffern, J.S. . . . . . . . . . . . . . . . . . 156

Sullivan, R.G. . . . . . . . . . . . . . . 140

Surface, J.M. . . . . . . . . . . . . . . . 94

Swift, G.W. . . . . . . . . . . . . . . 156

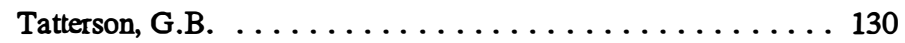

Taylor, D.D. . . . . . . . . . . . . . . . 106

Taylor, D.R. . . . . . . . . . . . . . . 52

Texeira, R.H. . . . . . . . . . . . . . . . . 129

Thompson, D.T. . . . . . . . . . . . . . 157

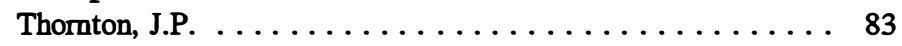

Tomasko, D. . . . . . . . . . . . . 88

Tome, C. . . . . . .

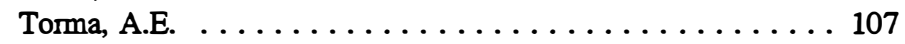

Traina, S. . . . . . . . . 16
Travis, C.C.

$62,63,69,69,73$

Trezek, G.J. . . . . . . . . . . . . . . . 63

Trochimczuk, A. . . . . . . . . . . . . . . 96

Tsang, W.. . . . . . . . . . . . . . . . . . 63

Tsang, W. . . . . . . . . $\ldots \ldots \ldots \ldots \ldots \ldots \ldots$ 28,63,69

Tsao, T. $\ldots \ldots \ldots \ldots \ldots \ldots \ldots \ldots \ldots \ldots \ldots \ldots \ldots \ldots \ldots$

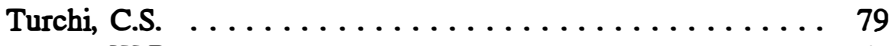

Tumer, W.D. . . . . . . . . . . . . . . . . . 64

Tuten, D.S. . . . . . . . . . . . . . . . 155,155

Tweksbury, T.L. . . . . . . . . . . . . . . 52

Ulerich, N.H. $\ldots \ldots \ldots \ldots \ldots \ldots \ldots \ldots \ldots \ldots \ldots \ldots$

Valent, P.J. . . . . . . . . . . . . . . . . 113

Vander Molen, R.H. . . . . . . . . . . . . . . . . . . 64

Van Miegroet, H. . . . . . . . . . . . . . . . . 114

Venables, B. . . . . . . . . . . . . . . . . . . 68

Venables, B.J. . . . . . . . . . . . . . . . . . . 49

Vogel, R.A. .......................... 156

Vogt, D.P. . . . . . . . . . . . . . . . . . 25

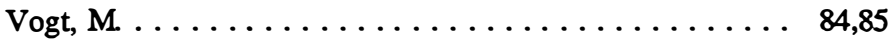

Walker, D. . . . . . . . . . . . . . . . . . 113

Walsh, J., $\ldots \ldots \ldots \ldots \ldots \ldots \ldots \ldots \ldots \ldots . . \ldots \ldots$

Walsh, P. . . . . . . . . . . . . . . . . . 65

Walter, D.K. . . . . . . . . . . . . . . 11,12,50

Walter, D.W. . . . . . . . . . . . . . . . . . 107

Walton, R.M. . . . . . . . . . . . . . . . 96

Walzer, A.E. . . . . . . . . . . . . . . . . 114

Ward, P.P. . . . . . . . . . . . . . . . 158

Watson, J. . . . . . . . . . . . . . . . . . . 123

Wene, E.G. . . . . . . . . . . . $\ldots \ldots \ldots \ldots \ldots \quad 1,1,9$

Wentz, C.A. . . . . . . . . . . . . . . . 83

West, W.L. . . . . . . . . . . . . . . 130

Weyand, T.E. . . . . . . . . . . . . . . . . . 159

White, A.L. . . . . . . . . . . . . . . . . 159,159

White, D.H. . . . . . . . . . . . . . . . . 159

Wilkes, K.E. . . . . . . . . . . . . . 39

Wilkey, M.L. . . . . . . . . . . . . . . 95

Wohadlo, S. . . . . . . . . . . . . . . . 67,71

Wolfe, A.K. . . . . . . . . . . . . . . . 25,59,160

Wolfe, W. . . . . . . . . . . . . . . . . . . 16,16

Wolsky, A.M. . . . . . . . . . . . . . . . . 108

Wong, K.K.Y. . . . . . . . . . . . . . . . . . 109

Woodward, J. . . . . . . . . . . . . . . . . . . . 109

Yambert, M.W. . . . . . . . . . . . . . . . 63,73

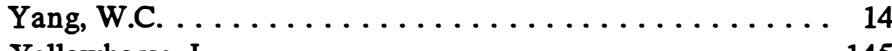

Yellowhorse, L. . . . . . . . . . . . . . . . . . . 145

Young, J.C. . . . . . . . . . . . . . . . . . . 41

Young, S.C. . . . . . . . . . . . . . . . . . 95

Yourong, L. . . . . . . . . . . . . . . 161

Zalosh, R.G. ....................... 109

Zilfi, J. ........................ 106

Zimmerle, T. ..................... 117

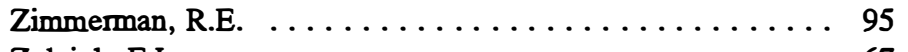

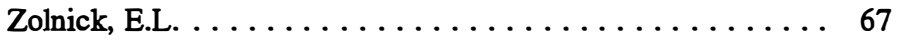

Zygmunt, S.J. . . . . . . . . . . . . . . . 161 


\section{REPORT DOCUMENTATION PAGE}

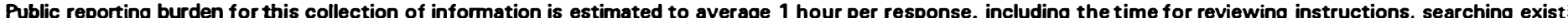

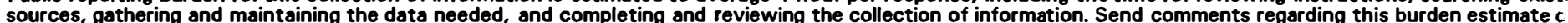

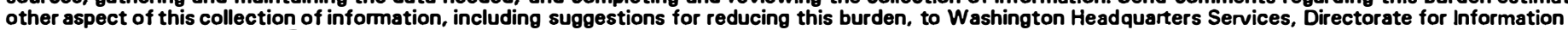

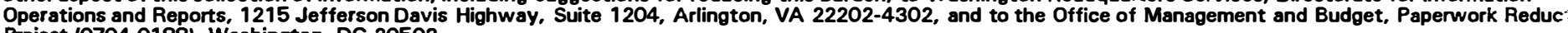
Project (0704-0188), Washington, DC 20503.

\begin{tabular}{|l|c|c|}
\hline 1. AGENCY USE ONLY (Leave blank) & $\begin{array}{c}\text { 2. REPORT DATE } \\
\text { July } 1994\end{array}$ & $\begin{array}{c}\text { 3. REPORT TYPE AND DATES COVERED } \\
\text { Final Report }\end{array}$ \\
\hline
\end{tabular}

4. TITLE AND SUBTITLE

Municipal Solid Waste Management. A Bibliography of U.S. Department of Energy Contractor Reports Through 1993

\section{AUTHOR(S)}

NREL technical monitor: Philip Shepherd

7. PERFORMING ORGANIZATION NAME(S) AND ADDRESS(ES)

National Renewable Energy Laboratory

National Renewable Energy Laboratory

1617 Cole Boulevard

Golden, CO 80401-3393

\section{SUPPLEMENTARY NOTES}

12a. DISTRIBUTION/AVAILABILITY STATEMENT

National Technical Information Service

U.S. Department of Commerce

5285 Port Royal Road

Springfield, VA 22161

\section{FUNDING NUMBERS}

(C)

(TA) WM111010

\section{ABSTRACT (Maximum 200 words)}

This bibliography updates an earlier work, and provides information about technical reports on energy from municipal solid waste that were prepared under grants or contracts from the U.S. Department of Energy. The reports listed focus on energy from municipal waste technologies and energy conservation in wastewater treatment. There are three indexes: author, subject and a title index. All reports are available in either microfiche or hard copy, and may be ordered from NTIS.

\section{SUBJECT TERMS}

Municipal solid waste, biomass, combustion, emissions, landfills, recycling
15. NUMBER OF PAGES

182

16. PRICE CODE

A09

\section{SECURITY CLASSIFICATION} OF REPORT
19. SECURITY CLASSIFICATION OF ABSTRACT
20. LIMITATION OF ABSTRACT
Standard Form 298 (Rev. 2-89) Prescribed by ANSI Std. 239-18 298-102 